\title{
Plant stanol esters: Effects on cardiovascular risk markers and cholesterol metabolism
}

Citation for published version (APA):

Plat, J. (2001). Plant stanol esters: Effects on cardiovascular risk markers and cholesterol metabolism.

[Doctoral Thesis, Maastricht University]. Universiteit Maastricht. https://doi.org/10.26481/dis.20011123jp

Document status and date:

Published: 01/01/2001

DOI:

10.26481/dis.20011123jp

Document Version:

Publisher's PDF, also known as Version of record

\section{Please check the document version of this publication:}

- A submitted manuscript is the version of the article upon submission and before peer-review. There can be important differences between the submitted version and the official published version of record.

People interested in the research are advised to contact the author for the final version of the publication, or visit the DOI to the publisher's website.

- The final author version and the galley proof are versions of the publication after peer review.

- The final published version features the final layout of the paper including the volume, issue and page numbers.

Link to publication

\footnotetext{
General rights rights.

- You may freely distribute the URL identifying the publication in the public portal. please follow below link for the End User Agreement:

www.umlib.nl/taverne-license

Take down policy

If you believe that this document breaches copyright please contact us at:

repository@maastrichtuniversity.nl

providing details and we will investigate your claim.
}

Copyright and moral rights for the publications made accessible in the public portal are retained by the authors and/or other copyright owners and it is a condition of accessing publications that users recognise and abide by the legal requirements associated with these

- Users may download and print one copy of any publication from the public portal for the purpose of private study or research.

- You may not further distribute the material or use it for any profit-making activity or commercial gain

If the publication is distributed under the terms of Article $25 \mathrm{fa}$ of the Dutch Copyright Act, indicated by the "Taverne" license above, 
Plant Stanol Esters: Effects on Cardiovascular Risk Markers and Cholesterol Metabolism 


\section{iftín}

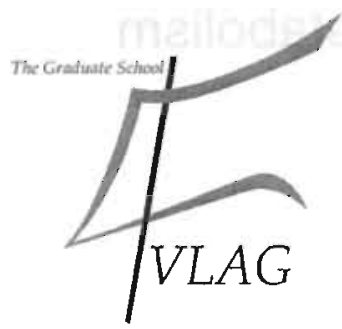

The study presented in this the?:5s was performed at the Nutrition and Toxicology Research Institute Maastricht (NUTRIM), which participates in the graduate school VLAG-2 (Food Technology, Agrobiotechnology, Nutrition and Health Sciences) accredited by the Royal Netherlands Academy of Arts and Sciences.

Productie: Datawyse, Maastricht

(i) Jogchum Plat, Maastricht, 2001

ISBN 90-9015336-5 


\section{Plant Stanol Esters: Effects on Cardiovascular Risk Markers and Cholesterol Metabolism}

\section{PROEFSCHRIFT}

ter verkrijging van de graad van doctor

aan de Universiteit Maastricht,

op gezag van de Rector Magnificus,

Prof. dr. AC Nieuwenhuijzen Kruseman, volgens het besluit van het College van Decanen,

in het openbaar te verdedigen

op vrijdag 23 november 2001 om 12.00 uur

door

Jogchum Plat

Geboren te Epe, 08-05-1970 


\section{Promotores}

Prof. dr. ir. R.P. Mensink

Prof. dr. G. Hornstra

Beoordelingscommissie

Prof. dr. ir. W.H.M. Saris (voorzitter)

Prof. K. Von Bergmann (University of Bonn, Germany)

Prof. dr. M.H. Hofker

Prof. dr. M.B. Katan (Wageningen Universiteit)

Dr. B.H. Wolffenbuttel

The author is grateful for the financial support by the RAISIO GROUP for making publication of this thesis possible. 
Aan mijn ouders,

Voor Anita en Stijn 


\section{Contents}

\section{Chapter 1}

General introduction

\section{Chapter 2}

Effects of plant sterols and stanols on lipid metabolism and cardiovascular risk (Nutrition Metabolism and Cardiovascular Diseases. 2001;11:31-40)

\section{Chapter 3}

Vegetable oil based versus wood based stanol ester mixtures: effects on serum lipids and hemostatic factors in non hypercholesterolemic subjects (Atherosclerosis 2000;148:101-112)

\section{Chapter 4}

Effects of diets enriched with two different plant stanol ester mixtures on plasma ubiquinol-10 and fat-soluble antioxidant concentrations (Metabolism 2001;50:520-529)

\section{Chapter 5}

Effects on serum lipids, lipoproteins and fat-soluble antioxidant concentrations of consumption frequency of margarines and shortenings enriched with plant stanol esters. (Eur J Clin Nutr 2000;54:671-677)

\section{Chapter 6}

Hypocholesterolemic mechanisms of plant stanol esters: effects on LDL receptor mRNA and cell-surface protein expression, and on HMG-CoA reductase mRNA expression in non-hypercholesterolemic subjects (submitted)

\section{Chapter 7}

Relationship of genetic variation in genes encoding apolipoprotein A-IV, scavenger receptor $\mathrm{Bl}, \mathrm{HMG}-\mathrm{CoA}$ reductase, CETP, and apolipoprotein $\mathrm{E}$ with cholesterol metabolism and the response to plant stanol ester consumption (submitted)

\section{Chapter 8}

Oxidized plant sterols in human serum and lipid infusions as measured by combined gas-liquid chromatography-mass spectrometry (J Lipid Res; 2001: in press) 

Chapter 9

General Discussion

Summary

203

Samenvatting in het nederlands

Dankwoord

213

Curriculum Vitae

217

Publications 
Chapter 1

General introduction 


\section{Introduction}

Atheroscierosis, the leading cause of morbidity and mortality in the Western world, is a group of syndromes that can be divided into three main categories: coronary heart diseases (angina pectoris, myocardial infarction), cerebrovascular diseases (stroke, transient ischemic attacks), and peripheral arterial diseases (gangrene, intermittent claudication). During the last years, the prognosis of in particular patients with coronary heart disease (CHD) has improved. This is mainly due to a better understanding of the pathology underlying $\mathrm{CHD}$, which makes successful intervention strategies possible. Such interventions are not only of medical relevance, but have also a large socioeconomical impact, because of the costs involved and because disease in general is the cause of social and psychological problems. It is therefore extremely important to further unravel the mechanisms underlying the development of CHD in order to develop new strategies and interventions for a further improvement of cardiovascular risk management.

Interventions to lower the risk for $\mathrm{CHD}$ can be directed towards three different stages of atherosclerotic lesion development: initiation, progression and regression. Ideally, such intervention strategies should be initiated at a very young age, since fatty streak formation, the first step in the formation of an atherosclerotic plaque, is an ongoing process, which already starts during childhood. In fact, autopsy studies showed that fatty streak formation in the aorta and coronary arteries was already present at the age of 5 (1). These fatty streaks progressed rapidly till the age of 15 to 24 years and the earliest fibrous plaques could already be present at the age of 20 . Another approach is to delay the progression or to initiate even regression of already existing lesions. The ongoing aging of the population in the coming decades will lead to a higher prevalence of patients with sclerotic vessels and / or even clinical manifestations of atherosclerosis. This emphasizes that prevention of CHD is relevant for all ages.

Many factors associated with the risk for CHD have been identified during the last decades. These risk factors are often divided into modifiable and non-modifiable risk factors (table 1). Especially the modifiable risk factors are interesting for those willing to reduce their risk for coronary heart disease. An important modifiable risk factor, already established more than 40 years ago, is a high serum total cholesterol concentration. In the following years it appeared that an even more important risk factor for $\mathrm{CHD}$ was the distribution of 
cholesterol over the different lipoproteins. Lipoproteins are lipid-protein particles that make transport of lipophylic compounds through the hydrofylic blood stream possible. An unfavorable fasting lipoprotein profile is characterized by a high cholesterol concentration in the low-density lipoproteins (LDL), and / or a low cholesterol concentration in the high-density lipoproteins (HDL). Moreover, evidence is accumulating that also a raised serum triacylglycerol concentration is positively related with cardiovascular risk (2).

Table 1: Some factors associated with an increased risk for CHD

\begin{tabular}{lc}
\hline Modifiable & Non-Modifiable \\
\hline Smoking & Age \\
Unfavorable lipoprotein profile & Male Gender \\
$-\quad$ high LDL cholesterol & Family history of CHD \\
$-\quad$ low HDL cholesterol & Genetic background \\
$-\quad$ high triacylglycerol & \\
High blood pressure & \\
Diabetes Mellitus & \\
Obesity & \\
Lack of exercise & \\
Thrombogenic factors
\end{tabular}

\section{Coronary heart disease}

Coronary heart disease is a response towards the injured endothelium of the vessel wall, which can be caused by several mediators, such as high (modified) LDL cholesterol concentrations, specific pathogens such as chlamydia and cytomegalovirus, or mechanical stress. In particular, a high serum LDL cholesterol concentration is a strong risk factor for CHD. Oxidation or modification of polyunsaturated fatty acids and sterols of LDL particles trapped in the vessel wall seems to be a crucial step in the process of atherogenesis $(3,4)$. Through oxidation, modified LDL is formed, which initiates the expression of adhesion molecules such as VCAM and ICAM on the luminal side of the endothelial cells. It also increases the synthesis of several growth factors, chemokines (MCP-1), and inflammatory cytokines. In response, leucocytes start expressing various integrines such as VLA-4 and LFA-1 and then become extremely adhesive to the damaged endothelium via integrineadhesion molecule interactions. By this mechanism, leucocytes are very effectively recruited to the place of endothelial damage (5). Next, the recruited monocytes extravasate to the underlying intima layer and monocytes transform into macrophages, a process initiated by the many cytokines and growth factors synthesized by activated leucocytes, endothelial and smooth muscle cells 
(figure 1). The permeability of the damaged endothelium increases, which facilitates the transport of (modified) lipoproteins from the circulation into the subendothelium. Decomposition products of the lipid hydroperoxides in the oxidized LDL particle attach covalently to the positively charged lysines and cysteines from the apoB-100 protein in LDL. As a consequence the apoB-100 molecule becomes less positively charged and is not longer recognized by the negatively charged binding domain of the LDL receptor, which normally removes LDL from the circulation. Oxidized LDL, however, is efficiently cleared by monocytes and macrophages via unregulated scavenger receptor mediated uptake, which ultimately results in the formation of lipid-loaden cells (foam cells) (6). These foam cells promote the formation of fatty streaks in the intima layer of the vascular wall, which deteriorates endothelial function further. Due to the increasing numbers and volume of foam cells, the covering endothelial cells becomes damaged. These damaged cells, together with the underlying foam cells and extracellular matrix, cause platelets to adhere to the proteoglycans and other parts of the extracellular matrix of the subendothelium. Platelets then become activated, which results in the formation of a loose thrombus. Activation of the coagulation cascade stabilizes the thrombus, and the damaged endothelium is replaced by the overlaying thrombus. The arterial wall, however, is now locally thickened and hardened, which reduces the luminal diameter and elasticity of the vessel and affects blood flow. If the process of endothelial injury continues, the fatty streak develops into an intermediate lesion and then into an advanced complicated lesion, which may rupture. This results in the formation of a thrombus, which may loosen from the vessel wall, starts circulating through the blood stream, and may ultimately obstruct a critical vessel. Consequently, the tissue depending on the supply of blood through this vessel becomse hypoxic and die. It is estimated that approximately $50 \%$ of all myocardial infarctions can be explained by plaque rupture followed by thrombosis.

In contrast to LDL, HDL cholesterol concentrations are inversely correlated with the incidence of coronary heart disease. HDL mediates the efflux of cholesterol from non-hepatic cells towards the liver and / or steroidogenic organs. In the liver, HDL derived cholesterol is mainly used for bile acid synthesis and excreted from the body. In the steroidogenic organs, it is used for synthesis of vitamin $\mathrm{D}$ and steroid hormones.

Besides the generally accepted relation with LDL and HDL cholesterol, also the association between triacylglycerol-rich lipoproteins - the very low- 
density lipoproteins (VLDL) - and coronary heart disease becomes more and more recognized. In case of high serum triacylglycerol concentrations, there is a competition between VLDL and chylomicrons in the postprandial state for lipolysis by lipoprotein lipase. Consequently, concentrations of triacylglycerolrich lipoproteins in the circulation remain elevated, which is considered to be pro-atherogenic since both VLDL and chylomicrons are precursors for the socalled remnant lipoproteins. These remnants may subsequently enter the endothelium and stimulate the formation of an atheroslerotic plaque (7).

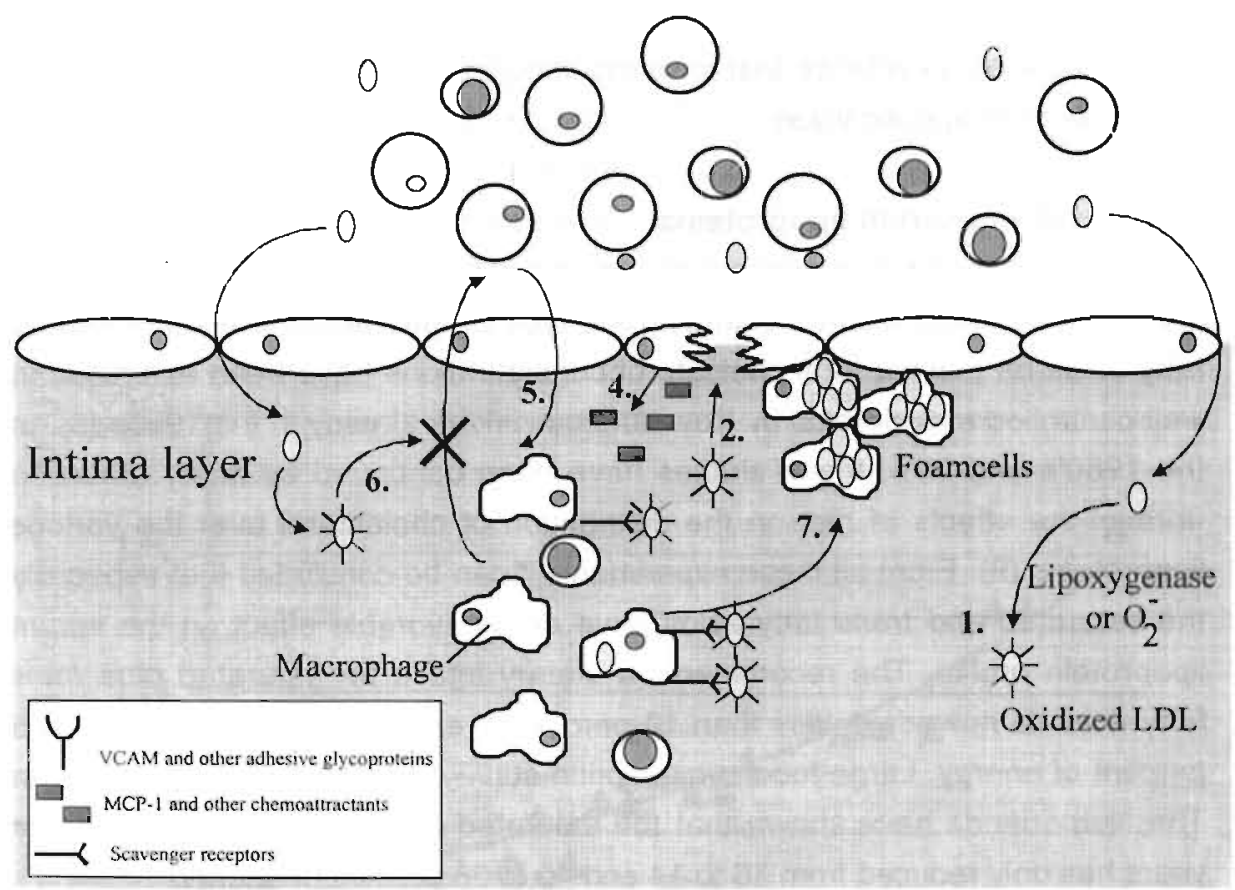

Figure 1: Schematic representation of seven steps in the formation of an atherosclerotic lesion. (1) LDL enters the intima layer and is oxidized by various factor such as reactive oxygen species or lipoxygenase. (2) Oxidized LDL is cytotoxic and causes damage to the endothelium, (3) which results in the expression of adhesion molecules to which the monocytes and T-lymphocytes attach. (4) Damaged endothelial cells excrete chemo-attractants such as MCP-1, causing a continuous recruitment of leucocytes. (5) Monocytes pass the endothelium and become macrophages. (6) Oxidized LDL prevents the return of the macrophages to the circulation, and (7) the arrested macrophages absorb large amounts of oxidized LDL and become foam cells. This process finally results in the formation of an atherosclerotic lesion. 
For many subjects, an unfavorable lipoprotein profile can be improved by changing dietary habits. Formerly, only for LDL cholesterol concentrations a causal relationship with $\mathrm{CHD}$ has been proven. Dietary recommendations have therefore mainly focused on reducing LDL cholesterol concentrations. The protective role of $\mathrm{HDL}$ in the process of atherosclerosis, however, becomes more and more accepted. These effects may - at least partly - be ascribed to the apolipoproteins A-I and A-IV, the two major proteins of HDL. From studies with transgenic animals, it appeared that apoA-I overexpression delayed atherosclerotic lesion formation and caused regression of pre-existing lesions, while apoA-IV overexpression also protected against atherosclerosis. Further, there is emerging evidence that lowering elevated triacylglycerol concentrations might have therapeutic value.

\section{Dietary fat and serum lipoproteins}

Serum lipoprotein concentrations can not only be modified by changing total fat intake, but also by changing the type of fatty acids. Effects of dietary fatty acids on plasma total cholesterol concentrations have been examined in well-controlled experiments by Keys and coworkers already in the 1950s (8). In the 1980's and 90's, these studies have been continued by many others to unravel the effects of diet on the distribution of cholesterol over the various lipoproteins (9). From all these experiments it can be concluded that especially the saturated and trans fatty acids have an unfavorable effect on the serum lipoprotein profile. The recommended dietary intake for saturated plus trans fatty acids is nowadays less than 10 percent of energy and for total fat 30-35 percent of energy. Large food consumption surveys in 1987, 1992 and 1998 in The Netherlands have shown that the saturated and total fat intake in these years has only reduced from 16 to 14 and 40 to 36 percent of energy.

A meta-analysis of 17 randomized dietary intervention trials, showed that a $10 \%$ reduction in total cholesterol lowered the occurrence of $\mathrm{CHD}$ with approximately $13 \%$ and total mortality around $6 \%$. These interventions were mainly focussed on reducing saturated fat at the expense of unsaturated fat, although in some studies other life-style interventions - such as weight reduction - were included as well (10). Except for changing dietary fat and fatty acid intake, several other dietary changes have also positive effects on the serum lipoprotein profile. For example, increasing fiber intake as well as weight reduction in overweight subjects favorably affect serum lipid and lipoprotein concentrations. 
The relationship between the mortality of CHD and serum cholesterol concentrations is progressive and continuous (11). As shown in figure 2, the risk for mortality due to CHD rises exponentially, in particular when cholesterol concentrations exceed the range of 4 to $5 \mathrm{mmol} / \mathrm{L}$. However, in general only those people with highly elevated serum cholesterol concentrations are treated with cholesterol-lowering drugs. This will indeed lower their CHD-risk, but it will not lead to a major improvement in the morbidity and mortality in the entire population. This is due to the simple fact that the absolute number of patients with high serum cholesterol concentrations is relatively low. In fact, CHD mortality is the highest in subjects with serum cholesterol concentrations between 4.7 and $6.5 \mathrm{mmol} / \mathrm{L}$ (12). Their absolute risk for CHD is lower compared to patients with higher concentrations, but their numbers are much higher. This means that lowering cardiovascular risk for this group also has a large health impact for the population as a whole.

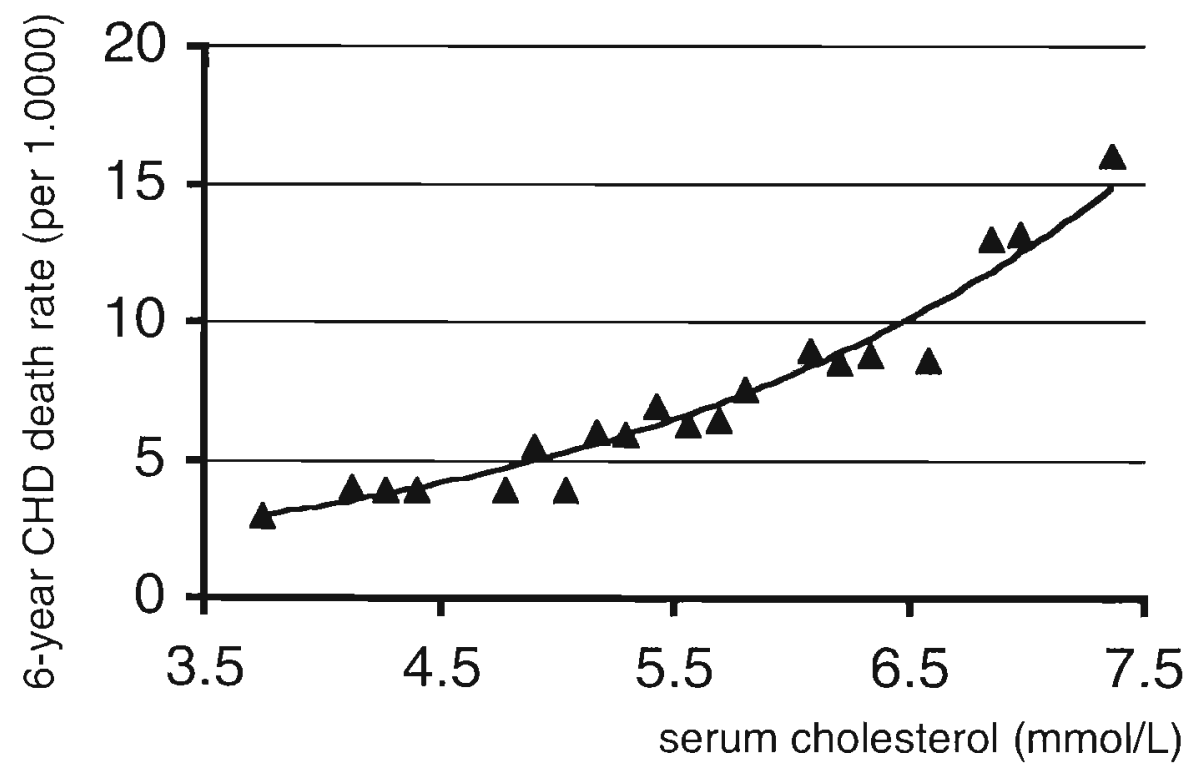

Figure 2: The relationship between the mortality of $\mathrm{CHD}$ and serum cholesterol concentrations is progressive and continuous. On the $x$-axis serum cholesteral concentrations and on the $y$-axis CHD mortality numbers are depicted (based on reference 11). 
Patients with current episodes of coronary heart disease or with a high risk for this disease should always be directed towards certain lifestyle interventions, and secondly - if indicated - to drug treatment. Currently HMGCoA reductase inhibitors (compounds that inhibit the endogenous cholesterol synthesis) are the most frequently used drug for lowering elevated serum total and LDL cholesterol concentrations. It is, however, generally agreed that statins treatment should be limited to subjects with high cholesterol concentrations or with a high risk for CHD due to a combination of risk factors (13). Thus, a person with a moderately increased serum cholesterol concentration (for example $6.1 \mathrm{mmol} / \mathrm{L}$ ) - but without manifest coronary heart disease and / or other risk factors - is not indicated for drug treatment. As mentioned above, the largest numbers of CHD-patients will be found among people with mildly or moderately elevated cholesterol concentrations. Presently, these subjects are only advised to follow a healthy life style, which includes a prudent diet. As outlined above by changing certain dietary habits the unfavorable serum lipoprotein profile can be improved. However, the hypocholesterolemic effect of the dietary changes alone might not always be enough. Particularly in this situation the recent development of functional foods offers new possibilities.

\section{Functional foods}

We are currently facing a change in the perception in the concept of 'healthy diet'. There is a shift going on towards the possibilities of nutrition from the elimination of nutrient deficiencies towards an improvement of health and quality of life. This awareness has resulted in the development of functional foods, which claim to have beneficial effects for consumers. According the functional food science in Europe (FUFOSE) project the definition of a functional food is a food which contains a food component (whether a nutrient or not) that affects one or more targeted functions in the body in a positive way. It can however also include foods in which a potentially harmful component has (or components have) been removed by technological means (14).

Of course a relevant question is whether consumption of these functional foods endorse an unhealthy life style. In other words, can an unhealthy diet be 'neutralized' by the consumption of functional foods? This is - and should never be - advocated. Ideally, consumption of functional foods is additional to the implementation of a healthy life style. For example, as already mentioned, an obligatory step in the treatment of an unfavorable lipoprotein profile is to advise to use a prudent diet. However, this will not be sufficient for all people to reach the aimed reduction in LDL cholesterol, consumption of products enriched with 
plant stanol esters - which are effective in combination with a lipid-lowering diet (15) - can be a helpful addition.

The possible contribution of functional foods to the improvement of health in general also concerns the aspect of dietary compliance. It is generally known that it is extremely difficult to keep people motivated to follow dietary guidelines for many years. Nutrition plays an important social role in our daily life. Initially patients are extremely motivated and really want to follow a healthy diet, but within a certain period of time many fall back into their old behavior. Indeed, a recent meta-analysis has shown that the reduction in serum cholesterol concentrations attributable to the dietary intervention was $8.5 \%$ at 3 months and was reduced after around 1 year to approximately $5.5 \%(16)$. These results show that a reasonable LDL cholesterol reduction can easily be achieved with dietary counseling. On the longer term, however, it is difficult to adhere for many reasons to this healthy life style. In this case the introduction of functional foods might offer new possibilities to reach the goals of cholesterol lowering diets, also on the longer term. By introducing a wide range of functional foods, such as plant stanol ester enriched light-margarines, low-fat yogurts, salad dressings (based on unsaturated fatty acids), light-cheese spreads, skimmed milk, etc. it now becomes possible to use a healthy diet (according the dietary recommended allowances), which in addition supplies plant stanol esters. Since a person may be more motivated to consume the plant stanol ester enriched products, this is a way to easily introduce the originally healthy products in some ones social life, and consequently combine a healthy life-style with functional foods. Reaching the targeted reduction in LDL cholesterol will now help to keep people motivated on the longer term to adhere to the guidelines of a prudent diet.

\section{Plant stanol esters as functional foods}

Plant stanol esters incorporated into margarines are one of the first examples of a functional food with proven effectiveness. As already discussed, such functional foods are not only of particular interest for patients with mild to moderate hypercholesterolemia, but also for hypercholesterolemic patients on drug therapy. The cholesterol-lowering effect of statin therapy alone is not always sufficient, while combination therapy, for example statins with resins, is effective. With the introduction of cholesterol-lowering functional foods it is now also possible to combine statins with these products in order to reach the 
hypocholesterolemic goals. (17). Another attractive possibility is that the dose of drugs can be lowered through the use of plant stanol ester enriched products.

\section{Short history of plant sterol and stanol esters}

About 50 years ago, it was observed that feeding soy-beans to chickens resulted in decreased serum cholesterol levels (18). Further studies showed similar effects in rabbits and humans, and it appeared that these effects could be ascribed to the soy-sterols (19-22). The initial crystalline plant sterols were, however, poorly soluble in fat and very large quantities (10 to $20 \mathrm{~g} / \mathrm{d}$ ) were needed to obtain substantial reductions in serum cholesterol levels. This has limited the practical use of plant sterols as cholesterol-lowering agents for many years.

In the seventies it was found that esterification with fatty acids increased the solubility of plant sterols in fat from $2 \%$ to $20 \%$, with no effects on its effectiveness (23). This finding greatly enhanced the practical use of plant sterols. Later studies also demonstrated that the fat solubility of plant stanols increased after esterification with fatty acids (24). By esterification, levels up to $15 \%(\mathrm{w} / \mathrm{w})$ plant stanols as its fatty acid esters can easily be incorporated in margarines.

The cholesterol lowering capacity of free sitosterol and sitostanol have been compared in animals and humans. In male Wistar rats, for example, a diet with $1.0 \%$ cholesterol $(w / w)$ plus $0.1 \%, 0.5 \%$, or $1.0 \%$ free sitosterol or free sitostanol lowered total cholesterol levels in a dose-dependent manner. Sitostanol, however, appeared to be more effective with respect to serum cholesterol reductions, and also lowered the absorption of dietary cholesterol more effectively than sitosterol (25). The first study in humans that compared side-by-side the serum cholesterol reductions of free plant sterols and stanols also showed a more pronounced reduction in children consuming free plant stanols compared to free plant sterols (26). However, the design of this study was not adequate, since diets were fed sequentially and results could therefore have been confounded by unknown drifts with time. Later studies did not find a difference between esterified plant sterols and stanol esters. Both plant sterol esters and plant stanol esters have been found to lower cholesterol absorption (27) and LDL cholesterol concentrations to the same extent $(27,28)$. 


\section{Effects of plant sterols and stanol on intestinal cholesterol absorption}

Plant sterols and stanols are structurally related to cholesterol and are in the intestinal tract incorporated into the mixed micelles. As plant sterols and stanols are more hydrophobic than cholesterol, they have a higher affinity for micelles than cholesterol has. Consequently, they replace cholesterol from the mixed micelles. This results in a reduced intestinal cholesterol absorption and a higher fecal excretion of cholesterol and its metabolites (figure 3). Except for dietary cholesterol, plant stanol esters also lower biliary cholesterol absorption. This may explain why plant sterols and stanols are also effective, when dietary cholesterol intake is low.
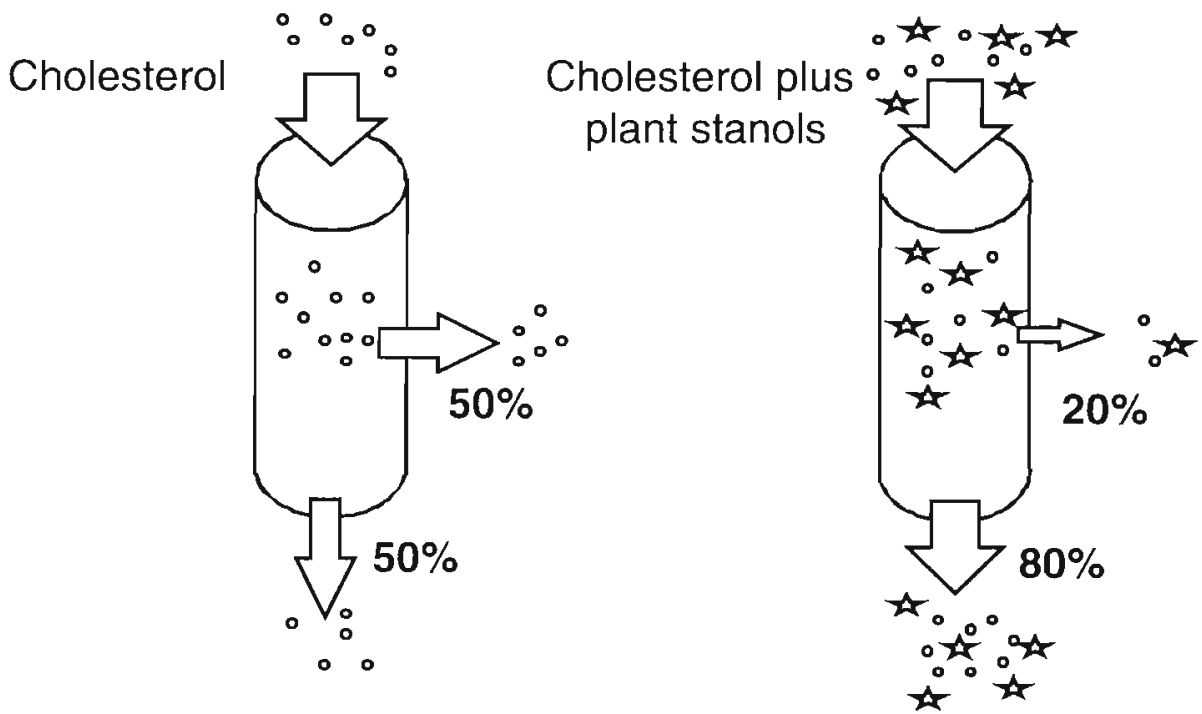

Figure 3: Approximately $50 \%$ of the cholesterol (open circles) in the intestine is absorbed by the enterocytes, while the other $50 \%$ is excreted as such or as metabolites via the faeces (left panel). If plant stanols (black stars) are also present in the intestinal Iumen, cholesterol absorption is reduced to approximately $20 \%$, while excretions increases to $80 \%$ (right panel). The plant stanols themselves are hardly absorbed.

A still unsolved question is why plant sterols and stanols are not absorbed to the same extent as cholesterol. It is theoretically possible that a specific carrier exists that transports cholesterol over the intestinal brush border, but not plant sterols and stanols. Such a carrier, however, has still not been identified. In fact, the precise mechanism by which micellar cholesterol crosses the brush border membrane is still unknown. One hypothesis proposes that this process is 
driven by passive diffusion, partly because a specific sterol carrier protein responsible for active intestinal cholesterol absorption has not yet been identified. Scavenger receptor class B type I (SR-BI) protein, present in the brush border membrane, may possibly be involved, since cholesterol absorption can be inhibited by addition of SR-BI antibodies (29). Also another recent study strongly suggested the existence of a specific saturable cholesterol transporter in the intestinal mucosa $(30,31)$. If a specific cholesterol intestinal carrier is found, it is of course interesting to examine effects of plant sterols and stanols on this transporter.

To summarize, it is known that plant stanol esters lower cholesterol incorporation into mixed micelles and consequently lowers intestinal cholesterol absorption and serum LDL cholesterol concentrations. Many effects of plant stanol esters are however unknown or have not been carefully studied. Therefore, in this thesis studies are presented that have not only examined the effects of plant stanol esters on various parameters associated with coronary heart disease, but also analyzed effects on cholesterol metabolism at the molecular level.

\section{Outline of the thesis}

This thesis describes the results of two human intervention studies in non-hypercholesterolemic subjects. The studies were not only designed to look at the effects of plant stanol esters on cardiovascular risk markers, but also to further unravel their effects on cholesterol metabolism. In a third study, the presence of plant sterol oxidation products (oxyphytosterols) in serum from phytosterolemic patients was analyzed.

Chapter 2 is a review on the effects of plant sterol and stanol esters on lipoprotein metabolism and cardiovascular risk markers. In the other chapters the results of the three studies, as mentioned in the previous paragraph, are described - divided into three sections. Section (I) presents effects on lipids, (apo)lipoproteins and fat-soluble antioxidants. In section (II) effects of plant stanol esters consumption on cholesterol metabolism and its interaction with genetic background are described, while section (III) pays attention to the oxidation of plant sterols. 


\section{(I) Lipids, (apo)lipoproteins and fat-soluble antioxidants}

It was known from the famous North-Karelia study as well as from other studies, that plant stanol esters incorporated into rapeseed oil based margarines lowered the concentrations of the atherogenic LDL particles in the Finnish population (32) by $13 \%$. In these studies, pine-wood based stanol ester mixtures were used, composed of $92 \%$ sitostanol and $8 \%$ campestanol. However, plant stanols can also be derived from vegetable oils, but such mixtures contain only $68 \%$ sitostanol and $32 \%$ campestanol. It has been postulated that the less absorbable plant sterols or stanols reduced cholesterol absorption more effectively. As humans absorb less sitostanol than campestanol, differences in plant stanol ester composition might therefore affect a mixture's effects on the serum lipoprotein profile. In the study described in chapter 3, we compared the hypocholesterolemic effects of the wood-based plant stanol esters with those of vegetable-oil based plant stanol esters, which differ in their sitostanol / campestanol ratios. Besides effects on lipids and lipoproteins, also changes in coagulation and fibrinolytic parameters were analyzed.

Since plant stanol esters lower the absorption of cholesterol, we reasoned that also the metabolism of other lipophylic compounds may also be affected. In chapter 4 we have therefore examined changes in serum concentrations of fatsoluble vitamins (retinol) and dietary derived antioxidants (tocopherols, and carotenoids) and have related these changes to changes in cholesterol absorption. Ubiquinone-10, another fat-soluble antioxidant, is hardly derived from the diet, but mainly endogenously synthesized as a side product of the cholesterol synthesis cascade. This may suggest that changes in the activity of HMG-CoA reductase, the rate limiting enzyme for cholesterol synthesis, affects plasma ubiquinone levels As plant stanol ester consumption increases cholesterol synthesis, we have also examined effects on plasma ubiquinone concentrations.

At the time we had finished our first study, the general believe was that the cholesterol-lowering effect of plant stanol esters was mainly due to the decrease in the solubility of cholesterol into the mixed micelles. Therefore, it was thought that plant stanol esters should be consumed at each cholesterolcontaining meal in order to reach an optimal effect. To examine if this was true, we carried out a second study to compare the hypocholesterolemic effects of $2.5 \mathrm{~g}$ plant stanol esters consumed at once (during lunch) with those of $2.5 \mathrm{~g}$ plant stanol esters consumed over the day at each meal (chapter 5). This difference of plant stanol intake over the day was proportional to cholesterol 
intake over the day.

\section{(II) Effects on cholesterol metabolism and the interaction with genetic background}

In chapter 6, we explored the mechanisms underlying the hypocholesterolemic response of plant stanol ester consumption. So far, most studies had focussed on effects on intestinal cholesterol absorption. We have now analyzed in mononuclear blood cells changes in LDL receptor MRNA and in LDL-receptor cell-surface protein concentrations. Moreover, in situations of a reduced supply of intestinal derived cholesterol to the liver, endogenous cholesterol synthesis is upregulated. Therefore, we also analyzed changes in endogenous cholesterol synthesis both by looking at changes in markers for cholesterol synthesis (lathosterol) as well as in mRNA concentrations of HMGCoA reductase.

Possible effects of genetic background on changes in cholesterol metabolism and serum lipoprotein concentrations after plant stanol ester consumption are reported in chapter 7. Except for apo-E polymorphism, effects of genetic variation in other proteins involved in cholesterol metabolism were evaluated. In this study we have analyzed the effects of apo-A-IV Gin ${ }^{360} \rightarrow \mathrm{His}$, apoA-IV Thr ${ }^{347} \rightarrow$ Ser, CETP Taq IB, SR-BI Hae III, and HMG-CoA reductase VNTR polymorphism.

\section{(III) Oxidation of plant sterols}

Cholesterol oxidation products are possible atherogenic compounds and can be derived from our diet, but can also be formed endogenously, either enzymatically or non-enzymatically. Especially non-enzymatic oxysterols are thought to be highly atherogenic. Most of these non-enzymatic cholesterol oxidation products are oxidized around the unsaturated bound between the C5 and $\mathrm{C} 6$ atom of the cholesterol molecule. $7 \beta-\mathrm{OH}-\mathrm{Cholesterol} \mathrm{in} \mathrm{particular} \mathrm{may}$ be a relevant oxysterol, since serum concentrations were found to predict the three-year increase in carotid wall thickness (33). The structure from plant stanols is different from cholesterol, because plant stanols have a saturated bound between the $\mathrm{C} 5$ and $\mathrm{C} 6$ atom. Therefore, plant stanols are not susceptible to oxidation at this position. However, plant sterols such as sitosterol and campesterol have, like cholesterol, a double bound between the $\mathrm{C} 5$ and $\mathrm{C} 6$ atom. Therefore, as described in chapter $\mathbf{8}$, we have examined if plant sterols are oxidized into comparable oxidation products, as described for cholesterol. To examine this, we have analyzed serum from phytosterolemic 
patients. Phytosterolemia is a rare autosomal recessive inherited disease and these patients have about 50 to 60 times higher serum plant sterol concentrations, up to $65 \mathrm{mg} / \mathrm{dl}$ or $1.57 \mathrm{mmol} / \mathrm{L}$. We expected that the prolonged half-life of plant sterols in serum of these patients extended the exposure to potential oxidizing mechanisms. In order to measure oxidized plant sterols in serum, a sensitive analytical method based on combined gas-liquid chromatography mass spectrometry (GC-MS) was developed.

Chapter 9 is the general discussion in which the main outcomes of all studies are discussed and placed into a broader perspective. Further, final conclusions as well as practical implications have been formulated.

\section{References}

1. Fernandez-Britto, JE, Wong $R$, deposition. Proc Natl Acad Sci USA Contreras D, Nordet $P$, Sternby $\mathrm{NH}$. Pthomorphometrical characteristics of atherosclerosis in youth. A multinational investigation of WHO/World Health Federation (19861996), using atheromic system. Nutr Metab Cardiovasc Dis 1999;9:210-219

2. Austin MA. Plasma triglyceride and coronary heart disease. Arterioscler Thromb 1991;11:2-14

3. Steinbrecher UP, Zhang $H$, Lougheed $M$. Role of oxidatively modified LDL in atherosclerosis. FreeRad Biol Med 1990:9;155-168

4. Steinberg D, Parthasarathy $S$, Garew TE, Khoo JC, Witztum JL. Beyond cholesterol. Modifications of low density lipoprotein that increase its atherogenicity. NEJM 1989:320;915924

5. Ross R. Atherosclerosis - An inflammatory disease. NEJM 1999;340:115-126

6. Goldstein JL, Ho YK, Basu SK, Brown MS. Binding site on mcrophages that mediates uptake and degradation of acetylated low density lipoprotein. producing massive cholesterol 1979:76;333-337

7. Hodis HN. Triglyceride rich lipoprotein remnant particles and risk of atherosclerosis. Circulation 1999;99:2852-2854

8. Keys A, Anderson JT, Grande F. Prediction of serum cholesterol responses of man to changes in fats in the diet. Lancet 1957;2:959

9. Mensink RP, Katan MB. Effects of dietary fatty acids on serum lipids and lipoproteins. A meta-analysis of 27 trials. Apterioscler Thromb 1992;12:911-919

10. Truswell AS. Review of dietary intervention studies: effect on coronary events and on total mortality. Aus NZ J Med 1994;24:98-106

11. Martin MJ, Hulley SB, Browner WS. Kuller LH, Wentworth D. Serum cholesterol, blood pressure and mortality: implications from a cohort of 361,662 men. Lancet 1986;11:933-936

12. Johnson $C L$, Rifkind $B M$, Sempos $C T$. Carrol MD, Bachorik PS, Briefel RA, Gordon DJ, Burt VL, Brown CD, Lippel K. Cleeman JI. Declining serum total cholesterol leveis among US adults: 
the national health and nutrition surveys. JAMA 1993;269:3002-3008

13. Centraal begeleidingsorgaan voor intercollegiale toetsing. Behandeling en preventie van coronaire hartziekten door verlaging van de plasma cholesterol concentratie. Consensus Cholesterol tweede herziening 1998

14. Functional Food Science in Europe. Brit J Nutr 1998;80, Suppl. 1, S3-S4

15. Hallikainen MA, Uusitupa Ml. Effects of 2 low-fat stanol ester-containing margarines on serum cholesterol concentrations as part of a low fat diet in hypercholesterolemic subjects. Am J Clin Nutr 1999;69: 403-410

16. Tang $\mathrm{JL}$, Armitage $\mathrm{JM}_{\mathbf{1}}$ Lancaster $\mathrm{T}$, Silagy CA, Fowler GH, Neil HAW. Systemic review of dietary intervention trials to lower blood total cholesterol in free living subjects. BMJ 1998;316:1213-1220

17. Blair S, Capuzzi DM, Gottlieb SO, Nguyen T, Morgan JM, Cater NB. Incremental reduction of serum total cholesterol and low-density lipoprotein cholesterol with the addition of plant stanol ester containing spread to statin treatment. Am J Cardiol 2000;86:46-52

18. Peterson DW. Elfect of soybean sterols in the diet on plasma and liver cholesterol in chicks. Proc Exp Biol Med 1951;78:143-147

19. Peterson DW, Nichols LW, Peck NF. Depression of plasma cholesterol in humans consuming butter-containing soy sterols. Fed Proc 1956;65:569

20. Pollak OJ. Successful prevention of experimental hypercholesterolemia and cholesterol atherosclerosis in the rabbit. Circulation 1953a;7:696-701
21. Pollak OJ. Reduction of blood cholesterol in man. Circulation 1953b;7:702-706

22. Pollak OJ. Prevention of hypercholesterolemia in the rabbit: successful prevention of cholesterol atherosclerosis. Reduction of blood cholesterol in man. Circulation 1952;6:459

23. Mattson FH, Volpenhein RA, Erickson BA. Effect of plant sterol esters on the absorption of dietary cholesterol. J Nutr 1977;107:1139-1146

24. Vanhanen, HT, Blomqvist $S$, Ehnholm C. Hyvönen M, Jauhiainen M, Torstila I, Miettinen TA. Serum cholesterol, cholesterol precursors, and plant sterols in hypercholesterolemic subjects with different apoE phenotypes during dietary sitostanolester treatment. J Lipid Res 1993;34: 1535-1544

25. Sugano M, Kamo F, Ikeda I. Lipidlowering activity of phytostanols in rats. Atherosclerosis 1976;24:301-309

26. Becker $M_{1}$ Staab $D$, von Bergmann $K$. Treatment of severe familial hypercholesterolemia in childhood with sitosterol and sitostanol. J Pediatr 1993:122: 292-296

27. Normén L, Dutta $P$, Lia A, Andersson $H$. Soy sterol esters and b-sitostanol ester as inhibitors of cholesterol absorption in human small bowel. Am $\mathrm{J}$ Clin Nutr 2000;71: 908-913

28. Hallikainen MA, Sarkkinen ES, Gylling $H$, Erkkila AT, Uusitupa MIJ. Comparison of the effects of plant sterol ester and plant stanol esterenriched margarines in lowering serum cholesterol concentrations in hypercholesterolaemic subjects on a low-fat diet. Eur J Clin Nutr 2000;54: 
671-677

29. Hauser $H_{1}$ Dyer $J_{H}$ Nandy $A_{2}$ Vega MA, Werder M, Bieliausaite $E$, Weber FE, Compassi S, Gemperli A, Boffeli D, Wehrli E, Schulthess $G$, Phillips MC. Identification of a receptor mediating absorption of cholesterol in the intestine. Biochem 1998;37: 17843=17850

30. Hernandez $M$, Montenegro J, Steiner M, Kim D, Sparrow C, Detmers PA, Wright SD, Chao $Y$. Intestinal absorption of cholesterol is mediated by a saturable, inhibitable transporter. Biochim Biophys Acta 2000;1486: 232 242

31. Detmers PA, Patel $S$, Hernandez $M$, Montenegro J, Lisnock J, Pikounis B. Steiner M, Kim D, Sparrow C, Chao $Y$, Wright SD. A target for choleterol absorption inhibitors in the enterocyte brush border membrane. Biochim Biophys Acta 2000;1486: 243-252

32. Miettinen TA, Puska $P$, Gylling $H_{\text {, }}$ Vanhanen $H$, Vartiainen $E$. Reduction of serum cholesterol with sitostanolester margarine in a mildly hypercholesterolemic population. N Eng J Med 1995;333:1308-1312

33. Salonen, JT, Nyyssonen $K$, Salonen R, Porkkala-Sarataho E, Tuomainen T, Diczfalusy U, Björkhem I. Lipoprotein oxidation and progression of carotid atherosclerosis. Circulation 1997:95:840-845 


\title{
Chapter 2
}

Effects of plant sterols and stanols on lipid metabolism and cardiovascular risk

\author{
Plat J, Mensink RP
}

Department of Human Biology, Maastricht University, The Netherlands

(Based on: Nutrition Metabolism and Cardiovascular Diseases 2001;11:31-40) 


\section{Abstract}

Functional foods enriched with plant sterols and stanols are currently widely available on the market in many countries. Due to their structural similarity with cholesterol, plant sterols and plant stanols lower intestinal absorption of cholesterol. This results in a 10-15\% reduction in LDL-cholesterol when daily intakes are 2-3 gram of plant sterols or stanols. Plant sterols and stanols are also effective as part of a cholesterol-lowering diet and in combination with cholesterol-lowering drugs.

Estimates for the absorption of plant sterols (sitosterol and campesterol) and of campestanol are around $10 \%$, and for sitostanol less than $5 \%$. Lipidstandardized plasma levels are very low. but do increase when statins are used. Extensive toxicological evaluation studies did not reveal any harmfull sideeffects. In human studies, side-effects were comparable to placebo treatment. However, lipid-standardized levels of the hydrocarbon carotenoids may decrease, although levels are still within the normal range. Together, these findings indicate that these functional foods have great potential in the prevention of coronary heart disease. However, post-marketing surveillance for functional foods in general is necessary, for example to monitor possible adverse effects, and to describe consumers and consumption patterns. 


\section{Cholesterol absorption}

Cholesterol from the intestinal lumen originates for approximately $80 \%$ from endogenous synthesis and for $20^{\circ}$, from dietary sources. Because the solubility of cholesterol in aqueous systems such as the intestinal chyme is low, its absorption depends on the formation of mixed micelles: mixtures of free cholesterol, bile salts, phospholipids, monoglycerides and free fatty acids. These micelles transport cholesterol across the unstirred water layer, a lamellar interphase between the intestinal lumen and the mucosal cells (Figure 1). Micelles are not absorbed as intact aggregates, but the various components are taken up by the enterocytes at independent rates (1). Intracellular cholesterol is subsequently esterified by acyl-coenzyme $A$ : cholesterol acyltransferase (ACAT), thereby preventing the diffusion or transportation of free cholesterol back into the intestinal lumen. Two different ACAT enzymes are known, but in the intestine only ACAT-2 is responsible for esterification of sterols (2). Finally, cholesterol esters are assembled into chylomicrons, which are secreted into the lymphatic system and transported to the blood circulation.

The mechanism by which micellar cholesterol crosses the brush border membrane is still unknown. It has been suggested that this process is driven by passive diffusion (3), because a specific sterol carrier protein responsible for active intestinal cholesterol absorption was not known. Some studies have now suggested that sterol carrier protein-2 (SCP-2) is a regulatory protein for cholesterol uptake from the lumen, but Ikeda et al (4) have clearly shown that SCP-2 does not play an essential role in cholesterol transfer. However, the presence of scavenger receptor class B type I (SR-BI) protein in the brush border membrane and the inhibition of cholesterol absorption after addition of SR-BI antibodies do suggest a role for SR-BI in intestinal cholesterol absorption (5). Recently, it has been reported that the level of intestinal cholesterol absorption is mediated by heterodimers of the retinoid $X$ receptor $(R X R)$ with oxysterol receptors (LXR) which regulate the expression of ATP binding cassette protein $(A B C-1)$ and cholesterol 7-alpha hydroxylase (6). ABC-1. however, is not involved in the transport of cholesterol into the enterocyte, but in the transport of cholesterol out of the enterocytes, back into the lumen. These findings may explain only one aspect of the regulation of intestinal cholesterol absorption, as the results of two other recent studies strongly suggest the existence of a specific saturable cholesterol transporter in the intestinal mucosa $(7,8)$ 
Estimates of intestinal cholesterol absorption range between $34-70 \%$ $(9,10)$. As plant sterols and stanols interfere with the incorporation of cholesterol into the mixed micelles, they do lower intestinal cholesterol absorption.

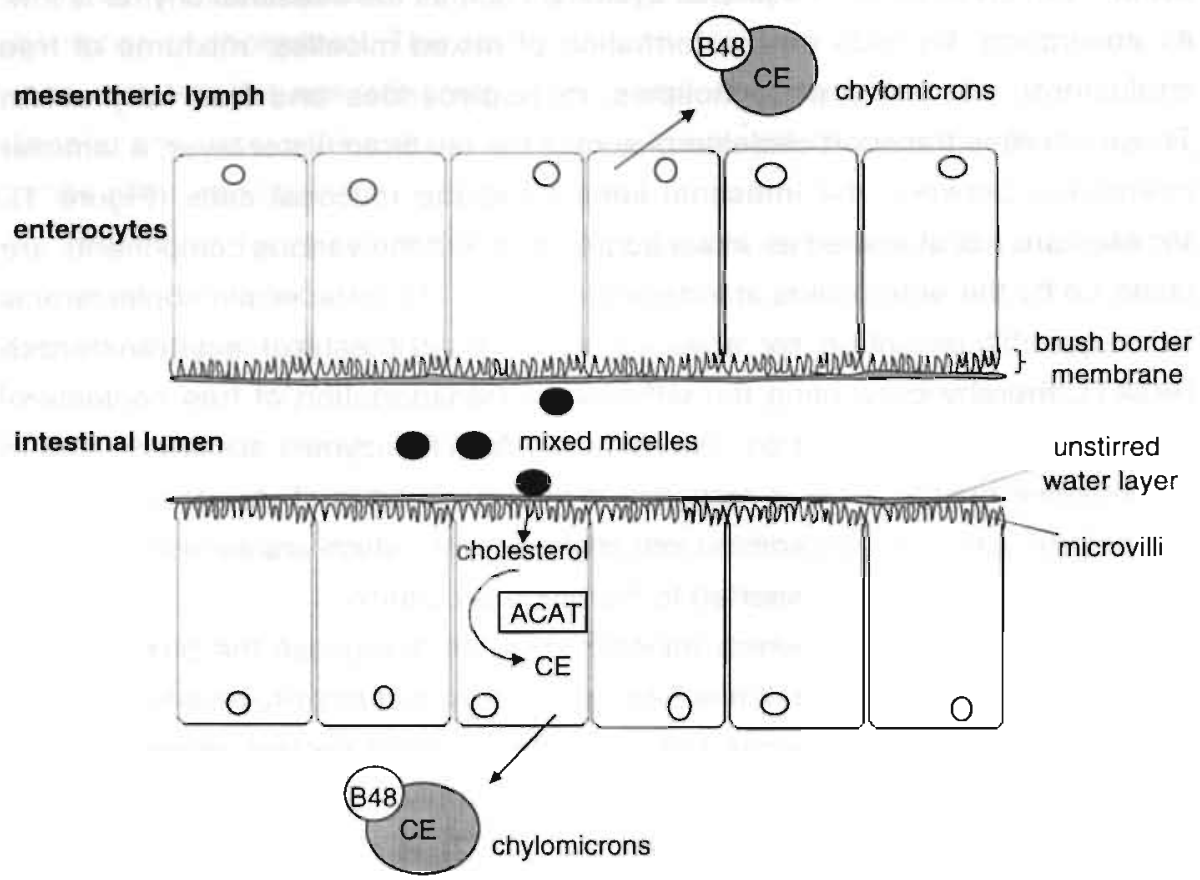

Fiçure 1: Dietary and biliary cholesterol is incorporated into mixed micelles together with free fatty acids, mono- and di-acylglycerides, phospholipids and bile acids. Mixed micelles transport the lipophylic compounds across the unstirred water layer followed by uptake in the enterocyte. For this, cholesterol must be transported across the brush border membrane consisting of the microvilli covering the luminal side of the enterocytes. Intracellular esterification of cholesterol by Acyl-coenzyme A: cholesterol acyltransferase (ACAT) is needed to facilitate the incorporation of cholesterol esters (CE) into chylomicrons. Chylomicrons are excreted on the basolateral side of the enterocyte into the mesentheric lymph after which the chylomicrons are transported into the circulation.

\section{Plant sterols and stanols}

Plant sterols such as $\beta$-sitosterol, campesterol, and stigmasterol are the natural occurring equivalent in the fauna of the mammalian cholesterol. As they are not synthesized by man, all plant sterols present in human body are derived from the diet. 
Several classes of plant sterols exist. Sitosterol, the predominant plant sterol in nature, and campesterol and stigmasterol are 4-desmethylsterols (11). These plant sterols have one or more unsaturated bonds that can be saturated with hydrogen, which results in the formation of plant stanols: sitostanol and campestanol. As shown in figure 2, both plant sterols and stanols are structurally related to cholesterol. Plant sterols and stanols are present in small amounts in several dietary plant products such as vegetable oils, nuts, seeds, cereals and beans. Also small amounts of the 4,4-dimethylsterols such as lupeol and alpha-amyrin are found in nature. As compared with 4desmethylsterol, these plant sterols show less structural overlap with cholesterol. Moreover, 4,4-dimethysterols are not hypocholesteroleremic $(12,13)$ and will therefore not be discussed in this review.

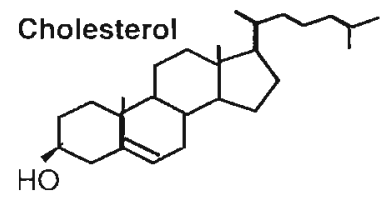

4,4-dimethylsterols
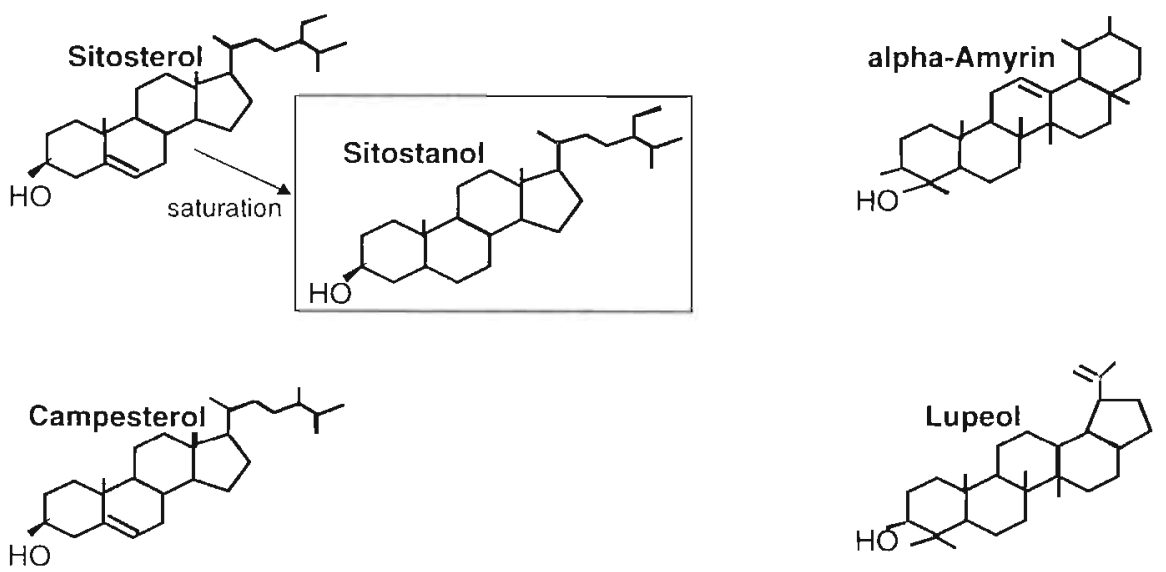

Figure 2: On top the structure of one molecule cholesterol is shown. On the left side two 4desmethylsterols (sitosterol and campesterol) are shown, while it is also indicated how sitostanol can be formed from sitosterol by saturation of the double bond. 4,4 dimethylsterols such as alpha-amyrin and lupeol are depicted on the right side.

The amounts of 4-desmethylsterols (sitosterol, campesterol, brassicasterol and stigmasterol) in Western diets equals almost the amount of dietary cholesterol and average daily plant sterol consumption is $160-360 \mathrm{mg}$ (14). 
Intakes, however, vary widely between population groups. Vegetarians, for example, have a relatively high plant sterol consumption due to their characteristic eating habits (15). Although intakes of plant sterols and cholesterol are comparable, intestinal absorption between these two types of sterols differs considerably. Compared to cholesterol, plant sterols are poorly absorbed, which suggests that the enterocytes discriminate between cholesterol and plant sterols that differ only from cholesterol by an additional methyl or ethyl group at the C-24 position. Absorption of plant stanols is also low, or even lower. The underlying mechanism for this interesting phenomenon is still unclear. It is known, however, that plant sterols and stanols are poorly esterified by intestinal ACAT (16). Since sterols need to be esterified for incorporation into chylomicrons, absence of an adequate esterification in the enterocyte might explain the poor absorption of plant sterols into the lymph. Furthermore, the poor absorption of plant sterols and stanols may also to some extent be due to selective uptake of plant sterols and stanols over the brush border membrane (17).

Plasma plant sterol concentrations are about 15-30 times higher than plasma plant stanol concentrations, but still around 200 times lower than those of cholesterol (18). These differences can be partly explained by differences in intakes, but also by differences in absorption and metabolism. Absorption of plant sterols and stanols is low as compared with cholesterol, but differences between the individual plant sterols and stanols do exist. Heinemann et al. (19) have shown that both the absorption rate and the percent absorption of free campesterol $(9.6 \%)$ and campestanol $(12.5 \%)$ was significantly higher than that of stigmasterol $(4.8 \%)$ and sitosterol $(4.2 \%)$, while sitostanol absorption was negligible. In addition, half-life of plant sterols and stanols in the circulation is relatively short compared to that of cholesterol, since plant sterols and stanols are rapidly eliminated via bile. In contrast to cholesterol, plant sterols are not converted into C24 bile acids (20), but mainly excreted in its free form or, at least in rats, as $\mathrm{C} 21$ acids (21). The biliary excretion for sitosterol may be faster than that for campesterol. This can be explained by the lower substrate specificity of sitosterol for hepatic ACAT compared to campesterol, which results in a poor hepatic esterification of sitosterol (22). Since the major excretory route for sterols from the body is through the bile as unesterified sterols, sitosterol excretion may be higher (23). This may suggest that in the liver esterified campesterol is excreted into the circulation again, packed in VLDL particles, although this has never been investigated. Due to a higher 
intestinal absorption as well as a slower biliary excretion, campesterol concentrations in the circulation are twice as high as compared with those of sitosterol, even when plant sterol esters mixtures are consumed that contain more sitosterol (47\%) than campesterol (25\%) (12). Plasma concentrations of plant stanols are much lower than those of plant sterols, which can at least partly be explained by its lower intestinal absorption (19). After plant stanol ester consumption, however, both plasma and biliary plant stanol levels were increased, but still lower than those of plant sterols (18).

Like cholesterol, plant sterols and stanols are lipophylic and transported by lipoproteins. Although their relative concentrations ( $\mu \mathrm{mol} / \mathrm{mmol}$ cholesterol) are the highest in HDL, in absolute terms ( $\mu \mathrm{mol}$ ) plant sterols are mainly transported by LDL, simply because LDL concentrations are much higher than those of HDL (24). Studies with isolated rat livers, perfused with plant sterol-rich lipoproteins from phytosterolemic patients, have shown that unesterified plant sterols carried to the liver in HDL are excreted into the bile, while plant sterols from LDL or VLDL are not (25). As reviewed by Botham and Bravo (26), the flow of lipoprotein derived cholesterol and endogenously synthesized cholesterol to the various pools is also strictly controlled. LDL-derived cholesterol is excreted for only a small part into bile and the major proportion reenters the circulation packed in VLDL particles together with newly synthesized cholesterol. HDL cholesterol is mainly excreted as such into bile or used for bile acid synthesis, which illustrates the function of HDL in the reverse cholesterol transport. This may suggest that plant sterols and stanols delivered to the liver by other lipoproteins than HDL are excreted into the circulation again via VLDL particles. If so, than it is important to undertand how HDL acquires plant sterol and stanols. These important issues certainly need further investigation.

\section{Effects of plant sterols and stanols on cholesterol metabolism}

Due to their structural similarity with cholesterol, plant sterols and stanols do replace cholesterol from the mixed micelles in the intestine. As plant sterols and stanols are more hydrophobic than cholesterol, they have a higher affinity for micelles. Consequently, cholesterol is displaced from the micelles, which results in a reduced intestinal cholesterol absorption. It has been shown that plant stanol esters not only lower dietary, but also biliary cholesterol absorption (27). This may explain why plant sterols and stanols are also effective when dietary cholesterol intake is low $(28,29)$. 
Studies with rats fed diets containing cholesterol, cholesterol plus sitosterol or cholesterol plus sitostanol for 10 days showed that in vivo sitostanol tended to reduce the micellar solubility of cholesterol more effectively than sitosterol (30). In humans, sitosterol infusion in the duodenum reduced cholesterol absorption by $50 \%$, while sitostanol infusion reduced cholesterol absorption by $85 \%$ (31). Absorption, however, was measured across a segment of $40 \mathrm{~cm}$ of the intestinal tract. Whether results are representative for the entire intestine is not known. Finally, serum cholesterol reductions were more pronounced in children when consuming free plant stanols compared to free plant sterols (32). Diets, however, were fed sequentially and results could therefore have been confounded by unknown drifts with time. Differences between free sitosterol and sitostanol were not found after esterification, since both sitosterol esters and sitostanol esters lowered cholesterol absorption (33) and LDL cholesterol concentrations to the same extent $(33,34)$. As only free plant sterols and stanols compete with cholesterol for incorporation into the mixed micelles, plant sterol or stanol esters need to be cleaved by intestinal cholesterol esterase. Cleavage appears to be very efficient, as in ileostoma fluid of colectomized patients consuming $2 \mathrm{~g}$ plant stanols as its fatty acid esters, plant stanols were for $90 \%$ in its free form (18). For plant sterol esters, such information does not exist in the literature. However, $0.8 \mathrm{~g}$ free plant sterols or esterified plant sterois lower LDL cholesterol levels to the same extent $(13,35)$, suggesting that at least at these relatively low doses cleavage of plant sterol esters is also very efficient.

The reduced cholesterol absorption caused by plant sterol and stanol ester consumption increases endogenous cholesterol synthesis (18). This will result in a changed contribution of endogenously synthesized cholesterol to the hepatic cholesterol pool, which may theoretically alter bile metabolism or VLDLproduction.

In colectomized patients plant stanol ester consumption did not affect biliary composition, the molar percentage of cholesterol in bile and the absolute amount of cholesterol excreted through bile (18). Begeman et al. (36), however, have reported a $12 \%$ decrease in biliary cholesterol saturation after consumption of plant sterols. In a study with gall stone patients, no effect of plant sterols on bile saturation was found (37). Thus, effects of plant sterols and stanols on bile metabolism are not conclusive.

Fasting plasma VLDL cholesterol concentrations and triacylglycerol concentrations are not affected by plant sterol or stanol ester consumption. It 
can be hypothesized, however, that VLDL-output may be increased, although this has never been examined. If hepatic cholesterol synthesis is increased, hepatic apoB100 production may also be increased (38). This may result in an increased VLDL-output, followed by a more rapid lipolysis and / or VLDL clearance resulting in unchanged VLDL cholesterol concentrations. Indeed, plant stanol ester consumption lower LDL production from VLDL and IDL in NIDDM men (39). IDL and LDL may subsequently be cleared more rapidly from the circulation, as we have recently shown that consumption of plant stanol esters resulted in an increased LDL receptor expression on human mononuclear blood cells (40).

Recently, we have examined if, for an optimum effectiveness, it was necessary to consume plant stanol esters with each cholesterol-containing meal. For this, thirty-nine subjects consumed in random order no plant stanols, $2.5 \mathrm{~g}$ plant stanols at lunch, and $2.5 \mathrm{~g}$ plant stanols divided over the three meals (breakfast $0.42 \mathrm{~g}$, lunch $0.84 \mathrm{~g}$, and dinner $1.25 \mathrm{~g}$, which is proportional to dietary cholesterol intake). Since consumption of plant stanol esters only at lunch resulted in a similar LDL-cholesterol reduction as compared to consumption of plant stanol esters divided over the three meals, we concluded that it is not necessary to consume plant stanols at each meal or simultaneously with dietary cholesterol (41). This suggests that the reduced incorporation of cholesterol into mixed micelles may not be the only mechanism for plant stanol induced cholesterol reductions. We therefore hypothesized that plant stanols remain in the intestinal lumen or may enter the enterocytes and affect intestinal lipoprotein metabolism as well. Further research is therefore necessary to fully understand the mechanisms by which plant sterols and stanols change lipoprotein metabolism.

\section{Phytosterolemia}

Although absorption of plant sterols is normally relatively low, some people have extremely high serum plant sterol concentrations, even up to $65 \mathrm{mg} / \mathrm{dL}$ (1.57 mmol/L), which is approximately 50-60 times higher compared to concentrations in healthy subjects. These subjects suffer from a rare inherited metabolic disease called phytosterolemia of which approximately 40 patients have been diagnosed worldwide (42). Although their serum cholesterol concentrations are only moderately elevated, premature atherosclerosis and xanthomatosis are already prevalent at a very young age $(43,44)$. The exact reason for this early plaque development is unclear, although plant sterols have been found in higher amounts - both absolute and as a percentage of total 
sterols - in their atherosclerotic leasions (45) compared to amounts in laesions from non-phytosterolemic subjects. Plant sterols, plant stanols and cholesterol were deposited, not only in the leasion, but also in other tissues (except the brain) in approximately the same increased ratio as in plasma.

Phytosterolemia is probably a multi-genetic disease, but the genes responsible have not been identified yet (46). Cholesterol absorption of phytosterolemic subjects seems normal (44), but there may be an intestinal defect to discriminate between cholesterol and plant sterols, resulting in an excessive plant sterol absorption. This higher absorption is accompanied by a defect to excrete sterols rapidly in bile (47). Moreover, phytosterolemic patients have a reduced cholesterol $7 \alpha$-hydroxylase (cyp7a1) activity - the rate limiting step in bile acid synthesis - probably due to inhibition of cyp7a1 by sitosterol (48). Not only the neutral bile acid synthetic pathway (cyp7a1) is inhibited. Studies with hepatic microsomes suggest that plant sterols also inhibit the acidic bile acid synthetic pathway, which is catalyzed by sterol 27 -hydroxylase (49). Furthermore, whole body cholesterol synthesis is reduced in phytosterolemic subjects (44) and it has been suggested that high intracellular (plant) sterol pools are sensed by sterol sensors regulating cellular cholesterol homeostasis (46). Biliary cholesterol excretion, however, is lower, possibly to compensate for the lower endogenous cholesterol synthesis (44). These metabolic abnormalities of phytosterolemic subjects may result in higher plant sterol concentrations, while serum cholesterol concentrations are only moderately increased.

\section{Plant sterols and stanols in combination with cholesterol lowering diets or drugs}

Earlier it has been suggested that plant sterols and stanols are only effective when consumed as part of a high cholesterol diet (50). A recent study, however, has shown that a low-fat plant stanol ester margarine reduced serum LDL cholesterol concentrations with on average $13.7 \%$ in hypercholesterolemic subjects, consuming a low-fat, low cholesterol diet (nearly a step 2 diet) (28). Also a plant sterol mixture containing $20 \%$ free sitostanol is effective as part of a prudent American diet (29).

HMG-CoA reductase inhibitors (statins) are currently the first choice for treating patients with hypercholesterolemia, while bile acid sequestrants (resins) and nicotinic acid are less frequently prescribed. Efficacy of the various statins varies and they lower serum LDL cholesterol concentrations on average by 24 - 
$50 \%$ (51). Combination therapy with two different hypocholesterolemic compounds, which each affect another pathway of cholesterol metabolism may be more effective in lowering cholesterol concentrations than single-drug therapy. So far several studies have shown that plant stanol esters are effective in combination with hypocholesterolemic agents. When 167 hypercholesterolemic subjects, who were already treated with different statins (lovastatin, pravastatin or simvastatin), consumed daily $3 \mathrm{~g}$ plant stanols as its fatty acid esters, serum total and LDL cholesterol concentrations were lowered by an additional $7 \%$ and $10 \%$, respectively (52). Surprisingly, combination of plant stanol esters with atorvastatin lowered serum LDL cholesterol by an additional $4 \%$ only. Efficacy of plant stanol esters in combination with statin therapy has also been demonstrated for other patient groups. As expected, pravastatin $(40 \mathrm{mg} / \mathrm{d})$ lowered lowered endogenous cholesterol synthesis and consequently serum LDL cholesterol concentrations with $38 \%$ in hypercholesterolemic non-insulin dependent diabetic men (NIDDM). Daily consumption of $3 \mathrm{~g}$ plant stanols as its fatty acid esters in stead of pravastatin showed a $14 \%$ reduction in serum LDL cholesterol concentrations. Combination of pravastatin with plant stanol esters lowered serum LDL cholesterol concentrations by $44 \%$ (53). These studies therefore show that combination of these two cholesterol-lowering compounds result in a larger response. Altematively, the same cholesterol-lowering efficacy at a lower pharmacological statin dose can be achieved, when plant stanol esters are consumed. Theoretically a synergistic effect on LDL cholesterol of statins in combination with plant stanol esters can be expected, since the increased endogenous synthesis due to plant stanol ester consumption may be blocked by statin treatment. It appears, however, that plant stanols and statins have rather additive than synergistic effects.

Neomycin and plant stanols, two components that lower intestinal cholesterol absorption, also have additive effects (54). Treatment with neomycin $(1.5 \mathrm{~g} / \mathrm{d})$, which is currently not longer used as a hypocholesterolemic agent, lowered serum LDL cholesterol concentrations by $29 \%$ due to a $49 \%$ reduction in cholesterol absorption. Combination of neomycin with $3 \mathrm{~g}$ plant stanols as its fatty acid esters a day lowered intestinal cholesterol absorption further to $79 \%$ and serum LDL cholesterol concentrations to $37 \%$. Interestingly, a daily consumption of more than $3 \mathrm{~g}$ plant stanols has hardly any additional effects (55). This may suggest that neomycin affects intestinal cholesterol absorption in another way. Neomycin disturbs intestinal micelle formation, which results in a micellar lipid precipitation (56). Therefore, plant stanols and neomycin both 
affect the incorporation of cholesterol into micelles, but possibly by different mechanisms.

Statin therapy not only affects cholesterol synthesis, but possibly also intestinal sterol absorption, as serum cholesterol-standardized concentrations of plant sterols and stanols are increased after statin treatment (57). Combination therapy of lovastatin with cholestyramine increased serum cholesterolstandardized plant sterol concentrations ever further by $49 \%$ compared to statin treatment alone (57).

Retrospective analysis of samples from the well-known $4 S$ study has now shown that subjects with a low endogenous cholesterol synthesis at baseline did hardly benefit from simvastatin therapy in terms of mortality. This finding was remarkable, since LDL cholesterol reductions were not related on (to) endogenous cholesterol synthesis at baseline (58). It was suggested by the authors that subjects with a low cholesterol synthesis have a high intestinal sterol absorption, as evidenced by high serum plant sterol levels. This may have potential negative effects on plaque development, since plant sterols and stanols are found in atherosclerotic leasions from phytosterolemic patients (45). A causal relationship between increased plasma plant sterol concentrations and atherosclerosis has, however, never been demonstrated. More importantly, it should be realized that serum plant sterol concentrations in phytosterolemic patients are many times higher than those of statin-treated patients. On the other hand, high plant sterol concentrations were found to track over time and were associated with increased premature coronary heart disease, independent of serum cholesterol concentrations (59). Whatever the explanations, these findings warrant that the clinical effects of combination therapy of cholesterollowering drugs with plant sterols and stanols should be monitored carefully over time.

\section{CHD risk}

On average, approximately a 3\% (Step 1 diet) or a 5.6\% (Step2 diet) reduction in LDL cholesterol levels can be achieved by dietary counseling in free living subjects (60). By incorporating plant sterols and stanols into a cholesterol-lowering diet. LDL cholesterol levels may be lowered by a further 9 $13 \%$, which may result in a sustained improvement in cardiovascular risk. Law (55) has recently summarized all published double blind trials using margarines with plant sterols and stanols. It was estimated that at a daily intake of $2 \mathrm{~g}$ of plant sterols or stanols a $25 \%$ risk reduction for heart disease could be 
expected. Although very plausible, it has formerly not been proven that a reduction in LDL cholesterol through consumption of plant sterols or stanols reduces cardiovascular risk. To examine this important question, studies with transgenic mice have been initiated and both plant sterol and stanol esters reduces plaque formation (61-63). It is also very relevant to know if plant sterols and stanols also initiate the regression - or at least delay the progression - of atherosclerotic leasions. To examine this, atherosclerosis was induced in apoEdeficient mice by feeding a Western diet, followed by a period of plant sterol feeding (64). Surprisingly, no effect on regression of atherosclerotic lesions was found. In fact, plaque size increased in both the control and the plant sterol group, but it should be noted that the plant sterols induced serum cholesterol reduction was not optimal, which may have confounded the results. However, the increase in leasion size was still less in the plant sterol group $(+28 \%)$ as compared to the control group $(+40 \%)$. No regression studies have been published with plant stanols or in man.

\section{Safety of plant sterols and stanols}

Since plant sterols and stanols will be incorporated into functional foods more and more, extensive safety evaluation studies have been conducted to evaluate their potential to be used as a safe functional food ingredient. Studies with animal and cell models did not reveal any evidence for in vitro estrogenic activity or in vivo uterothropic activity of both plant sterols and stanols $(65,66)$. Furthermore, in rats no adverse effects were found on the development of both the $F 1$ and $F 2$ generation or on reproductive performance (67-69). Finally, no genotoxicity (70) or any other adverse effects in rats (71) could be demonstrated for plant stanol esters

One aspect that deserves attention is the possibly lowered plasma concentrations of fat-soluble compounds other than cholesterol, especially the fat soluble antioxidants and vitamins. We have recently summarized the effects of plant sterol or stanol ester consumption on $\alpha+\beta$-carotene and $\alpha$-tocopherol concentrations in humans participating in placebo-controlled, double-blind intervention studies (72). LDL-cholesterol standardized $\alpha+\beta$-carotene concentrations decreased after consumption of plant sterols or stanols in almost all trials, while LDL-standardized $\alpha$-tocopherol concentrations were not affected. Although levels of carotenoids and tocopherols were still within the normal ranges, the clinical importance of the slight reductions in plasma carotenoids (mainly the lipophylic hydrocarbon carotenoids) is currently unknown. Plasma retinol concentrations were not affected. 
Except for effects on fat-soluble antioxidants, we have also analyzed effects of plant stanol esters on vitamin D concentrations. In a recently performed trial (for details, see ref. 73), we could not demonstrate, at relatively high intakes of 3.8 to 4.0 gram plant stanols as it fatty acid ester a day, an effect of two different mixtures of plant stanol esters on serum concentrations of 25hydroxy vitamin D (unpublished data, Plat and Mensink). At lower intakes, other studies could also not demonstrate an effect of plant sterols or stanols on 25hydroxy vitamin $D$ concentrations $(28,35,74-76)$.

Serum concentrations of vitamin $\mathrm{K}$ were not significantly decreased after consumption of 0.83 to $3.24 \mathrm{~g}$ plant sterol esters for 3.5 weeks (35). Also the activity of vitamin $\mathrm{K}$ dependent coagulation-factors do not change after 8 weeks consumption of 3.8 to 4.0 plant stanol esters (73). In the same study, fibrinolytic parameters were also not affected. Finally, plant stanol ester consumption did not increase bleeding tendency and changing the dose of warfarin in warfarintreated patients was not necessary (77).

As already mentioned, small amounts of plant sterols and stanols are incorporated into various tissues such as the liver, aorta, lungs, and red blood cells (45). Recently it was reported that consumption of plant sterols decreased the survival rate of stroke-prone spontaneously hypertensive (SHRSP) rats (78). It was suggested that the partial replacement of cholesterol by plant sterols in red blood cells membranes made these cells more rigid and less flexible, which may have contributed to the shortened life-span of the SHRSP rats. However, it was discussed that results may have been specific for this animal model and that the safety of plant sterols in human nutrition for the general population is unquestionable. Thus, with the current knowledge, it seems that at recommended daily intakes of 2-3 grams plant sterols and stanols can be considered as safe hypocholesterolemic components. Further, plant stanol ester enriched margarines are available on the Finnish market since 1995 and no major side-effects have been reported. However, monitoring of long term safety is recommended, not only for plant sterols and stanols, but for functional foods in general.

\section{Conclusion}

Functional foods enriched with plant sterols and stanols are currently widely available on the market. Due to their structural similarity with cholesterol, plant sterols and plant stanols lower intestinal absorption of both dietary and biliary cholesterol. As a consequence, endogenous cholesterol synthesis and 
LDL-receptor expression increase, while LDL production decreases. The overall effect is a reduction in serum LDL-cholesterol of $10-15 \%$ at daily intakes of $2-3$ gram of plant sterols or stanols. Plant sterols and stanols are also effective as part of a cholesterol-lowering diet and in combination with cholesterol-lowering drugs.

Estimates for the absorption of plant sterols (sitosterol and campesterol) and of campestanol are around 10\%, and for sitostanol less than 5\%. Lipidstandardized plasma levels are very low, but do increase when statins are used. The question about the atherogenicity of plant sterols has been raised (79), mainly because patients suffering from the rare inherited metabolic disease "phytosterolemia" have very high plant sterol concentrations and premature atherosclerosis. However, it must be noted that plasma plant sterol concentrations in these patients are more than 50 times higher compared to plasma plant sterol concentrations in healthy subjects during plant sterol consumption. Also, intervention studies with transgenic mice have demonstrated that both plant sterols and stanols reduce laesion development.

Extensive toxicological evaluation studies did not reveal any harmfull sideeffects. In human studies, side-effects were comparable to placebo treatment. However, lipid-standardized levels of the hydrocarbon carotenoids may decrease, although levels are still within the normal range. Together, these findings indicate that these functional foods have great potential in the prevention of coronary heart disease. However, post-marketing surveillance for functional foods in general is necessary, for example to monitor possible adverse effects, and to describe consumers and consumption patterns.

\section{References}

1. Westergaard $H$, Dietschy JM. The mechanism whereby bile acid micelles increase the rate of fatty acid and cholesterol uptake into the intestinal mucosal cell. J Clin Invest 1976;58: 97-108

2. Anderson RA, Joyce $C$, Davis $M$, Reagen JW, Clark M, Shelness $G$, Rudel LL. Identification of a form of acyl-Coa: cholesterol acyltransferase specific to liver and intestine in nonhuman primates, 」 Biol Chem 1988;272: 26747-26754
3. Grundy SM. Absorption and metabolism of dietary cholesterol. Ann Rev Nutr 1983;3: 71-96

4. Ikeda I, Sugano M, Scallen TJ, Vahouny GV, Gallo LL. Transfer of cholesterol and sitostanol from rat intestinal brush border membranes to phospholipid liposomes: effects of SCP-2, Agric Biol Chem 1990;10: 2649a-2653a

5. Hauser $H$, Dyer JH, Nandy A, Vega MA, Werder M. Bieliausaite E, Weber FE, Compassi S, Gemperti A, Boffeli D, Wehrli $E$, Schulthess G, Phillips 
MC. Identification of a receptor mediating absorption of cholesterol in the intestine. Biochem 1998;37: 17843-17850

6. Repa JJ, Turley SD, Labaccaro JMA, Medina J, Li L, Lustig $K$, Shan B, Heyman RA, Dietchy JM, Mangelsdorf DJ. Regulation of absorption and $A B C 1$-mediated efflux of cholesterol by RXR heterodimers. Science 2000;289: 1524-1529

7. Hernandez M, Montenegro J, Steiner M, Kim D, Sparrow C. Detmers PA, Wright $S D$, Chao $Y$. Intestinal absorption of cholesterol is mediated by a saturable, inhibitable transporter. Biochim Biophys Acta 2000;1486: 232-242

8. Detmers $P A_{1}$ Patel $S$, Hernandez $M$, Montenegro J, Lisnock J, Pikounis B, Steiner M, Kim D, Sparrow C. Chao $\checkmark$, Wright SD. A target for choleterol absorption inhibitors in the enterocyte brush border membrane. Biochim Biophys Acta 2000;1486: 243-252

9. Grundy SM, Mok HYI. Determination of cholesterol absorption in man by intestinal perfusion $\mathrm{J}$ Lipid Res 1977; 18: 263-271

10. Kesaniemi YA, Miettinen TA. Cholesterol absorption efficiency regulates plasma cholesterol level in the Finnish population, Eur J Clin Invest 1987; 17: 391-395

11. Ling WH, Jones PJH. Minireview dietary phytosterols: a review of metabolism, benefits and side effects. Life Sciences 1995:57: 195206:

12. Weststrate JA, Meijer GW. Plant sterol-enriched margarines and reduction of plasma total- and LDLcholesterol concentrations in normocholesterolaemic and mildy hypercholesterolemic subjects. Eur J Clin Nutr 1998:52: 334-43

13. Sierksma A, Weststrate JA, Meijer GW. Spreads enriched with plant sterols, either esterified 4,4dimethylsterals or free 4desmethylsterols, and plasma totaland LDL-cholesterol concentrations. Brit J Nutr 1999;82: 273-282

14 Miettinen TA, Tilvis RS, Kesäniemi YA. Serum plant sterols and cholesterol precursors reflect cholesterol absorption and synthesis in volunteers of a randomly selected male population. Am J Epidemiol 1990;131: 20-31

15. Nair PP, Turjman $N$, Kessie $G$, Calkins B, Goodman GT, Davidovitz $\mathrm{H}_{2}$ Nimmagadda G. Diet, nutrition intake and metabolism in populations at high and low risk for colon cancer. Am J Clin Nutr 1984;40 (4 Suppl.): 927-930

16. Field FJ., Mathur SN. $\beta$-sitosterol: esterification by intestinal acylcoenzyme A: cholesterol acyltransferase (ACAT) and its effect on cholesterol esterification. J Lipid Res 1983;24: 409-417

17. Child P, Kuksis A. Uptake of 7dehydro derivatives of cholesterol, campesterol, and $\beta$-sitosterol by rat erythrocytes, jejunal villus cells, and brush border membranes. J Lipid Res 1983;24: 552-565

18. Miettinen TA, Vuoristo $M_{2}$ Nissinen $M$, Jarvinen $H$, Gylling $H$. Serum. biliary and fecal cholesterol and plant sterols in colectomized patients before and during consumption of 
stanol ister margarine. Am J Clin Nutr 2000;71: 1095-1102

19. Heinemann T, Axtmann G, von Bergmann $K$. Comparison of intestinal absorption of cholesterol with different plant sterols in man. Eur J Clin Invest 1993;23: 827-831

20. Boberg KM, Einarsson K, Bjorkhem I. Apparent lack of conversion of sitosterol into C24-bile acids in humans. J Lipid Res 1990;31: 10831088

21. Boberg $K M$, Lund $E$, Olund $J$, Bjorkhem I. Formation of C21 bile acids from plant sterols in rats, $\mathrm{J}$ Biol Chem 1990;265: 7967-7975

22. Tavani DM, Nes WR, Billheimer JT. The sterol substrate specificity of acyl CoA: cholesterol acyltransferase from rat liver. J Lipid Res 1982;23: 774-781

23. Robins SJ, Brunengraber $\mathrm{H}$. Origin of biliary cholesterol and lecithin in the rat: contribution of new synthesis and preformed hepatic stores. J Lipid Res 1982;23:604-608

24. Tilvis RS, Miettinen TA. Serum plant sterols and their relation to cholesterol absorption. Am J Clin Nutr 1986;43: 92-97

25. Robins SJ, Fasulo JM. High density lipoproteins but not other lipoproteins provide a vehicle for sterol transport to bile. J Clin Invest 1997;3:380-384

26. Botham KM, Bravo $E$. The role of lipoprotein cholesterol in biliary steroid secretion. Studies with in vivo experimental models. Prog Lipid Res 1995;34: 71-97

27. Gylling $H_{x}$ Radhakrishnan $R$, Miettinen TA. Reduction of cholesterol in postmenopausal women with previous myocardial infarction and cholesterol malabsorption induced by dietary sitostanol ester margarine. Circulation 1997;36: 4226-4231

28. Hallikainen MA, Uusitupa MI. Effects of 2 low-fat stanol ester-containing margarines on serum cholesterol concentrations as part of a low fat diet in hypercholesterolemic subjects. Am J Clin Nutr 1999;69: 403-410

29. Jones PJH, Ntanios FY, RaeiniSarjaz M, Vanstone CA. Cholesterollowering efficacy of a sitostanolcontaining phytosterol mixture with a prudent diet in hyperlipidemic men. Am J Clin Nutr 1999;69: 1144-1150

30. Keda, I, Tanabe $Y$, Sugano $M$. Effects of sitosterol and sitostanol on micellar solubility of cholesterol. J Nutr Sci Vitaminol 1989;35: 361-369

31. Heinemann T, Kullak-Ublick GA, Pietruck B, von Bergmann $K$. Mechanisms of action of plant sterols on inhibition of cholesterof absorption; Comparison of sitosterol and sitostanol. Eur $\mathrm{J}$ Clin Pharmacol 1991;40 [suppl.1]: s59-s63

32. Becker $M$, Staab $D$, von Bergmann K. Treatment of severe familial hypercholesterolemia in childhood with sitosterol and siostanol. J Pediatr 1993;122: 292-296

33. Normén L, Dutta $P$, Lia A, Andersson H. Soy, siterol esters and b-s.tostanol ester as inhibitors, of cholesterol absorption in human small bowel. Am $\mathrm{J}$ Clin Nutr 2000;71: 908-913

34. Hallikainen MA, Sarkkinen ES, Gylling $H$, Erkkila AT, Uusitupa MlJ. Comparison of the effects of plant: sterol ester and plant stanol esterenriched margarines in lowering serum cholesterol conceritrations in 
hypercholesterolaemic subjects on a low-fat diet. Eur J Clin Nutr 2000;54: 671-677

35. Hendriks HFJ, Weststrate JA, van Vliet T, Meijer GW. Spreads enriched with three different levels of vegetable oil sterols and the degree of cholesterol lowering in nomocholesterolemic and mildly hypercholesterolemic subjects. Eur J Clin Nutr 1999;53:319-327

36. Begemann $F$, Bandomer $G$, Herget HJ. The influence of $\beta$-sitosterol on biliary cholesterol saturation and bile acid kinetics in man. Scand $\mathrm{J}$ Gastroent 1978;13: 57-63

37. Tangedahl TN, Thistle JL, Hofmann AF, Matseshe JW. Effect of $\beta$ sitosterol alone or in combination with chenic acid on cholesterol saturation of bile and cholesterol absorption in gallstone patients. Gastroent 1979;76: 1341-1346

38. Thompson GR, Naoumova RP, Watts GF. Aole of cholesterol in regulating apolipoprotein $B$ secretion by the liver. J Lipid Res 1996;37: 439-447

39. Gylling $H$, Miettinen TA. Serum cholesterol and lipoprotein metabolism in hypercholesterolemic NIDDM patients before and during sitostanol ester-margarine treatment, Diabetologia 1994;37: 773.780

40. Plat J Mensink RP. Effects of plant stanol esters on LDL receptor expression on mononuclear cells from non-hyperchalesterolemic subjects. Atherosclerosis 2000;151: 86

41. Plat $J$, van Onselen ENM, van Heugten MMA: Mensink FiP. Effects on serum lipids, lipoproteins and fat soluble antioxidant concentrations of consumption frequency of margarines and shortenings enriched with plant stanol esters. Eur J Clin Nutr 2000;54: 671-677

42. Bjorkhem I, Boberg KM. Inborn errors in bile acid biosynthesis and storage of sterols other than cholesterol, in: The metabolic basis of inherited diseases. Sciver CR, Beaudet AL, Sly WS, Valee D (editors). New York, NY: McGraw Hill, 1994;2073-2100

43. Lütjohann $D$, von Bergmann $K$. Phytosterolemia: diagnosis, characterization, and therapeutical approaches. Ann Med 29: 181-184

44. Mietinen TA (1980) Phytosterolemia, xanthomatosis and premature atherosclerotic arterial disease: a case with high plant sterol absorption, impaired sterol elimination and low cholesterol synthesis. Eur J Clin Invest 1997;10: 27-35

45. Salen G, Horak I, Rothkopf M, Cohen JL, Speck J, Tint GS, Shore V, Dayal B, Chen T, Shefer S. Lethal atherosclerosis associated with abnormal plasma and tissue sterol composition in sitosterolemia with xanthomatosis. J Lipid Res 1985;26: 1126-1133

46. Patel SB, Salen G, Hidaka $H$, Kwiterovich PO, Stalenhoef $\mathrm{AFH}$ Miettinen TA, Grundy SM, Lee $M$, Rubenstein JS, Polymeroloulos $\mathrm{MH}$, Brownstein MJ. Mapping a gene involved in regulating dietary cholesterol absorption: The sitosterolemia locus is found at chromosome 2p21, J Clin Invest 1998; 102: 1041-1044

47. Bhattacharyya AK, Connor WE, Lin 
DS, McMurry MM, Shulman RS. Sluggish sitosterol turnover and hepatic failure to excrete sitosterol into bile cause expansion of body pool of sitosterol in patients with sitosterolemia and xanthomatosis. Arterioscler Thromb 1991;11: 1287 1294

48. Shefer S, Salen G, Nguyen L, batta AK, Packin V. Tint GS. Hauser S. Competative inhibition of bile acid synthesis by endogenous cholestanol and sitosterol in sitosterolemia with xanthomatosis: Effect on cholesterol 7a-hydroxylase, J Clin Invest 1988;82:1833-1839

49. Nguyen LB, Shefer S, Salen G, Tint SG, Batta AK. Competitive inhibition of hepatic sterol 27-hydroxylase by sitosterol: decreased activity in sitosterolemia. Proc Assoc Am Physicians 1998;110: 32-39

50. Denke MA. Lack of efficiacy of lowdose sitostanol therapy as an adjunct to a cholesterol-lowering diet in men with moderate hypercholesterolemia. Am J Clin Nutr 1995;61:392-396

51. Knopp RM. Drug treatment of lipid disorders. N Engl J Med 1999;341: 498-511

52. Blair S, Capuzzi DM, Gottlieb SO, Nguyen T, Morgan JM, Cater NB. Incremental reduction of serum total cholesterol and low-density lipoprotein cholesterol with the addition of plant stanol ester containing spread to statin treatment. Am J Cardiol 2000:86:46-52

53. Gylling $\mathrm{H}$, Miettinen TA. Effects of inhibiting cholesterol absorption and synthesis on cholesterol and lipoprotein metabolism in hypercholesterolemic non-insulin- dependent diabetic men. J Lipid Res 1996;37: 1776-1785

54. Gylling $\mathrm{H}$, Miettinen TA. The effect of cholesterol absorption inhibition on low density lipoprotein cholesterol level. Atheroscilerosis 1995; 117: 305308

55. Law M. Plant sterol and stanol margarines and health. BMJ 2000;320: 861-864

56. Thompson GR, Barrowman J, Gutierrez L, Dowling RH. Action of neomycin on the intraluminal phase of lipid absorption. J Clin Invest 1971;50: 319-323

57. Uusitupa MIJ, Miettinen TA, Happonen $P$, Ebeling $T$, Turtola $H$, Voutilainen E, Pyorala K. Lathosterol and other noncholesterol sterols during treatment of hypercholesterolemia with lovastatin alone and with cholestyramine or guar gom. Arterioscler Thromb 1982;12: 807-813

58. Miettinen TA, Gylling $H$, Strandberg $T$, Sarna S. Baseline serum cholestanol as predictor of recurrent coronary events in subgroup of Scandinavian simvastatin survival study. BMJ 1998;316: 1127-1130

59. Glueck JG, Speirs J, Tracy $T$, Streicher $P$, Illig $E$, Vandegrift J. Relationships of serum plant sterols (phytosterols) and cholesterol in 595 hypercholesterolemic subjects, and familial aggregation of phytosterals, cholesterol, and premature coronary heart disease in hypercholesterolemic probands and their first-degree relatives. Metabolism 1991;40: 842-848

60. Tang $\mathrm{JL}$, Armitage JM, Lancaster $\mathrm{T}$, Silagy CA, Fowler GH, Neil HAW. 
Systemic review of dietary intervention trials to lower blood total cholesterol in free living subjects. BMJ 1998;316: 1213-1220

61. Moghadasian $\mathrm{MH}$, McManus BM, Godin DV, Rodrigues B. Frohlich JJ. Proatherogenic and antiatherogenic effects of probucol and phytosterols in apolipoprotein E-deficient mice. Circulation 1999;99: 1733-1739

62. Moghadasian $\mathrm{MH}, \mathrm{McManus} \mathrm{BM}$, Pritchard $\mathrm{PH}_{2}$ Frohlich JJ. Tall oilderived phytosterols reduce atherosclerosis in apoE deficient mice. Arterioscler Thromb Vasc Biol 1997:17: 119-126

63. Volger OL, van der Boom J, de Wit ECM, Duyvenvoorde van $W$. Hornstra G, Plat J, Havekes LM, Princen HMG, Mensink RP. Dietary vegetable- wood- or vegetable/wood derived stanol esters reduce atherosclerotic leasion size and severity in apoE*3-Leiden transgenic mice. Atherosclerosis 2000;151: 77

64. Moghadasian MH, Godin DV, McManus BM, Frohlich JJ. Lack of regression of atheroscierotic lesions in phytosterol treated apoE deficient mice. Life Sci 1999;64: 1029-1036

65. Baker VA, Hepburn PA, Kennedy SJ, Jones PA, Lea LJ, Sumpter JP, Ashby J. Safety evaluation of phytosterol esters. Part 1. Assesement of oestrogenicity using a combination of in vivo and in vitro assays. Food Chem Toxicol 1999;37: 13-22

66. Thurnbull D, Frankos VH, Leeman WR, Jonker D. Short-term tests of estrogenic potential of plant stanols and plant stanol esters. Reg Toxicol Pharmocol 1999:29:211-215
67. Slesinsky RS. Turnbull D, Frankos VH, Woterbeek APM, WaalkensBerendsen DH. Developmental toxicity study of vegetable oil-derived stanol fatty acid esters. Reg Toxicol Pharmocol 1999;29: 227-233

68. Waalkens-Berendsen $\mathrm{D} \mathrm{H}$, Wolterbeek APM, Wijnands MVW, Richold M, Hepburn PA. Safety evaluation of phytosterol esters. part 3. Two generation reproduction study in rats with phytosterol esters- a novel functional food. Food Chem Tox 1999;37: 683-696

69. Whittaker $\mathrm{MH}$, Frankos $\mathrm{VH}$, Woterbeek APM, WaalkensBerendsen DH. Two-generation reproductive toxicity study of plant stanol esters in rats. Reg Toxicol Pharmocol 1999;29: 196-204

70. Thurnbull D, Frankos VH, van Delft JHM, DeVogel N. Genotoxicity evaluation of wood-derived and vegetable oil-derived stanol esters. Reg Toxicol Pharmocol 1999;29: 205-210

71. Thurnbull D, Whittaker MH, Frankos $\mathrm{VH}$, Jonker D. 13 week oral toxicity study with stanol esters in rats. Reg Toxicol Pharmocol 1999;29: 216-226

72. Plat J, Kerckhoffs DAJM, Mensink RP. Therapeutic potential of plant sterols and stanols. Curr Opin Lipidol 2000 (in press)

73. Plat J, Mensink RP. Vegetable oil based versus wood based stanol ester mixtures: effects on serum lipids and hemostatic factors in nonhypercholesterolemic subjects. Atherosclererosis 2000;148: 101-112

74. Hallikainen MA, Sarkkinen ES, Uusitupa MI. Plant stanol esters affect serum cholesterol 
concentrations of hypercholesterolemic men and women in a dose-dependent manner. J Nutr 2000;130: 767-776

75. Gylling $H$, Miettinen TA. Cholesterol reduction by different plant stanol mixtures and with variable fat intake. Metabolism 1999;48: 575-580

76. Andersson A, Karlström B, Mohsen A, Vessby. Cholesterol-lowering effects of a stanol ester-containing low-fat margarine used in conjunction with a strict lipid-lowering diet. Eur Heart J Supplements 1999;1: S80S90

77. Nguyen TT, Dale LC. Plant stanol esters and vitamin K. Mayo Clinic Proc 1999;4: 642-643

78. Ratnayake WMN, L'Abbe MR, Mueller R, Hayward S, Plouffe $L$, Hollywood $R_{r}$ Trick K. Vegetable oils high in phytosterols make erythrocytes less deformable and shorten the life span of stroke-prone spontaneously hypertensive rats. J Nutr 2000;130: 1166-1178

79. Miettinen TA, Strandberg TE, Gylling $\mathrm{H}$, for the Finnish Investigators of the Scandinavian Simvastatin Survival Study Group. Noncholesterol sterols and cholesterol lowering by long-term simvastatin treatment in coronary patients; relation to basal serum cholestanol. Arterioscler Thromb Vasc Biol 2000;20: 1340-1346 


\title{
Chapter 3
}

Vegetable oil based versus wood based stanol ester mixtures:

Effects on serum lipids and hemostatic factors in non hypercholesterolemic subjects

\author{
Plat J, Mensink RP
}

Department of Human Biology, Maastricht University, The Netherlands

(Based on: Atherosclerosis 2000;148:101-112) 


\section{Abstract}

A pine wood based stanol ester mixture - composed of sitostanol (92\%) and campestanol $(8 \%)$ - effectively lowers cholesterol absorption and consequently LDL-cholesterol concentrations. It has been postulated that the less absorbable plant sterols reduces cholesterol absorption more effectively. As sitostanol is absorbed less than campestanol, we decided to examine if a vegetable oil based stanol ester mixture with $68 \%$ sitostanol and $32 \%$ campestanol is less effective as the wood based stanol ester mixture. For this, 112 non-hypercholesterolemic men and women consumed for four weeks a rapeseed oil (LEAR) based margarine and shortening. For the next 8 weeks, 42 subjects continued with these products, while the other subjects received products with a vegetable oil $(n=36)$ or a pine wood based stanol ester mixture $(n=34)$. Consumption of $3.8 \mathrm{~g}$ vegetable oil based stanols (2.6 g sitostanol plus $1.2 \mathrm{~g}$ campestanol) lowered LDL cholesterol with $14.6 \pm 8.0 \% \quad(-0.37 \mathrm{mmol} / \mathrm{L}$ versus the control group; $\mathrm{P}<0.001 ; 95 \% \mathrm{Cl}$ for the difference, -0.22 to $-0.51 \mathrm{mmol} / \mathrm{L}) .4 .0 \mathrm{~g}$ pine wood based stanols $(3.7 \mathrm{~g}$ sitostanol plus $0.3 \mathrm{~g}$ campestanol) showed a comparable decrease of $12.8 \pm 11.2 \%(-0.34$ $\mathrm{mmol} / \mathrm{L} ; \mathrm{P}<0.001 ; 95 \% \mathrm{Cl}-0.18$ to $-0.51 \mathrm{mmol} / \mathrm{L})$. Decreases in LDL cholesterol were not different between the two experimental groups $(P=0.793)$, while apo $E$ genotype did not have a major impact on this hypocholesterolemic response. Serum HDL cholesterol and triacylglycerol concentrations were not changed. The decreases in apo $B$ in both experimental groups differed significantly $(P<0.001)$ from changes in the control group. Coagulation and fibrinolytic parameters were not affected. We therefore conclude that vegetable oil and wood based stanol ester mixtures, with a different sitostanol/campestanol ratio, have similar LDL cholesterol lowering effects in a non-hypercholesterolemic population. 


\section{Introduction}

Plant sterols are non-nutritive compounds, which are present in minor amounts in several plant products, such as vegetable oils, nuts and seeds, cereals and beans. Western diets provide daily about 160 to $360 \mathrm{mg}$ plant sterols, which consist for approximately $80 \%$ of $\beta$-sitosterol, some campesterol and stigmasterol, while also trace amounts of saturated plant sterols (plant stanols) are found (1). Plant sterols, which are structurally related to cholesterol, are not synthesized by the human body (2), are poorly absorbed (3-6), and are effectively excreted by the liver (2). Therefore, serum levels are very low, usually below $1.0 \mathrm{mg} / \mathrm{dL}$ (7).

Plant sterols lower intestinal cholesterol absorption $(4,8,9)$, and consequently serum total and low density lipoprotein (LDL) cholesterol concentrations. These effects were already noticed in the early fifties, first by feeding cholesterol in combination with plant sterols to chickens (10) and rabbits (11), and later in experiments with humans in which soysterols were supplemented (12). However, at least $3 \mathrm{~g}$ of free sitosterols a day are needed to lower LDL cholesterol concentrations to a significant extent (8). Such amounts can never be provided by normal foods. Also enrichment of food products with plant sterols is from a production technology and food quality point of view difficult, since sitosterol is poorly soluble in both fat and water.

Hydrogenation of the delta 5 double bound of plant sterols results in the formation of plant stanols, such as sitostanol and campestanol. Sitostanol may be even more effective in lowering intestinal cholesterol absorption (4) and LDL cholesterol concentrations (6). Like plant sterols, plant stanols are not readily incorporated into food products. Esterification of plant stanols with rapeseed oil fatty acids, however, increases their solubilization in dietary fats (13), which optimizes its practical use. For example, in margarine levels up to $15 \%(\mathrm{w} / \mathrm{w})$ plant stanol as its fatty acid ester can easily be achieved. These plant stanol ester mixtures have also been demonstrated to lower LDL cholesterol in several intervention studies (1416), which mostly used pine wood based stanol ester mixtures, mainly composed of sitostanol $(92 \%)$ and campestanol $(8 \%)$. However, plant stanols can also be derived from vegetable oils, though such mixtures contain less sitostanol (68\%) and more campestanol $(32 \%)$. It has been postulated that the less absorbable plant sterols reduces cholesterol absorption more effectively (17). As humans absorb sitostanol less than campestanol (3), differences in plant stanol ester composition may affect a mixtures effects on the serum lipoprotein profile. Therefore, we have compared a plant stanol ester mixture derived from vegetable oils with the commonly used wood based stanol ester mixture. In contrast to the earlier studies, which were performed in hypercholesterolemic populations, we conducted this study with non-hypercholesterolemic men and women. Furthermore, since subjects 
carrying an apo $\varepsilon 4$ allele have an intrinsic higher intestinal cholesterol absorption, they may benefit more from plant stanol ester enriched foods (18). Differences in response to both stanol ester mixtures among the various apoE genotypes were therefore also examined. Finally, it has been shown that both in in vitro and in vivo, sitosterol induces t-PA synthesis $(19,20)$. Since plant stanol esters reduce plasma sitosterol concentrations (15), changes in t-PA and other hemostatic parameters were studied as well.

\section{Methods}

\section{Subjects}

Volunteers were recruited via posters in the university and hospital buildings and by advertisements in local newspapers. 225 subjects who showed interest received an information brochure about the purpose and the protocol of the study, which was approved by the medical ethical committee of the Maastricht University. In the end 170 subjects from Maastricht and surrounding municipals were willing to participate, and were invited for two screening visits. 123 subjects met all of our eligibility criteria: aged 18-65 years, serum total cholesterol concentration $<6.5$ $\mathrm{mmol} / \mathrm{L}$, serum triacylglycerol concentration $<3.0 \mathrm{mmol} / \mathrm{L}$, body mass index $(\mathrm{BMI})<$ $30 \mathrm{~kg} / \mathrm{m}^{2}$, diastolic blood pressure $<95$, systolic blood pressure $<160 \mathrm{~mm} \mathrm{Hg}$, estimated daily cholesterol intake $>200 \mathrm{mg}$, no proteinuria or glucosuria, no use of prescribed diets or medication known to affect serum lipid levels or hemostasis, and no history of coronary heart disease. Serum lipids were determined on two separate occasions with an interval of at least three days. Blood pressure was measured four times after a 10 minute rest and the last three values were averaged. Cholesterol intake was estimated with a short frequency list, asking for the consumption of products known to be rich in cholesterol and to contribute substantially to daily cholesterol intake. All subjects gave their written informed consent before the start of the study.

After screening, five subjects withdrew and 118 subjects started the study, of which five subjects did not complete the run-in period. Those subjects withdrew because the daily requested consumption of margarine and shortening was found too much $(n=2)$, family circumstances $(n=1)$ or job and school commitments $(n=2)$. During the intervention period one subject withdrew, due to lack of motivation. Thus, 112 subjects, 41 males and 71 females, completed the study. Fifteen males and 8 females smoked, 2 males and 2 females were vegetarians, 38 women used oral contraceptives and 4 women were post menopausal. Subjects with these characteristics were equally divided over the three experimental groups (see diets and design). 
Diets and design

After a fasting blood sample was taken, subjects were asked to replace for four weeks, at breakfast and lunch, their habitual margarine for a low erucic acid rapeseed (LEAR) oil based margarine containing $74 \%$ absorbable fats and $26 \%$ water. Minimal daily margarine intake was set at $20 \mathrm{~g}$. Family members not participating in the study, were not allowed to use this margarine. In addition, volunteers had to replace their usual baking fat for a rapeseed oil based shortening, containing $98 \%$ absorbable fats. Minimal daily shortening intake was set at $10 \mathrm{~g}$. The shortening was used at diner, for example for preparing meat, fish or eggs. Afterwards the fat had to be used to make a sauce, which had to be eaten entirely. It was of course also possible to make a sauce directly from the shortening. The shortening could be used by other family members as well. In those cases subjects had to prepare their meals in a multiple of $10 \mathrm{~g}$ shortening according to the number of persons eating the meal. The participating subject had to eat at least the amount of sauce corresponding with $10 \mathrm{~g}$ shortening. The margarine and the shortening were packed respectively in 200 and $400 \mathrm{~g}$ tubs. The volunteers had to come at least once a week to the Department to receive a new supply of products. Parts that were left over at the end of the week had to be returned and were weighed back to calculate margarine and shortening usage in that week. The weekly estimated amount was translated into an estimated daily intake. For the shortenings, this amount was corrected for the number of persons that was cooked for. In case young children from a participating subject had eaten from the shortening as well, it was estimated that a child ate $5 \mathrm{~g}$. In the end, the plant stanol intake was calculated from a subjects' daily margarine and shortening intake.

At the end of the four week run-in period, subjects were randomly allocated to one of the three treatment groups, stratified for sex and age. Characteristics of the three intervention groups are listed in table 1. The control group continued to use the rapeseed oil based margarine and shortening for another eight weeks, while a second group used the same margarine and shortening to which a vegetable oil based stanol ester mixture was added, and a third group used the same margarine and shortening with an added wood based stanol ester mixture. All products were coded with a color label to blind the subjects and the investigators. 


\begin{tabular}{|c|c|c|c|c|c|}
\hline \multirow[b]{2}{*}{ Number of males } & $\begin{array}{l}\text { Control } \\
\text { group }\end{array}$ & \multicolumn{2}{|c|}{$\begin{array}{l}\text { Vegetable oil based } \\
\text { group }\end{array}$} & \multicolumn{2}{|c|}{$\begin{array}{l}\text { Wood based } \\
\text { group }\end{array}$} \\
\hline & 16 & \multicolumn{2}{|r|}{13} & \multicolumn{2}{|c|}{12} \\
\hline Number of females & 26 & \multicolumn{2}{|r|}{23} & \multicolumn{2}{|c|}{22} \\
\hline Age (years) & $33 \pm 16$ & 33 & 15 & $33 \pm$ & 15 \\
\hline $\mathrm{BMI}\left(\mathrm{kg} / \mathrm{m}^{2}\right)$ & $23.0 \pm 2.8$ & 22.2 & \pm 4.7 & $23.4 \pm$ & 3.1 \\
\hline \multicolumn{6}{|l|}{ Blood pressure $(\mathrm{mm} \mathrm{Hg})$} \\
\hline Diastolic & $74 \pm$ & 75 & \pm & $75 \pm$ & 8 \\
\hline Systolic & $119 \pm 12$ & 122 & $\pm \quad 12$ & $123 \pm$ & 12 \\
\hline Total cholesterol (mmol/L) & $4.97 \pm 0.73$ & 5.09 & \pm 0.81 & $5.00 \pm$ & 0.93 \\
\hline Triacylglycerol (mmol/L) & $0.88 \pm 0.37$ & 0.98 & \pm 0.55 & $1.12 \pm$ & 0.69 \\
\hline
\end{tabular}

Values are means $\pm \mathrm{SD}(\mathrm{N}=112)$

The plant stanol ester mixtures were obtained by saturation of sitosterol, stigmasterol and campesterol, extracted from their respective sources, giving sitostanol and campestanol, followed by transesterification of free sitostanol and campestanol with rapeseed oil fatty acids (RAISIO GROUP, Raisio, Finland). The plant stanol esters were then mixed with the experimental margarines and shortenings. The vegetable oil based stanol ester mixture consisted of $70 \%$ sitostanol ester and 30\% campestanol ester, while the wood based stanol ester mixture contained approximately $93 \%$ sitostanol ester and $7 \%$ campestanol ester. Both experimental margarines contained $74 \%$ fat and $6.5 \mathrm{~g}$ plant stanols $/ 100 \mathrm{~g}$ product and both experimental shortenings contained $82 \%$ fat and $15 \mathrm{~g}$ plant stanols / $100 \mathrm{~g}$ product. Both experimental margarines had a similar fat content and fatty acid composition compared to the control margarine, as plant stanols were added at the expense of water. Both experimental shortenings contained $16 \%$ less absorbable fat compared to the control shortening, due to fat replacement by plant stanols. A more detailed composition of all three margarines and shortenings has been presented elsewhere (21).

At a minimal daily intake of $20 \mathrm{~g}$ experimental margarine and $10 \mathrm{~g}$ experimental shortening, the aimed consumption of plant stanols was at least $2.8 \mathrm{~g}$ for both intervention groups. The margarine and shortening were used in such a way that plant stanol intake was divided over three meals, in correspondence with the distribution of cholesterol intake over the day. Therefore the largest amount of plant stanols had to be consumed at diner since during this meal cholesterol intake is generally higher as compared to other meals.

To estimate their energy and nutrient intakes, subjects recorded in the last week of both the run-in and the intervention period, their food intake during the 
previous four weeks by filling in food frequency lists, consisting of 100 items. Food frequency lists were checked immediately in the presence of the subjects by a dietician. Items were coded and the composition of the diets was calculated according the Dutch food composition table (22), to which the $\alpha$-linolenic acid content of the various food items was added manually. Results from this food frequency lists correlated well with those from three day food diaries (data not shown). In addition the percentage energy from linoleic acid during the run-in period as estimated with the food frequency list correlated positively with the proportion of linoleic acid in erythrocyte membranes at the end of the run-in period $(r=0.21, P=0.029, N=112)$, indicating the reliability of the frequency list. The subjects recorded in diaries any signs of illness, medication used, menstrual phase and any deviations from the protocol. In addition, subjects were asked not to change their habitual diet, level of physical exercise, smoking habits, use of alcohol or oral contraceptives intake during the study. Body weight was recorded every week in order to correct for possible changes in weight. which was not necessary.

\section{Blood sampling and analyses}

Blood sampling

Blood samples were taken at weeks $0,3,4,8,11$ and 12 after an ovemight fast. Subjects were not allowed to drink alcohol the day preceding, or to smoke on the morning of blood sampling. All venipunctures were performed by the same person, at the same location and approximately at the same time of the same day of the week, with subjects in recumbent position after laying down for 10 minutes, using a $1.2 \mathrm{~mm}$ needle (Sherwood Medical Company, St. Louis, USA). No blood was sampled on Mondays to exclude effects of possible deviating behavior during the weekends.

First $3 \mathrm{ml}$ EDTA blood was collected for hematological parameters at weeks 0,4 , and 12 as already described (21), or other analyses at weeks 3 and 11 (to be reported elsewhere). Next, at weeks 3, 4, 11 and 12 only, two $5 \mathrm{ml}$ CTAD tubes (Diatube $\mathrm{H}$, Diagnostica Stago) were filled for measurement of coagulation and fibrinolytic parameters. The first CTAD tube was precooled on ice, directly put on ice after sampling, centrifuged at $2000 \times \mathrm{g}\left(4^{\circ} \mathrm{C}, 30\right.$ minutes) within one hour after sampling, and used for measurement of PAl-1 activity and t-PA antigen levels. The second CTAD tube was kept at room temperature, centrifuged at $2000 \times \mathrm{g}$ (room temperature, 30 minutes) within one hour after sampling, and used for determination of coagulation factors. Then a $10 \mathrm{ml}$ EDTA tube (Monoject sterile, Sherwood Medical, Ballymoney, North Ireland) was drawn for isolating DNA at week 0 and obtaining plasma (final EDTA concentration $1 \mathrm{~g} / \mathrm{L}$ ) in the other weeks for additional measurements (to be reported elsewhere). Plasma was obtained by 
centrifugation at $2000 \times \mathrm{g}$ for thirty minutes at $4^{\circ} \mathrm{C}$ directly after sampling. The pellet from the bottom fraction of the EDTA tube was used at week 0,4 and 12 for preparation of red blood cells for analysis of fatty acid composition. Finally, a $10 \mathrm{ml}$ clotting tube (CORVAC, integrated serum separator tube, Sherwood Medical Company, St. Louis, USA) was filled at weeks $0,3,4,8,11$, and 12. Serum was obtained by centrifugation at $2000 \mathrm{xg}$ for thirty minutes at $4^{\circ} \mathrm{C}$, minimally one hour after venipuncture. All plasma and serum samples were snap-frozen and stored in small portions directly after sampling at $-80^{\circ} \mathrm{C}$.

\section{Lipids and apolipoproteins}

Total cholesterol (CHOD/PAP method; Roche Diagnostics Systems, Hofmann-La Roche Ltd., Basel, Swiss), HDL cholesterol (CHOD/PAP method; Roche Diagnostics Systems, Hofmann-La Roche Ltd., Basel, Swiss) after precipitation of apoB containing lipoproteins by adding phosphotungstic acid and magnesium ions (precipitation method; Monotest cholesterol, Boehringer Mannheim, Mannheim, Germany), and triacylglycerols (GPO-Trinder; Sigma Diagnostics St Louis) were analyzed in serum enzymatically. All samples from one subject were analyzed within one run at the end of the study. The coefficient of variation within runs was $1.9 \%$ for total cholesterol, $3.0 \%$ for $\mathrm{HDL}$ cholesterol and $3.0 \%$ for triacylglycerol. LDL cholesterol was calculated according to the Friedewald equation (23). The lipid and lipoprotein concentrations of samples from week 3 and 4 and from week 11 and 12 were averaged for data analysis.

Apolipoprotein $A-1$ and $a p o B$ were measured using an immunoturbidimetric reaction (UNI-KIT ApoA-I and UNI-KIT ApoB, Roche). The variation coefficients within runs were $2.0 \%$ for apoA-1 and $1.0 \%$ for apoB. Plasma $L p(a)$ concentrations were analyzed by an enzyme-linked immunosorbent assay (ELISA), using a commercial kit (Biopool, Umea, Sweden). The variation coefficient within runs was $5.7 \%$. Samples of week 3 and 4 and samples of week 11 and 12 were pooled before analysis of apoA-1, apoB and $L p(a)$. All samples from one subject were analyzed within one run.

\section{ApoE polymorphism}

ApoE genotyping was performed by restriction fragment length polymorphism (RFLP). Leukocytes were isolated from EDTA anticoagulated whole blood by addition of lysis buffer ( $155 \mathrm{mM} \mathrm{NH}_{4} \mathrm{Cl}, 10 \mathrm{mM} \mathrm{KHCO}_{3}, 0.1 \mathrm{mM} \mathrm{Na}_{2}$ EDTA), followed by centrifugation. DNA from the leucocyte pellet was isolated using the QIAamp Blood Kit (Westburg b.v. Leusden, The Netherlands) and amplified in a Thermolyne Amplitron ${ }^{\circledR}$ II PCR apparatus (Barnstead, Thermolyne Corporation, Dubuque, USA). Each reaction tube contained approximately $0.6 \mu \mathrm{g}$ DNA, 11 pmol of each 
primer, 1.25 units Taq polymerase (Pharmacia Biotech, Roosendaal, The Netherlands), $0.66 \mathrm{mM}$ of each dNTP (Pharmacia Biotech, Roosendaal, The Netherlands), $2 \mathrm{mM} \mathrm{MgCl}_{2}$, and 10\% (v/v) DMSO (Merck, Darmstadt, Germany) in a final volume of $30 \mu \mathrm{L}$. Before cycling started, each sample was denaturated for 7 minutes at $95^{\circ} \mathrm{C}$. Thirty-three cycles, consisting of 1 minute at $95^{\circ} \mathrm{C}$ (denaturation), 75 seconds at $60^{\circ} \mathrm{C}$ (primer annealing), 2 minutes at $70^{\circ} \mathrm{C}$ (extension) were performed, followed by 10 minutes elongation at $70^{\circ} \mathrm{C}$. Next 12 units $\mathrm{Cfol}$ (Promega Corporation, Madison, USA) were added directly to digest the PCR reaction product $\left(2\right.$ hours at $37^{\circ} \mathrm{C}$ ). The digested apoE DNA samples were loaded on a $5 \%$ agarose gel (Gibco Ultrapure), electrophoresed for 1.5 hours at $125 \mathrm{~V}$ and stained with ethidiumbromide. DNA fragments were visualized by UV at $312 \mathrm{~nm}$ using a VDS Imagemaster (Pharmacia Biotech, San Francisco, USA). ApoE genotypes were determined by using fragments of known size, a X174 DNA / Hinfl marker (Promega Corporation, Madison, USA) and a 100 bp ladder (Pharmacia Biotech, Roosendaal, The Netherlands).

\section{Coagulation and fibrinolysis}

Coagulation and fibrinolytic parameters were determined at the end of the run-in period (week 3 and 4 ) and the experimental period (week 11 and 12). CTAD plasma obtained in weeks 3 and 4 , as well as in weeks 11 and 12, was pooled before analysis. Samples from one subject were analyzed within the same run. A reference pool plasma was prepared of blood from 7 healthy volunteers by the same procedures as those for the volunteers. Factor VII amidolytic (FVIlam), factor VII coagulant (FVIIC) and antithrombin III (AT-III) activities were expressed as percent of this standard pool plasma. Plasma fibrinogen concentrations $(\mathrm{g} / \mathrm{L})$ were assessed by the method of Clauss (24). FVIlam activity (\% of normal), and antithrombin III activity (\% of normal) were both determined by chromogenic assays (Coaset FVII / Coamatic antithrombin, Chromogenix, Mölndal, Sweden). FVIlc activity (\% of normal) was analyzed as described (25). PAl-1 activity (AU/mL) was measured with a chromogenic assay (Spectrolyse( $(\mathrm{pL}) \mathrm{PAl}-1$, Biopool, Umea, Sweden). Tissue plasminogen activator (t-PA) antigen was determined by an immunoassay (Imulise TM $t P A$, Biopool, Umea, Sweden). The coefficients of variation within runs were $1.5 \%$ for fibrinogen, $5.4 \%$ for factor VIlam, $4.2 \%$ for antithrombin III, $1.7 \%$ for FVIlc activity, $4.0 \%$ for PAl- 1 activity and $5.8 \%$ for t-PA.

\section{Red blood cell fatty acid composition}

Red blood cells were washed twice with a physiologicai salt solution and stored at $-80^{\circ} \mathrm{C}$ until lipid extraction, which was performed within one week after sampling. Total lipids were extracted using a modified Folch method (26). 


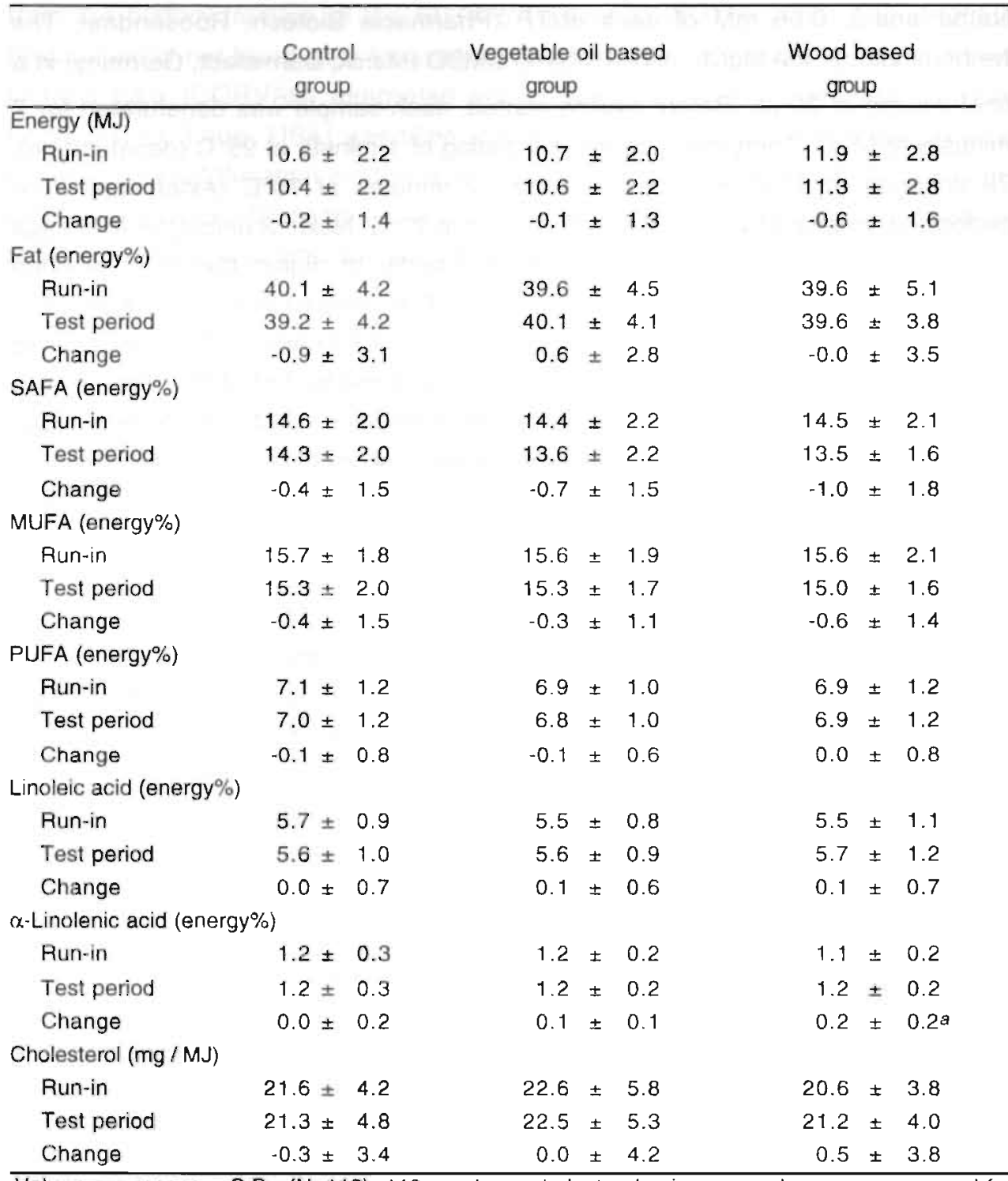

Values are means \pm S.D., $(\mathrm{N}=112) .112$ non-hypercholesterolemic men and women consumed for four weeks (run-in) a rapeseed oil (LEAR) based margarine and shortening, low in stanolesters. For the next 8 weeks (test period), 42 subjects continued with these products, while the other subjects received products with a vegetable oil based stanolester mixture $(2.6 \mathrm{~g}$ sitostanol and $1.2 \mathrm{~g}$ campestanol; $n=36$ ) or a pine wood based stanol ester mixture $(3.7 \mathrm{~g}$ sitostanol and $0.3 \mathrm{~g}$ campestanol; $n=34$ ). Dietary intakes were calculated from food frequency lists filled in during the last week of both the run-in and the test period. SAFA: saturated fatty acids, MUFA: monounsaturated fatty acids, PUFA: polyunsaturated fatty acids.

a $P<0.001$ control group versus wood based group 
Phospholipids were separated from the total lipid extract with a Bond Elut $\mathrm{NH} 2-$ aminopropyl column (Rochrom, Rotterdam, The Netherlands). Next the extract was saponified and methylated and the fatty acid methyl esters were separated and quantified by gas chromatography, using a CP-Sil 88 polar capillary column (Chrompack, Middelburg, the Netherlands) as described before (26).

\section{Statistics}

Data from the 112 subjects, who completed the study, were included in the analyses. Before the start of the study it was calculated that the power to detect a true difference of $0.30 \mathrm{mmol} / \mathrm{L}$ for LDL cholesterol between treatments was $85 \%$. Changes were calculated for each subject as the difference between values of the experimental period and run-in period. The differences in changes between the groups were tested with ANOVA. When a significant diet effect was found $(P<0.05)$, the three treatments were compared pairwise and corrected for three group comparisons $(\alpha=0.017)$ using the Bonferroni multi comparison test. Effects of gender and smoking on the responses were examined by including these two factors as well as its interaction term with treatment into the statistical model. Changes in $L p(a)$ were not normally distributed and therefore tested with the nonparametric Kruskal-Wallis test. The interaction between genotype and treatment was examined with ANOVA. The assumption of Hardy-Weinberg equilibrium for apoE genotype was tested by means of gene counting and chi-square analysis. All statistical analyses were performed with Statview 4.5 (27).

\section{Results}

Dietary intake, daily margarine and shortening consumption, and body weight

Table 2 shows that energy intake and the proportion of energy from carbohydrates, fatty acids and protein, as well as cholesterol intake were essentially the same in all three groups during both the run-in and the experimental periods. All three groups showed an increase in red blood cell membrane alinolenic acid content, indicating a good compliance since the rapeseed oil based margarine and shortening are rich in $\alpha$-linolenic acid (data not shown). Mean estimated daily margarine intake during the run-in period was $26 \pm 7 \mathrm{~g}$ for all three groups (table 3 ). Changes in intake during the experimental period were small and not significantly different between the three groups. Shortening intake in the three groups varied between $15 \pm 6$ to $18 \pm 7 \mathrm{~g}$ during the run-in period and was about $15 \pm 6 \mathrm{~g}$ during the experimental period. Total plant stanol intake did not change in the control group and increased on average with $3.8 \pm 0.6 \mathrm{~g}$ in the vegetable based group and with $4.0 \pm 1.8 \mathrm{~g}$ in the wood based group. Although the increased consumption of total plant stanols in both intervention groups was similar 
Table 3: Mean daily margarine, shortening, plant sterol and stanol intake, derived from the margarines and shortenings during the study

\begin{tabular}{|c|c|c|c|c|c|c|c|}
\hline Margarine (g) & \multicolumn{3}{|c|}{$\begin{array}{r}\text { Control } \\
\text { group }\end{array}$} & \multicolumn{2}{|c|}{$\begin{array}{l}\text { Vegetable oil based } \\
\text { group }\end{array}$} & \multicolumn{2}{|c|}{$\begin{array}{l}\text { Wood based } \\
\text { group }\end{array}$} \\
\hline Ruก-in & 26 & \pm & 8 & $26 \pm$ & 6 & $26 \pm$ & 8 \\
\hline Test period & 26 & \pm & 7 & $26 \pm$ & 5 & $27 \pm$ & 9 \\
\hline Change & 0 & \pm & 4 & $-1 \pm$ & 4 & $1 \pm$ & 5 \\
\hline \multicolumn{8}{|l|}{ Shortening (g) } \\
\hline Run-in & 18 & \pm & 7 & $15 \pm$ & 6 & $17 \pm$ & 11 \\
\hline Test period & 16 & \pm & 6 & $15 \pm$ & 4 & $15 \pm$ & 9 \\
\hline Change & -2 & \pm & 5 & $-1 \pm$ & 5 & $-2 \pm$ & 5 \\
\hline \multicolumn{8}{|l|}{ Sitosterol (mg) } \\
\hline Run-in & 77 & \pm & 19 & $74 \pm$ & 16 & $77 \pm$ & 28 \\
\hline Test period & 75 & \pm & 20 & $170 \pm$ & 26 & $144 \pm$ & 57 \\
\hline Change & -2 & \pm & 11 & $96 \pm$ & $17 b$ & $68 \pm$ & $35 x$ \\
\hline \multicolumn{8}{|l|}{ Sitostanol (mg) } \\
\hline Run-in & 9 & \pm & 2 & $9 \pm$ & 1 & $9 \pm$ & 3 \\
\hline Test period & 9 & \pm & 2 & $2586 \pm$ & 426 & $3714 \pm$ & 622 \\
\hline Change & 0 & \pm & 1 & $2577 \pm$ & $423 b$ & $3705 \pm$ & $619 a c$ \\
\hline \multicolumn{8}{|c|}{ Campesterol (mg) } \\
\hline Run-in & 57 & \pm & 14 & $55 \pm$ & 12 & $56 \pm$ & 20 \\
\hline Test period & 55 & \pm & 15 & $126 \pm$ & 19 & $95 \pm$ & 37 \\
\hline Change & -2 & \pm & 8 & $71 \pm$ & $13 b$ & $39 \pm$ & $21 a c$ \\
\hline \multicolumn{8}{|c|}{ Litmpestanol (mg) } \\
\hline Run-in & 0 & \pm & 0 & $0 \pm$ & 0 & $0 \pm$ & 0 \\
\hline Test period & 0 & \pm & 0 & $1215 \pm$ & 199 & $329 \pm$ & 143 \\
\hline Change & 0 & \pm & 0 & $1215 \pm$ & $199 b$ & $329 \pm$ & 143 ac \\
\hline \multicolumn{8}{|c|}{ Total plant sterol (mg) } \\
\hline Run-in & 160 & \pm & 40 & $155 \pm$ & 33 & $159 \pm$ & 57 \\
\hline Test period & 155 & \pm & 41 & $4117 \pm$ & 671 & $4296 \pm$ & 863 \\
\hline Change & 5 & \pm & 22 & $3962 \pm$ & $648 b$ & $4137 \pm$ & $810 a$ \\
\hline \multicolumn{8}{|c|}{ of which plant stanol (mg) } \\
\hline Run-in & 9 & \pm & 2 & $9 \pm$ & 2 & $9 \pm$ & 3 \\
\hline Test period & 9 & \pm & 2 & $3800 \pm$ & 624 & $4043 \pm$ & 765 \\
\hline Change & 0 & \pm & 1 & $3791 \pm$ & $623 b$ & $4034 \pm$ & $762 a$ \\
\hline
\end{tabular}

Values are means \pm S.D., $(\mathrm{N}=112)$.

a $\mathrm{P}<0.001$ control group versus wood based group

b $P<0.001$ control group versus vegetable oil based group

c $P<0.001$ vegetable oil based group versus wood based group

$(\mathrm{P}=0.328)$, changes in the intake of the individual plant stanols reflected the composition of the margarine and shortening, indicating an exchange of 
campestanol for sitostanol. During the test period, changes in body weight of subjects were marginal and were $-0.5 \pm 1.1 \mathrm{~kg}$ for the control group, $-0.4 \pm 1.1 \mathrm{~kg}$ for the vegetable based group and $-0.5 \pm 1.0$ for the wood based group. Inspection of the diaries did not reveal any serious deviations from the protocol.
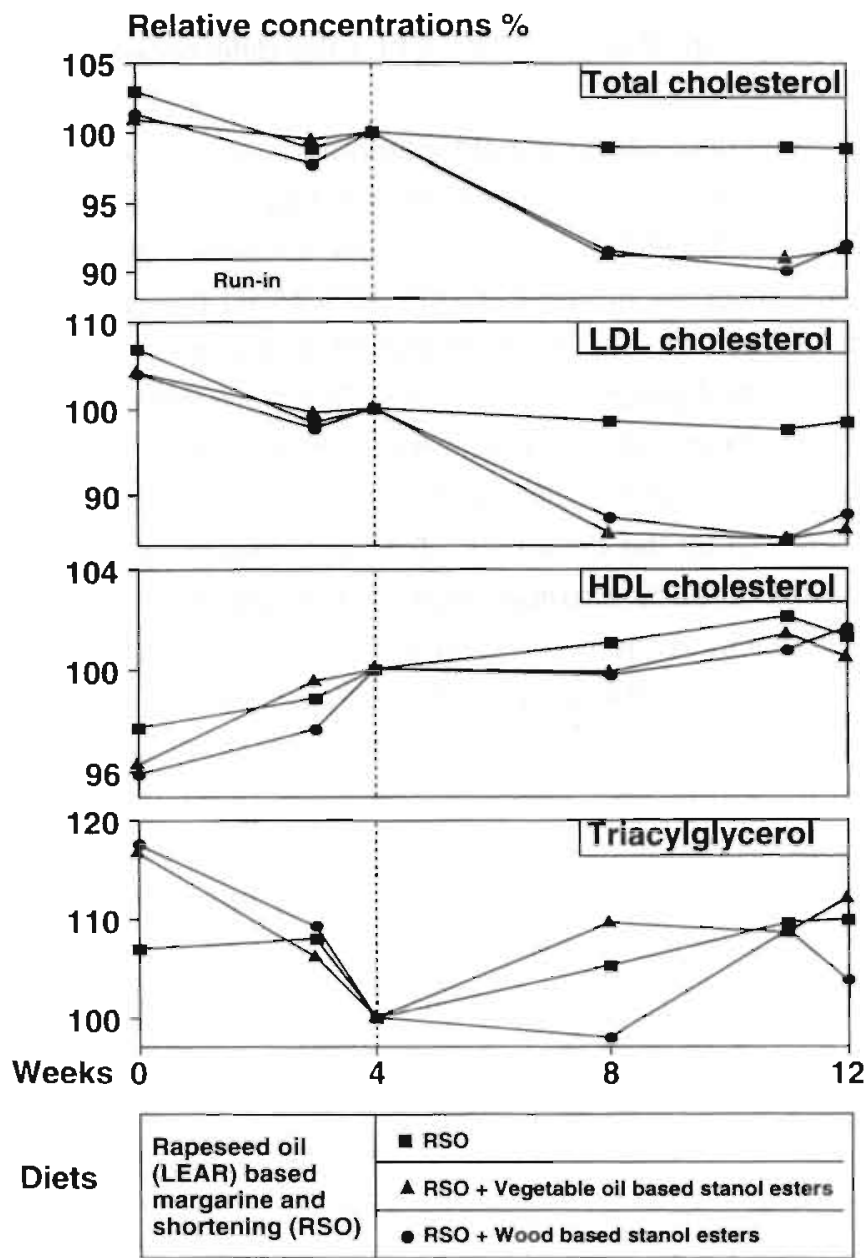

Figure 1: Relative concentrations of serum total, LDL and HDL cholesterol, and triacylglycerol during the study. Concentrations of lipids and lipoproteins in week 4 were set at $100 \%$.

Serum lipids, lipoproteins and apolipoproteins

Mean changes in serum lipid values are shown in table 4 and figure 1. During the run-in period serum total and LDL cholesterol concentrations showed a slight, but similar, decrease in all three groups. The vegetable based stanol mixture further lowered serum total cholesterol concentrations with $0.43 \pm 0.28 \mathrm{mmol} / \mathrm{L}$ after 
eight weeks, a decrease of $8.6 \pm 5.1 \%$. This change was significantly different from the change of $-0.04 \pm 0.40 \mathrm{mmol} / \mathrm{L}$ in the control group $(P<0.001 ; 95 \%$ confidence interval $(\mathrm{CI})$ for the difference in changes between the two groups, -0.23 to -0.55 $\mathrm{mmol} / \mathrm{L})$. Addition of the wood based stanol mixture caused a decrease of $0.42 \pm 0.39 \mathrm{mmol} / \mathrm{L}$, or $8.1 \pm 7.5 \%$. This change was also significantly different from the change in the control group $(\mathrm{P}<0.001 ; 95 \% \mathrm{Cl}$ for the difference, -0.20 to -0.56 $\mathrm{mmol} / \mathrm{L})$.

The decrease in total cholesterol in both intervention groups was completely due to a decrease in LDL cholesterol concentrations. LDL cholesterol reductions were $0.43 \pm 0.26 \mathrm{mmol} / \mathrm{L}$ or $14.6 \pm 8.0 \%$ in the vegetable oil based group (a change of $-0.37 \mathrm{mmol} / \mathrm{L}$ versus the control group; $\mathrm{P}<0.001 ; 95 \% \mathrm{Cl}$ for the difference, -0.22 to $-0.51 \mathrm{mmol} / \mathrm{L})$, and $12.8 \pm 11.2 \%$ or $0.41 \pm 0.36 \mathrm{mmol} / \mathrm{L}$ in the wood based group ($0.34 \mathrm{mmol} / \mathrm{L}$ versus the control group; $\mathrm{P}<0.001 ; 95 \% \mathrm{Cl}$ for the difference, -0.18 to $0.51 \mathrm{mmol} / \mathrm{L})$. Both plant stanol ester mixtures had similar effects on serum total cholesterol ( $P=0.925 ; 95 \% \mathrm{Cl}$ for the difference, -0.16 to $0.15 \mathrm{mmol} / \mathrm{L}$ ) and $\mathrm{LDL}$ cholesterol $(P=0.793 ; 95 \% \mathrm{Cl}$ for the difference, -0.17 to $0.13 \mathrm{mmol} / \mathrm{L}$ ), while effects of both interventions were already maximal after four weeks (figure 1). The LDL cholesterol lowering effect was evident in 34 out of 36 subjects from the vegetable oil based group, and in 29 out of 34 subjects in the wood based group (figure 2) and did not correlate with the dietary cholesterol intake $(r=-0.12, P=0.323, N=70)$.

Serum HDL cholesterol and triacylglycerol concentrations were not significantly different between the groups. The LDL to HDL cholesterol ratio, however, decreased in the vegetable based group from $1.98 \pm 0.93$ to $1.67 \pm 0.74$, which differed significantly from the change in the control group $(P=0.012 ; 95 \% \mathrm{Cl}$ for the difference, -0.11 to -0.38 ) while the ratio in the wood based group showed a reduction from $2.12 \pm 1.08$ to $1.78 \pm 0.82(\mathrm{P}<0.001 ; 95 \% \mathrm{Cl}$ for the difference, -0.12 to -0.43 ). The ratio in the control group remained constant around 1.90. Changes in the $\mathrm{LDL}$ to $\mathrm{HDL}$ cholesterol ratio were not different between both plant stanol ester groups ( $\mathrm{P}=0.697 ; 95 \% \mathrm{Cl}$ for the difference, -0.12 to 0.19 ). As compared with the control group, the total to HDL cholesterol ratio decreased with $0.32 \pm 0.31$ in the vegetable oil based group $(P=0.003 ; 95 \% \mathrm{Cl}$ for the difference, -0.10 to -0.41$)$ and with $0.38 \pm 0.43$ in the wood based group $(\mathrm{P}<0.001 ; 95 \% \mathrm{Cl}$ for the difference, -0.13 to -0.49 ), whereas there was no difference in changes between both experimental groups ( $P=0.500 ; 95 \% \mathrm{Cl}$ for the difference, -0.11 to 0.24 ).

Table 5 shows that in the vegetable oil based group serum apoB concentrations decreased significantly with $89 \pm 75 \mathrm{mg} / \mathrm{L}$, which was significantly more than the slight increase of $11 \pm 95 \mathrm{mg} / \mathrm{L}$ in the control group $(\mathrm{P}<0.001 ; 95 \% \mathrm{Cl}$ for the difference, -60 to $-139 \mathrm{mg} / \mathrm{L}$ ). A similar effect was observed in the wood based group in which the decrease was $63 \pm 95 \mathrm{mg} / \mathrm{L}$, a change versus the control group of 
$-74 \mathrm{mg} / \mathrm{L}(\mathrm{P}<0.001 ; 95 \% \mathrm{Cl}$ for the difference, -30 to $-118 \mathrm{mg} / \mathrm{L})$. Changes in apoB between the two experimental groups did not differ significantly $(P=0.237: 95 \% \mathrm{Cl}$ for the difference, -66 to $15 \mathrm{mg} / \mathrm{L}$ ). Serum apoA-1 and $L p(a)$ concentrations were not affected by addition of both plant stanol mixtures. In addition, none of these effects were dependent on gender or smoking habits.

Table 4: Effects of vegetable oil based and wood based stanol esters on serum lipid and lipoprotein concentrations during the study

\begin{tabular}{|c|c|c|c|}
\hline & $\begin{array}{l}\text { Control } \\
\text { group }\end{array}$ & $\begin{array}{l}\text { Vegetable oil based } \\
\text { group }\end{array}$ & $\begin{array}{l}\text { Wood based } \\
\text { group }\end{array}$ \\
\hline \multicolumn{4}{|c|}{ Total cholesterol (mmol/L) } \\
\hline Run-in & $4.93 \pm 0.78$ & $4.99 \pm 0.72$ & $4.98 \pm 0.91$ \\
\hline Test period & $4.89 \pm 0.82$ & $4.56 \pm 0.69$ & $4.55 \pm 0.80$ \\
\hline Change & $-0.04 \pm 0.40$ & $-0.43 \pm 0.28 c$ & $-0.42 \pm 0.39^{a}$ \\
\hline \multicolumn{4}{|c|}{ LDL cholesterol (mmol/L) } \\
\hline Run-in & $2.96 \pm 0.73$ & $2.94 \pm 0.74$ & $2.94 \pm 0.90$ \\
\hline Test period & $2.90 \pm 0.73$ & $2.51 \pm 0.66$ & $2.54 \pm 0.72$ \\
\hline Change & $-0.06 \pm 0.37$ & $-0.43 \pm 0.26 c$ & $-0.41 \pm 0.36 a$ \\
\hline \multicolumn{4}{|c|}{ HDL cholesterol $(\mathrm{mmol} / \mathrm{L})$} \\
\hline Run-in & $1.60 \pm 0.31$ & $1.63 \pm 0.41$ & $1.55 \pm 0.42$ \\
\hline Test period & $1.60 \pm 0.28$ & $1.63 \pm 0.38$ & $1.57 \pm 0.40$ \\
\hline Change & $0.01 \pm 0.16$ & $0.00 \pm 0.11$ & $0.01 \pm 0.13$ \\
\hline \multicolumn{4}{|c|}{ Triacylglycerol (mmol/L) } \\
\hline Run-in & $0.82 \pm 0.26$ & $0.91 \pm 0.53$ & $1.05 \pm 0.69$ \\
\hline Test period & $0.84 \pm 0.32$ & $0.91 \pm 0.44$ & $0.98 \pm 0.62$ \\
\hline Change & $0.02 \pm 0.21$ & $-0.01 \pm 0.26$ & $-0.07 \pm 0.34$ \\
\hline \multicolumn{4}{|c|}{ LDL / HDL cholesterol ratio } \\
\hline Run-in & $1.94 \pm 0.67$ & $1.98 \pm 0.93$ & $2.12 \pm 1.08$ \\
\hline Test period & $1.87 \pm 0.63$ & $1.67 \pm 0.74$ & $1.78 \pm 0.82$ \\
\hline Change & $-0.07 \pm 0.31$ & $-0.31 \pm 0.27 b$ & $-0.34 \pm 0.38 a$ \\
\hline
\end{tabular}

Values are means \pm S.D., $(\mathrm{N}=112) .112$ non-hypercholesterolemic men and women consumed for four weeks (run-in) a rapeseed oil (LEAR) based margarine and shortening, low in stanolesters. For the next 8 weeks (test period), 42 subjects continued with these products, while the other subjects received products with a vegetable oil based stanolester mixture $(2.6 \mathrm{~g}$ sitostanol and 1.2 $\mathrm{g}$ campestanol; $\mathrm{n}=36$ ) or a pine wood based stanol ester mixture $(3.7 \mathrm{~g}$ sitostanol and $0.3 \mathrm{~g}$ campestanol; $n=34$ ). For the run-in period (run-in), samples from weeks 3 and 4 were averaged, and for the test period, samples from weeks 11 and 12. Changes were calculated as the difference between values of the test period and run-in period. To convert values for total, LDL and HDL cholesterol to milligrams per deciliter, multiply by 38.67 . To convert values for triacylglycerols to milligrams per deciliter, multiply by 88.54 .

a $P<0.001$ control group versus wood based group

b $P<0.017$ control group versus vegetable oil based group

c $P<0.001$ control group versus vegetable oil based group 


\section{ApoE polymorphism}

The observed frequencies of the different apoE genotypes were in HardyWeinberg equilibrium and in consistency with percentages in the Caucasian population. Apo E2/2 showed a frequency of $0.9 \%(\mathrm{~N}=1)$, apoE3/2 of $8 \%(\mathrm{~N}=9)$, apoE4/2 of $1.7 \%(\mathrm{~N}=2)$, apoE3/3 of $64.3 \%(\mathrm{~N}=72)$, apoE3/4 of $24.1 \%(\mathrm{~N}=27)$ and apoE $4 / 4$ of $0.9 \%(\mathrm{~N}=1)$. At the end of the run-in period, mean LDL cholesterol levels in the apoE2 (E2/2, E2/3, E2/4) group were $2.25 \pm 0.63 \mathrm{mmol} / \mathrm{L}$, in the apoE3 (E3/3) group $2.97 \pm 0.77 \mathrm{mmol} / \mathrm{L}(\mathrm{P}=0.002$ versus apoE2 group), and in the apoE4 (E4/3 and $E 4 / 4)$ group $3.18 \pm 0.72 \mathrm{mmol} / \mathrm{L}(\mathrm{P}<0.001$ versus apoE2 group). LDL cholesterol concentrations between the apoE3 and apoE4 group did not differ significantly $(P=0.218)$.

Table 5: Effects of vegetable oil based and wood based plant stanol esters on serum apolipoprotein $A-I, B$ and $L p(a)$ concentrations during the study

\begin{tabular}{|c|c|c|c|}
\hline & $\begin{array}{l}\text { Control } \\
\text { group }\end{array}$ & $\begin{array}{l}\text { Vegetable oil based } \\
\text { group }\end{array}$ & $\begin{array}{l}\text { Wood based } \\
\text { group }\end{array}$ \\
\hline \multicolumn{4}{|l|}{ Apo A-I (mg/L) } \\
\hline Run-in & $1690 \pm 253$ & $1702 \pm 285$ & $1654 \pm 269$ \\
\hline Test period & $1637 \pm 253$ & $1651 \pm 296$ & $1610 \pm 261$ \\
\hline Change & $-53 \pm 117$ & $-51 \pm 73$ & $-44 \pm 154$ \\
\hline \multicolumn{4}{|l|}{$A p o B(m g / L)$} \\
\hline Run-in & $902 \pm 154$ & $916 \pm 212$ & $891 \pm 256$ \\
\hline Test period & $912 \pm 179$ & $828 \pm 208$ & $828 \pm 235$ \\
\hline Change & $11 \pm 95$ & $-89 \pm 15^{c}$ & $-63 \pm 95 i$ \\
\hline \multicolumn{4}{|l|}{$L p(a)(m g / L)$} \\
\hline Run-in & (5 to 690) & 42 (3 to 405$)$ & $104(6 \text { to } 419)^{b}$ \\
\hline Testt period & 59 (2. to 765$)$ & 36 (4 to 465$)$ & $126 \quad(5$ to 396$)$ \\
\hline Change & $-1 \quad(-129$ to 166$)$ & $-3 \quad(-67$ to 61$)$ & $-4 \quad(-228$ to 197$)$ \\
\hline
\end{tabular}

Values are means \pm S.D or median (ranges), $(\mathrm{N}=112$ ).

112 non-hypercholesterolemic men and women consumed for four weeks (run-in) a rapeseed dil (LEAR) based margarine and shortening, low in stanolesters. For the next 8 weeks (test period), 42. subjects continued with these products, while the other subjects received products with a vegetable oil based stanolester mixture ( $2.6 \mathrm{~g}$ sitostanol and $1.2 \mathrm{~g}$ campestanol; $n=36$ ) or a pine wood based stanol ester mixture ( $3.7 \mathrm{~g}$ sitostanol and $0.3 \mathrm{~g}$ campestanol; $\mathrm{n}=34$ ).

For the run-in period (run-in), samples from weeks 3 and 4 were pooled before analysis, and for the test period, samples from weeks 11 and 12. Changes were calculated as the difference between values of the test period and run-in period.

a $\mathrm{P}<0.001$ control group versus wood based group

b $P<0.017$ vegetable oil based group versus wood based group

c $\mathrm{P}<0.001$ control group versus vegetable oil based group 
Figure 2 shows that the vegetable oil based stanol ester induced reductions in LDL cholesterol were moderately, though not significantly, larger in the apoE4 group $(-0.47 \pm 0.28 \mathrm{mmol} / \mathrm{L}$ versus $-0.14 \pm 0.35 \mathrm{mmol} / \mathrm{L}$ in the control group) and apoE3 group $(-0.44 \pm 0.24 \mathrm{mmol} / \mathrm{L}$ versus $-0.03 \pm 0.38 \mathrm{mmol} / \mathrm{L}$ in the control group) compared to the apoE2 group $(-0.28 \pm 0.25 \mathrm{mmol} / \mathrm{L}$ versus $-0.15 \mathrm{mmol} / \mathrm{L}$ in the control group). Similar results were found for the wood based stanol ester mixture, which decreased LDL cholesterol concentrations by $-0.33 \pm 0.33 \mathrm{mmol} / \mathrm{L}$ in the apoE2 group versus $-0.39 \pm 0.24 \mathrm{mmol} / \mathrm{L}$ and $-0.53 \pm 0.36 \mathrm{mmol} / \mathrm{L}$ in the apoE3 and apoE4 groups respectively. Since the reductions in LDL cholesterol were comparable between the vegetable oil and the wood based groups, the results of both groups were combined so as to increase the number of subjects in each apoE group. However, even then did apoE-genotype not affect the changes in LDL cholesterol.

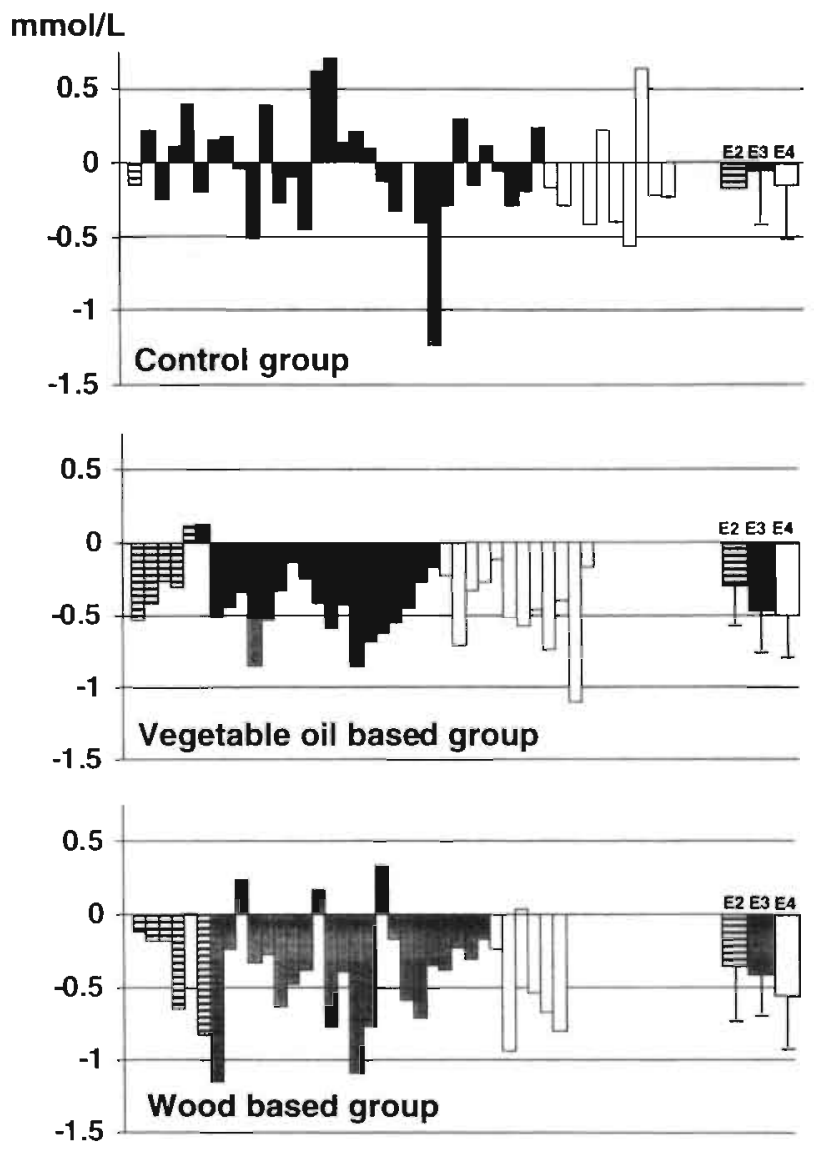

Figure 2: Individual changes in LDL cholesterol ( $\mathrm{mmo} / \mathrm{L}$ ) during the study in subjects with different apoE genotypes. Subjects of the apoE2 group have the apoE2/2, apoE2/3 or apoE2/4 genotype, subjects of the apoE3 group have the apoE3/3 genotype, while the apoE4 group consists of subjects who have the apoE3/4 or apoE $4 / 4$ genotype. 


\section{Coagulation and fibrinolysis}

Table 6 shows that changes in fibrinogen, FVIIc, FVIIam, AT-III, PAI-1 and t-PA were not significantly different between the groups. AT-III, however, tended to increase in the wood based group versus the control group $(P=0.030)$ and versus the vegetable oil based group $(P=0.018)$. Furthermore, fibrinogen concentrations tended to increase in the wood based group compared to the vegetable oil based group $(P=0.021)$.

Table 6: Effects of vegetable oil based and wood based stanol esters on coagulation and fibrinolytic parameters

\begin{tabular}{|c|c|c|c|c|c|c|c|c|}
\hline & \multicolumn{2}{|c|}{$\begin{array}{l}\text { Control } \\
\text { group }\end{array}$} & \multicolumn{3}{|c|}{$\begin{array}{l}\text { Vegetable oil based } \\
\text { group }\end{array}$} & \multicolumn{3}{|c|}{$\begin{array}{l}\text { Wood based } \\
\text { group }\end{array}$} \\
\hline Run-in & 2.96 & 0.16 & 2.90 & \pm & 0.14 & 2.95 & \pm & 0.15 \\
\hline Test period & 2.94 & 0.15 & 2.94 & \pm & 0.16 & 2.97 & \pm & 0.16 \\
\hline Change & -0.01 & 0.10 & 0.04 & \pm & 0.12 & 0.02 & \pm & 0.07 \\
\hline \multicolumn{9}{|c|}{ Factor VII coagulant activity ( $\%$ of normal) } \\
\hline Run-in & 90.2 & \pm 15.6 & 87.7 & \pm & 16.7 & 84.4 & \pm & 13.0 \\
\hline Test period & 91.4 & \pm 14.9 & 87.6 & \pm & 16.1 & 88.4 & \pm & 12.7 \\
\hline Change & 1.2 & 7.9 & -0.1 & \pm & 8.3 & 4.1 & \pm & 9.4 \\
\hline \multicolumn{9}{|c|}{ Factor VII amidolytic activity ( $\%$ of normal) } \\
\hline Run-in & 85.0 & \pm 20.5 & 86.3 & \pm & 27.4 & 88.6 & \pm & 19.3 \\
\hline Test period & 82.6 & \pm 19.3 & 85.8 & \pm & 31.5 & 84.6 & \pm & 21.3 \\
\hline Change & -2.5 & \pm 13.1 & -0.6 & \pm & 13.2 & -4.1 & \pm & 13.6 \\
\hline \multicolumn{9}{|c|}{ Antithrombin III activity (\% of normal) } \\
\hline Run-in & 95.7 & \pm 11.2 & 93.8 & \pm & 11.7 & 91.8 & \pm & 11.8 \\
\hline Test period & 92.4 & 9.5 & 89.9 & \pm & 12.8 & 92.7 & \pm & 13.0 \\
\hline Change & -3.3 & 7.8 & -3.8 & \pm & 9.2 & 0.9 & \pm & 7.5 \\
\hline \multicolumn{9}{|c|}{ Plasminogen Activator Inhibitor type 1 activity (AU/mL) } \\
\hline Run-in & 9.4 & 5.2 & 10.3 & \pm & 5.4 & 11.4 & \pm & 9.0 \\
\hline Test period & 9.5 & 5.3 & 10.6 & \pm & 7.0 & 13.0 & \pm & 11.1 \\
\hline Change & 0.1 & 4.9 & 0.3 & \pm & 3.7 & 1.6 & \pm & 5.0 \\
\hline \multicolumn{9}{|c|}{ Tissue Plasminogen Activator ( $\mathrm{ng} / \mathrm{mL}$ ) } \\
\hline Run-in & 5.8 & 2.5 & 5.2 & \pm & 2.7 & 5.2 & \pm & 3.6 \\
\hline Test period & 5.5 & 2.5 & 5.3 & \pm & 3.0 & 5.2 & \pm & 3.4 \\
\hline Change & -0.2 & 1.4 & 0.1 & \pm & 1.1 & 0.0 & \pm & 0.9 \\
\hline
\end{tabular}

Values are means \pm S.D., $(\mathrm{N}=112)$. 112 non-hypercholesterolemic men and women consumed for four weeks (run-in) a rapeseed oil (LEAR) based margarine and shortening, low in stanolesters. For the next 8 weeks (test period). 42 subjects continued with these products, while the other subjects received products with a vegetable oil based stanolester mixture $(2.6 \mathrm{~g}$ sitostanol and 1.2 g campestanol; $n=36$ ) or a pine wood based stanol ester mixture ( $3.7 \mathrm{~g}$ sitostanol and $0.3 \mathrm{~g}$ campestanol; n=34). For the run-in period (run-in), samples from weeks 3 and 4 were pooled before analysis, and for the test period, samples from weeks 11 and 12. Changes were calculated as the difference between values of the test period and run-in period. 


\section{Discussion}

Wood based stanol ester mixtures have repeatedly been shown to lower LDL. cholesterol concentrations in man. So far, however, only studies with hypercholesterolemic Finnish subjects have been published (28) and we have now demonstrated that this plant stanol ester mixture is effective in other population groups as well. In addition, our study has shown that a vegetable oil derived stanol ester mixture with $68 \%$ sitostanol and $32 \%$ campestanol has the same favorable effect on the serum lipoprotein profile as the wood based stanol ester mixture containing $93 \%$ sitostanol and $7 \%$ campestanol.

It has been suggested that the intestinal absorbability of plant sterols and stanols is inversely related to its inhibiting effects on cholesterol absorption (29). As sitostanol is not absorbed at all (5) and campestanol for about $12 \%(3)$, a greater LDL cholesterol lowering effect of the wood based stanol ester mixture was expected. We did, however, not find any differences between the two plant stanol ester mixtures for which there are at least two possible explanations. First of all, it is conceivable that the maximal feasible LDL cholesterol reduction was already achieved with the $2.6 \mathrm{~g}$ sitostanol as provided by the vegetable oil based stanol esters mixture. Based on other studies we have earlier postulated that consumption of more than $2.5 \mathrm{~g}$ sitostanols does not further lower LDL cholesterol concentrations (28). If this is indeed correct, than the extra intake of $1.1 \mathrm{~g}$ sitostanol in the wood based group would have been of no additional benefit. Secondly, it is possible that the postulated difference between sitostanol and campestanol esters to lower cholesterol absorption might be marginal or does not results in different LDL cholesterol concentrations. Unfortunately, no side-by-side comparison has been made between the hypocholesterolemic effects of sitostanol and campestanol esters in humans.

In agreement with other studies both plant stanol ester mixtures did not affect HDL cholesterol concentrations. This is remarkable, since a decrease in dietary cholesterol intake lowers HDL cholesterol (30). Also inhibition of dietary cholesterol absorption by neomycin reduces HDL cholesterol concentrations (31). Obviously, a lower dietary cholesterol intake, as well as the inhibition of dietary cholesterol absorption by neomycin, has other metabolic consequences than inhibition of cholesterol absorption by plant stanol esters.

Due to the unchanged HDL cholesterol concentrations, the LDL to HDL cholesterol ratio was changed in a favorable way in both experimental groups. ApoB concentrations were reduced to the same extent as LDL cholesterol, implicating that the number of LDL particles was reduced. Whether the composition of the LDL particles was changed can however not be concluded from our data (32). 
Subjects carrying an apo $\varepsilon 2$ allele (apoE2/2, E2/3 and E2/4) show a lower intrinsic cholesterol absorption compared to apoE3/3 and apoE4 (E4/3 and E4/4) subjects (18) and have -as in our study- lower LDL cholesterol levels $(18,33)$. Several intervention studies have now indicated that apoE4 subjects may benefit most from a reduced dietary cholesterol intake (34). Since plant stanol esters interfere with cholesterol absorption, apoE4 subjects may therefore profit more from dietary plant stanol ester enrichment. In agreement with the results of Vanhanen et al. (13), we did not find a significant difference in responses between apoE4 and non-apoE4 subjects, although the decrease in LDL cholesterol tended to be smaller in the apoE2 group compared to both the apoE4 and the apoE3 group. However, the number of apoE2 subjects in our study was small and studies with more apoE2 subjects are needed to examine in more detail the effect of apoE genotype on the $\mathrm{LDL}$ cholesterol lowering effect of plant stanol esters.

In a recent study, a margarine with soysterol esters lowered LDL cholesterol levels to the same extent as a pine wood based stanol ester enriched margarine (Beneco(i) $(35)$. It was therefore concluded that soysterol esters are as effective as pine wood based stanol esters. However, the estimated daily total plant sterol intake of $3.25 \mathrm{~g} /$ day was relatively high and $0.5 \mathrm{~g}$ more than plant stanol intake. Further side-by-side comparisons are therefore needed, preferably at lower intakes, to compare the cholesterol lowering effects of plant sterol esters with those of the plant stanol esters.

Plant stanol ester consumption may lower the absorption of fat soluble dietary components. Indeed, $\alpha$ - and $\beta$-carotene concentrations have been reported to decrease after consumption of pine wood based stanol esters (36). This prompted us to study the effects of both plant stanol ester mixtures on clotting factor VII, which synthesis depends on vitamin $\mathrm{K}$, a fat soluble vitamin. As both factor VII coagulant and amidolytic activities were not affected, it appears that, even if vitamin $K$ absorption may have been affected, this did not have any functional consequences for factor VII.

Effects on fibrinolytic parameters were also measured, because in vitro and in vivo studies have shown that sitosterol increase t-PA synthesis (19) and activity $(19,20)$. As consumption of sitostanol esters decrease plasma concentrations of sitosterol (15), the possible favorable effect of sitosterol on t-PA might be counteracted by dietary plant stanol ester enrichment. However, we did not find a difference in t-PA antigen response between the control group and both plant stanol ester groups.

The activity of antithrombin-III, a potent inhibitor of coagulation, tended to increase in the wood based group compared to the control group. Whether this effect is real and has functional consequences needs to be examined in future 
studies. None of the other measured proteins, involved in the coagulation and fibrinolytic system, were affected.

In this study, the margarine and shortening were used in such a way that plant stanol intake was divided over three meals, in correspondence with the distribution of cholesterol intake over the day. Therefore the largest amount of plant stanols was consumed at dinner. Mattson et al. (37) suggested the importance of the simultaneous presence of plant sterols and cholesterol in the intestine for maximal effectiveness. However, whether the consumption frequency over the day really affects the hypocholesterolemic response remains to be established.

The reductions in LDL cholesterol were observed when subjects were consuming their habitual diets, without restrictions on fat or cholesterol intake. Dietary cholesterol intake, however, did not correlate with changes in LDL cholesterol concentrations. In addition, similar LDL cholesterol reductions have been found at lower dietary cholesterol and fat intakes (16), probably because endogenously derived cholesterol is also present in the gut. It therefore appears that total cholesterol and fat intake is not a major determinant of the LDL cholesterol lowering efficacy of plant stanol esters.

From our results we conclude that vegetable oil based and wood based stanol ester mixtures lower serum LDL cholesterol concentrations in a nonhypercholesterolemic population on a free living diet to the same extent, with as much as $13-15 \%$. However, it is not clear whether campestanol is equally effective as sitostanol. HDL cholesterol concentrations were not affected, while both plant stanol ester mixtures did not cause any short-term side effects (21). Therefore, plant stanol enriched margarines appears to be a suitable strategy to reduce serum cholesterol concentrations, although careful monitoring of possible side effects on the longer term is warranted

\section{References}

1. Ling WH, Jones PJH. Minireview dietary phytosterols: a review of metabolism. benefits and side effects. Life Sciences 1995;57:195-206

2. Salen G, Ahrens EH, Grundy SM. Metabolism of $\beta$-sitosterol in man. $J$ Clin Invest 1970;49:952-967

3. Heinemann T. Axtmann $G$, von Bergmann K. Comparison of intestinal absorption of cholesterol with different plant sterols in man. Eur $J$ Clin Invest 1993;23:827-831

4. Heinemann T, Kullak-Ublick GA, Pietruck
$B$, von Bergmann K. Mechanisms of action of plant sterols on inhibition of cholesterol absorption; Comparison of sitosterol and sitostanol. Eur J Clin Pharmacol 1991:40 [suppl.1]:s59-s63

5. Heinemann $T$, Leiss $O$, von Bergmann $K$. Elfect of low dose sitostanol on serum cholesterol in patients with hypercholesterolemia. Atherosclerosis $1986 ; 6: 219-223$

6. Becker M, Staab D, von Bergmann K. Treatment of severe familial hypercholesterolemia in childhood with 
sitosterol and sitostanol. J Pediatr 1993;122:292-296

7. Miettinen TA, Tilvis RS, Kesāniemi YA. Serum plant sterols and cholesterol precursors reflect cholesterol absorption and synthesis in volunteers of a randomly selected male population. Am J Epidemiol 1990;131:20-31

8. Lees, A. M., H. Y. I. Mok, R. S. Lees, M. A. McCluskey, and S. M. Grundy. Plant sterols as cholesterol-lowering agents: clinical trials in patients with hypercholesterolemia and studies of sterol balance. Atherosclerosis 1977; 28:325-338.

9. Mattson, F. H., R. A. Volpenhein, and B. A. Erickson. Effect of plant sternl esters on the absorption of dietary cholesterol. $J$ Nutr 1977;107:1139-1146.

10. Peterson, D. W. Effect of soybean sterols in the diet on plasma and liver cholesterol in chicks. Proc Exp Biol Med 1951;78:143-147.

11. Pollak OJ. Successful prevention of experimental hypercholesterolemia and cholesterol atherosclerosis in the rabbit. Circulation 1953;7:696-701

12. Peterson DW, Nichols L.W, Peck NF, Chaikoff IL. Depression of plasma cholesterol in humans consuming butter containing soy sterols. Fed Proc 1956:65:569

13. Vanhanen $\mathrm{HT}$, Blomqvist $\mathrm{S}_{\mathrm{i}}$ Ehnholm $\mathrm{C}$ Hyvönen $M$, Jauhiainen $M$, Torstila I, Miettinen TA. Serum cholesterol, cholesterol precursors, and plant sterols in hypercholesterolemic subjects with different apoE phenotypes during dietary sitostanol-ester treatment. J Lipid Res 1993;34: 1535-1544

14. Miettinen TA, Puska $P$, Gylling $H$, Vanhanen $\mathrm{H}$, Vartiainen $\mathrm{E}$. Reduction of serum cholesterol with sitostanol-ester margarine in a mildiy hypercholesterolemic population. N Eng J Med 1995;333:1308-1312
15. Vanhanen $\mathrm{HT}$, Kajander J, Lehtovirta $\mathrm{H}$, Miettinen TA. Serum levels, absorption efficiency, faecal elimination and synthesis of cholesterol during increasing doses of dietary sitostanol esters in hypercholesterolaemic subjects. Clin Sci 1994;87:61-67

16. Gylling $H$, Radhakrishnan $R$, Miettinen TA. Reduction of cholesterol in postmenopausal women with previous myocardial infarction and cholesterol malabsorption induced by dietary sitostanol ester margarine. Circulation 1997;96:4226-4231

17 Ikeda I, Tanaka K, Sugano M, Vahouny GV, Gallo LL. Inhibition of cholesterol absorption in rats by plant sterols. J Lipid Res 1988;29:1573-1582

18. Kesäniemi YA, Ehnholm $C$, Miettinen TA. Intestinal cholesterol absorption efficiency in man is related to apoprotein $E$ phenotype. I Clin Invest 1987;80:578-581

19. Shimonake $M$, Hagiwara $H$, Kojima $S$, Inada $Y$. Successive study on the production of plasminogen activator in cultured endothelial cells by phytosterol. Thromb Res 1984;36:217-222

20. Hoffmann A, Klöcking HP. Influence of B-sitosterol on the fibrinolytic potential in rabbits. Folia Heamatol Int Mag Klin Morphol Blutforsch 1988; 115:189-196

21. Plat J, Mensink RP. Safety aspects of dietary phytostanols. Postgr Med 1998;A special report, November:32-38

22. Stichting Nevo. NEVO tabel, Nederlands voedingstoffenbestand (Dutch food composition table). Den Haag: Voorlichtingsbureau voor de voeding, 1989

23. Friedewald WT, Levy RI, Frederickson DS. Estimation of the concentration of low-density lipoprotein cholesterol in plasma, without use of preparative 
ultracentrifuge. Clin Chem 1972;18:499-502

24. Clauss A. Gerinnungsphysiologische snellmethode zur bestimmung des fibrinogens. Acta Heamatol 1957;226:237-246

25. Deijk van WA, Dam-Mieras van MCE, Muller AD, Hemker HC. Evaluation of a coagulation assay determining the activity of factor VII in plasma. Heamost 1983;13:192-197

26. Al MDM, Houwelingen van $A C$, Kester $A D M$, Hasaart THM, Jong de AEP', Hornstra G. Maternal essential fatty acid patterns during normal pregnancy and their relationship to the neonatal essential fatty acid status. Br J Nutr 1995; 74:55-68

27. Statview (for the Macintosh) manual. Abacus Concepts, Statview Abacus Concepts Inc Berkeley CA USA 1992

28. Mensink RP, Plat J. Efficacy of dietary phytostanols. Postgr Med 1998;A special report, November:27-31

29. Ikeda I, Tanabe $Y$, Sugano M. Effects of sitosterol and sitostanol on micellar solubility of cholesterol. J Nutr Sci Vitaminol 1989;35:361-369

30. Katan MB, Beynen AC, Vries de JHM, Nobels A. Existence of consistent hypoand hyperresponders to dietary cholesterol in man. Am J Epidemiol 1986;123:221-234

31. Kesäniemi YA, Grundy SM. Turnover of low density lipoproteins during inhibition of cholesterol absorption by neomycin. Arterioscler 1984:4: 41-48

32. Tallis GA, Shephard MDS, Sobecki S, Whiting MJ. The total apolipoprotein $\mathrm{B} / \mathrm{LDL}$-cholesterol ratio does not predict LDL particle size. Clin Chim Acta1995:240:63-73

33. Miettinen TA, Gylling $H$, Vanhanen $H$. Serum cholesterol response to dietary cholesterol and apoprotein $E$ phenotype. The Lancet 1988;26:1261
34. Lopez-Miranda J, Ordovas JM, Mata P, Lichtenstein AH, Clevidence B, Judd JT, Schaefer EJ. Effect of apolipoprotein E phenotype on dietinduced lowering of plasma low density lipoprotein cholesterol. J Lipid Res 1994;35:1965-1975

35. Weststrate JA, Meijer GW. Plant sterolenriched margarines and reduction of plasma total- and LDL-cholesterol con centrations in normocholesterolaemic and mildly hypercholesterolaemic subjects. Eur J Clin Nutr 1998;52:334-343

36. Gylling $\mathrm{H}$, Miettinen TA. Sitostanol ester margarines lower serum total and LDL cholesterol level in humans. Annual meeting abstracts: session 111997

37. Mattson FH, Grundy SM, Crouse JR. Optimizing the effect of plant sterols on cholesterol absorption in man. Am J Clin Nutr 1982;35:697-700 


\title{
Chapter 4
}

Effects of diets enriched with two different plant stanol ester mixtures on plasma ubiquinol-10 and fat-soluble antioxidant concentrations

\author{
Plat J, Mensink RP
}

Department of Human Biology, Maastricht University, The Netherlands

(Based on: Metabolism 2001;50:520-529) 


\section{Abstract}

Plant stanols lower intestinal cholesterol absorption. This causes a decrease in serum low density lipoprotein (LDL) cholesterol, despite a compensatory increase in cholesterol synthesis. We therefore hypothesized that plant stanols also change LDL-cholesterol standardized concentrations of ubiquinol-10 (a side product of the cholesterol synthesis cascade) and of those fat-soluble antioxidants, which are mainly carried by LDL. To examine this, 112 non-hypercholesterolemic subjects consumed for 4 weeks a rapeseed oil (LEAR) based margarine and shortening. For the next 8 weeks, 42 subjects consumed the same products, while the other subjects received products with vegetable oil based stanols $(2.6 \mathrm{~g}$ sitostanol plus $1.2 \mathrm{~g}$ campestanol daily; $n=36$ ) or wood based stanols $(3.7 \mathrm{~g}$ sitostanol plus $0.3 \mathrm{~g}$ campestanol daily; $n=34$ ).

Consumption of both plant stanol ester mixtures increased cholesterol synthesis and lowered cholesterol absorption, as indicated by increased serum cholesterol-standardized lathosterol and decreased plant sterol concentrations, respectively. Compared to the control group, absolute plasma ubiquinol-10 concentrations were lowered by $12.3 \pm 18.9 \%(-0.14 \mu \mathrm{g} / \mathrm{mL}$ versus the control group; $\mathrm{P}=0.004 ; 95 \%$ confidence interval $(\mathrm{Cl})$ for the difference in changes, -0.05 to -0.22 $\mu \mathrm{g} / \mathrm{mL})$ in the vegetable-oil based group and by $15.4 \pm 13.0 \%(-0.17 \mu \mathrm{g} / \mathrm{mL}$ versus the control group; $P<0.001 ; 95 \% \mathrm{Cl}$ for the difference, -0.08 to $-0.27 \mu \mathrm{g} / \mathrm{mL}$ ) in the woodbased group. Changes in LDL-cholesterol standardized ubiquinol-10 concentrations were not significantly different between the groups. The most lipophylic antioxidants, the hydrocarbon carotenoids ( $\beta$-carotene, $\alpha$-carotene and lycopene), decreased most, followed by the less lipophylic oxygenated carotenoids (lutein/zeaxanthin and $\beta$-cryptoxanthin), and the tocopherols. These reductions were related to the reduction in LDL, which carry most of these antioxidants. The decrease in the hydrocarbon carotenoids, however, was also significantly associated with the decrease in cholesterol absorption. LDL-cholesterol standardized antioxidant concentrations were not changed, except for $\beta$-carotene, which were still, although not significantly, lowered by about $10 \%$.

We conclude that the increase in endogenous cholesterol synthesis during plant stanol ester consumption does not result in increased LDL-cholesterol standardized concentrations of ubiquinol-10, a side product of the cholesterol synthesis cascade. Furthermore, decreases in absolute fat-soluble antioxidant concentrations are related to those in LDL cholesterol. For the most lipophylic carotenoids, however, a part of the reduction was also related to the decrease in cholesterol absorption. 


\section{Introduction}

Ubiquinone-10 (coenzyme Q10) is well-known for its role as electron transporter in the mitochondrial respiratory chain (1). It is, however, also present in the plasma, where it is almost entirely transported by low-density lipoproteins (LDL) $(2,3)$, mainly in its reduced form (ubiquinol-10) (4). Ubiquinol-10 is a powerful antioxidant $(1,5)$, even stronger than $\alpha$-tocopherol $(6)$. In contrast to other fat soluble antioxidants, ubiquinone is hardly derived from the diet (7), but is endogenously synthesized as a side product of the cholesterol synthesis cascade (Figure 1). This may suggest that inhibition of $\mathrm{HMG}-\mathrm{CoA}$ reductase, the rate limiting enzyme for cholesterol synthesis, reduces ubiquinone plasma levels, which indeed has been demonstrated after statin treatment $(8,9)$.

Plant stanols are useful hypocholesterolemic agents and daily intakes of 2-3 gram reduce serum LDL cholesterol concentrations by $10-15 \%$ (10). This effect is, at least partly, caused by a decrease in intestinal cholesterol absorption, which induces an increase in endogenous cholesterol synthesis (11), possibly by a higher HMGCoA reductase activity (12). Therefore, consumption of plant stanols may also increase ubiquinol synthesis. On the other hand, plant stanols may not only lower LDL cholesterol concentrations, but also those of other lipophylic compounds. Indeed, lipid-standardized plasma concentrations of $\alpha$-and $\beta$-carotene (13-16), and of lycopene (14) were reduced after consumption of plant stanol or plant sterol esters. Lipid-standardized $\alpha$-tocopherol levels, however, were hardly changed (1315).

Information of plant stanols on plasma levels of other carotenoids and tocopherols, which also exert important biological functions $(17,18)$, is missing. We therefore decided to study the effects of two different plant stanol ester mixtures on plasma concentrations of ubiquinol-10 and of several carotenoids and tocopherol isomers. In addition, it was examined if changes in these antioxidants were related to the reduced cholesterol absorption, as caused by plant stanols. Serum concentrations of plant sterols and cholesterol precursors were analyzed as markers for cholesterol absorption and cholesterol synthesis, respectively.

\section{Methods}

Subjects

Characteristics of the population have been described in detail elsewhere (19). Briefly, 112 participants - 41 males and 71 females - from Maastricht and surrounding municipals completed the study. Their ages were $33 \pm 16$ years (mean \pm SD), their body mass index (BMI) $23 \pm 2.8 \mathrm{~kg} / \mathrm{m}^{2}$, while serum total cholesterol concentrations were $4.97 \pm 0.73 \mathrm{mmol} / \mathrm{L}$ and serum triacylglycerol 
concentrations $0.88 \pm 0.37 \mathrm{mmol} / \mathrm{L}$. Subjects were normotensive, had no proteinuria or glucosuria, had no history of coronary heart disease and did not use prescribed diets or medication known to affect serum lipids. Fifteen males and 8 females smoked, 2 males and 2 females were vegetarians, 38 women used oral contraceptives and 4 women were post menopausal. All subjects gave their written informed consent before the start of the study. The protocol of the study had been approved by the medical ethical committee of the Maastricht University.

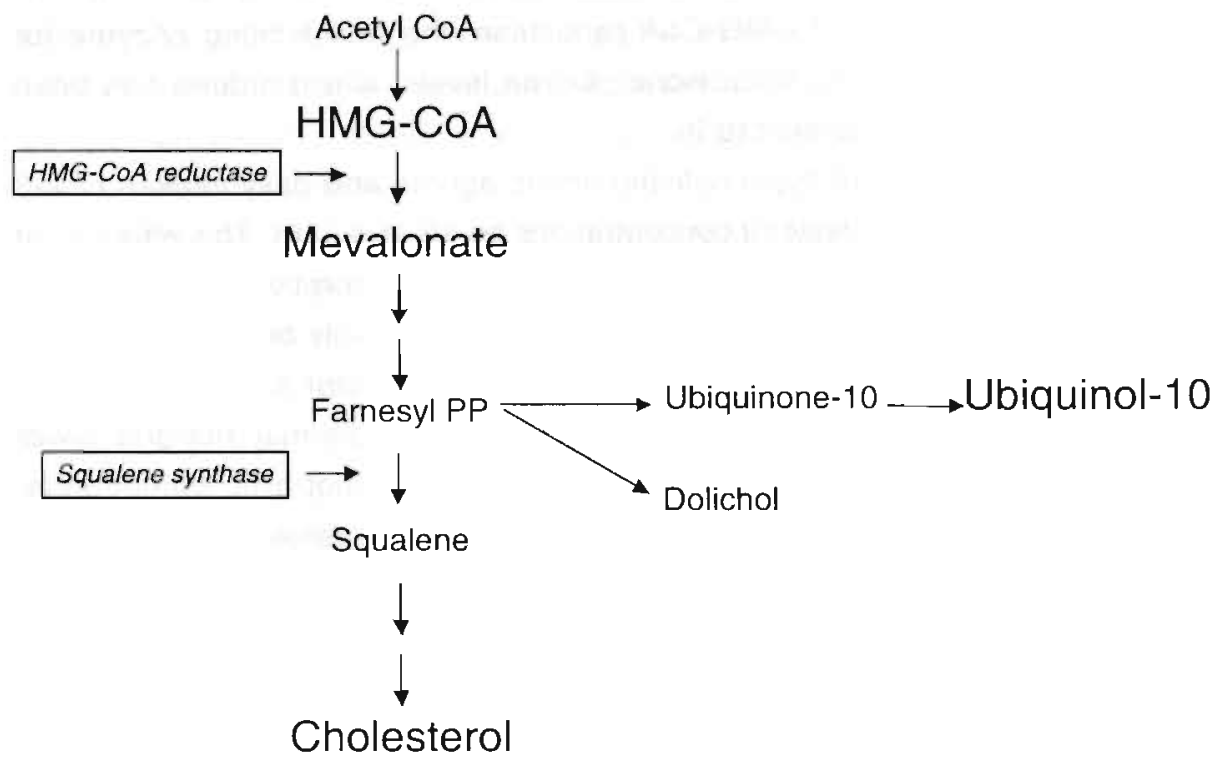

Figure 1: Schernatic view of the biosynthesis of cholesterol and non-sterol isoprenes (ubiquinone-10, dolichol). Regulatory proteins are indicated by rectangles.

\section{Diets and Design}

Details of this study on the effects of two different plant stanol ester mixtures on various cardiovascular risk markers have been published before (19). Briefly, subjects were provided with low erucic acid rapeseed oil (LEAR) based margarine and shortening to replace their usual margarine and baking fat. The minimal daily margarine intake was $20 \mathrm{~g}$, whereas at least $10 \mathrm{~g}$ shortening a day had to be eaten. The participants used the margarine at breakfast and lunch, and the shortening at diner.

During a four week run-in period, subjects received a control margarine and shortening to which no plant stanol esters were added. Subjects were then randomly allocated to one of the three treatment groups, stratified for sex and age. The control 
group continued to use the control rapeseed based margarine and shortening for another eight weeks, while the second and the third group used the same margarine and shortening with an added vegetable oil or wood based plant stanol ester mixture. Both plant stanol ester mixtures were derived by saturation of sitosterol, stigmasterol and campesterol, followed by transesterification of the obtained free sitostanol and campestanol with rapeseed oil (RAISIO GROUP, Raisio, Finland). Transesterified stanol esters were subsequently mixed with the margarines and shortenings. The two plant stanol ester mixtures differed in their stanol composition. The vegetable oil based mixture consisted of $70 \%$ sitostanol and $30 \%$ campestanol, while the wood based plant stanol mixture contained approximately $93 \%$ sitostanol and $7 \%$ campestanol. Both the control margarine and shortening as well as the experimental products were fortified with normal amounts of vitamin A and D. $\beta$-Carotene was used as a coloring agent, while vitamin $E$ was present as a natural compound. The exact compositions of both experimental margarines and shortenings have been presented elsewhere (20). All products were coded with a color label to blind the subjects and the investigators.

Body weight was recorded every week and did not change during the study. Furthermore, subjects recorded in diaries any signs of illness, medication used, menstrual phase and any deviations from the protocol. In addition, subjects were asked not to change their habitual diets, levels of physical exercise, smoking habits or use of alcohol or of oral contraceptives during the study.

To estimate their energy and nutrient intakes, subjects recorded in the last week of the run-in and the intervention period, their food intake during the previous four weeks by filling in food frequency lists, consisting of 100 items. Food frequency lists were checked immediately in the presence of the subjects by a dietician, and energy and nutrient intakes were calculated as described (19).

\section{Blood sampling and analyses}

\section{Blood sampling}

At the end of the run-in period (weeks 3 and 4), and at the end of the intervention period (weeks 11 and 12), blood was sampled after an overnight fast. Subjects abstained from drinking alcohol the day preceding, and smoking the morning of blood sampling. After about $13 \mathrm{~mL}$ blood was sampled for additional measurements (to be reported elsewhere), blood was drawn in a precooled $\left(4^{\circ} \mathrm{C}\right) 10$ $\mathrm{mL}$ EDTA tube (Monoject sterile, Sherwood Medical, Ballymoney, North Ireland) to obtain plasma at a final EDTA concentration of $1 \mathrm{~g} / \mathrm{L}$, and in a $10 \mathrm{~mL}$ clotting tube to obtain serum. Plasma was obtained directly and serum minimally one hour after venipuncture by centrifugation at $2000 \times \mathrm{g}$ for thirty minutes at $4^{\circ} \mathrm{C}$. 
In weeks 3 and 4 as well as in weeks 11 and 12, a midportion of plasma was snap-frozen and stored directly at $-80^{\circ} \mathrm{C}$ for analysis of antioxidant concentrations. In weeks 4 and 12 only, saccharose and BHT were added to another midportion of the plasma, at final concentrations of respectively $6 \mathrm{~g} / \mathrm{L}$ and $250 \mathrm{mg} / \mathrm{L}$. These samples were directly used for analyses of plasma ubiquinone and ubiquinol-10 concentrations. Serum aliquots were stored immediately at $-80^{\circ} \mathrm{C}$ for analysis of lipid and lipoprotein, plant sterol and cholesterol precursor concentrations.

\section{Plant sterols and cholesterol precursors}

For analysis of serum cholesterol, serum plant sterols and stanols (sitosterol, sitostanol, campesterol, and campestanol), and cholesterol precursors (lathosterol) by gas chromatography (GC), serum of weeks 3 and 4, and of weeks 11 and 12, was pooled before analyses. Samples of one subject were analyzed in the same analytical run to exclude variations between runs. First, $200 \mu \mathrm{L}$ serum was saponified for 1.5 hours at $70^{\circ} \mathrm{C}$ with $2 \mathrm{~mL}$ of a mixture consisting of a $10 \mathrm{M} \mathrm{KOH}$ solution in water and ethanol $(1: 9 \%(\mathrm{v} / \mathrm{v}))$. After cooling down to room temperature, $1.4 \mathrm{~mL}$ water was added, mixed, and then $2 \mathrm{~mL}$ hexane was added. This mixture was shaken vigorously and centrifuged for 2 minutes at $2000 \times \mathrm{xg}$. The hexane layer was transferred to another tube, and the hexane extraction was repeated once to improve recovery. The hexane extracts were combined and evaporated to dryness at $37^{\circ} \mathrm{C}$ under a moderate nitrogen flow. The nonsaponifiable serum lipids were silylated for 15 minutes after addition of $200 \mu \mathrm{L}$ Bis (trimethylsilyl)-trifluoracetamid (BSTFA) (Merck, Darmstadt, Germany) containing 1\% trimethylchlorosilane (TMCS) (Sigma-Alderich Chemie BV, Zwijndrecht, The Netherlands), and $100 \mu \mathrm{L}$ pyridine (Merck, Darmstadt, Germany). After evaporation under a moderate nitrogen flow at $50^{\circ} \mathrm{C}$, the samples were dissolved in $500 \mu \mathrm{L}$ pentane. Samples were then analyzed with a GC8000 Top gas chromatograph (Carlo Erba, Milan, Italy) fitted with a $25 \mathrm{~m}$ AT1701 capillary column with an inner diameter of $0.32 \mathrm{~mm}$ and $0.30 \mu \mathrm{m}$ film thickness (Alltech, Breda, The Netherlands) using cold on-column injection. $1 \mu \mathrm{L}$ of the samples was injected into the GC. Helium was used as carrier gas. The temperature of the injector was $20^{\circ} \mathrm{C}$ after secondary cooling. The oven temperature was programmed at $40^{\circ} \mathrm{C}$ for 1 minute, followed by a rise to $250^{\circ} \mathrm{C}$ at a rate of 79 ${ }^{\circ} \mathrm{C} /$ minute and then kept constant for 5 minutes. Next, the temperature increased to $265^{\circ} \mathrm{C}$ at a rate of $1^{\circ} \mathrm{C} /$ minute and then kept constant for 15 minutes. The flame ionization detector temperature was set at $270^{\circ} \mathrm{C} .100 \mu \mathrm{g}$ of $5 \alpha$-cholestane and $2 \mu \mathrm{g}$ of $5 \beta$-cholestan-3 $\alpha$-ol (Sigma-Alderich Chemie BV, Zwijndrecht, The Netherlands) were added to all serum samples before extraction and used as internal standards for respectively cholesterol and non-cholesterol sterols. A standard mixture was used 
to identify the sterols by means of the retention times. A serum pool was prepared of blood from 34 healthy volunteers after four weeks plant stanol ester consumption. This pool was stored at $-80^{\circ} \mathrm{C}$ and analyzed twice in each run. Coefficients of variation within runs were $3.8 \%$ for cholesterol, $8.4 \%$ for sitosterol, $4.8 \%$ for campesterol, $10.0 \%$ for sitostanol, $11.0 \%$ for campestanol, and $6.7 \%$ for lathosterol. Sterol concentrations were expressed per mmol total cholesterol.

\section{Ubiquinone-10 and ubiquinol-10}

Plasma ubiquinol-10 concentrations were analyzed in samples before and after in vitro treatment with sodium borohydride $\left(\mathrm{NaBH}_{4}\right)$ (Fluka Chemica, Neu-Ulm, Swiss), which reduces ubiquinone-10 into ubiquinol-10. Ubiquinone-10 concentrations were calculated as the difference in ubiquinol-10 concentrations between the treated and the untreated samples. Extractions and analyses were carried out in the dark to minimize photochemical decomposition of ubiquinol-10.

Extraction of ubiquinone from plasma was performed as described by Edlund et al. (2). Briefly, $300 \mu \mathrm{l}$ sample was mixed with $25 \mu \mathrm{l}$ internal standard (ubiquinol-9, final concentration $40 \mu \mathrm{g} / \mathrm{mL}$ in ethanol) and $1 \mathrm{~mL}$ isopropanol. After mixing thoroughly, the tubes were placed on melting ice for ten minutes, while mixing was repeated every two minutes. Samples were then centrifuged for eight minutes at $2500 \times \mathrm{xg}$ and $4^{\circ} \mathrm{C}$, and $175 \mu \mathrm{L}$ of the supernatant was pipetted into an amber colored $2 \mathrm{~mL}$ vial, which was placed directly at $4^{\circ} \mathrm{C} .350 \mu \mathrm{L}$ of the remaining supernatant was transferred into a pre-cooled glass tube to which $10 \mu \mathrm{l} \mathrm{NaBH}_{4}(0.25 \%(\mathrm{~m} / \mathrm{v})$ in methanol) was added and vortexed. The tube was placed for 10 minutes on melting ice, while vortexing was repeated every two minutes. Finally, $175 \mu \mathrm{L}$ of this reduced sample was transferred into a second amber colored vial.

Ubiquinol-10 plasma concentrations were determined by using freshly prepared standard mixtures of ubiquinol-10 and ubiquinol-9, which were prepared from ubiquinone-9 and ubiquinone-10 (Fluka Chemica, Neu-Ulm, Swiss) also by treatment with $\mathrm{NaBH}_{4}$. Standards were extracted using a comparable procedure as described for the samples. Briefly, to a $1 \mathrm{~mL}$ ubiquinone-10 or ubiquinone- 9 stock solution in ethanol $(100 \mu \mathrm{g} / \mathrm{mL}), 50 \mu \mathrm{L} \mathrm{NaBH} 4(0.25 \%$ in methanol) was added, and incubated for 30 minutes on melting ice in the dark. Next, $1 \mathrm{~mL}$ water was added to the tube, vortexed, and mixed with $4 \mathrm{~mL}$ hexane. This solution was centrifuged for 4 minutes at $1000 \mathrm{xg}$ at $4^{\circ} \mathrm{C}$. The hexane phase was removed and transferred into another precooled tube. This extraction procedure was repeated once. Both hexane phases, were mixed, evaporized to dryness under nitrogen, and dissolved in $2 \mathrm{~mL}$ ethanol. The exact concentrations of the standard solutions were measured spectrophotometrically at $290 \mathrm{~nm}$ by using the extinction $E_{1} \%=46.6 \mathrm{~L} \mathrm{~mol}^{-1} \mathrm{~cm}^{-1}$ 
for ubiquinol-10 and $E_{1 \%}=49.7 \mathrm{~L} \mathrm{~mol}^{-1} \mathrm{~cm}^{-1}$ for ubiquinol-9. Four standard solutions with increasing ubiquinol-10 concentrations and constant ubiquinol-9 (40 $\mu \mathrm{g} / \mathrm{mL}$ ) concentrations, diluted with $30 \mathrm{mmol} / \mathrm{L}$ lithiumphosphate in a mixture of methanol:ethanol:isopropanol (22.5:73.6:3.9) (v/v/v) were prepared. Since standard solutions and plasma samples all contained the same concentration ubiquinol-9, the ratio of ubiquinol-10 to ubiquinol-9 could be used to calculate plasma ubiquinol-10 concentrations. Calibration samples were placed at the start and at the end of each run.

The HPLC system consisted of a cartridge guard column E, $5 \mu \mathrm{m}$ Inertsil ODS2 and a $3 \mu \mathrm{m}$ Inertsil ODS-3 column, $150 \times 4,0 \mathrm{~mm}$ (GL Sciences Inc. Tokyo, Japan). A working electrode against an $\mathrm{Ag} / \mathrm{AgCl}$ reference electrode in saturated $\mathrm{LiCl}$ constituted the electrochemical detection system. Analyses were performed at $+0.6 \mathrm{~V}, 30^{\circ} \mathrm{C}$ and at a flow rate of $0.5 \mathrm{~mL} / \mathrm{minute}$. The mobile phase consisted of 30 $\mathrm{mmol} / \mathrm{L}$ lithiumphosphate in the methanol:ethanol:isopropanol mixture. Peaks were recorded and analyzed with Gynkosoft Chromatography Data System 4.12 (Gynkotek HPLC, Germering, Germany).

Ubiquinone and ubiquinol-10 concentrations were determined in 111 instead of 112 subjects, since one analysis failed. A plasma pool was prepared of blood from 5 healthy volunteers by the same procedures as those for the volunteers. This pool was stored at $-80^{\circ} \mathrm{C}$ and analyzed twice in each run. Coefficients of variations within runs were $6.1 \%$ and between runs $5.4 \%$ for ubiquinol-10, and $5.4 \%$ and $7.5 \%$ for total coenzyme Q10.

\section{Antioxidants}

The concentrations of lipophylic antioxidants in plasma samples were determined after storage at $-80^{\circ} \mathrm{C}$ for three to four months, which does not affect antioxidant concentrations (21). Tocopherols and carotenoids were determined simultaneously according to a modification of the assay of Hess et al. (22), as described by Oostenbrug et al. (23). Briefly, plasma samples were extracted twice with hexane, while retinylacetate was used as internal standard. The amounts of lipid soluble antioxidants were determined by reversed phase HPLC. Samples from one subject of weeks 3 and 4 as well as of weeks 11 and 12 were pooled before analysis and analyzed in the same analytical run. The mean recovery of retinylacetate was $95.3 \pm 1.7 \%$.

\section{Lipids and lipoproteins}

Serum lipids and lipoproteins were analyzed as described (19). The mean LDL cholesterol concentrations from weeks 3 and 4 and from weeks 11 and 12 were 
averaged to calculate LDL-cholesterol standardized antioxidant concentrations, whereas LDL cholesterol concentrations from week 4 and 12 were used to calculate LDL-cholesterol standardized ubiquinol-10 concentrations.

\section{Statistics}

Data from 112 subjects who completed the study, were included in the analyses. Results are expressed as means \pm S.D. Changes for all parameters were calculated for each subject as the difference between values of the experimental period and run-in period. The differences in changes between both intervention groups and the control group were tested with analysis of variance (ANOVA). When a significant diet effect was found $(P<0.05)$, the three treatments were compared pairwise and corrected for three group comparisons $(\alpha=0.017)$ using the Bonferroni multi comparison test. Effects of gender and smoking on the responses were examined by including these factors as well as its interaction terms with treatment into the statistical model. Multiple regression analysis was used to examine the relationship between changed in cholesterol absorption and antioxidant concentrations. All statistical analyses were performed with Statview 4.5 (24).

\section{Results}

Serum lipids and lipoproteins

Consumption for eight weeks decreased serum total cholesterol from 4.93 $\mathrm{mmol} / \mathrm{L}$ to $4.89 \mathrm{mmol} / \mathrm{L}$ on the control diet, from $4.89 \mathrm{mmol} / \mathrm{L}$ to $4.56 \mathrm{mmol} / \mathrm{l}$ on the vegetable oil based diet $(P<0.001$ versus the control group; $95 \%$ confidence interval (CI) for the difference in changes between the two groups, -0.23 to $-0.55 \mathrm{mmol} / \mathrm{L}$ ) and from $4.98 \mathrm{mmol} / \mathrm{L}$ to $4.55 \mathrm{mmol} / \mathrm{L}$ on the wood based diet $(P<0.001$ versus the control group; $95 \% \mathrm{Cl}$ for the difference, -0.20 to $-0.56 \mathrm{mmol} / \mathrm{L})$. LDL cholesterol concentrations changed from $2.96 \mathrm{mmol} / \mathrm{L}$ to $2.90 \mathrm{mmol} / \mathrm{L}$ on the control diet, from $2.94 \mathrm{mmol} / \mathrm{L}$ to $2.51 \mathrm{mmol} / \mathrm{L}$ on the vegetable oil based diet $(P<0.001$ versus the control group; $95 \% \mathrm{Cl}$ for the difference, -0.22 to $-0.51 \mathrm{mmol} / \mathrm{L}$ ) and from 2.94 $\mathrm{mmol} / \mathrm{L}$ to $2.54 \mathrm{mmol} / \mathrm{L}$ on the wood based diet $(P<0.001$ versus the control group; $95 \% \mathrm{Cl}$ for the difference, -0.18 to $-0.51 \mathrm{mmol} / \mathrm{L})$. The decreases in total and LDL cholesterol between both intervention groups were not significantly different from each other $(P=0.925$ and $P=0.793$, respectively). HDL cholesterol and triacylglycerol concentrations were not changed after consumption of the two plant stanol ester mixtures (19). 
Table 1: Effects of vegetable oil and wood based plant stanol esters on cholesterol-standardized serum plant sterol and stanol, and lathosterol concentrations during the study

\begin{tabular}{|c|c|c|c|}
\hline & $\begin{array}{l}\text { Control } \\
\text { group }\end{array}$ & $\begin{array}{l}\text { Vegetable oil based } \\
\text { group }\end{array}$ & $\begin{array}{l}\text { Wood based } \\
\text { group }\end{array}$ \\
\hline \multicolumn{4}{|c|}{ Sitosterol $\left(10^{2} \times \mu \mathrm{mol} / \mathrm{mmol}\right.$ cholesterol) } \\
\hline Run-in & $113.8 \pm 32.7$ & $113.9 \pm 43.3$ & $117.6 \pm 57.8$ \\
\hline Test period & $105.9 \pm 35.4$ & $69.6 \pm 24.1$ & $62.9 \pm 23.8$ \\
\hline Change & $-7.8 \pm 22.4$ & $-44.3 \pm 26.9^{*}$ & $-54.7 \pm 41.5 \dagger$ \\
\hline \multicolumn{4}{|c|}{ Campesterol $\left(10^{2} \times \mu \mathrm{mol} / \mathrm{mmol}\right.$ cholesterol) } \\
\hline Run-in & $304.3 \pm 76.5$ & $302.2 \pm 100.9$ & $303.5 \pm 119.3$ \\
\hline Test period & $298.4 \pm 82.3$ & $209.4 \pm 53.2$ & $189.5 \pm 61.2$ \\
\hline Change & $-5.9 \pm 39.2$ & $-92.8 \pm 63.0^{*}$ & $-114.0 \pm 77.3 \dagger$ \\
\hline \multicolumn{4}{|c|}{ Sitostanol ( $10^{2} \times \mu \mathrm{mol} / \mathrm{mmol}$ cholesterol) } \\
\hline Rurn-in & $7.1 \pm 4.2$ & $8.4 \pm 4.8$ & $7.3 \pm$ \\
\hline Test period & $7.6 \pm 3.7$ & $15.8 \pm 5.8$ & $16.3 \pm 6.0$ \\
\hline Change & $0.4 \pm$ & $7.4 \pm 4.3^{*}$ & $9.0 \pm$ \\
\hline \multicolumn{4}{|c|}{ Campestanol (102 $\times \mu \mathrm{mol} / \mathrm{mmol}$ cholesterol) } \\
\hline Run-in & $10.7 \pm 7.7$ & $8.9 \pm 4.5$ & $9.5 \pm 6.9$ \\
\hline Test period & $10.1 \pm$ & $17.9 \pm 8.3$ & $13.0 \pm \quad 7.7$ \\
\hline Change & $-0.6 \pm$ & $9.0 \pm 7.3^{*}, \ddagger$ & $3.5 \pm 8.0$ \\
\hline \multicolumn{4}{|c|}{ Lathosterol (102 $\times \mu \mathrm{mol} / \mathrm{mmol}$ cholesterol) } \\
\hline Run-in & $97.0 \pm 37.3$ & $95.5 \pm 28.7$ & $99.7 \pm 34.2$ \\
\hline Test period & $97.5 \pm 33.9$ & $115.3 \pm 37.9$ & $114.5 \pm 35.6$ \\
\hline Change & $0.5 \pm 19.5$ & $19.8 \pm 24.9 \S$ & $14.8 \pm 18.9 ?$ \\
\hline
\end{tabular}

Values are means \pm S.D. 112 non-hypercholesterolemic men and women consumed for four weeks (run-in) a low erucic acid (LEAR) rapeseed oil based margarine and shortening, without plant stanol esters. For the next 8 weeks (test period), 42 subjects continued with these products, while the other subjects received products with a vegetable oil based stanol ester mixture $(2.6 \mathrm{~g}$ sitostanol and $1.2 \mathrm{~g}$ campestanol; $n=36$ ) or a pine wood based stanol ester mixture $(3.7 \mathrm{~g}$ sitostanol and $0.3 \mathrm{~g}$ campestanol; $n=34$ ). Changes were calculated as the difference between values of the experimental period and run-in period.

* $\mathrm{P}<0.001$ control group versus vegetable oil based group

$\dagger P<0.001$ control group versus wood based group

₹ $P<0.01$ wood based group versus vegetable oil based group

$\S P<0.017$ control group versus vegetable oil based group

II $P<0.017$ control group versus wood based group

\section{Plant sterols and cholesterol precursors}

Total plant sterol intake, as derived from the experimental products (about 155 $\mathrm{mg}$ ), did not change during the study and was not significantly different between the 
three groups (19). Compared to the control group. cholesterol-standardized serum plant sterol concentrations (sitosterol and campesterol) were decreased to the same extent after consumption of the vegetable oil or wood based stanol ester mixtures. indicating a reduction in cholesterol absorption (Table 1). Compared to the control and the wood based group, the cholesterol-standardized serum campestanol concentration was significantly increased in the vegetable oil based group $(P<0.001$ and $P=0.003$, respectively), most likely due to the higher dietary campestanol intake. Cholesterol-standardized sitostanol concentrations were increased in both stanol ester groups. This effect was slightly more pronounced in the sitostanol ester rich wood based group, although the change did not differ significantly from that in the vegetable oil based group. These results suggest that plant stanols are absorbed to a small extent, and that changes in serum plant stanol concentrations reflect their dietary intakes. Cholesterol-standardized serum levels remained, however, at very low levels. The cholesterol-standardized concentration of the cholesterol precursor lathosterol increased significantly with $22.2 \%$ in the vegetable oil group $(P<0.001)$ and with $17.8 \%$ in the wood based group $(P<0.001)$ as compared to a change of $3.1 \%$ in the control group, indicating an increased cholesterol synthesis.

\section{Ubiquinone-10 and ubiquinol-10 concentrations}

Table 2 shows that consumption of the plant stanol ester mixtures lowered the plasma concentrations of ubiquinol-10 and total coenzyme Q10. For ubiquinol-10, this decrease was $0.12 \pm 0.18 \mu \mathrm{g} / \mathrm{mL}$ or $12.3 \pm 18.9 \%$ in the vegetable oil based group, which was significantly different from the change of $0.01 \pm 0.19 \mu \mathrm{g} / \mathrm{mL}$ in the control group ( $P=0.004 ; 95 \% \mathrm{Cl}$ for the difference, 0.05 to $0.22 \mu \mathrm{g} / \mathrm{mL}$ ). Consumption of the wood based stanol ester mixture caused a decrease of $0.16 \pm 0.24 \mu \mathrm{g} / \mathrm{mL}$ or $15.4 \pm 23.0 \%,(P<0.001$ versus the control group; $95 \% \mathrm{Cl}$ for the difference, 0.08 to $0.27 \mu \mathrm{g} / \mathrm{mL}$ ). Both plant stanol ester mixtures decreased ubiquinol-10 concentrations to the same extent $(P=0.473 ; 95 \% \mathrm{Cl}$ for the difference, -0.06 to $0.14 \mu \mathrm{g} / \mathrm{mL}$ ). Total coenzyme $Q 10$ reductions paralleled changes in ubiquinol-10 concentrations.

Since changes in ubiquinol-10 and total coenzyme Q10 concentrations paralleled changes in LDL cholesterol concentrations, changes in LDL-cholesterol standardized ubiquinol-10 and total coenzyme Q10 concentrations did not differ significantly between the groups (Table 2). Effects were not different for men and women and were not related to smoking characteristics. 
Table 2: Effects of vegetable oil and wood based plant stano! esters on absolute and LDLcholesterol standardized plasma ubiquinol-10 and total coenzyme Q10 concentrations during the study

\begin{tabular}{|c|c|c|c|c|c|c|c|c|c|}
\hline & \multicolumn{3}{|c|}{$\begin{array}{l}\text { Control } \\
\text { group }\end{array}$} & \multicolumn{3}{|c|}{$\begin{array}{l}\text { Vegetable oil based } \\
\text { group }\end{array}$} & \multicolumn{3}{|c|}{$\begin{array}{l}\text { Wood based } \\
\text { group }\end{array}$} \\
\hline \multicolumn{10}{|c|}{ Ubiquinol-10 $(\mu \mathrm{g} / \mathrm{mL})$} \\
\hline Run-in & 0.76 & \pm & 0.16 & 0.85 & \pm & 0.24 & 0.81 & \pm & 0.29 \\
\hline Test period & 0.78 & \pm & 0.24 & 0.73 & \pm & 0.19 & 0.65 & \pm & 0.17 \\
\hline Change & 0.01 & \pm & 0.19 & -0.12 & \pm & $0.18 \ddagger$ & -0.16 & \pm & $0.24 \dagger$ \\
\hline \multicolumn{10}{|c|}{ Total coenzyme Q10 $(\mu \mathrm{g} / \mathrm{mL})$} \\
\hline Run-in & 0.85 & \pm & 0.20 & 0.95 & \pm & 0.28 & 0.90 & \pm & 0.31 \\
\hline Test period & 0.83 & \pm & 0.24 & 0.77 & \pm & 0.19 & 0.70 & \pm & 0.19 \\
\hline Change & .0 .02 & \pm & 0.19 & -0.18 & \pm & $0.21 \ddagger$ & -0.20 & \pm & $0.25 \dagger$ \\
\hline \multicolumn{10}{|c|}{ Ubiquinol-10 ( $\mu \mathrm{mol} / \mathrm{mmol}$ LDL cholesterol) } \\
\hline Run-in & 0.31 & \pm & 0.09 & 0.35 & \pm & 0.10 & 0.32 & \pm & 0.09 \\
\hline Test period & 0.32 & \pm & 0.10 & 0.36 & \pm & 0.15 & 0.31 & \pm & 0.11 \\
\hline Change & 0.01 & \pm & 0.07 & 0.01 & \pm & 0.10 & -0.01 & \pm & 0.09 \\
\hline \multicolumn{10}{|c|}{ Total coenzyme Q10 ( $\mu \mathrm{mol} / \mathrm{mmol}$ LDL cholesterol) } \\
\hline Run-in & 0.34 & \pm & 0.10 & 0.39 & \pm & 0.11 & 0.36 & \pm & 0.10 \\
\hline Test period & 0.34 & \pm & 0.10 & 0.38 & \pm & 0.14 & 0.33 & \pm & 0.11 \\
\hline Change & 0.00 & \pm & 0.07 & -0.01 & \pm & 0.10 & -0.03 & \pm & 0.09 \\
\hline
\end{tabular}

See table 1. Values from one subject of the vegetable oil based group are missing.

$\ddagger P<0.017$ control group versus vegetable oil based group

$+P<0.001$ control group versus wond based group

\section{Antioxidant concentrations}

Consumption of the two plant stanol ester mixtures significantly lowered total carotenoid and total tocopherol concentrations, whereas retinol concentrations were not affected (Table 3 ). These effects were not modified by gender or smoking. Figure 2 shows the effects of the diets on the various carotenoids, phytofluene and tocopherol isomers. Antioxidants are presented in order of decreasing lipophylicity. These results suggest that the most lipophylic antioxidants were affected most by the two plant stanol ester mixtures. The vegetable oil based stanol ester mixture decreased $\beta$-carotene, $\delta$-tocopherol, and $\alpha$-tocopherol by respectively $0.092 \pm 0.085$ $\mu \mathrm{mol} / \mathrm{L}$ or $26.1 \pm 22.6 \%, 0.037 \pm 0.077$ or $10.7 \pm 38.3 \%$, and $2.029 \pm 2.608 \mu \mathrm{mol} / \mathrm{L}$ or $7.8 \pm 9.9 \%$ (Figure 2). These changes were significantly different from the changes in the control group for $\beta$-carotene $(\mathrm{P}=0.014 ; 95 \% \mathrm{Cl}$ for the difference, -0.016 to -0.108 $\mu \mathrm{mol} / \mathrm{L})$, for $\delta$-tocopherol $(\mathrm{P}=0.008 ; 95 \% \mathrm{Cl}$ for the difference, -0.013 to -0.082 
$\mu \mathrm{mol} / \mathrm{L})$, and for $\alpha$-tocopherol $(\mathrm{P}<0.001 ; 95 \% \mathrm{Cl}$ for the difference, -1.352 to -4.377 $\mu \mathrm{mo} / \mathrm{L})$. Consumption of the wood based stanol ester mixture decreased significantly concentrations of lycopene $\quad(-0.147 \mu \mathrm{mol} / L$ versus the control group: $\mathrm{P}=0.002 ; 95 \% \mathrm{Cl}$ for the difference, -0.056 to $-0.238 \mu \mathrm{mol} / \mathrm{L}$ ), as well as phytofluene $\left(-0.205 \mathrm{mV} \mathrm{min}^{*} / \mu \mathrm{l}\right.$; amplification 100 versus the control group: $\mathrm{P}<0.001 ; 95 \% \mathrm{Cl}$ for the difference, -0.108 to $-0.302 \mathrm{mV}^{*} \mathrm{~min} / \mu \mathrm{l}$; amplification 100), lutein/zeaxanthin ($0.056 \mu \mathrm{mol} / \mathrm{L}$ versus the control group: $\mathrm{P}<0.012 ; 95 \% \mathrm{Cl}$ for the difference, -0.016 to $-0.096 \mu \mathrm{mol} / \mathrm{L})$, and $\alpha$-tocopherol $(-3.195 \mu \mathrm{mol} / L$ versus the control group: $P<0.001$; $95 \% \mathrm{Cl}$ for the difference, -1.601 to $-4.789 \mu \mathrm{mol} / \mathrm{L})$. The decrease of phytofluene in the wood based group was different from the change in the vegetable based group as well $(\mathrm{P}=0.001 ; 95 \%$ for the difference, -0.056 to $-0.268 \mathrm{mV} \times \mathrm{min} / \mu \mathrm{l}$; amplification $100)$. The difference in changes in $\beta$-carotene concentrations nearly reached statistical significance compared to the control group $(P=0.027 ; 95 \%$ for the difference, -0.002 to $-0.110 \mu \mathrm{mol} / \mathrm{L})$.

\section{$\%$ change}

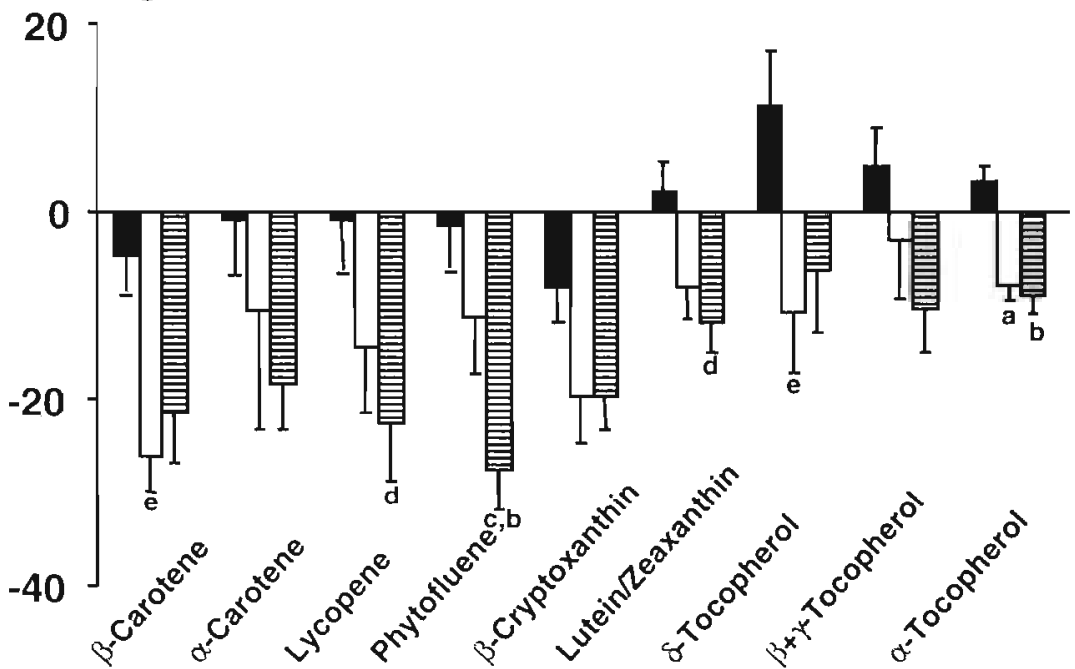

\section{Control $\square$ Vegetable oil based $\equiv$ Wood based}

Figure 2: Percent changes of absolute plasma antioxidant concentrations $(\mu \mathrm{mol} / \mathrm{L})$ during the study. Values are means \pm SE. For the run-in period (run-in), samples from weeks 3 and 4 were averaged, and for the test period, samples from weeks 11 and 12. Changes were calculated as the difference between values of the test period and run-in period. Percent changes were calculated versus the end of the run-in period.

a $P<0.001$, e $P<0.017$ control group versus vegetable oil based group

b $P<0.001, d P<0.017$ control group versus wood based group

c $P=0.001$ wood based group versus vegetable oil based group 
Table 3: Effects of vegetable oil and wood based plant stanol esters on absolute and LDLcholesterol standardized plasma lipid soluble antioxidant and retinol concentrations during the study

\begin{tabular}{ccc}
$\begin{array}{c}\text { Control } \\
\text { group }\end{array}$ & Vegetable oil based & Wood based \\
& group & group \\
\hline
\end{tabular}

Total carotenoids $(\mu \mathrm{mol} / \mathrm{L})$

$\begin{array}{lrl}\text { Run-in } & 1.656 & \pm 0.548 \\ \text { Test period } & 1.568 & \pm 0.506 \\ \text { Change } & -0.087 & \pm 0.305\end{array}$

$$
\begin{aligned}
1.623 & \pm 0.462 \\
1.331 & \pm 0.445 \\
-0.292 & \pm 0.3199
\end{aligned}
$$$$
1.666 \pm 0.651
$$$$
1.261 \pm 0.429
$$$$
-0.405 \pm 0.374 \dagger
$$

Hydrocarbon carotenoids ( $\mu \mathrm{mol} / \mathrm{L}$ )

$\begin{array}{lrl}\text { Run-in } & 0.961 & \pm 0.387 \\ \text { Test period } & 0.899 & \pm 0.344 \\ \text { Change } & -0.061 & \pm 0.216\end{array}$

$$
\begin{aligned}
0.916 & \pm 0.311 \\
0.717 & \pm 0.297 \\
-0.199 & \pm 0.2439
\end{aligned}
$$$$
0.919 \pm 0.438
$$$$
0.644 \pm 0.262
$$$$
-0.275 \pm 0.266 \dagger
$$

Oxygenated carotenoids $(\mu \mathrm{mol} / \mathrm{L})$

$\begin{array}{lrl}\text { Run-in } & 0.695 & \pm 0.216 \\ \text { Test period } & 0.669 & \pm 0.227 \\ \text { Change } & -0.026 & \pm 0.144\end{array}$

$$
\begin{aligned}
& 0.707 \pm 0.230 \\
& 0.614 \pm 0.257 \\
& -0.093 \pm 0.149
\end{aligned}
$$$$
0.747 \pm 0.311
$$$$
0.617 \pm 0.252
$$$$
-0.130 \pm 0.160 \Omega
$$

Total tucopherols ( $\mu \mathrm{mol} / \mathrm{L}$ )

$\begin{array}{lrl}\text { Run-in } & 26.152 & \pm 6.223 \\ \text { Test period } & 26.601 & \pm 5.247 \\ \text { Change } & 0.449 & \pm 2.591\end{array}$

$$
\begin{aligned}
26.688 & \pm 5.430 \\
24.471 & \pm 4.532 \\
-2.217 & \pm 2.630 \ddagger
\end{aligned}
$$$$
27.432 \pm 6.460
$$$$
24.756: 6.201
$$$$
-2.676 \pm 3.145 \dagger
$$

Retinol ( $\mu \mathrm{mol} / \mathrm{L}$ )

$\begin{array}{lll}\text { Run-in } & 1.896 & \pm 0.355 \\ \text { Test period } & 1.909 & \pm 0.373 \\ \text { Change } & 0.013 & \pm 0.225\end{array}$

\begin{tabular}{|c|c|c|c|c|c|c|}
\hline Run-in & 0.337 & \pm 0.135 & 0.319 & \pm 0.099 & 0.334 & \pm 0.181 \\
\hline Test period & 0.324 & \pm 0.133 & 0.294 & \pm 0.123 & 0.273 & \pm 0.139 \\
\hline Change & -0.013 & \pm 0.091 & -0.025 & \pm 0.091 & -0.061 & \pm 0.088 \\
\hline
\end{tabular}

$$
\begin{array}{r}
1.983 \pm 0.413 \\
1.969 \pm 0.480 \\
-0.014 \pm 0.208
\end{array}
$$$$
2.125 \pm 0.387 \S
$$$$
2.097 \pm 0.457
$$$$
-0.028 \pm 0.277
$$

Total carotenoids ( $\mu \mathrm{mol} / \mathrm{mmol}$ LDL-cholesterol)

$\begin{array}{lrl}\text { Run-in } & 0.581 & \pm 0.194 \\ \text { Test period } & 0.565 & \pm 0.203 \\ \text { Change } & -0.016 & \pm 0.130\end{array}$

$\begin{aligned} 0.570 & \pm 0.159 \\ 0.551 & \pm 0.187 \\ -0.019 & \pm 0.117\end{aligned}$

$0.607 \pm 0.274$

$0.540 \pm 0.242$

$-0.067 \pm 0.127$

Hydrocarbon carotenoids ( $\mu \mathrm{mol} / \mathrm{mmol}$ LDL-cholesterol)

Oxygenated carotenoids ( $\mu \mathrm{mol} / \mathrm{mmol}$ LDL-cholesterol)

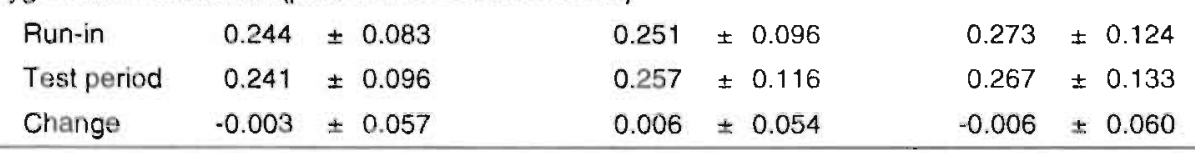


Table 3; continued

Total tocopherols (umol/mmol LDL-cholesterol)

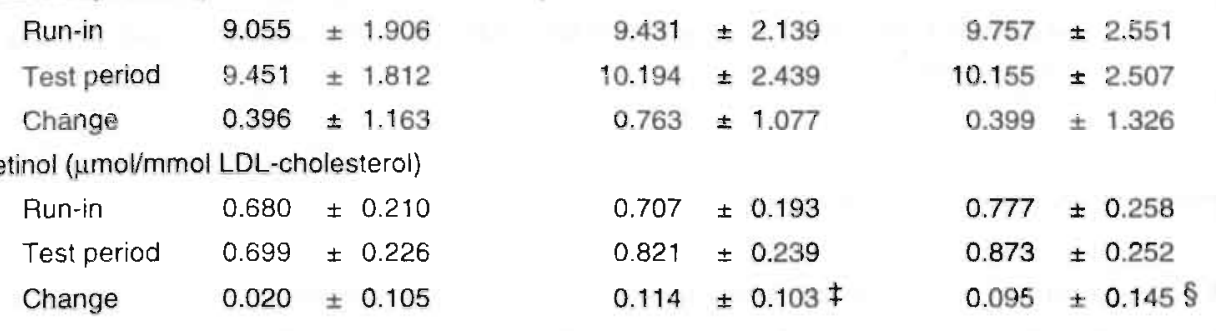

Values are means \pm S.D. For the run-in period, samples from weeks 3 and 4 were averaged, and for the test period, samples from weeks 11 and 12. Changes were calculated as the difference between values of the test period and run-in period.

Total carotenoids were calculated as the sum of $\alpha$ - and $\beta$-carotene, lycopene, lutein/zeaxanthin and $\beta$-cryptoxanthin. Hydrocarbon carotenoids were calculated as the sum of $\alpha$ - and $\beta$-carotene and lycopene. Oxygenated carotenoids were calculated as the sum of lutein/zeaxanthin and $\beta$ cryptoxanthin. Total tocopherols were calculated as the sum of $\alpha, \beta+\gamma$ and $\delta$-tocopherol.

$\ddagger P<0.001$ control group versus vegetable oil based group

$\dagger P<0.001$ control group versus wood based group

$\S P<0.017$ control group versus wood based group

I $\mathrm{P}=0.017$ control group versus vegetable oil based group

After plant stanol ester consumption, changes in LDL-cholesterol standardized antioxidant concentrations ( $\mu \mathrm{mol} / \mathrm{mmol} L D L$ cholesterol) were - except for the $16.6 \pm 26.9 \%$ reduction in phytofluene concentrations (a change of $-0.059 \pm 0.106$ $\mathrm{mV}^{*} \mathrm{~min} / \mathrm{nmol} \mathrm{LDL}$ cholesterol; amplification 100 versus the change of $-0.000 \pm 0.073$ $\mathrm{mV}{ }^{*} \mathrm{~min} / \mathrm{nmol} \mathrm{LDL}$ cholesterol; amplification 100 in the control group; $\mathrm{P}=0.003 ; 95 \%$ for the difference, -0.018 to $-0.100 \mathrm{mV}$ min/nmol LDL cholesterol; amplification 100) not longer significant. Changes, however, were in general negative for the hydrocarbon carotenoids (i.e. $\beta$-carotene, $\alpha$-carotene and lycopene), about zero for the oxygenated carotenoids (lutein/zeaxanthin, $\beta$-cryptoxanthin), and positive for the tocopherols (figure 3 ). When antioxidant concentrations were standardized for total cholesterol or for total cholesterol plus triacylglycerol conclusions remained essentially similar. 
Table 4: Results of multiple linear regression analyses to examine the association between serum cholesterol-standardized campesterol concentrations and hydrocarbon carotenoid, oxygenated carotenoid, or tocopherol concentrations after adjustment for changes in total cholesterol concentrations

\begin{tabular}{|c|c|c|c|c|c|}
\hline \multicolumn{3}{|c|}{ Variables } & \multicolumn{3}{|c|}{ Regression coefficient } \\
\hline Model & Dependent & Independent & $b$ & $\mathrm{SE}(\mathrm{b})$ & P-value \\
\hline \multirow[t]{3}{*}{ A } & $\Delta$ Hydrocarbon & $\Delta$ Total cholesterol & 0.162 & 0.090 & 0.078 \\
\hline & carotenoids & $\Delta \mathrm{TC}$ standardized campesterol & 0.099 & 0.043 & 0.023 \\
\hline & & Intercept & -0.064 & & \\
\hline \multirow[t]{3}{*}{$\mathrm{B}$} & $\Delta$ Oxygenated & $\Delta$ Total cholesterol & 0.182 & 0.054 & 0.001 \\
\hline & carotenoids & $\Delta \mathrm{TC}$ standardized campesterol & 0.011 & 0.025 & 0.673 \\
\hline & & Intercept & -0.022 & & \\
\hline \multirow[t]{3}{*}{$\mathrm{C}$} & $\Delta$ Tocopherols & $\Delta$ Total cholesterol & 5.076 & 0.884 & $<0.001$ \\
\hline & & $\Delta \mathrm{TC}$ standardized campesterol & 0.216 & 0.416 & 0.605 \\
\hline & & Intercept & -0.046 & & \\
\hline
\end{tabular}

The results of the lipid-standardized concentrations of tocopherols and oxygenated carotenoids, which did not change, suggest that the decreases in absolute oxygenated carotenoid and tocopherol concentrations are mainly related to decreases in serum cholesterol concentrations, as the lipoproteins are the major carrier for lipid-soluble antioxidants. The changes in the lipid-standardized concentrations of the hydrocarbon carotenoids, however, were still negative. This may suggest that reductions in absolute hydrocarbon carotenoid concentrations were associated with the decrease in cholesterol absorption caused by the plant stanols. To examine this issue in more detail, we related changes in serum cholesterol-standardized campesterol concentrations (as marker for cholesterol absorption (11)) with changes in plasma antioxidant concentrations. Since antioxidants and campesterol are both transported by lipoproteins, changes in total cholesterol were included into the regression model as well. Multiple regressions models were calculated for the less polar hydrocarbon carotenoids (the sum of $\beta$ carotene, $\alpha$-carotene and lycopene concentrations), the more polar oxygenated carotenoids (lutein/zeaxanthin and $\beta$-cryptoxanthin), and for the tocopherol isomers ( $\alpha$-tocopherol, $\delta$-tocopherol and $\beta+\gamma$-tocopherol) (Table 4). The regression coefficient for total cholesterol predicted that decreasing the total cholesterol concentration with $1 \mathrm{mmol} / \mathrm{L}$ will decrease hydrocarbon carotenoid concentrations with $0.162 \mu \mathrm{mol} / \mathrm{L}$, while the regression coefficient for cholesterol-standardized campesterol predicted 
that decreasing the cholesterol-standardized campesterol concentration with 100 (102x $\mu \mathrm{mol} / \mathrm{mmol}$ cholesterol) will decrease $\beta$-carotene concentrations with 0.099 $\mu \mathrm{mol} / \mathrm{L}$ (Table 4 , model A). Thus, by using the observed changes of $0.43 \mathrm{mmol} / \mathrm{L}$ for total cholesterol and of 103.1 (102 $\times \mu \mathrm{mol} / \mathrm{mmol}$ cholesterol) for cholesterolstandardized campesterol concentrations, it can be predicted that the effects of these two parameters on total hydrocarbon carotenoid concentrations were -0.069 $\mu \mathrm{mol} / \mathrm{L}(95 \% \mathrm{Cl},-0.147$ to $0.008 \mu \mathrm{mol} / \mathrm{L})$ and $-0.102 \mu \mathrm{mol} / \mathrm{L}(95 \% \mathrm{Cl},-0.189$ to $0.014 \mu \mathrm{mol} / \mathrm{L})$, respectively. This indicates that the changes in hydrocarbon carotenoid concentrations were significantly related to the reduced cholesterol absorption. For the oxygenated carotenoids and the tocopherols (Table 4, model B and $C$ ) changes were only significantly related to changes in total cholesterol. The ratio of the carrier associated contribution and the cholesterol absorption associated contribution to the hydrocarbon carotenoid reduction was 0.6 . Compared to the 7.1 ratio for the oxygenated carotenoids and the 9.9 ratio for the tocopherols, this suggests that in particular the lipophylic hydrocarbon carotenoid reductions were associated with the reduced cholesterol absorption. Although the tendency was similar, the relationship between the changes in the individual carotenoids and tocopherols with cholesterol absorption did not reach statistical significance.

Retinol and vitamin $\mathrm{E}$ intakes from the margarines and shortenings were comparable between the three groups, while $\beta$-carotene intake was slightly lower in the vegetable oil based group $(127 \pm 21 \mu \mathrm{g})$ compared to the control group $(150 \pm 40$ $\mu \mathrm{g})(\mathrm{P}=0.008)$. This was due to a slightly lower $\beta$-carotene content of the vegetable oil based margarine and shortening (20). Total dietary vitamin $E$ intake during the experimental period in the control group $(13.5 \pm 3.0 \mathrm{mg})$ was also comparable to the intakes in the vegetable oil based group $(13.8 \pm 3.2 \mathrm{mg})$ and the wood based group $(14.5 \pm 4.0 \mathrm{mg})$.

\section{Discussion}

As in other studies (16), we have found that plant stanol esters lowered intestinal cholesterol absorption but increased cholesterol synthesis. Reducing cholesterol synthesis with statins has been demonstrated to lower plasma ubiquinol10 concentrations $(8,9,25)$. In contrast, squalestatin. a specific squalene synthase inhibitor, significantly decreased the incorporation of $[3 \mathrm{H}]$ mevalonate into cholesterol, whereas the incorporation into ubiquinone was increased three to four fold (26). These findings suggest that a change in the farnesyl-PP pool size, the branching intermediate for cholesterol and ubiquinone synthesis, may be a determinant of ubiquinone-10 synthesis. We therefore hypothesized that an increase in cholesterol production, as induced by plant stanol ester consumption, may increase ubiquinone- 
10 synthesis and subsequently plasma ubiquinol-10 concentrations. Our study, however, demonstrated for the first time that dietary enrichment with plant stanol esters lowered absolute concentrations of plasma ubiquinol-10. In fact, this is to our knowledge for the first time that a dietary intervention has been shown to change plasma ubiquinol-10 concentrations. Changes in LDL-cholesterol standardized ubiquinol-10 concentrations, however, were similar in all groups. It might therefore be hypothesized that LDL, which is the major carrier of ubiquinol, was already saturated with ubiquinol, and that the reduction in the absolute amount of plasma ubiquinol-10 was simply a carrier effect. However, daily ubiquinone supplementation, which is efficiently reduced to ubiquinol-10 during uptake, increased plasma ubiquinol-10 concentrations three to four fold $(27,28)$. After statin treatment, LDLcholesterol standardized ubiquinol-10 concentrations were reduced (25), although not always significantly (29). This is surprising as, according the flux diversion hypothesis (30) - combined with the higher affinity of the ubiquinone synthesizing enzyme for farnesyl-PP as compared with the affinity of squalene synthase (31) partial HMGCoA reductase inhibition by statin treatment is expected to increase the ubiquinol-10 to cholesterol ratio, or at least not to change this ratio. In a study with heterozygous $\mathrm{FH}$ patients, treatment with cholestyramine, a bile acid sequestrant that increases endogenous cholesterol synthesis, also decreased plasma ubiquinone concentrations insignificantly by $13 \%$, while the ubiquinone to LDL cholesterol ratio was significantly increased (29). These findings suggest that changes in ubiquinol-10 synthesis can not simply be predicted from changes in cholesterol synthesis. For our study, one explanation for the unchanged LDL-cholesterol standardized concentrations of ubiquinol-10 may be that plant stanol ester consumption increased cholesterol and ubiquinol-10 synthesis to the same extent. In this way, the ubiquinol10 / cholesterol ratio of VLDL particles excreted into the circulation by the liver may not have changed during the study. Since VLDL is subsequently metabolized via IDL into LDL, and IDL and LDL cholesterol clearance may increase due to a higher LDLreceptor expression (33), ubiquinol-10 clearance may also increase, resulting in an unchanged ubiquinol-10 / LDL cholesterol ratio. Of course, other explanations are also possible such as an increased reuse of ubiquinol-10 in the liver or a decreased incorporation of newly synthesized cholesterol into VLD. Studies with stable isotopes are therefore needed to examine if ubiquinol-10 synthesis is truly affected by plant stanol ester consumption. 


\section{$\%$ change}

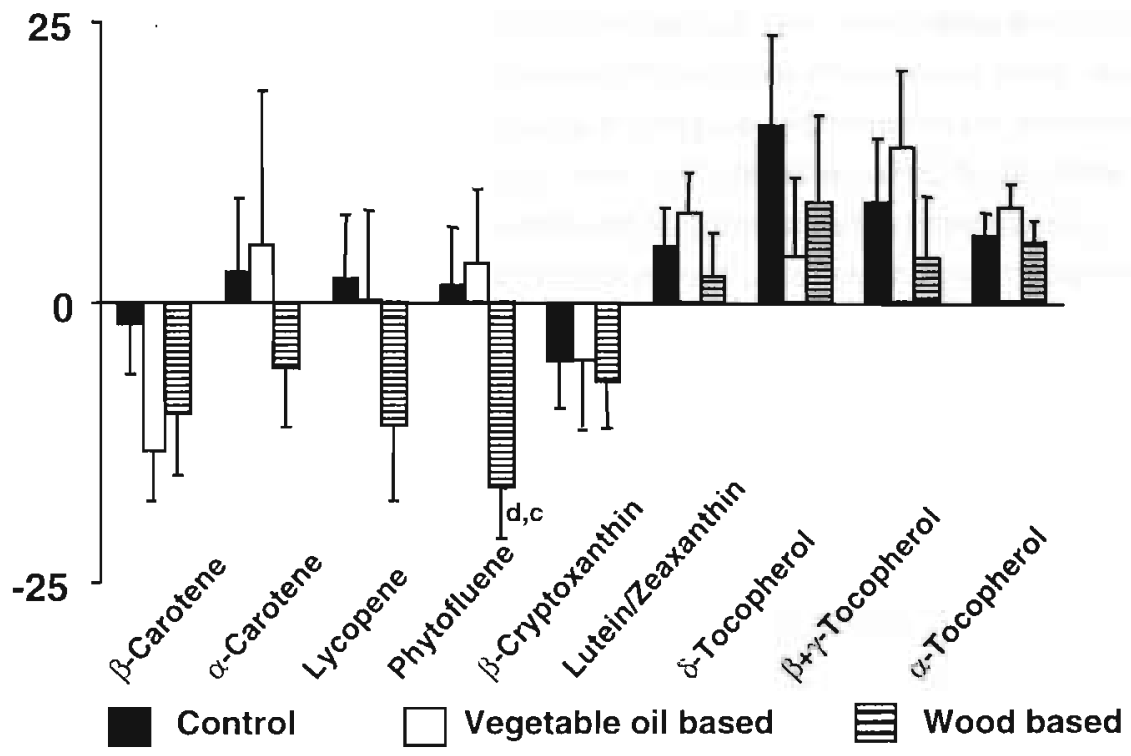

Figure 3: Percent changes of LDL-cholesterol standardized plasma antioxidant concentratıons ( $\mu \mathrm{mol} / \mathrm{mmol} \mathrm{LDL}$ cholesterol) during the study. Values are means \pm SE.

For the run-in period (run-in), samples from weeks 3 and 4 wert averaged, and for the test period, samples from weeks 11 and 12. Changes were calculated as the difference between values of the test period and run-in period. Percent changes were calculated versus the end of the run-in period.

$c P=0.001$ wood based group versus vegetable oil based group

$d P<0.017$ control group versus wood based group

Other studies have found that plant stanol esters lowered both plasma absolute and lipid-standardized $\alpha+\beta$-carotene and lycopene concentrations (14), and absolute $\alpha$-tocopherol concentrations $(33,34)$. Comparable results have been found for other compounds that interfere with cholesterol, bile or fat absorption, such as plant sterols (14), cholestyramine (35), neomycin (36) an olestra (37). We have now demonstrated that plant stanol esters, with daily intakes equivalent to $3.8-4.0 \mathrm{~g}$ plant stanols, lower plasma absolute levels of other carotenoids and tocopherol isomers as well. In addition, it was demonstrated that effects were not similar for the various carotenoids and tocopherols. The hydrocarbon carotenoids, i.e. $\alpha$ - and $\beta$ carotene, and lycopene showed the most pronounced decreases, followed by the oxygenated carotenoids and the tocopherols, while retinol concentrations were hardly changed. This order of changes is comparable to that of the sequence of these compounds in decreasing lipophylicity. Thus, the most lipophylic antioxidants - 
the hydrocarbon carotenoids - showed the largest reductions. Mucosal uptake of lipophylic compounds requires incorporation into mixed micelles. The amount of carotenoid taken up in the mixed micelle depends on the polarity of the compound (38). Therefore, it is tempting to suggest that plant stanol esters affect not only the micellar solubility of cholesterol (39), but also of the most lipophylic antioxidants. This concept is supported by the finding that the reductions in plasma concentrations of the most lipophylic antioxidants, the hydrocarbon carotenoids, were significantly related to the decrease in cholesterol absorption. This association was not found for the oxygenated carotenoids and the tocopherols, which are more polar. It should be noted, that absolute plasma retinol concentrations did not change after plant stanol consumption. For humans, $\beta$-carotene is the most important dietary provitamin $A$. The reduction in $\beta$-carotene might therefore also be explained by its increased conversion into retinol in the enterocyte. However, only direct measurements of fatsoluble antioxidant absorption can unravel the exact mechanism underlying the antioxidant reductions. It should be noted, however, that for all antioxidants studied, the major part of the reductions is simply explained by the decrease in LDL, the major carrier of these antioxidants. In contrast to our speculations, sheanut oil derived plant sterols, which are 4,4'-dimethylsterols, do significantly lower absolute and lipid standardized $\alpha+\beta$-carotene and lycopene concentrations (14), but do not change serum cholesterol concentrations. Thus, changes in cholesterol absorption and carotenoid concentrations are not necessarily associated with each other. It therefore seems that the presence of $4,4^{\prime}$-dimethylsterols in the intestinal lumen affects hydrocarbon carotenoid metabolism independent of effects on cholesterol absorption.

In summary, consumption of both vegetable and wood based plant stanol ester mixtures lower absolute plasma ubiquinol-10 concentrations, but does not change the ratio of ubiquinol-10 to LDL cholesterol. Absolute plasma carotenoid and vitamin E concentrations were also lowered, though concentrations of $\beta$-carotene $(40,41)$ and other antioxidants studied (23,) remained within the normal range. These effects were most pronounced for the most lipophylic antioxidants and were for the hydrocarbon carotenoids only - although not significantly - , also evident after standardization for LDL-cholesterol. These reductions were mainly explained by a reduction in carrier capacity, although the decrease in the hydrocarbon carotenoids was also related to the reduced cholesterol absorption. An important question is whether these changes in antioxidant concentrations affect health. At this moment, it is only possible to speculate about the clinical relevance of the observed changes in antioxidant concentrations. Compared with large intervention trials with $\beta$-carotene 
or vitamin E supplements (42), the changes in antioxidant concentrations observed in our study were very small. Further, it is not very likely that the changes in antioxidants counterbalance the positive effects of plant stanols on LDL cholesterol concentrations, and animal studies have indeed demonstrated that plant stanol ester consumption reduce cardiovascular risk (43). Modest effects on other health parameters can, however, not be excluded. Therefore, the in vivo relevance of these present findings and whether the total body antioxidant status is affected needs further study.

\section{References}

1. Ernster L, Dallner G. Biochemical, physiological and medical aspects of ubiquinone function. Biochim Biophys Acta 1995;1271:195-204

2. Edlund PO. Determination of coenzyme Q10, -tocopherol and cholesterol in biological samples by coupled-column liquid chromatography with coulometric and ultraviolet detection. J Chromatogr 1988;425:87-97

3. Johansen $\mathrm{K}$. Theorell $\mathrm{H}$, Karlsson J. Coenzyme Q10, alpha-tocopherol and free cholesterol in HDL and LDL fractions. Ann Med 1991:23:649-656

4. Kontush $A$, Hübner $C$, Finckh $B$, Antioxidative activity of ubiquinol-10 at physiologic concentrations in human low density lipoprotein. Biochim Biophys Acta 1995:1258:177-187

5. Ernster $L$, Forsmark-Andrée $P$. Ubiquinal: an endogenous antioxidant in aerobic organisms. Clin Investig 1993:71:S60-S65

6. Stocker R, Bowry VW, Frei B. Ubiquinol10 protects human low density lipoprotein more efficiently against lipid peroxidation than does $\alpha$-tocopherol. Proc Natl Acad Sci USA 1991;88:16461650

7. Kamei M, Fujita T, Kanbe. The distribution and content of ubiquinone in foods. Internat $J$ Vit Nutr Res

\section{6:56:57-63}

8. Willis RA, Folkers K, Tucker JL. Lovastatin decreases coenzyme $Q$ levels in rats. Proc Natl Acad Sci USA 1990:87:8928-8930

9. Folkers $K$, Langsjoen $P$, Willis $R$ Lovastatin decreases Coenzyme $Q$ levels in humans. Proc Natl Acad Sci USA 1990;87:8931-8934

10. Mensink RP, Plat J. Efficacy of dietary phytostanols. Postgr Med :A special report, 1998; November:27-31

11. Miettinen TA, Tilvis RS, Kesãniemi YA. Serum plant sterols and cholesterol precursors reflect cholesterol absorption and synthesis in volunteers of a randomly selected male population. Am J Epidemiol 1990;131:20-31

12. Björkhem I, Miettinen TA, Reihnér $E$, Ewerth S, Angelin B, Einaisson K. Correlation between serum levels of some cholesterol precursors and activity of $\mathrm{HMG-COA}$ reductase in human liver. J Lipid Res 1987;28:1137-1143

13. Gylling $H$, Puska $P$, Vartiainen $E$. Retinol, vitamin D, carctenes and atocopherol in serum of a moderately hypercholesterolemic population consuming sitostanol ester margarine. Atherosclerosis 1999;145:279-285

14. Weststrate JA, Mejer GW. Plant sterolenriched margarines and reduction of 
plasma total- and LDL-cholesterol concentrations in normocholesterolaemic and mildly hypercholesterolaemic subjects. Eur J Clin Nutr 1998;52:334-343

15. Hendriks HFJ, Weststrate JA, Vliet van $T$. Spreads enriched with three different levels of vegetable oil sterols and the degree of cholesterol lowering in normocholesterolaemic and mildly hypercholesterolaemic subjects. Eur J Clin Nutr 1999;53:319-327

16. Gylling $H$, Miettinen TA. Cholesterol reduction by different plant stanol mixtures and with variable fat intake.

Metabolism 1999;48:575-580

17. Bertram JS, Bortkiewicz H. Dietary carotenoids inhibit neoplastic transformation and modulate gene expression in mouse and human cells. Am J Clin Nutr 1995;62 (Suppl):1327s$1336 \mathrm{~s}$

18. Christen S, Woodall AA, Shigenaga MK. Gamma-tocopherol traps mutagenic electrophiles such as $N O(X)$ and complements alpha-tocopherol: physiological complications. Proc Natl Acad Sci USA 1997;94:3217-22

19. Plat J, Mensink RP. Vegetable oil based versus wood based stanol ester mixtures: effects on serum lipids and hemostatic factors in nonhypercholesterolemic subjects. Atherosclerosis 2000;148:101-112

20. Plat J, Mensink RP. Dietary plant stanol ester mixtures: effects on safety parameters and erythrocyte membrane fatty acid composition in nonhypercholesterolemic subjects. Eur Heart J 1999; 1(Supp!):s58-s63

21. Craft NE, Brown ED, Smith JC Jr. Effects of storage and handling conditions on concentrations of individual carotenoids, retinol, and tocopheral in plasma. Clin Chem 1988;24: $44-48$

22. Hess $D$, Keller HE, Oberlin $B$. Simultaneous determination of retinol, tocopherols, carotenes and lycopene in plasma by means of high-performance liquid chromatography on reversed phase. Internat J Vit Res 1991;61:232238

23. Oostenbrug GS, Mensink RP, Hardeman MR. Exercise performance, red blood cell deformability, and lipid peroxidation: effects of fish oil and vitamin E. J Appl Physiol 1997;83:746752

24. Statview (for the Macintosh) manual. 1992; Berkeley, CA: Abacus Concepts, Statview Abacus Concepts Inc.

25. Palomäki A, Malminiemi K, Solakivi T. Ubiquinone supplementation during lovastatin treatment: effect on LDL oxidation ex vivo. J Lipid Res 1988;39:1430-1437

26. Thelin A, Peterson E, Hutson JL. Effect of squalestatin 1 on the biosynthesis of the mevalonate pathway lipids. Biochim Biophys Acta 1994;1215:245-249

27. Thomas SR, Neuzil J, Stocker R. Cosupplementation with coenzyme $Q$ prevents the prooxidant effect of $\alpha$ tocopherol and increases the resistance of LDL to transition metal-dependant oxidation initiation. Arterioscler Tromb Vasc Biol 1996;16:687-696

28. Mohr D, Bowry VW, Stocker R. Dietary supplementation with coenzyme Q10 results in increased levels of ubiquinol10 within circulating lipopriteins and increased resistance of human lowdensity lipoprotein to the initiation of lipid peroxidation. Biochim Biophys Acta 1992;1126:247-254 
29. Elmberger PG, Kalén A, Lund E. Effect of pravastatin and cholesteryramine on products of the mevalonate pathway in familial hypercholesterolemia. J Lipid Res 1991;32:935-940

30. Brown MS, Goldstein JL. Multivalent feedback regulation of HMG-CoA reductase, a control mechanism coordinating isoprenoid synthesis and cell growth. J Lipid Res 1980;21:505517.

31. Appelkvist EL, Åberg F, Guan Z. Regulation of coenzyme $Q$ biosynthesis. Molec Aspects Med 1994;15:s37-s46

32. Gylling HK, Puska P, Vartiainen E. Serum retinol, $\alpha$-tocopherol, carotenes and lipid peroxide production duriong serum cholesterol lowering by sitostanol ester margarine in a mildly hypercholesterolemic population. Circulation 1996;94 (Suppl. 1):578

33. Plat J, Mensink RP. Consumption of plant stanol esters increase LDL receptor expression in mononuclear cells from non-hypercholesterolemic subjects . Atherosclerosis 2000;151:86

34. Hallikainen MA, Uusitupa MIJ. Effects of 2 low-fat stanol ester-containing margarines on serum cholesterol concentrations as apart of a low-fat diet in hypercholesterolemic subjects. Am J Clin Nutr 1999;69:403-10

35. Elinder LS, Hadell K, Johansson J. Probucol treatment decreases serum concentrations of diet-derived antioxidants. Arterioscler Thromb Vasc Biol 1995; 15; 1057-1063

36. Ayres EJ, Hoeg JM, Bailey KR. The effect of neomycin on plasma alpha tocopherol levels in type II hyperlipoproteinemia. Drug Nutr Interact 1986;4:325-331

37. Koonsvitsky BP, Berry DA, Jones MB. Olestra affects serum

concentrations of $\alpha$-tocopherol and carotenoids but not vitamin $\mathrm{D}$ or vitamin $\mathrm{K}$ status in free living subjects. J Nutr 1997; 127:1636s-1645s

38. Borel P, Grolier P, Armand M. AzaisBraesco V. Carotenoids in biological emulsions: solubility, surface-to-core distribution, and release from lipid droplets. J Lipid Res 1996;37:250-61

39. Ikeda I, Tanabe $Y$, Sugano M. Effects of sitosterol and sitostanol on micellar solubility of cholesterol. I Nutr Sci Vitaminol 1989:35:361-369

40. Burri BJ. Beta-carotene and human health: A review of current research. Nutr Res 1997;17:547-580

41. Berg van den $H$. Carotenoid interactions. Nutr Rev 1999;57:1-10

42. The effect of vitamin $E$ and beta carotene on the incidence of lung cancer and other cancers in males smokers. The Alpha -Tocopherol, Beta Carotene Cancer Prevention Study Group. N Eng J Med 1994;330:10291035

43. Volger OL, van der Boom J, de Wit ECM, van Duyvenvoorde $W$, Hornstra G, Plat J, Havekes LM, Princen HMG, Mensink RP. Dietary vegetable-, woodor vegetable/wood-derived stanol esters reduce atherosclerotic lesion size and severity in $\mathrm{APO}^{*} 3$-Leiden transgenic mice. Atherosclerosis 2000;151: 77-78 


\section{Chapter 5}

Effects on serum lipids, lipoproteins and fat-soluble antioxidant concentrations of consumption frequency of margarines and shortenings enriched with plant stanol esters.

Plat J, Onselen van ENM, Heugten van MMA, Mensink RP

Department of Human Biology, Maastricht University, The Netherlands

(Based on: Eur J Clin Nutr 2000;54:671-677) 


\section{Abstract}

Objective: To examine in humans the effects on serum lipids, lipoproteins and fatsoluble antioxidants of a daily consumption of $2.5 \mathrm{~g}$ plant stanols, consumed either once per day at lunch or divided over the three meals.

Design: A randomized, double-blind, placebo controlled, cross-over design.

Subjects: Thirty-nine healthy normocholesterolemic or mildly hypercholesterolemic subjects participated.

Interventions: Each subject consumed in random order no plant stanols, $2.5 \mathrm{~g}$ plant stanols at lunch, and $2.5 \mathrm{~g}$ plant stanols divided over the three meals $(0.42 \mathrm{~g}$ at breakfast, $0.84 \mathrm{~g}$ at lunch, and $1.25 \mathrm{~g}$ at dinner, which is proportional to dietary cholesterol intake). Each period lasted four weeks. Plant stanols were esterified with fatty acids from low erucic rapeseed oil (LEAR) and incorporated into margarines or shortenings.

Results: Consumption of $2.5 \mathrm{~g}$ plant stanols at lunch results in a similar LDL-cholesterol lowering efficacy compared to consumption of $2.5 \mathrm{~g}$ plant stanols divided over the three meals $[-0.29 \mathrm{mmol} / \mathrm{L}$ compared to the control period $(\mathrm{P}<0.001 ; 95 \% \mathrm{Cl}:-0.19$ to -0.39 $\mathrm{mmol} / \mathrm{L}$ for the once per day diet and $-0.31 \mathrm{mmol} / \mathrm{L}(\mathrm{P}<0.001 ; 95 \% \mathrm{Cl}:-0.20$ to -0.41 $\mathrm{mmol} / \mathrm{L}$ ) for the three times per day period. HDL cholesterol and triacylglycerol concentrations did not change. After standardization for LDL-cholesterol, the sum of the most lipophylic hydrocarbon carotenoids (i.e. $\alpha$-carotene, $\beta$-carotene and lycopene) in particular was slightly, though not significantly, lowered by $-0.017 \pm 0.018 \mu \mathrm{mol} / \mathrm{mmol}$ LDL cholesterol $(P=0.307)$ after the once per day period and by $-0.032 \pm 0.016$ $\mu \mathrm{mol} / \mathrm{mmol} L D L$ cholesterol $(P=0.049)$ after the three times per day period.

Conclusions: Our findings suggest that for lowering LDL cholesterol concentrations it is not necessary to consume products rich in plant stanol ester at each meal or simultaneously with dietary cholesterol. 


\section{Introduction}

Plant stanols are useful hypocholesterolemic agents since a daily intake of $2-3 \mathrm{~g}$ lowers LDL cholesterol concentrations by $10-15 \%$ as found in various populations $(1,2)$. The proposed mechanism is that plant stanols reduce the micellar solubility of cholesterol and consequently lower intestinal absorption of both exogenous and endogenous cholesterol (3). This suggests that plant stanol esters should be consumed at each meal to obtain a maximal cholesterol lowering effect. However, consuming plant stanol esters at lunch and dinner only (4) showed a decrease in LDL cholesterol comparable to that when consumed three times daily $(5,6)$. This suggests that plant stanols are active in the intestinal tract for at least a few hours. It has, however, never systematically been evaluated, if the efficacy of plant stanols to lower serum LDL cholesterol depends on consumption frequency.

The main purpose of the present study therefore is to examine in a normocholesterolemic and mildly hypercholesterolemic population the effects on serum lipids and lipoproteins of a margarine and shortening enriched with plant stanol esters, consumed three times per day, versus an equal dose of plant stanol esters, consumed once per day. Also effects on plasma fat soluble antioxidant concentrations were evaluated, as these may be affected by consumption of plant sterol and stanol esters $(4,7)$.

\section{Methods}

\section{Subjects}

Forty-three subjects from Maastricht and surrounding areas applied for the study. Twenty-six of these volunteers had participated in a previous study on the effects of plant stanol esters on serum lipids and lipoproteins (6), while the others were recruited via posters in public buildings. Subjects were invited for a screening visit to see if they met our eligibility criteria: age 18-65 years, fasting serum total cholesterol concentration $<6.5 \mathrm{mmol} / \mathrm{L}(251 \mathrm{mg} / \mathrm{dL}$ ), fasting serum triacylglycerol concentration $<3.0 \mathrm{mmol} / \mathrm{L}$ (266 $\mathrm{mg} / \mathrm{dL}$ ), body mass index $<30 \mathrm{~kg} / \mathrm{m}^{2}$, diastolic blood pressure $<95 \mathrm{~mm} \mathrm{Hg}$, systolic blood pressure $<160 \mathrm{~mm} \mathrm{Hg}$, no presence of proteinuria or glucosuria, no use of medication or a diet known to affect serum lipids, and no history of coronary heart disease. Volunteers had not donated blood at least four weeks before or during this trial, and did not participate in another biomedical study. All subjects gave their written informed consent before the start of the study. A population of normocholesterolemic and mildly hypercholesterolemic subjects was used, since the serum cholesterol lowering efficacy of plant stanol esters -expressed as percentage-does not depend on 
initial serum LDL cholesterol concentrations $(1,2)$. Hypercholesterolemic subjects were not included, as many of these patients have (a history of) cardiovascular disease, or use medication or a diet known to affect serum lipids, which were all exclusion criteria.

One subject was excluded for a serum total cholesterol concentration $>6.5$ $\mathrm{mmol} / \mathrm{L}$ and two subjects decided not to participate. Consequently, the study started with 40 volunteers. One subject dropped out during the first week, because she could not combine the study protocol with her lifestyle. The remaining 39 volunteers, 28 women and 11 men, completed the study successfully. These participants were $31 \pm 14$ years of age (mean $\pm \mathrm{SD}$ ) and had a body mass index of $22.7 \pm 2.6 \mathrm{~kg} / \mathrm{m}^{2}$. Before the study started, mean serum total cholesterol and triacylglycerol concentrations were $4.74 \pm 0.85 \mathrm{mmol} / \mathrm{L}$ (range $2.83-6.28 \mathrm{mmol} / \mathrm{L}$ ) and $0.99 \pm 0.39 \mathrm{mmol} / \mathrm{L}$ (range $0.39-1.84$ $\mathrm{mmol} / \mathrm{L}$ ) in women and $4.94 \pm 0.89 \mathrm{mmol} / \mathrm{L}$ (range $3.37-6.15 \mathrm{mmol} / \mathrm{L}$ ) and $0.97 \pm 0.53$ $\mathrm{mmol} / \mathrm{L}$ (range $0.44-2.02 \mathrm{mmol} /$ ) in men. Seventeen women had cholesterol concentrations below $5.0 \mathrm{mmol} / \mathrm{L}$ (normocholesterolemic) and 11 women had cholesterol concentrations between 5.0 and $6.5 \mathrm{mmol} / \mathrm{L}$ (mildly hypercholesterolemic). For men, these figures were 7 and 4 respectively. One man and three women smoked cigarettes, nineteen women used oral contraceptives and one woman was postmenopausal.

\section{Design and diets}

The study, which was approved by the Medical Ethics Committee of Maastricht University, had a double blind, placebo controlled crossover design (figure 1). Each subject received three different diets for 4 weeks in one of the six possible treatment orders. There was no washout period between the three different dietary periods. Before the start of the study, the subjects were randomly allocated to one of the six groups. The participants were instructed to maintain their customary lifestyles and home diets throughout the study. During the study, they recorded in diaries any symptoms, visits to physicians, medication used, menstrual phase, alcohol use and any deviation from the protocol. Body weight was recorded weekly.

During the study, the subjects were required to replace at breakfast and at lunch their habitual margarines for an experimental margarine of which, at breakfast 10 gram and at lunch $20 \mathrm{gram}$, had to be consumed. Within one hour after dinner, each participant also had to eat a cake or cookie, which contained 10 gram of an experimental shortening. These cakes and cookies were prepared every week by a local bakery especially for this study. To control fat and fatty acid intake as much as 
possible, each participant also received during each period a shortening without plant stanol esters that had to be used for baking and cooking.

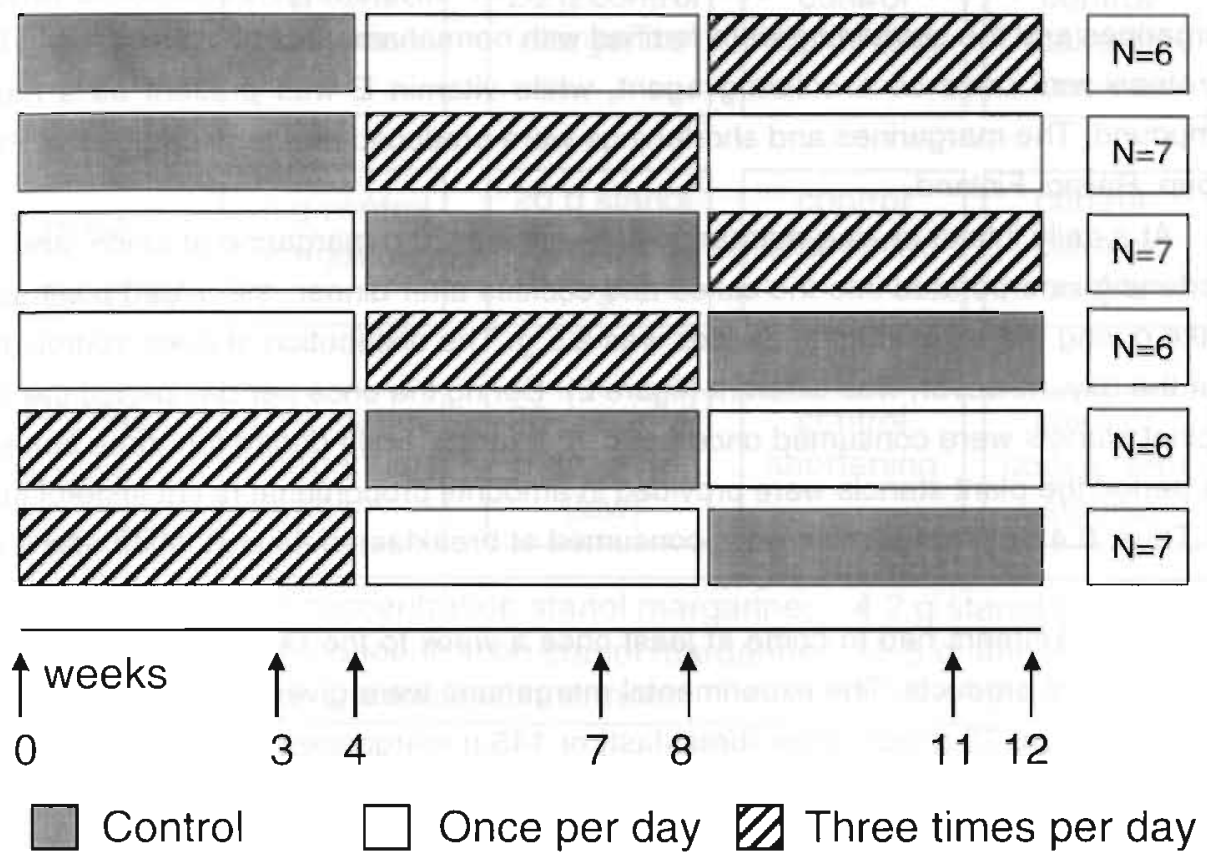

Figure 1: Experimental design of the study.

One experimental margarine contained $4.2 \mathrm{~g} / 100 \mathrm{~g}$ plant stanols as its fatty acid (low plant stanol ester margarine), and another margarine $12.5 \mathrm{~g} / 100 \mathrm{~g}$ (high plant stanol ester margarine). The plant stanol concentrations in the experimental shortening was $12.5 \mathrm{~g} / 100 \mathrm{~g}$. Products provided during the control period did not contain any plant stanol esters.

The mixture of vegetable oil and pinewood derived plant stanols contained approximately $76 \%$ sitostanol and $24 \%$ campestanol. Sitostanol was prepared from $\beta$ sitosterol and stigmasterol, and campestanol from campesterol, both by hydrogenation. Free sitostanol and campestanol were transesterified with rapeseed oil fatty acids, forming fat-soluble sitostanol and campestanol esters. The plant stanol esters were then mixed with the experimental margarines and shortening. The plant stanol esters were added to the experimental margarines at the expense of water and to the experimental 
shortening at the expense of absorbable fats. All the margarines and shortenings were prepared from low erucic acid rapeseed oil (LEAR) and contained 68\% (margarines), $99 \%$ (control shortening) or $86 \%$ (experimental shortening) absorbable fats. All margarines and the shortening were fortified with normal amounts of vitamin $A$ and $D$. $\beta$ Carotene was used as a coloring agent, while vitamin $E$ was present as a natural compound. The margarines and shortenings were produced and provided by the Raisio Group, Raisio, Finland.

At a daily intake of $10 \mathrm{~g}$ margarine at breakfast, $20 \mathrm{~g}$ margarine at lunch, and $10 \mathrm{~g}$ shortening incorporated into the cakes and cookies after dinner, the aimed plant stanol intake during the experimental periods was $2.5 \mathrm{~g}$. The distribution of plant stanol intake over the day, however, was different (figure 2). During the once per day period the $2.5 \mathrm{~g}$ of plant stanols were consumed once per day at lunch, while during the three times per day period the plant stanols were provided in amounts proportional to cholesterol intake (8). Thus, $0.42 \mathrm{~g}$ plant stanols were consumed at breakfast, $0.84 \mathrm{~g}$ at lunch and $1.25 \mathrm{~g}$ at dinner.

The volunteers had to come at least once a week to the Department to receive a new supply of products. The experimental margarines were given in color-labeled tubs, which contained $75 \mathrm{~g}$ margarine (breakfast) or $145 \mathrm{~g}$ margarine (lunch). The cookies or cakes were provided in similarly color-labeled bags. The tubs and the bags provided margarine, cakes and cookies for one week. Parts of all experimental products that were left over at the end of the week had to be returned and were weighed back to calculate the consumption of the experimental margarines and shortenings for that week. The shortening without plant stanol esters was packed in a tub of $200 \mathrm{~g}$, which could be used for more than one week.

During the last week of each period, the participants had to fill in a food frequency questionnaire about their eating habits of the previous four weeks, in order to estimate their energy and nutrient intakes. Details of the food frequency questionnaire has been published before (6). A dietician immediately checked the questionnaires in presence of the subject, for completeness and inconsistencies. Food intake was divided over breakfast, between breakfast and lunch (morning-snacks), lunch, afternoonsnacks, dinner and evening-snacks. Composition of the diets was calculated as described before (6). 


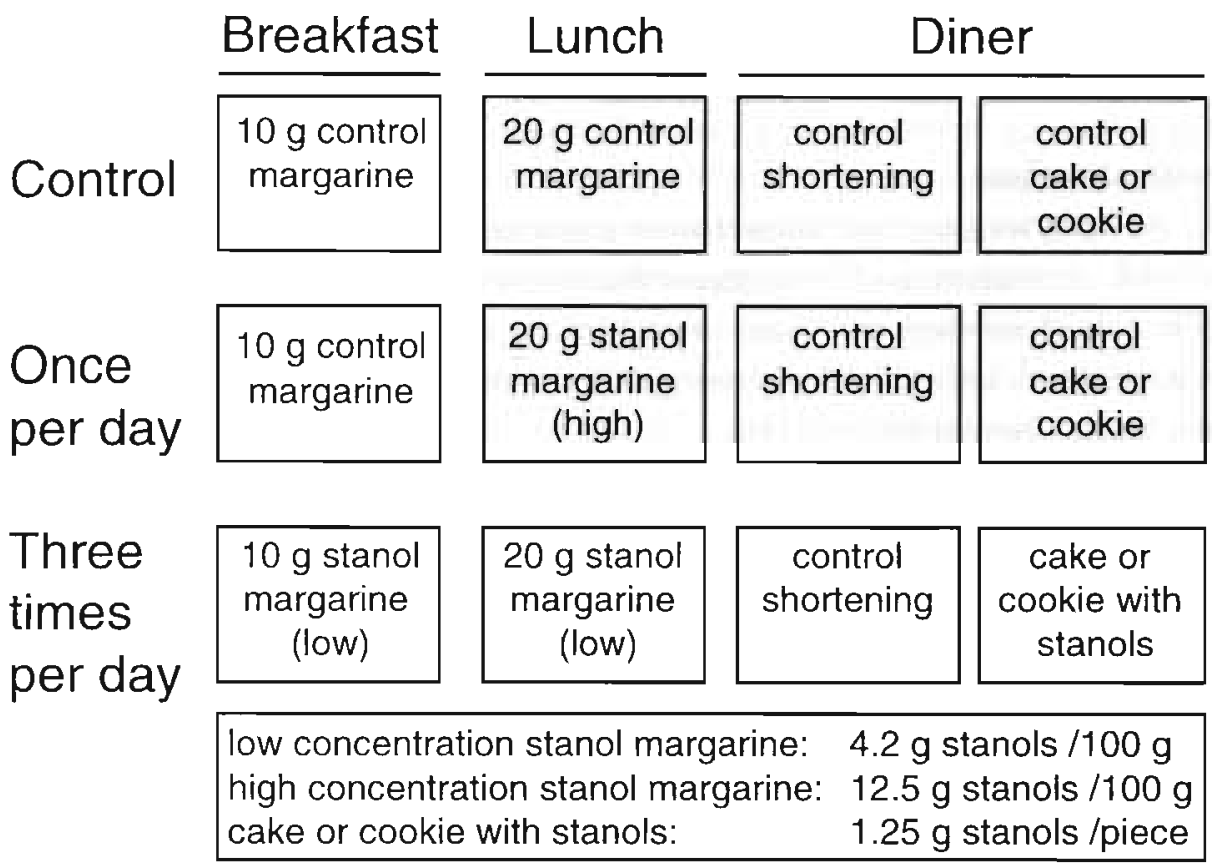

Figure 2: Distribution of plant stanol intake over the day.

\section{Blood sampling}

Blood was sampled after an overnight fast and after abstinence from drinking alcohol the preceding day and smoking on the morning before blood sampling. All venipunctures were performed by the same person, at the same location and approximately at the same time of the day. No blood was sampled on Mondays. Blood was sampled once at the beginning of the study (day 1) and twice at the end of each dietary period (weeks 3 and 4,7 and 8,11 and 12).

A $10 \mathrm{ml}$ clotting tube was always sampled (CORVAC: integrated serum separator tube, Sherwood Medical Company, St. Louis, USA). Serum was obtained by low-speed centrifugation at $2000 \mathrm{~g}$ for 15 minutes at $4^{\circ} \mathrm{C}$, at least one hour after venipuncture, and then immediately stored in small portions at $-80^{\circ} \mathrm{C}$. Serum was used for lipids and lipoprotein analysis. At weeks $0,4,8$ and 12 blood was also sampled using a $10 \mathrm{ml}$ EDTA tube (Sherwood Medical (Monoject). Plasma was prepared from EDTA blood by centrifuging at $2000 \mathrm{~g}$ for 30 minutes at $4^{\circ} \mathrm{C}$. Aliquots were snap-frozen and stored directly at $-80^{\circ} \mathrm{C}$ for analysis of antioxidants. Serum and EDTA blood were also used for 
analysis of parameters for liver and kidney function, C-reactive protein concentrations and hematological parameters. These parameters were not affected by the diets (9).

\section{Chemical analysis}

All samples from one subject were analyzed in the same analytical run for total and HDL cholesterol and triacylglycerol concentrations as described before (4). The coefficients of variation within runs were $1.9 \%$ for serum total cholesterol, $2.0 \%$ for $\mathrm{HDL}$ cholesterol and $3.4 \%$ for triacylglycerol. LDL cholesterol concentrations were calculated using the Friedewald equation (10).

Plasma concentrations of tocopherols ( $\alpha$-tocopherol, $\delta$-tocopherol, and $\beta+\gamma$ tocopherol), several carotenoids ( $\alpha$-carotene, $\beta$-carotene, lycopene, lutein/zeaxanthin, $\beta$ cryptoxanthin and phytofluene) and retinol were determined simultaneously, as described $(11,12)$. Briefly, plasma samples were extracted twice with hexane, while retinylacetate was used as internal standard. Antioxidant concentrations were determined by reversed phase high pressure liquid chromatography (HPLC). Samples from one subject of weeks 3,8 and 12 were analyzed in the same analytical run. The mean recovery of retinylacetate was $96.0 \pm 7.9 \%$.

\section{Statistical analysis}

The data were analyzed with the General Linear Models (GLM) procedure of the SAS program (13). For each subject, lipid and lipoprotein concentrations of weeks 3 and 4 , of 7 and 8 , and of weeks 11 and 12 were first averaged. The model to examine diet effects included subject, diet, period, carry-over effect and diet*sex as independent variables. Since the carry-over effect, period and the diet*sex interaction term never reached statistical significance, these terms were subsequently omitted from the model. Thus the final model included subject and diet. When the analysis indicated a significant effect of diet $(P<0.05)$, the Tukey method was used to compare the diets pairwise. All values are presented as their means \pm standard deviations (SD), except in figure 3 in which values are presented as means \pm SE.

\section{Results}

\section{Dietary intakes and body weight}

Table 1 shows the estimated daily plant sterol and stanol intakes, as derived from the experimental margarines and shortenings. As expected, total intakes of plant stanols during the once per day diet $(2468 \pm 173 \mathrm{mg})$ and during the three times per day diet $(2456 \pm 121 \mathrm{mg})$ were significantly higher than those during the control diet 
$(P<0.001)$. Total plant stanol $(P=0.672)$ and sitostanol $(P=0.578)$ intake was similar during the once per day period and the three times per day period. The slightly higher campestanol intake of $23 \mathrm{mg}$ or $4 \%$, during the once per day period, compared to the three times per day period, was significant $(\mathrm{P}<0.001)$. This difference was due to a slight difference in the sitostanol / campestanol ratio of the plant stanol ester mixtures used for the preparation of the low and the high stanol ester margarines.

The daily energy intake and the proportion of energy from the macronutrients and alcohol, as well as cholesterol and fiber consumption were essentially the same during the three periods of the study. Slight, statistically significant, differences existed in the intakes of fatty acids. This was mainly due to the slightly lower absorbable fat content of the stanol ester shortening compared to the control shortening.

During the control period, mean estimated daily margarine intake at breakfast was $10.1 \pm 0.6 \mathrm{~g}$, at lunch was $18.8 \pm 1.8 \mathrm{~g}$, while the estimated shortening incorporated into the cakes and cookies consumed after dinner was $9.6 \pm 0.8 \mathrm{~g}$. For the once per day period, these values were respectively $10.1 \pm 0.6 \mathrm{~g}, 19.3 \pm 1.4 \mathrm{~g}$ and $9.6 \pm 0.8 \mathrm{~g}$, and for the three times per day period respectively $10.2 \pm 0.6 \mathrm{~g}, 18.8 \pm 1.7 \mathrm{~g}$, and $9.6 \pm 0.6 \mathrm{~g}$. Table 2 shows the estimated plant stanol intakes as derived from the margarines and shortening, as well as the cholesterol intakes as divided over breakfast, lunch, and dinner, which were all as anticipated. The cakes or cookies prepared with the experimental shortenings were consumed approximately $22 \pm 20$ minutes after dinner with no difference between the three periods.

During the different periods of the study, changes in body weight were marginal. At the start of the study mean body weight was $64.5 \pm 10 \mathrm{~kg}$ for women and $75.2 \pm 9 \mathrm{~kg}$ for men. At the end of the control period body weight was $64.7 \pm 10 \mathrm{~kg}$ for women and $75.7 \pm 9 \mathrm{~kg}$ for men and at the end of the once per day diet and the three times per day diet, mean body weights were $64.2 \pm 10 \mathrm{~kg}$ and $64.5 \pm 10 \mathrm{~kg}$ for women and $75.3 \pm 9 \mathrm{~kg}$ and $75.7 \pm 9 \mathrm{~kg}$ for men respectively. These values were not significantly different ( $P=0.982$ for the diet of diet for women and $P=0.993$ for men). 
Table 1. Estimated daily intake of plant sterols and plant stanols, energy and nutrients, during the three different diets

\begin{tabular}{|c|c|c|c|c|c|c|c|c|}
\hline \multirow{3}{*}{$\begin{array}{l}\text { Total plant sterols }(\mathrm{mg})^{5} \\
\text { of which plant stanols }(\mathrm{mgl})^{5}\end{array}$} & \multicolumn{3}{|c|}{$\begin{array}{l}\text { Control } \\
\text { period }\end{array}$} & \multicolumn{2}{|c|}{$\begin{array}{c}\text { Once } \\
\text { per day period }\end{array}$} & \multicolumn{3}{|c|}{$\begin{array}{l}\text { Three times } \\
\text { per day period }\end{array}$} \\
\hline & 228 & \pm & 44 & 2729 & $\pm 199^{\circ}$ & 2682 & \pm & $146^{*}$ \\
\hline & 0 & \pm & 0 & 2468 & $\pm 173^{a}$ & 2456 & \pm & $121^{*}$ \\
\hline Sitosterol $(\mathrm{mg})^{5}$ & 112 & \pm & 22 & 132 & $\pm 22^{\mathrm{a}}$ & 123 & \pm & $21^{\mathrm{b}}$ \\
\hline Sitostanol (mg) & 0 & \pm & 0 & 1867 & $\pm 131^{\circ}$ & 1879 & \pm & $92^{\circ}$ \\
\hline Campesterol $(\mathrm{mg})^{5}$ & 81 & \pm & 15 & 97 & $\pm \quad 15^{a}$ & 82 & \pm & $15^{\mathrm{a}}$ \\
\hline Campestanol (mg) & 0 & \pm & 0 & 601 & $\pm \quad 42^{\mathrm{a}}$ & 578 & \pm & $28^{\mathrm{ac}}$ \\
\hline Energv (MJ) & 11.0 & \pm & 2.4 & 11.1 & $\pm \quad 2.5$ & 11.0 & \pm & 2.4 \\
\hline Fat (energy\%) & 38.8 & \pm & 4.4 & 38.9 & $\pm \quad 4.1$ & 38.2 & \pm & 4.3 \\
\hline SAFA & 13.3 & \pm & 1.9 & 12.8 & \pm 1.9 & 13.5 & \pm & $2.0^{c}$ \\
\hline MUFA & 16.2 & \pm & 2.2 & 16.4 & \pm 2.1 & 15.7 & \pm & $2.0^{\circ}$ \\
\hline PUFA & 7.4 & \pm & 1.3 & 7.7 & \pm 1.0 & 7.1 & \pm & $1.2^{\mathrm{c}}$ \\
\hline Linoleic acid & 5.7 & \pm & 1.1 & 6.0 & $\pm \quad 0.9$ & 5.5 & \pm & $1.1^{\mathrm{c}}$ \\
\hline$\alpha$-Linolenic acid & 1.3 & \pm & 0.2 & 1.3 & $\pm \quad 0.2$ & 1.1 & \pm & $0.2^{\mathrm{ac}}$ \\
\hline Cholesterol (mg/MJ) & 21 & \pm & 4.5 & 21 & \pm 5.9 & 21 & \pm & 4.5 \\
\hline Protein (energy\%) & 12.9 & \pm & 1.5 & 12.7 & \pm 1.5 & 12.6 & \pm & 1.4 \\
\hline Carbohydrates (energy\%) & 45.8 & \pm & 1.2 & 46.1 & \pm 4.8 & 46.7 & \pm & 5.3 \\
\hline Alcohol (energy $\%$ ) & 1.9 & \pm & 1.8 & 1.6 & \pm 1.4 & 1.8 & \pm & 1.9 \\
\hline Fibre (mg/MJ) & 2.4 & \pm & 0.5 & 2.5 & $\pm \quad 0.5$ & 2.5 & \pm & 0.5 \\
\hline
\end{tabular}

Values are means \pm S.D. Thirty-nine subjects consumed no plant stanols (control period), $2.5 \mathrm{~g}$ plant stanols ( $1.88 \mathrm{~g}$ sitostanol and $0.58 \mathrm{~g}$ campestanol) once a day (at lunch), or $2.5 \mathrm{~g}$ plant stanols ( $1.88 \mathrm{~g}$ sitostanol and $0.58 \mathrm{~g}$ campestanol) divided over three meals $(0.42 \mathrm{~g}$ at breakfast, $0.84 \mathrm{~g}$ at lunch and $1,25 \mathrm{~g}$ at dinner). Each period lasted four weeks. All plant stanols were transesterified with rapeseed oil fatty acids and were administered as its fatty acid esters.

5 Estimated plant sterol and stanol intake as derived from the experimental margarines and shortenings. Dietary intakes were calculated from food frequency lists filled in during the last week of each period. SAFA: saturated fatty acids, MUFA: monounsaturated fatty acids, PUFA: polyunsaturated fatty acids.

a $P<0.001$ compared to the control period.

b $P<0.01 \quad$ compared to the control period.

c $P<0.001 \quad$ compared to the once per day period.

\section{Serum lipids and lipoproteins}

Table 3 shows that plant stanol ester consumption once a day lowered serum total cholesterol concentrations with $0.32 \mathrm{mmol} / \mathrm{L}$ or $12 \mathrm{mg} / \mathrm{dL}$ compared to the control 
period, a reduction of $6.3 \% \pm 6.2 \%(\mathrm{P}<0.001 ; 95 \%$ confidence interval $(\mathrm{Cl}):-0.20$ to -0.44 $\mathrm{mmol} / \mathrm{L})$. Consumption of a similar amount of plant stanol esters, distributed over the day with the three meals, lowered total cholesterol concentrations by $0.33 \mathrm{mmol} / \mathrm{L}$ or 13 $\mathrm{mg} / \mathrm{dL}$, a reduction of $6.6 \% \pm 7.8 \%$ compared to the control period $(\mathrm{P}<0.001 ; 95 \% \mathrm{Cl}$ : 0.21 to $-0.45 \mathrm{mmol} / \mathrm{L})$. The difference of $0.01 \mathrm{mmol} / \mathrm{L}$ for total cholesterol between the once per day period and the three times per day period was not significant $(\mathrm{P}=0.808$; $95 \% \mathrm{Cl}:-0.11$ to $0.13 \mathrm{mmol} / \mathrm{L})$.

Table 2. Plant stanol and cholesterol intakes at breakfast, lunch and, dinner during the three different diets.

Breakfast Lunch Dinner

\begin{tabular}{|c|c|c|c|c|c|c|c|c|}
\hline \multicolumn{9}{|l|}{ Control period } \\
\hline Total plant stanols $\mathrm{s}^{\S}(\mathrm{mg})$ & 0.0 & \pm & 0.0 & 0.0 & 0.0 & 0.0 & \pm & 0.0 \\
\hline Cholesterol (mg) & 40 & \pm & 31 & 46 & \pm 27 & 122 & \pm & 36 \\
\hline \multicolumn{9}{|l|}{ Once per day period } \\
\hline Total plant stanols ${ }^{5}(\mathrm{mg})$ & 0.0 & \pm & 0.0 & 2468 & $\pm 173^{a}$ & 0.0 & \pm & 0.0 \\
\hline Cholesterol (mg) & 34 & \pm & 34 & 50 & \pm 35 & 119 & \pm & 41 \\
\hline \multicolumn{9}{|l|}{ Three times per day period } \\
\hline Total plant stanols $(\mathrm{mg})$ & 436 & \pm & $26^{\mathrm{ab}}$ & 806 & $\pm 73^{a b}$ & 1215 & \pm & $69^{a b}$ \\
\hline Cholesterol (mg) & 38 & \pm & 32.1 & 44 & \pm 32 & 113 & \pm & 38 \\
\hline
\end{tabular}

See table 1

5 Estimated plant stanol intake as derived from the experimental margarines and shortenings.

a $P<0.001 \quad$ compared to the control period.

b $\mathrm{P}<0.001$ compared to the once per day period.

Effects of plant stanol esters on serum total cholesterol were mainly caused by effects on serum LDL cholesterol which were, compared to the control period, significantly decreased with $0.29 \mathrm{mmol} / \mathrm{L}$ or $12 \mathrm{mg} / \mathrm{dL}(-9.4 \% \pm 9.1 \%$; $\mathrm{P}<0.001 ; 95 \% \mathrm{Cl}$ : 0.19 to $-0.39 \mathrm{mmol} / \mathrm{L}$ ) after the once per day period and with $0.31 \mathrm{mmol} / \mathrm{L}$ or $12 \mathrm{mg} / \mathrm{dL}$ ($10.4 \% \pm 11.9 \% ; \mathrm{P}<0.001 ; 95 \% \mathrm{Cl}:-0.20$ to $-0.41 \mathrm{mmol} / \mathrm{L}$ ) after the three times per day period. As for total cholesterol, the difference of $0.02 \mathrm{mmol} / \mathrm{L}$ for LDL cholesterol concentrations between the once per day period and the three times per day period was not significantly different $(P=0.764 ; 95 \% \mathrm{Cl}:-0.09$ to $+0.11 \mathrm{mmol} / \mathrm{L})$. Serum HDL cholesterol and triacylglycerol concentrations were not changed by the diets. Therefore, 
the total to HDL cholesterol ratios were significantly lower at the end of the once per day period $(3.4 \pm 1.4 ; P=0.002)$ and at the end of the three times per day period $(3.4 \pm 1.3$; $\mathrm{P}<0.001)$, compared to the control diet $(3.6 \pm 1.5)$.

Table 3. Fasting lipid and lipoprotein concentrations at the end of the three difterent diets.

\begin{tabular}{|c|c|c|c|c|c|c|c|c|}
\hline \multirow[b]{2}{*}{ Total cholesterol } & \multicolumn{2}{|c|}{$\begin{array}{l}\text { Control } \\
\text { period }\end{array}$} & \multicolumn{3}{|c|}{$\begin{array}{c}\text { Once } \\
\text { per day period }\end{array}$} & \multicolumn{3}{|c|}{$\begin{array}{l}\text { Three times } \\
\text { per day period }\end{array}$} \\
\hline & 5.02 & \pm 0.88 & 4.70 & \pm & $0.85^{a}$ & 4.69 & \pm & $0.91^{\mathrm{a}}$ \\
\hline LDL cholesterol & 3.04 & \pm 0.86 & 2.74 & \pm & $0.81^{\mathrm{a}}$ & 2.73 & \pm & $0.87^{\mathrm{a}}$ \\
\hline HDL cholesterol & 1.50 & \pm 0.39 & 1.48 & \pm & 0.41 & 1.49 & \pm & 0.37 \\
\hline Triacylglycerol & 1.05 & \pm 0.44 & 1.04 & \pm & 0.45 & 1.02 & \pm & 0.43 \\
\hline $\begin{array}{l}\text { Total to HDL } \\
\text { cholesterol ratio }\end{array}$ & 3.6 & $\pm \quad 1.5$ & 3.4 & \pm & $1.4^{\mathrm{b}}$ & 3.4 & \pm & $1.4^{\mathrm{a}}$ \\
\hline
\end{tabular}

See table 1. Concentrations are expressed in $\mathrm{mmol} / \mathrm{L}$, except for the total cholesterol to $\mathrm{HDL}$ cholesterol ratio. To convert values for total, HDL and LDL cholesterol to milligrams per deciliter, multiply by 38.67 . To convert values for triacylglycerols to milligrams per deciliter, multiply by 88.54 .

a $\mathrm{P}<0.001 \quad$ compared to the control period.

b $P<0.01 \quad$ compared to the control period.

\section{Fat soluble antioxidants}

Consumption of plant stanol esters, either once or three times a day, significantly lowered absolute $\alpha$-tocopherol and $\beta$-carotene concentrations (Table 4). The reduced lycopene and $\beta$-cryptoxanthin concentrations nearly reached significance after the once per day period $(P=0.044$ and 0.032 respectively), while concentrations of both antioxidants were significantly lower after the three times per day period (both $P=0.001$ ). In addition, during the three times per day period also phytofluene $(P=0.008)$, and $\beta+\gamma$ tocopherol $(P=0.007)$ concentrations were significantly decreased, and changes in lutein/zeaxanthin concentrations nearly reached significance $(P=0.023)$. Retinol concentrations were not affected by plant stanol ester consumption.

Although differences between the once and the three times per day period never reached statistical significance, changes for all antioxidants studied were more pronounced after the three times per day period. Also, changes were larger for the sum of the less polar hydrocarbon carotenoids (i.e. $\alpha$-carotene, $\beta$-carotene and lycopene) compared to reductions for the sum of the more polar oxygenated carotenoids (i.e. 
lutein/zeaxanthin and $\beta$-cryptoxanthin) and the sum of the tocopherols which are more polar than the carotenoids.

Table 4. Retinol and fat soluble antioxidant concentrations at the end of the three different diets.

\begin{tabular}{lrrrrrrr}
\hline & \multicolumn{2}{c}{$\begin{array}{c}\text { Control } \\
\text { period }\end{array}$} & \multicolumn{2}{c}{$\begin{array}{c}\text { Once } \\
\text { per day period }\end{array}$} & \multicolumn{2}{c}{$\begin{array}{c}\text { Three times } \\
\text { per day period }\end{array}$} \\
& 2.12 & \pm 0.41 & 2.10 & \pm 0.38 & 2.14 & \pm 0.41 \\
Retinol & 0.21 & \pm 0.16 & 0.19 & \pm 0.09 & 0.17 & \pm 0.07 \\
$\delta$-Tocopherol & 2.67 & \pm 1.06 & 2.58 & \pm 0.95 & 2.32 & $\pm 0.89^{\mathrm{b}}$ \\
$\beta+\gamma$-Tocopherol & 24.40 & \pm & 4.19 & 23.32 & $\pm 3.78^{\mathrm{b}}$ & 22.58 & $\pm 3.90^{\mathrm{a}}$ \\
$\alpha$-Tocopherol & 0.37 & \pm 0.16 & 0.34 & \pm 0.21 & 0.32 & $\pm 0.20^{\mathrm{b}}$ \\
Phytofluene & 0.43 & \pm 0.15 & 0.41 & \pm 0.12 & 0.40 & \pm 0.13 \\
Lutein/Zeaxanthin & 0.33 & \pm 0.12 & 0.31 & \pm 0.14 & 0.30 & $\pm 0.14^{\mathrm{b}}$ \\
$\beta$-Cryptoxanthin & 0.72 & \pm 0.28 & 0.64 & \pm 0.27 & 0.60 & $\pm 0.28^{\mathrm{b}}$ \\
Lycopene & 0.05 & \pm 0.04 & 0.04 & \pm 0.03 & 0.04 & \pm 0.03 \\
$\alpha$-Carotene & 0.32 & \pm 0.18 & 0.26 & $\pm 0.13^{\mathrm{a}}$ & 0.25 & $\pm 0.13^{\mathrm{a}}$ \\
$\beta$-Carotene & & & & & & & \\
\end{tabular}

See table 1 . Concentrations are expressed in $\mu \mathrm{mol} / \mathrm{L}$, except for phytofluene which is expressed in $\mathrm{mV} \min / \mu \mathrm{L}$ (amplification 100).

a $P<0.001$ as compared to the control period.

b $P<0.01$ as compared to the control period.

After standardization of the antioxidant concentrations for LDL cholesterol (table 5), none of the antioxidant concentrations was significantly different from the concentrations at the end of the control period. Changes in LDL cholesterol standardized hydrocarbon carotenoids were still slightly negative on the once per day diet $-0.017 \pm 0.018 \mu \mathrm{mol} / \mathrm{mmol} L \mathrm{LL}$ cholesterol $(P=0.307)$ and $-0.032 \pm 0.016 \mu \mathrm{mol} / \mathrm{mmol}$ LDL cholesterol $(P=0.049)$ on the three times per day diet. In contrast, after standardization for LDL cholesterol, changes were slightly positive for the oxygenated carotenoids and the tocopherols (Figure 3) 
Table 5. LDL cholesterol standardized antioxidant concentrations at the end of the three different diets.

\begin{tabular}{lllllll}
\hline & \multicolumn{2}{c}{$\begin{array}{c}\text { Control } \\
\text { period }\end{array}$} & $\begin{array}{c}\text { Once } \\
\text { per day period }\end{array}$ & \multicolumn{2}{c}{$\begin{array}{c}\text { Three times } \\
\text { per day period }\end{array}$} \\
\hline$\delta$-Tocopherol & 0.07 & \pm 0.04 & 0.07 & \pm 0.03 & 0.07 & \pm 0.03 \\
$\beta+\gamma$-Tocopherol & 0.92 & \pm 0.32 & 0.96 & \pm 0.32 & 0.91 & \pm 0.36 \\
$\alpha$-Tocopherol & 8.68 & \pm 2.30 & 8.91 & \pm 2.32 & 9.05 & \pm 2.51 \\
Phytofluene & 0.13 & \pm 0.06 & 0.14 & \pm 0.08 & 0.12 & \pm 0.08 \\
Lutein/Zeaxanthin & 0.15 & \pm 0.06 & 0.16 & \pm 0.07 & 0.16 & \pm 0.07 \\
$\beta$-Cryptoxanthin & 0.12 & \pm 0.06 & 0.13 & \pm 0.08 & 0.13 & \pm 0.08 \\
Lycopene & 0.25 & \pm 0.11 & 0.25 & \pm 0.12 & 0.23 & \pm 0.11 \\
$\alpha$-Carotene & 0.02 & \pm 0.02 & 0.02 & \pm 0.02 & 0.02 & \pm 0.02 \\
$\beta$-Carotene & 0.12 & \pm 0.07 & 0.10 & \pm 0.07 & 0.10 & \pm 0.07 \\
& & & & & & \\
\hline
\end{tabular}

See table 1. Concentrations are expressed in $\mu \mathrm{mol} / \mathrm{mmol} \mathrm{LDL}$ cholesterol, except for phytofluene which is expressed in $\mathrm{mV}^{*} \mathrm{~min} / \mathrm{nmol}$ LDL cholesterol (amplification 100).

\section{Discussion}

Many studies have demonstrated that plant stanol esters, when consumed three times a day with each meal $(5,6,14)$ or two times a day at lunch and dinner $(4)$, lower serum total and LDL cholesterol concentrations. We have now demonstrated that a daily intake of $2.5 \mathrm{~g}$ plant stanols as its fatty acid esters, either consumed once per day (at lunch) or divided over three meals $(0.4 \mathrm{~g}$ at breakfast, $0.8 \mathrm{~g}$ at lunch and $1.2 \mathrm{~g}$ at dinner), resulted in a similar decrease in serum total and LDL cholesterol. The amount of plant stanols in the latter period was divided over the three meals in such a way that the largest intake was at dinner and the lowest intake at breakfast. This differentiation is largely in correspondence with the distribution of cholesterol intake over the day (8) (table 2). Our findings therefore demonstrate that it is not necessary to consume plant stanol ester products simultaneously with dietary cholesterol or with each meal. This provides variety and may increase compliance for potential consumers. Like in other studies, serum HDL cholesterol and triacylglycerol concentrations were not affected. As a result, the total to $\mathrm{HDL}$ cholesterol ratio was significantly lower at the end of both the once per day and the three times per day period, as compared to the control period. 


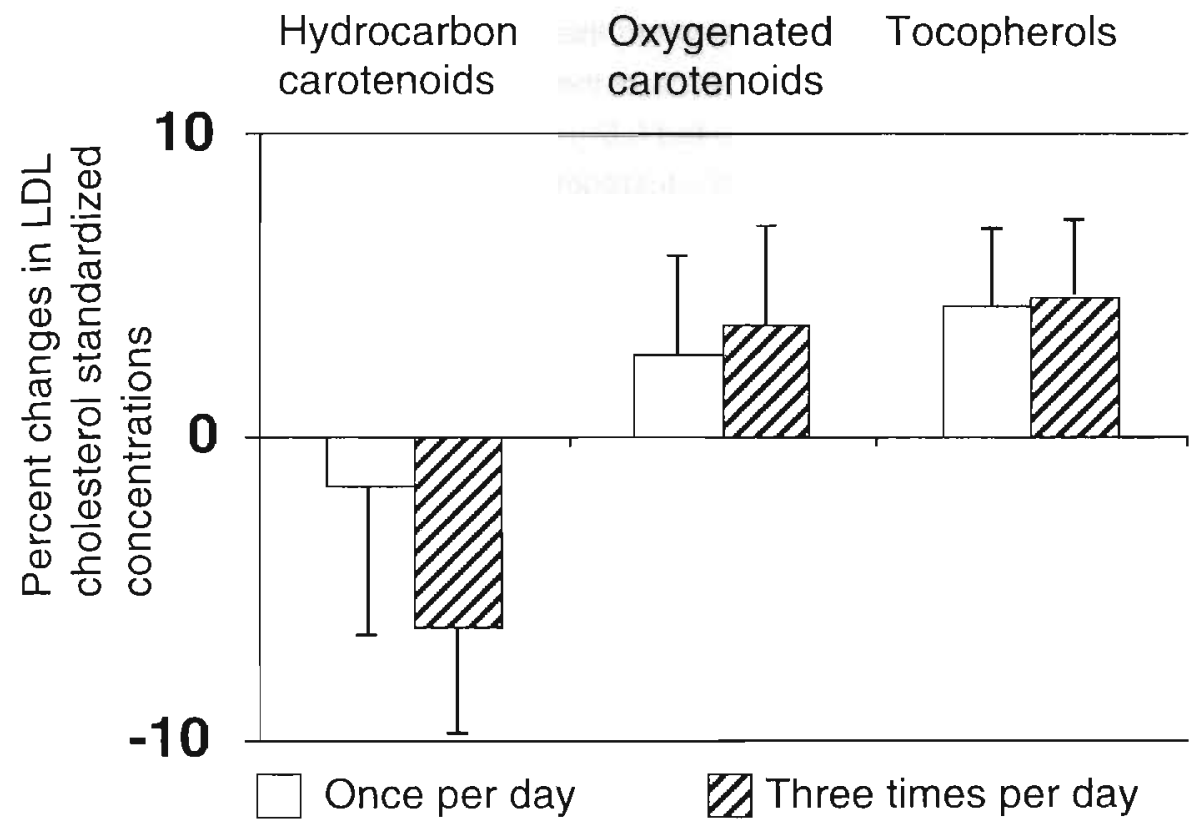

Figure 3: Percentage changes of LDL cholesterol standardized plasma hydrocarbon carotenoid, oxygenated carotenoid, and tocopherol concentrations ( $\mu \mathrm{mol} / \mathrm{mmol} \mathrm{LDL}$ cholesterol) at the end of the once per day period and the three times per day period, both compared to the concentrations at the end of the control period (means \pm SE). Hydrocarbon carotenoids were calculated as the sum of $\beta$-carotene, $\alpha$-carotene and lycopene, oxygenated carotenoids as the sum of luteinizeaxanthin and $\beta$-cryptoxanthin, and tocopherols as the sum of $\alpha$ tocopherol, $\beta+\gamma$-locopherol and $\dot{o}$-tocopherol.

The mechanism by which plant stanol esters affect lipoprotein metabolism and lower serum cholesterol concentrations has only partly been elucidated. It is, however, generally assumed that the intestinal absorption of both dietary and biliary cholesterol is reduced in the presence of plant stanols, since the micellar solubility of cholesterol is lowered (15). Therefore, it has been suggested that plant sterols, which also lower the micellar solubility of cholesterol, should be consumed at each cholesterol containing meal to achieve an optimal effect (16). However, this suggestion is not supported by our findings. We therefore hypothesize that plant stanols, or plant stanol esters, remain in the intestinal lumen or in the enterocytes for a while. Indeed, only $70 \%$ of an orally administered single bolus of ${ }^{14} \mathrm{C}$ labeled sitostanol to male wistar rats is found in the faeces after 24 hours (17). After two and three days the cumulative faecal excretions 
were $90 \%$ and $97 \%$ respectively. Thus, when the low absorption of sitostanol into the circulation (18) is neglected, at least $25-30 \%$ of the sitostanol is still in the intestinal tract after one day. However, when rats were fed $0.5 \%$ cholesterol and $0.5 \%$ sitostanol $(\mathrm{w} / \mathrm{w})$ for 18 days, the daily faecal excretion of sitostanol showed a recovery of approximately $100 \%$ (19). This implies that in rats, at least within 18 days, a steady state was reached and sitostanol intake equaled sitostanol excretion. This still does not elucidate whether sitostanol remains in the intestinal lumen -and if so, in which part- or in the enterocytes. It also does not answer the question for how long plant stanols are active in the intestine. Studies with caco-2 cells have addressed the question whether micellar ${ }^{14} \mathrm{C}$ labeled sitosterol could be taken up in the enterocyte and subsequently be excreted across the basolateral membrane (20). To our knowledge no such studies with sitostanol have been published. It appeared that sitosterol was indeed associated with the caco-2 cells. It was, however, not esterified intracellular and not excreted to the basolateral medium. This implicates that sitosterol can indeed remain in or can be associated with enterocytes. The functional significance of these findings, however, is unknown. Theoretically sitosterol could remain associated to the enterocytes only temporarily, be released into the lumen after several hours, and consequently affect micellar solubility of intestinal cholesterol at that moment. It can, however, also be speculated that plant sterols or stanols not only affect micellar solubility of cholesterol, but have additional effects on intestinal lipoprotein metabolism, as well.

In this study, serum LDL cholesterol concentrations were significantly reduced by 9 - 10\%, when plant stanol esters were consumed. In a previous study, also in a normocholesterolemic and mildly hypercholesterolemic population, serum LDL cholesterol concentrations decreased by $11-13 \%$, when $3.8 \mathrm{~g}$ or $4.0 \mathrm{~g}$ plant stanols as its fatty acid esters were consumed (6). As already discussed $(1,21)$, hardly any additional benefit is obtained when daily intake of plant stanols exceeds $2.2 \mathrm{~g}$.

Although total fat consumption during the three diet periods was similar, the fatty acid compositions of the diets were not entirely comparable. This was due to the slightly lower absorbable fat content of the stanol ester shortening compared to the control shortening. However, the marginal differences in the dietary fatty acid compositions were to small to have a major impact on serum lipoproteins. The LDL cholesterol lowering effect of the once per day period might have been overestimated by 0.02 $\mathrm{mmol} / \mathrm{L}$ compared to the control period, while the LDL cholesterol lowering effect of the three times per day diet might have been underestimated by 0.01 and $0.04 \mathrm{mmol} / \mathrm{L}$, when compared to the control period and the once per day period respectively (22). 
Consumption of $2.5 \mathrm{~g}$ plant stanols three times a day significantly lı wured most of the carotenoid and tocopherol isomers studied. In contrast. consumption of a similar amount of plant stanols once a day at lunch only resulted in reduced absolute $\alpha$ tocopherol and $\beta$-carotene concentrations. In addition, all antioxidants studied showed slightly lower concentrations at the end of the three times per day period compared to the concentrations at the end of the once per day period (Tables 4 and 5). These absolute reductions can be explained largely by a reduced number of LDL particles in the circulation, which are major carriers of the fat-soluble antioxidants. Therefore, the differences, were no longer significant after standardization for LDL cholesterol. Furthermore, we have shown that in particular the most lipophylic hydrocarbon carotenoid concentrations (i.e. c.carotene, $\beta$-carotene and lycopene) were lowered by plant stanol ester consumption. The mechanism and the biological significance of these effects, however, remain to be elucidated.

From our results we conclude that a daily consumption of $2.5 \mathrm{~g}$ plant stanols as its fatty acid esters either at lunch or divided over the three meals does not affect its serum LDL cholesterol lowering efficacy. This implies that it is not necessary to consume plant stanol esters simultaneously with dietary cholesterol or with each meal. We therefore hypothesize that plant stanols, or plant stanol esters, remain in the intestinal lumen, or possibly in or associated with the enterocytes. It can also be speculated that plant stanols not only affect micellar solubility of cholesterol, but have other intestinal effects on lipoprotein metabolism, as well. Therefore, further research will be necessary to elucidate the mechanism by which plant stanols lower LDL cholesterol.

\section{References}

1. Wester 1. Dose responsiveness to plant stanol esters. Eur Heart J 1999;(Suppl 1): s104-\$108

2. Law M. Plant sterol and stanol margarines and health. BMJ 2000;320:861-4.

3. Heinemann T, Kullak-Ublick GA, Pietruck $B$, von Bergmann K. Mechanisms of action of plant sterols on inhibition of cholesterol absorption; Comparison of sitosterol and sitostanol. Eur J Clin Pharmacol 1991;40 (Suppl.1):\$59-s63
4. Weststrate JA, Meijer GW. Plant sterolenriched margarines and reduction of plasma total- and LDL-cholesterol concentrations in normocholesterolaemic and mildy hyperchotesterolemic subjects. Eur J Clin Nutr 1998:52:334-43

5. Miettinen TA, Puska $P_{x}$ Gylling $H$, Vanhanen $H$, Vartiainen $E$. Reduction of serum cholesterol with sitostanol-ester margarine in a mildy hypercholesterolemic 
population. N Engl J Med 1995;333:130812

6. Plat J, Mensink RP. Vegetable oil based versus wood based stanol ester mixtures: effects on serum lipids and hemostatic factors in non-hyperchalesterolemic subjects. Atherosclererosis 2000:148:101112

7. Gylling $H$, Miettinen TA. Cholesterol reduction by different plant stanol mixtures and with variable fat intake. Metabolism 1999;48:575-580

8. Minısteries van Welzijn, Volksgezondheid en Cultuur en van Landbouw, Natuurbeheer en Visserij. Zo eet Nederland, 1992, Voorlichtingsbureau voor de voeding 1993

9. Plat J, Mensink RP. Dietary plant stanol ester mixtures; efects on safety parameters and erythrocyte membrane fatty acid composition in non-hypercholesterolemic subjects. Eur Heart J 1999;(Suppl 1):s58s63

10. Friedewald WT, Levy RI, Fredrickson DS, Estimation of the concentration of lowdensity lipoprotein cholesterol in plasma, without use of the preparative ultracentrifuge. Clin Chem 1972;18:499502

11. Hess D, Keller HE, Oberlin B, Bonfanti R, Schüep $\mathrm{W}$. Simultaneous determination of retinol, tocopherols, carotenes and lycopene in plasma by means of highperformance liquid chromatography on reversed phase. Internat $J$ Vit Res 1991;61:232-238

12. Oostenbrug GS, Mensink RP, Hardeman $M P$, de Vries $T$, Brouns F, Hornstra $G$. Exercise performance, red blood cell deformability, and lipid peroxidation: effects of fish oil and vitamin E. J Appl Physiol 1997;83:746-752

13. SAS Institute Inc. SAS: user's Guide Statistics, Version 5 Edition, Cary, NC: SAS Institute Inc, 1985

14. Gylling $H$, Radhakrishnan $R$, Miettinen TA. Reduction of cholesterol in postmenopausal women with previous myocardial infarction and cholesterol malabsorption induced by dietary sitostanol ester margarine. Circulation 1997;96: 422631

15. Ikeda I, Tanabe $Y$, Sugano M. Effects of sitosterol and sitostanol on micellar solubility of cholesterol. J Nutr Sci Vitaminol 1989;35:361-9

16. Mattson $\mathrm{FH}$, Grundy SM, Crouse JR. Optimizing the effect of plant sterols on cholesterol absorption in man. Am J Clin Nutr 1982;35:697-700

17. Ikeda I. Sugano M. Comparison of absorption and metabolism of $\beta$-sitosterol and $\beta$-sitostanol in rats. Atherosclerosis 1978;30:227-37

18. Hassan AS, Rampone AJ. Intestinal absorption and lymphatic transport of cholesterol and beta-sitostanol in the rat. J Lipid Res 1979;20:646-53

19. Sugano $M$, Morioka $H$, lkeda I. A comparison of hypocholesterolemic activity of $\beta$-sitosterol and $\beta$-sitostanol in rats. J Nutr 1977;107:2011-19

20. Field FJ, Born E, Mathur SN. Effect of micellar b-sitosterol on cholesterol metabolism in caco-2 cells. J Lipid Res 1997:36:348-360

21. Mensink RP, Plat J. Efficacy of dietary plant stanols. Postgrad Med (A Special Report), 1998;November:27-31 
22. Mensink RP, Katan MB. Effect of dietary fatty acids on serum lipids and lipoproteins. Arterioscler Thromb 1992;12:911-9 


\section{Chapter 6}

Hypocholesterolemic mechanisms of plant stanol esters: effects on

LDL receptor mRNA and cell-surface protein expression, and on HMG-CoA reductase mRNA expression in non-hypercholesterolemic Subjects

Plat J, Mensink RP

Department of Human Biology, Maastricht University, The Netherlands

(submitted) 


\section{Abstract}

Functional foods enriched with plant stanols lower atherogenic LDL cholesterol concentrations. This effect is, at least partly, caused by a decreased intestinal cholesterol absorption. Further, it has been suggested that LDL production is also reduced after plant stanol consumption, but it is unknown if LDL-receptor expression is affected and contributes to the LDL lowering effect of plant stanols. Also, markers for endogenous cholesterol synthesis (lathosterol) increases, but it is not known how this higher cholesterol synthesis is regulated at the molecular level.

In a double blind placebo controlled trial we have found that compared to the control group $(\mathrm{N}=15)$ daily consumption of 3.8-4.0 g plant stanol esters $(N=29)$ for eight weeks increased LDL-receptor mRNA levels in human mononuclear blood cells by $43 \% \quad(P=0.003)$. LDL receptor protein concentrations on the surface of monocytes and T-lymphocytes increased by $37 \%(P=0.003)$ and $25 \%(P=0.013)$, suggesting an increased translation. This increased protein expression appeared to be functional, since changes in serum LDL cholesterol correlated negatively with changes in LDL-receptor mRNA levels ( $r=-0.361 ; P=0.015)$ and with changes in $L D L-r e c e p t o r$ protein expression in monocytes $(r=-0.440 ; P<0.001)$ and $T$-lymphocytes $(r=-0.307 ; P=0.018)$. Based on these results, we suggest that the higher LDL-receptor expression contributed to a lowered LDL formation along the apoB cascade. Whole body cholesterol synthesis increased, as indicated by the rise in serum cholesterolstandardized lathosterol concentrations, but the $34 \%$ increased HMG-CoA reductase mRNA concentrations did not reach statistical significance. It also did not correlate significantly with changes in serum cholesterol-standardized lathosterol concentrations. This suggests that HMG-CoA reductase may be only partly regulated at a transcriptional level. 


\section{Introduction}

Cells in the human body need cholesterol, which can be derived from endogenous synthesis or from receptor mediated uptake of circulating lipoproteins such as intermediate density lipoproteins (IDL) and low-density lipoproteins (LDL) (1). Circulating lipoproteins are taken up by various receptors, all with their own specific ligands. LDL, for example, is mainly endocytosed by a specific apoB/E receptor, known as the LDL receptor. Transcription of the LDL-receptor gene is upregulated by low cellular free sterol concentrations and is initiated by activated sterol response element binding proteins (SREBPs) (2). The transcription of the rate-limiting enzyme for endogenous cholesterol synthesis, 3-hydroxy-3-methylglutaryl coenzyme A (HMG-CoA) reductase, is controlled in a similar way (3), although its activity depends on post-transcriptional modifications (4).

It is known that endogenous cholesterol synthesis increases, when functional foods enriched with plant stanol esters - currently on the market in many countries - are consumed, while concentrations of cholesterol in the atherogenic LDLs are lowered (5). These effects are initiated by a decrease in cholesterol absorption, due to the competition of plant stanols with intestinal cholesterol for incorporation into mixed micelles. How the increase in cholesterol synthesis is regulated at the molecular level is not known. In addition, it has never been investigated if changes in LDL-receptor expression also contribute to the LDL-cholesterol lowering effect of plant stanol esters.

In the present study we therefore analyzed in non-hypercholesterolemic subjects effects of plant stanol ester consumption on changes in mRNA levels of the LDL receptor and HMG-CoA reductase in mononuclear blood cells. mRNA expression profiles may provide information about effects at the transcriptional level, but not necessarily at the translational level. Therefore, we also analyzed changes in LDL receptor cell-surface protein expression. HMGCoA reductase protein was not analyzed, but serum cholesterol-standardized lathosterol concentrations - which correlate with HMG-CoA reductase activity (6) - were used instead.

\section{Methods}

\section{Design and Diets}

The study had a double blind, placebo-controlled, parallel design and consisted of two consecutive periods. During the first period of four weeks (runin period), all subjects had to replace their usual margarines and baking fats for a rapeseed-oil based margarine and shortening without added plant stanol 
esters. Subjects were then randomly allocated to one of the three treatment groups, stratified for sex and age. For the next eight weeks, the control group $(n=15)$ continued to use the rapeseed-oil based margarine and shortening, while the second and the third group used the same margarine and shortening to which a vegetable oil based $(n=14)$ or a wood based plant stanol ester mixture $(n=15)$ was added. Vegetable oil derived plant stanols contain about $68 \%$ sitostanol and $32 \%$ campestanol. For wood-based plant stanols, these values are respectively $92 \%$ and $8 \%$. Details on the production of plant stanol esters as well as on the composition of the experimental products have been described in detail elsewhere (7). The participants used the margarine at breakfast and lunch, and the shortening at diner. The minimal daily margarine intake was $20 \mathrm{~g}$, whereas at least $10 \mathrm{~g}$ shortening a day had to be eaten. This resulted in additional daily intake of $3.8 \mathrm{~g}$ plant stanols as its fatty acid ester in the vegetable oil based group and of $4.0 \mathrm{~g}$ in the wood based group. Estimated daily intake of plant stanols in the control group was less than $0.1 \mathrm{~g}$. All margarines and shortenings were prepared by the RAISIO GROUP, Raisio, Finland.

Body weight was recorded every week. Subjects recorded in diaries any signs of illness, medication used, menstrual phase and any deviations from the protocol. In addition, subjects were asked not to change their habitual diets, level of physical exercise, smoking habits or use of alcohol or of oral contraceptives during the study.

\section{Subjects}

This study was also designed to compare the effects of the two different plant stanol ester mixtures on fasting concentrations of serum lipid and lipoproteins, plasma antioxidants, serum cholesterol precursors, and serum plant sterols and stanols $(8,9)$. In that part of the study, 112 nonhypercholesterolemic subjects - 41 males and 71 females - from Maastricht and surrounding municipals participated. All participants were normotensive, had no proteinuria or glucosuria, had no history of coronary heart disease, and did not use prescribed diets or medication known to affect serum lipoprotein metabolism. For the present part of the study, we have selected randomly a subset of 44 subjects (16 males and 28 females) for analysis of LDL receptor and HMG-CoA reductase mRNA concentrations in mononuclear blood cells, and LDL receptor cell-surface protein expression. At the start of the study their mean age was $34 \pm 17$ years (means \pm S.D.), their body mass index (BMI) $23 \pm 3.1 \mathrm{~kg} / \mathrm{m}^{2}$, while serum total cholesterol concentrations were $5.00 \pm 0.76$ 
$\mathrm{mmol} / \mathrm{L}$, and serum triacylglycerol concentrations $0.98 \pm 0.61 \mathrm{mmol} / \mathrm{L}$. These characteristics did not differ significantly from those of the remaining 68 subjects.

Before the start of the study, all subjects gave their written informed consent. The protocol of the study was approved by the medical ethical committee of the Maastricht University

\section{Blood sampling}

At the end of the run-in period (weeks 3 and 4) as well as at the end of the intervention period (weeks 11 and 12), blood was sampled after an overnight fast. Subjects abstained from drinking alcohol the day before and from smoking on the morning of blood sampling. After about $23 \mathrm{~mL}$ blood was sampled for additional measurements as already reported elsewhere (8), blood was drawn into a $10 \mathrm{~mL}$ clotting tube to obtain serum for analysis of lipid and lipoproteins, plant sterols and cholesterol precursors, and in three $10 \mathrm{~mL}$ EDTA tubes (Monoject sterile, Sherwood Medical, Ballymoney, North Ireland) for total RNA isolation. Serum was obtained by centrifugation at $2000 \times \mathrm{g}$ for thirty minutes at $4^{\circ} \mathrm{C}$, minimally one hour after venipuncture. Serum aliquots were stored directly at $-80^{\circ} \mathrm{C}$ for later analysis.

\section{Analyses}

Both LDL receptor and HMG-CoA reductase mRNA as well as LDL receptor cell-surface protein expression were analyzed in mononuclear blood cells. The number of total white blood cells as well as the percent lymphocytes, monocytes and granulocytes, and C-reactive protein concentrations (as inflammatory parameter) did not change during the study (data not shown).

\section{Total RNA isolation}

Total RNA was isolated from peripheral blood mononuclear cells (PBMCs) as described by Chomczinski and Sacchi (10). Briefly, mononuclear cells were first isolated (AccuspinTM System-Histopaqueß-1077; Sigma Diagnostics) and washed with a sterile, DEPC treated, $0.9 \% \mathrm{NaCl}$ solution. The PBMC pellet was resuspended in DEPC treated solution D (4 M guanidinium isothiocyanate, $25 \mathrm{mM}$ sodiumcitrate ( $\mathrm{pH} 7.0$ ), 0.5\% sarcosyl, and $0.1 \mathrm{M} 2$ mercapto ethanol) and stored at $-20^{\circ} \mathrm{C}$ until RNA isolation. RNA was always isolated within one week after storage by chloroform extraction and isopropanol precipitation. Finally, the RNA pellet obtained in this way was washed in DEPC ethanol $(70 \%)$ and stored under $1500 \mathrm{~mL}$ DEPC ethanol $(70 \%)$ at $-80 \mathrm{C}$ until 
further analysis. Before the RT-PCR, the RNA pellet was resuspended in DEPC treated HPLC water, total RNA concentrations measured spectrofotometrically at $260 \mathrm{~nm}$, and RNA integrity examined after electrophoresis on a $0.8 \%$ agarose gel at $80 \mathrm{~V}$ for 30 minutes by examination of proper $18 \mathrm{~S}$ and $28 \mathrm{~S}$ rRNA bands.

\section{Competative RT-PCR}

Reverse transcription was performed with $500 \mathrm{ng}$ total cellular RNA. Each sample was reverse-transcribed four times, each time in the presence of a different amount of the RNA competitor AW109 (Perkin Elmer Cetus, Foster City, CA, USA). At first, RNA and AW109 were heated at $85^{\circ} \mathrm{C}$ for 5 minutes. Next, the RT mixture was added to the heated mixture of RNA and AW109. After addition, the concentrations of the components in the RT mixture were 3 $\mathrm{mM} \mathrm{MgCl}, 2,10 \mathrm{mM}$ DTT, 400 units M-MLV (Gibco, Life Technologies, Breda, The Netherlands). $5 \mu \mathrm{M}$ random hexamers (Perkin Elmer Cetus, Foster City, CA, USA), 20 units RNAse inhibitor (Gibco, Life Technologies, Breda, The Netherlands), and $0.375 \mathrm{mM}$ dNTPs (Pharmacia Biotech, Roosendaal, The Netherlands). After 10 minutes incubation at room temperature, the sample was incubated for 1.5 hour at $37^{\circ} \mathrm{C}, 3$ minutes at $95^{\circ} \mathrm{C}$ and then rapidly chilled to $4^{\circ} \mathrm{C}$.

To $4 \mu \mathrm{L}$ cDNA $37.5 \mathrm{pmol}$ HMG-CoA reductase specific primers and to 8 $\mu \mathrm{L}$ cDNA $37.5 \mathrm{pmol}$ LDL receptor specific primers were added. Primer sequences were identical to those described by Powell and Kroon (11), which resulted in a product of $258 \mathrm{bp}$ (mRNA) or $301 \mathrm{bp}$ (AW109) for the LDL receptor and 247 bp (mRNA) or 303 bp (AW109) for HMG-CoA reductase. The sense primers were 5'-cy-5 labeled. Consequently, the fluorescence label was incorporated into the PCR product during amplification and quantification of the amplification products was based on the fluorescence signal. The PCR mixture consisted further of $2.1 \mathrm{mM} \mathrm{MgCl}_{2}$ (PCR buffer), $0.3 \mathrm{mM}$ dNTPs, and $3.5 \mathrm{U}$ Taq DNA polymerase (Pharmacia Biotech, Roosendaal, The Netherlands) in a total volume of $50 \mu \mathrm{L}$. The cDNA was amplified for 26 cycles, which consisted each of 30 seconds denaturation at $94^{\circ} \mathrm{C}, 15$ seconds primer anealing at $55^{\circ} \mathrm{C}$, and 30 seconds extension at $72^{\circ} \mathrm{C}$. The number of PCR cycles was limited to 26 , as between 25 and 28 cycles the logaritmic amplification curves were found to be linear with a slope of approximately 1.9. When amplified simultaneously, amplification curves of both pAW109 and total RNA showed identical patterns.

$2.5 \mu \mathrm{L}$ of each PCR product was loaded on a $6 \%$ polyacrylamide gel in an ALF-express DNA sequencer (Pharmacia Biotech, Roosendaal, The Netherlands) to determine the amount of HMG-CoA reductase and LDL 
receptor mRNA copies. The fluorescent-labeled PCR fragments were quantified by using the fragment manager software (Pharmacia Biotech, Roosendaal, The Netherlands). Product size was verified by using a fluorescent labeled 50 bp ladder (Pharmacia Biotech, Roosendaal, The Netherlands). The concentration of the target mRNA was expressed per $\mu \mathrm{g}$ of total cellular RNA. Competative RT-PCR assays of two mRNA samples from one subject (before and after intervention) were analyzed simultaneously.

Flow cytometry for cell-surface LDLreceptor expression

For 63 subjects LDL receptor protein expression on the surface of blood mononuclear cells was measured. In 44 of these subjects, LDL-receptor and HMGCoA-reductase mRNA levels were also determined. No mRNA was available for the other 19 subjects. Mononuclear cells were isolated from EDTA blood using lymphoprep (Nycomed Pharma AS Diagnostics, Oslo, Norway) according to instructions of the manufacturer. Cryo-vials filled with the cells were stored immediately after isolation at $-80^{\circ} \mathrm{C}$ in a cryobox filled with isopropanol to stress the cells as little as possible. After 24 hours the vials were transferred into liquid nitrogen. Surface expression of the LDL receptor was determined by flow cytometry, using a non-labeled mouse monoclonal (mAb) IgG2b human LDL receptor antibody (Amersham Pharmacia Biotech, Uppsala, Sweden), and a secondary FITC-labeled sheep anti-mouse IgG antibody (DAKO, Glostrup, Denmark). LDL-receptor protein expression was measured in three subpopulations of human mononuclear cells by a double fluorescence staining protocol. For this we used PE-conjugated mAbs (CLB, Amsterdam, The Netherlands) to identify the monocytes (CD-14), T-lymphocytes (CD-3) and the B-lymphocytes (CD-19), making it possible to identify CD-14, CD-3 or CD-19 positive cells in the scatter/volume dot plot by electronic gating. Ten thousand cells from each sample were analyzed on the flow cytometer (Becton Dickinson, Franklin Lakes, NJ, USA). Fluorescence signals were depicted in a histogram in which the number of cells was plotted versus the fluorescence intensity signal. Integration of fluorescence readings was performed with software provided with the flow cytometer. The non-specific fluorescence intensity in the total PBMC population was determined for each sample after incubating the cells with CD45-PE. Specific fluorescence was calculated by subtracting the non-specific fluorescence intensity from the total fluorescence intensity. 


\section{Other measurements}

Serum lipid and lipoprotein concentrations, and serum plant sterol (sitosterol and campesterol) and cholesterol precursor (lathosterol) concentrations were analyzed as described before $(8,9)$.

\section{Statistics}

Changes were calculated for each subject as the difference between values of the experimental period and run-in period. Since changes in all parameters were comparable between the two experimental groups $(8,9)$, we have combined the results of the vegetable oil based and the wood based plant stanol esters groups into one experimental group $(n=29)$. The differences in changes between the groups were tested with a t-test $(\alpha=0.05)$. Pearson correlation coefficients were computed to examine linear relationships between various parameters. All statistical analyses were performed with Statview 4.5 (12). All values are expressed as means \pm S.D.

Table 1: Serum LDL cholesterol, lathosterol, campesterol and sitosterol concentrations during the study

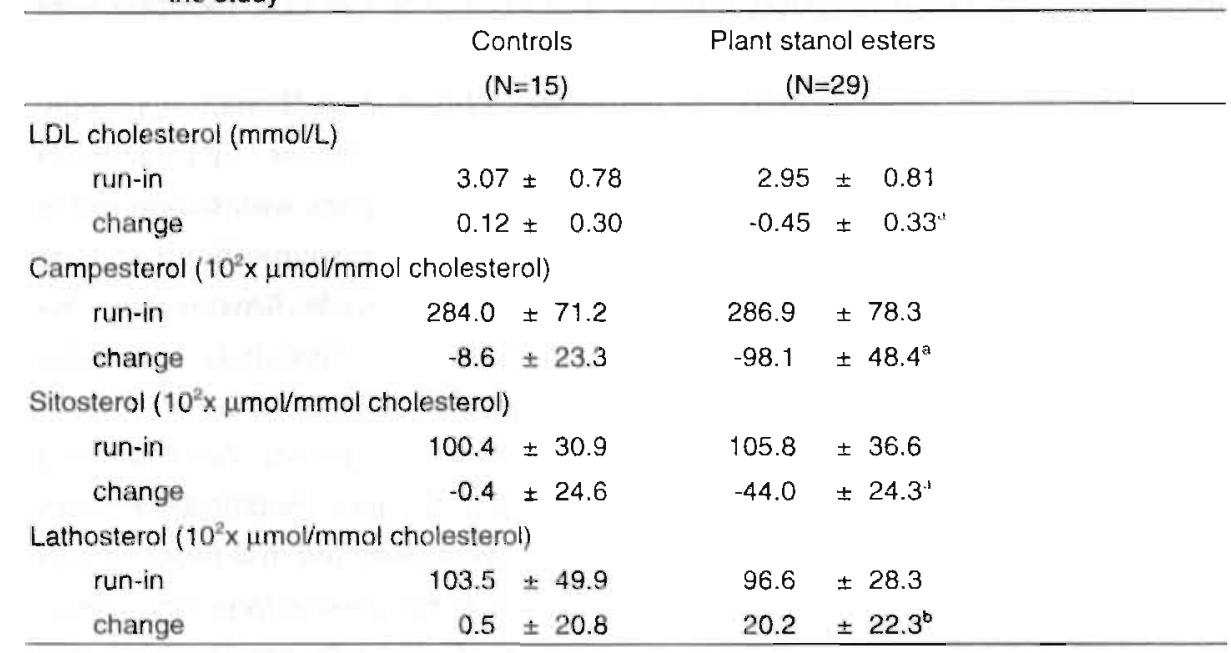

Values are means \pm S.D.

a $P<0.001$ compared to the control group,

${ }^{6} \mathrm{P}<0.01$ compared to the control group

\section{Results}

\section{Serum lipids and lipoproteins}

As shown in table 1, eight week's consumption of the plant stanol esters decreased serum LDL cholesterol concentrations by $0.45 \pm 0.33 \mathrm{mmol} / \mathrm{L}$ $(P<0.001$ versus the control group; 95\% confidence interval $(\mathrm{Cl})$ for the 
difference in changes between the two groups, -0.36 to $-0.78 \mathrm{mmol} / \mathrm{L})$. No effects on HDL cholesterol and triacylglycerol concentrations were found (data not shown). Effects on serum lipid and lipoprotein concentrations were comparable to those of the other 68 subjects who participated in the study (data not shown). This suggests that this randomly chosen subgroup was representative for the entire study population.

\section{Plant sterols and cholesterol precursors}

Compared to the control group, cholesterol-standardized serum plant sterol concentrations (sitosterol, campesterol) were significantly $(P<0.001)$ lower after plant stanol ester consumption, suggesting a reduced cholesterol absorption (table 1). The cholesterol-standardized lathosterol concentration was significantly higher in the experimental group $(P=0.007)$ compared to the control group, indicating an increased endogenous cholesterol synthesis. Again, results for these 44 subjects were comparable to those of the other 68 subjects (data not shown).

\section{$L D L$ receptor and HMGCoA reductase mRNA expression}

At the end of the run-in period, LDL receptor mRNA concentrations in mononuclear blood cells correlated positively with those of $\mathrm{HMG}-\mathrm{Co}$ A reductase mRNA $(r=0.619 ; P<0.001)$, illustrating the coordinated expression of both genes. Plant stanol ester consumption increased LDL receptor mRNA concentrations by $55.1 \pm 57.3 \%$ (or $17.9 \pm 13.5 \mathrm{mRNA}$ copies / $\mu \mathrm{g}$ total RNA) (figure 1). This change was significantly different from the change of $11.9 \pm$ $30.3 \%$ (or $4.3 \pm 13.3$ mRNA copies / $\mu \mathrm{g}$ total RNA) in the control group ( $P=0.003 ; 95 \% \mathrm{Cl}$ for the difference, 5.0 to $22.3 \mathrm{mRNA}$ copies / $\mu \mathrm{g}$ total RNA). There was no difference in changes of LDL receptor expression between both plant stanol ester mixtures $(P=0.999 ; 95 \% \mathrm{Cl}$ for the difference, -10.5 to 10.5 mRNA copies / $\mu \mathrm{g}$ total RNA). The change in LDL receptor mRNA concentrations correlated negatively with the change in serum LDL cholesterol concentrations $(r=-0.361 ; P=0.015)$. Thus, the largest LDL cholesterol reductions were seen in those subjects with the largest increases in LDL receptor mRNA concentrations 


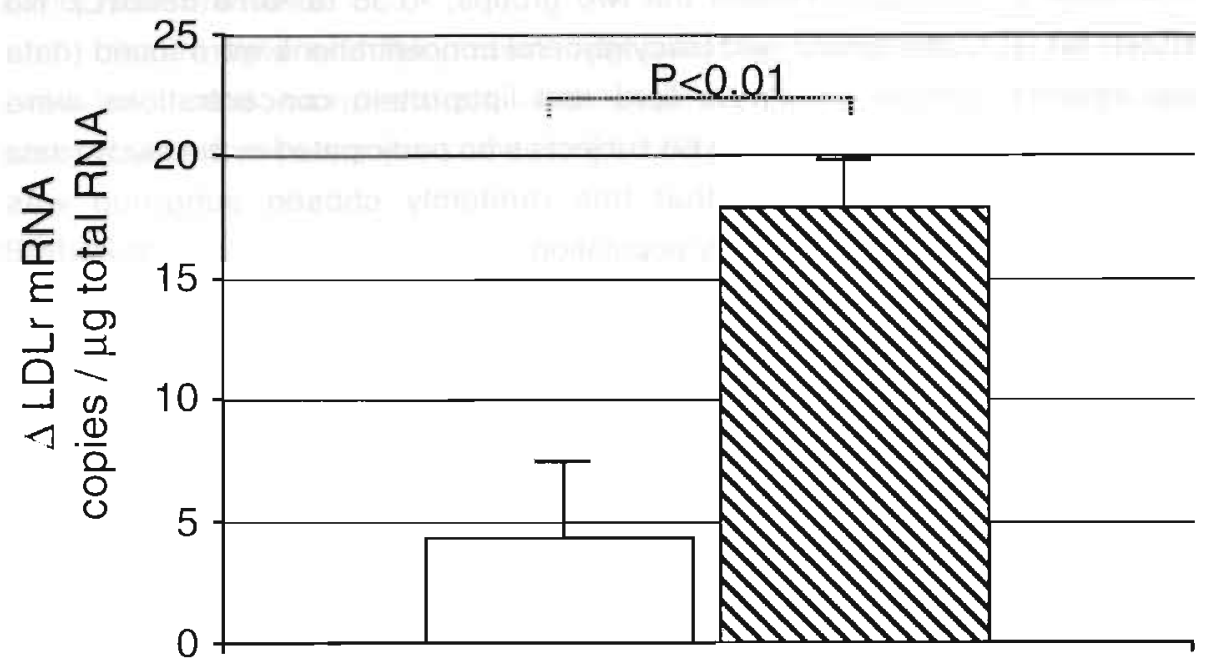

Figure 1: $\quad$ Changes in the number of LDL receptor mRNA copies / $\mu \mathrm{g}$ total RNA of mononuclear blood cells in the control group and the plant stanol ester group. Values are means $\pm S E$.

HMG-CoA reductase mRNA concentrations increased by $66.4 \pm 68.1 \%$ (or $183.9 \pm 182.4 \mathrm{mRNA}$ copies / $\mu \mathrm{g}$ total RNA) in the plant stanol ester group (figure 2), but this change did not reach statistical significance compared to the change of $32.5 \pm 28.7 \%$ (or $105.1 \pm 90.8$ mRNA copies / $\mu$ g total RNA) in the control group $(\mathrm{P}=0.124 ; 95 \% \mathrm{Cl}$ for the difference, -22.4 to 180.2 mRNA copies / $\mu \mathrm{g}$ total RNA). Effects on HMG-CoA reductase mRNA concentrations were similar during consumption of both plant stanol ester mixtures $(P=0.619 ; 95 \% \mathrm{Cl}$ for the difference, -106.5 to 175.5 mRNA copies / $\mu \mathrm{g}$ total RNA).

Correlation coefficients were also calculated to examine if changes in LDL receptor or HMG-CoA reductase mRNA concentrations were related to changes in markers for cholesterol synthesis and intestinal absorption. As shown in table 2, there was a positive trend between changes in LDL receptor mRNA concentrations with changes in cholesterol-standardized lathosterol concentrations ( $r=0.292 ; P=0.054)$ and a negative trend with changes in cholesterol-standardized campesterol concentrations ( $r=-0.285 ; P=0.061)$. These findings may indicate that subjects with the largest reduction in 
campesterol concentrations had the largest increase in cholesterol synthesis and $L D L$ receptor mRNA concentrations. There were no statistically significant relations between changes in HMG-CoA reductase mRNA with changes in serum LDL cholesterol concentrations ( $r=-0.095 ; P=0.541)$, changes in LDL receptor mRNA concentrations $(r=0.087 ; \mathrm{P}=0.576)$, or changes in serum cholesterol-standardized lathosterol $(r=0.018 ; P=0.908)$ or campesterol concentrations ( $r=-0.042 ; \mathrm{P}=0.789$ ).
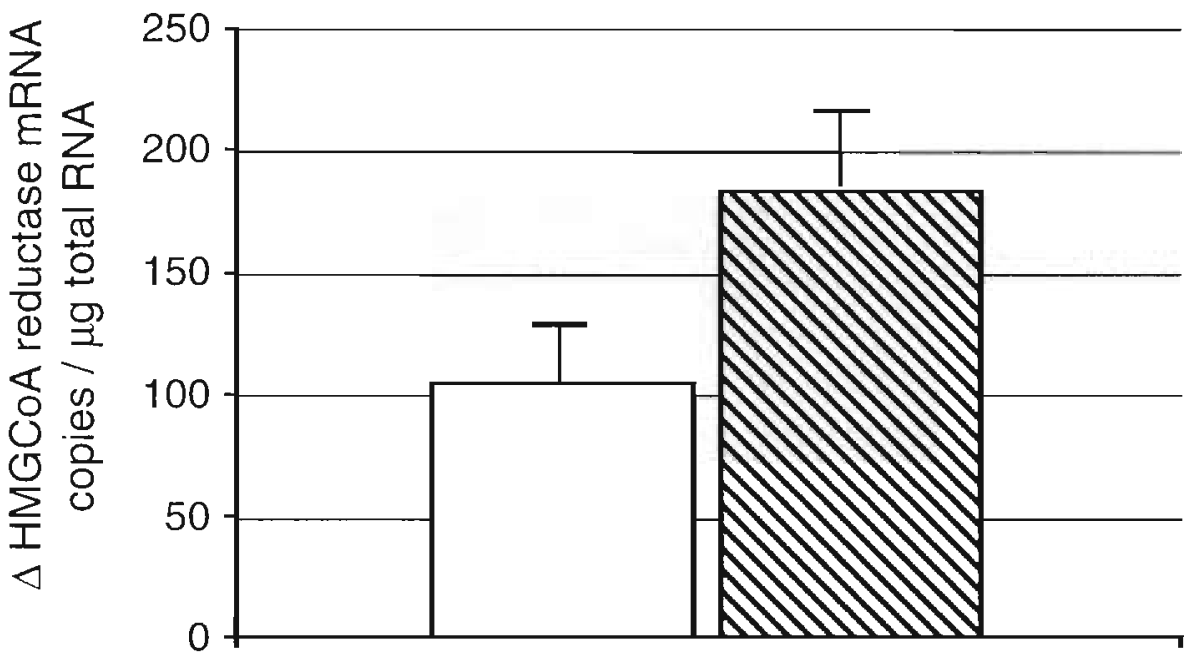

\section{Controls N Plant stanol esters}

Figure 2: Changes in the number of HMG-COA reductase mRNA copies / $\mu \mathrm{g}$ of mononuclear blood cells in the control group and the plant stanol ester group. Values are means $\pm \mathrm{SE}$.

\section{$L D L$ receptor cell-surface expression}

To examine whether changes in LDL receptor mRNA concentrations were translated into an increased number of LDL receptor molecules, we also determined the changes in LDL receptor cell-surface expression on mononuclear blood cells. As compared to changes in LDL receptor protein expression in the control group, consumption of plant stanol esters significantly increased LDL receptor protein levels in monocytes and T-lymphocytes by respectively $37 \%(P=0.003)$ and $25 \%(P=0.013)$, whereas the $13 \%$ higher 
expression in B-lymphocytes did not reach statistical significance $(P=0.419)$. The change in cell-surface LDL receptor protein expression in monocytes correlated with the change in LDL cholesterol $(r=-0.440 ; P<0.001)$, suggesting that the increased LDL receptor protein expression was functional (figure 3 ). For T-lymphocytes this correlation was also significant $(r=-0.307 ; P=0.018)$, whereas for B-lymphocytes no significant relation was found $(r=-0.018$; $P=0.898)$.

Table 2: Correlations between changes $(\Delta)$ in serum LDL cholesterol and cholesterolstandardized campesterol and lathosterol concentrations with changes in LDL receptor mANA and protein, and in HMG-COA reductase mRNA concentrations of mononuclear blood cells

\begin{tabular}{lccc}
\hline & $\Delta$ & $\Delta$ & $\Delta$ \\
& LDLr mRNA & LDLr protein & HMG-CoA mRNA \\
\hline$\Delta$ campesterol & $-0.285(0.060)$ & $-0.303(0.019)$ & $-0.042(0.789)$ \\
$\Delta$ Lathosterol & $0.292(0.054)$ & $0.275(0.035)$ & $0.018(0.908)$ \\
$\Delta$ LDL cholesterol & $-0.361(0.015)$ & $-0.440(<0.001)$ & $-0.095(0.541)$ \\
\hline
\end{tabular}

Values for 44 subjects (LDLr mRNA and HMG-CoA reductase mRNA) and 63 subjects (LDLr protein) are presented as correlation coefficients ( $P$-values).

\section{Discussion}

The LDL-cholesterol lowering effect of plant stanol esters has been shown in many human intervention studies (5). This effect is, at least partly, caused by a competition between cholesterol and plant stanols for incorporation into mixed micelles. The subsequent reduced solubility of cholesterol into the mixed micelles results in a decreased intestinal cholesterol absorption. Consequently, less cholesterol enters the circulation, which leads to an increase in cholesterol synthesis $(9,13)$ and a decrease in LDL synthesis (14). The underlying regulatory mechanisms of these two latter effects are, however, unknown. In the present study we therefore decided to examine changes in LDL receptor and HMG-CoA reductase mRNA concentrations during plant stanol ester consumption. Since mRNA concentrations do not necessarily reflect protein levels, we also analyzed changes in LDL receptor protein at the cellsurface of mononuclear blood cells. HMG-CoA reductase protein was not analyzed, but we have used serum cholesterol-standardized lathosterol concentrations as a functional marker for $\mathrm{HMG}-\mathrm{CoA}$ reductase activity instead. Cholesterol-standardized lathosterol is a validated marker for whole body 
cholesterol synthesis (15), that correlates with hepatic microsomal HMG-CoA reductase activity in humans (6).

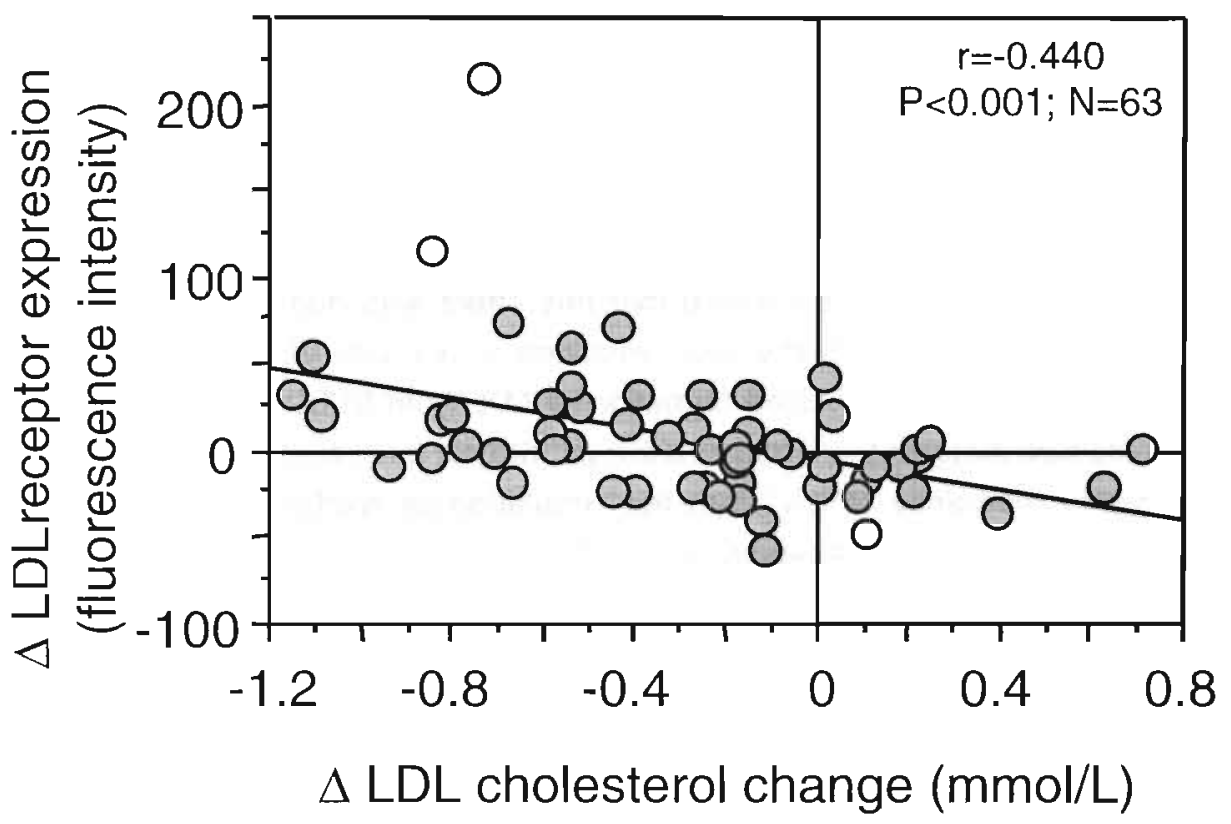

Figure 3: Relationship between changes in LDL receptor cell-surface protein in monocytes and serum LDL cholesterol concentrations.

We have now found that plant stanol ester consumption increased LDL receptor mRNA concentrations in mononuclear blood cells. In addition, LDL receptor protein concentrations on the surface of mononuclear blood cells were also increased, suggesting an increased translation of its mRNA. This increased protein expression was functional, since the observed changes in LDL cholesterol correlated negatively with the changes in cell-surface LDL receptor protein (figure 3 ). It is known that mononuclear cells are a heterogenous cell population and monocytes, when cultured in lipoprotein deficient serum, bind and degrade more ${ }^{125} \mathrm{I}$-LDL than lymphocytes do (16). Further, monocytes incorporate approximately 20 times more $\left[2 \cdot{ }^{14} \mathrm{C}\right]$ mevalonate into sterols than lymphocytes do (17). These finding suggest that cholesterol metabolism is more active in monocytes as compared to lymphocytes. In agreement with this, we found that at the end of the run-in period, LDL receptor expression on 
monocytes was two times higher as compared to T-lymphocytes and twelve times higher compared to B-lymphocytes. However, the relative increases in cell-surface LDL receptor protein expression after plant stanol ester consumption were similar in monocytes and T-lymphocytes. This suggests that - although monocytes showed higher values at baseline - both cell-types are equally responsive to diet-induced changes in LDL receptor expression. Blymphocytes, however, were hardly responsive to plant stanol ester-induced changes in LDL receptor expression.

Using radio labeled LDL, Gylling et al (14) have earlier shown that plant stanol ester consumption decreased LDL-production in non-insulin dependent diabetic men. It was speculated that this effect was due to a lower flux of intestinal cholesterol to the liver, resulting in a lower VLDL synthesis and subsequently into a reduced formation of LDL from VLDL and / or IDL. Our results now suggest that an alternative pathway is a lowered LDL formation via a higher clearance of IDL from the circulation as explained by the higher expression of the LDL receptor.

Gylling and coworkers further found a lowered production of IDL from VLDL (14). Since evidence for a specific VLDL receptor for the clearance of VLDL cholesterol in humans is scanty, it is debatable that the decreased IDL production is caused by an increased VLDL clearance. A more likely explanation may be a changed pathway for hepatic VLDL secretion. From in vitro studies with primary cells, Twisk et al (18) have concluded that a higher LDL receptor expression is related to an increased uptake of newly secreted apoB containing lipoprotein particles (nascent VLDL) and to an increased presecretory degradation of newly synthesized apoB. These pathways support the idea that the higher LDL receptor expression during plant stanol ester consumption indeed leads to a lower hepatic VLDL appearance into the circulation. In humans, however, VLDL production during plant stanol ester consumption has never been measured, but this certainly needs further study.

Plant stanol ester consumption not only upregulates LDL receptor expression, but also increases whole body cholesterol synthesis, as indicated by elevated serum cholesterol-standardized lathosterol concentrations. Changes in HMG-CoA reductase mRNA concentrations in mononuclear blood cells, however, did not reach statistical significance, despite a substantial increase of $34 \%$ in the plant stanol ester group. Also, changes in serum cholesterol-standardized lathosterol concentrations did not correlate with those 
in HMG-CoA reductase mRNA concentrations. This finding may suggest that HMG-CoA reductase activity is not only regulated at a transcriptional level, but that post-transcriptional steps are also important. The lack of correlation between changes in HMG-CoA reductase and cholesterol-standardized lathosterol concentrations further suggest that in man changes in HMG-CoA reductase mRNA do not necessarily reflect protein levels or activity. In rats it was indeed found that cholesterol feeding lowered HMG-CoA reductase expression at the level of translation and not at a trancriptional level $(19,20)$. Others, however, have reported in rats a clear correlation between HMG-CoA reductase mRNA and cholesterol synthesis after cholesterol feeding (21). These contradictory findings illustrate that the mechanisms regulating HMGCoA activity are complex and need further study.

In summary, in this study we have shown that plant stanol ester consumpton increases LDL receptor mRNA expression in human monocytes and T-lymphocytes. This higher LDL receptor mRNA expression is translated into a higher amount of cell-surface LDL receptor protein, which correlates with changes in serum LDL cholesterol. We therefore suggest that the increased $L D L$ receptor expression contributes to a lowered $L D L$ formation along the apoB cascade. The increase in HMG-CoA reductase activity, as shown by increased serum cholesterol-standardized serum lathosterol concentrations, may be only partly regulated at a transcriptional level. Although a positive relationship exists for LDL receptor and HMG-CoA reductase mRNA expression in mononuclear blood cells and the liver (11), it remains to be determined whether our results can be extrapolated to other tissues.

\section{References}

1. Brown MS, Goldstein JL. A receptor mediated pathway for cholesterol homeostasis. Science 1986;232:34-47

2. Brown MS, Goldstein JL. The SREBP pathway: regulation of cholesterol metabolism by proteolysis of a membrane-bound transcription factor. Cell 1997;89:331-340

3. Goldstein JL, Brown MS. Regulation of the mevalonate pathway. Nature 1990;343:425-430

4. Ness GC, Chambers CM. Feedback and hormonal regulation of hepatic 3 - hydroxy-3-methylglutaryl coenzyme $A$ reductase: the concept of cholesterol buffering capacity. Proc Soc Exp Biol Med 2000;224:8-19

5. Law M. Plant sterol and stanol margarines and health. BMJ 2000;320: 861-864

6. Björkhem /, Miettinen TA, Reihner $E$, Ewerth $S$, Angelin B, Einarsson $K$. Correlation between serum levels of some cholesterol precursors and activity of HMG-CoA reductase in 
human liver. J Lipid Res 1987;28:1137-1143,

7. Plat J, Mensink RP. Dietary plant stanol ester mixtures: effects on safety parameters and erythrocyte membrane fatty acid composition in non hypercholesterolemic subjects. Eur Heart J 1999; 1(Suppl):s58-s63

8. Plat J, Mensink RP. Vegetable oil based versus wood based stanol ester mixtures: effects on serum lipids and hemostatic factors in nonhypercholesterolemic subjects. Atherosclererosis 2000;148:101-112

9. Plat J, Mensink RP. Effects of diets enriched with two different plant stanol ester mixtures on plasma ubiquinol-10 and fat-soluble antioxidant concentrations. Metabolism 2001:50:520-529

10. Chomczinski $P$, Sacchi N. Single-step method of RNA isolation byacid guanidium thiocyanate-phenolchloroform extraction. Anal Biochem 1987:162:156-159

11. Powell EE, Kroon PA. Low density lipoprotein receptor and 3-hydroxy-3 methylglutaryl coenzyme $A$ reductase gene expression in human mononuclear leukocytes is regulated coordinately and parallels gene expression in human liver. J Clin Invest 1994:93:2168-2174

12. Statview (for the Macintosh) manual. Abacus Concepts, Statview Abacus Concepts inc Berkeley CA USA 1992

13. Gylling $H$, Puska $P$, Vartiainen $E$, Miettinen TA. Serum sterols during stanol ester feeding in a mildly hypercholesterolemic population. J Lipid Res 1999;40:593-600

14. Gylling $H$, Miettinen TA. Effects of inhibiting cholesterol absorption and synthesis on cholesterol and lipoprotein metabolism in hypercholesterolemic non-insulindependent diabetic men. J Lipid Res 1996;37:1776-1785

15. Kempen HJM, Glatz JFC, Gevers Leuven JA, Voort van der HA, Katan M.B. Serum lathosterol concentration is an indicator of whole- body cholesterol synthesis in humans. J Lipid Res 1988;29:1149-115

16. Chait A, Henze K, Mazzone T, Jensen $M$, Hammond $W$. Low density lipoprotein receptor activity in freshly isolated human blood monocytes and lymphocytes. Metabolism 1982;31:721-727

17. Fogelman AM, Seager J, Hokom M, Edwards PA. Separation of and cholesterol synthesis by human lymphocytes and monocytes. J Lipid Res 1979;20:379-388

18. Twisk J, Gillian-Daniel DL, Tebon A, Wang L, Barrett PHR, Attie AD. The role of the $L D L$ receptor in apolipoprotein B secretion. J Clin Invest 2000;105-521-532

19. Chambers CM, Ness GC. Dietary cholesterol regulates hepatic 3 hydroxy-3-methylglutaryl coenzyme A reductase gene expression in rats primarely at the level of translation. Arch Biochem Biophys 1998;354:317322

20. Ness GC, Keller RK, Pendleton LC. Feedback regulation of hepatic 3hydroxy-3-methylglutaryl-CoA reductase activity by dietery cholesterol is not due to altered mRNA levels. J Biol Chem 1991;266:1485414857

21. Jurevics $\mathrm{H}$, Hostettler J, Barrett $\mathrm{C}$, Morell P. Toews AD. Diurnal and 
dietary-induced changes in cholesterol synthesis correlate with levels of mRNA for HMG-CoA reductase. J Lipid Res 2000;42:1048-1053 


\section{Chapter 7}

Relationship of genetic variation in genes encoding apolipoprotein A-IV, scavenger receptor $\mathrm{BI}, \mathrm{HMG}-\mathrm{CoA}$ reductase, CETP, and apolipoprotein E with cholesterol metabolism and the response to plant stanol ester

consumption

Plat J, Mensink RP

Department of Human Biology, Maastricht University, The Netherlands

(submitted) 


\section{Abstract}

Differences in genetic constitution may affect cholesterol metabolism and responses to diet. Identification of common variations in genes related to dietary responsiveness is therefore an attractive goal to be able to prescribe individually tailored diets for the treatment of dyslipidemia. We have therefore examined relationships between serum lipids and lipoproteins, cholesterol-standardized campesterol and lathosterol concentrations with genetic variation, and the presence of a gene-diet interaction between plant stanol ester consumption. Candidate genes were apoA-IV, SR-BI, CETP, HMG-CoA reductase, and apoE. These relations were examined in 112 non-hypercholesterolemic subjects of whom 70 consumed for 8 weeks 3.8 to $4.0 \mathrm{~g}$ plant stanol esters a day.

At baseline, HDL concentrations of $1.56 \pm 0.36 \mathrm{mmol} / \mathrm{L}$ in SR-BI-2 allele carriers tended to be lower compared to the $1.72 \pm 0.42 \mathrm{mmol} / \mathrm{L}$ in SR-BI-1/1 subjects $(P=0.069)$. Cholesterol standardized lathosterol concentrations were also lower in the SR-BI-2 allele carriers $(P=0.002)$. Further, LDL cholesterol concentrations in apoE2 subjects, were lower compared to the LDL cholesterol concentration in apoE3 group $(P=0.002)$ and apoE4 subjects $(P<0.001)$. No significant differences between the polymorphisms and dietary responsiveness to plant stanol ester consumption could be found, which indicates that it is unlikely that one of the single polymorphisms analyzed in this study is a major factor in explaining the variation in serum LDL cholesterol responses. This suggests that all subjects who want to lower their cholesterol concentration, will benefit from plant stanol ester consumption, irrespective of their apoA-IV, SR-BI, HMG-CoA reductase, CETP or apoE genotype. 


\section{Introduction}

Well-controlled studies on the effects of dietary fatty acids and cholesterol on serum lipid and lipoprotein concentrations have shown that some people are more responsive to dietary changes than others (1) which may be due to differences in genetic background. Identification of common variations in genes related to dietary responsiveness is therefore an attractive goal to enable the prescription of individually tailored diets for the optimum treatment of dyslipidemia.

Probably the most frequently studied predisposing genetic factor to dietary responsiveness is the variation in the apolipoprotein $E$ (apoE) locus. ApoE3 is the most common allele, whereas the alleles E2 and E4 are less prevalent. ApoE genotype is associated with differences in fasting (2) and postprandial (3) serum cholesterol and triglyceride concentrations. These relationships have been explained by effects of apoE phenotype on intestinal cholesterol absorption (4) and affinity for apoE binding receptors (5). Studies on apoE genotype-diet interactions, however, are far from conclusive (6-11).

Except by fatty acids and cholesterol, serum lipid and lipoproteins are also influenced by other dietary components such as plant stanol esters. These compounds lower intestinal cholesterol absorption (12) and it has therefore been suggested that apoE genotype may affect the hypocholesterolemic response of plant stanol esters (13). We, however, could not find a statistically significant effect of apoE genotype on LDL cholesterol reductions during plant stanol ester consumption, although changes were less pronounced in apoE2 subjects than in apoE3 and E4 subjects (14). Except for effects on cholesterol absorption, plant stanol ester consumption affects other aspects of cholesterol metabolism as well $(15,16)$. Therefore, it would be interesting to examine if polymorphisms in other genes involved in lipid and lipoprotein metabolism are related to a subject's response to plant stanol ester consumption.

The aim of this study was now two-fold. At first we have examined relationships between serum lipids and lipoproteins, cholesterol-standardized campesterol concentrations - a marker for cholesterol absorption (17) - and cholesterol-standardized lathosterol concentrations - a marker for cholesterol synthesis $(17,18)$ - with genetic variations in selected gene loci. Secondly, we have analyzed the presence of a gene-diet interaction between plant stanol ester consumption with the same polymorphisms. Besides apoE, the selected candidate genes were apolipoprotein A-IV (apoA-IV), scavenger receptor-BI (SR-BI), HMGCoA reductase, and cholesterol ester transfer protein (CETP). 


\section{Methods}

\section{Subjects, diets and design}

Characteristics of the population have been described in detail before (14). In short, 41 males and 71 females from Maastricht and surroundings participated. They were all apparently healthy, non-hypercholesterolemic and normotensive. Their body mass index was $23 \pm 2.8 \mathrm{~kg} / \mathrm{m}^{2}$ (mean $\pm S D$ ) and their age was $33 \pm 16$ years. All subjects were asked to replace their habitual margarine and baking fat for a low erucic acid rapeseed oil (LEAR) based margarine and shortening during a four week run-in period. Subjects were then randomly allocated to one of the three treatment groups, stratified for sex and age. For the next eight weeks, the control group ( $n=42)$ continued to use the rapeseed-oil based margarine and shortening, while the second and the third group used the same margarine and shortening to which a vegetable oil based $(n=36)$ or a wood based $(n=34)$ plant stanol ester mixture was added. Vegetable oil derived plant stanols contain about $68 \%$ sitostanol and $32 \%$ campestanol. For wood-based plant stanols, these values are $92 \%$ and $8 \%$ respectively. Details on the production of plant stanol esters as well as on the composition of the experimental products have been described in detail elsewhere (19). The participants used the margarine at breakfast and lunch, and the shortening at diner. The minimal daily margarine intake was $20 \mathrm{~g}$, whereas at least $10 \mathrm{~g}$ shortening a day had to be eaten. This resulted in additional daily intake of 3.8 g plant stanols as its fatty acid ester in the vegetable oil based group and of $4.0 \mathrm{~g}$ in the wood based group. Estimated daily intake of plant stanols in the control group was less than $0.1 \mathrm{~g}$. All margarines and shortenings were prepared by the RAISIO GROUP, Raisio, Finland.

Energy and nutrient intakes were estimated by filling in food frequently lists at the end of the run-in and the experimental periods. As reported before, energy intake and the proportions of energy from carbohydrates, fatty acids, and protein, as well as cholesterol intake, did not change during the study (14). Body weight was recorded every week and did not change during the study. 


\section{Blood sampling and analysis}

\section{Blood sampling and DNA isolation}

At the end of the run-in period (weeks 3 and 4), as well as at the end of the experimental period (weeks 11 and 12), blood was sampled after an overnight fast. Subjects abstained from drinking alcohol the day preceding and from smoking the morning before blood sampling. Blood was drawn in a $10 \mathrm{ml}$ clotting tube to obtain serum, which was prepared by centrifugation at $2000 \times \mathrm{g}$ for thirty minutes at 4 " $\mathrm{C}$, minimally one hour after venipuncture. Serum aliquots were stored directly at $80^{\circ} \mathrm{C}$ to determine at the end of the study serum lipids and lipoproteins, and plant sterols and cholesterol precursor concentrations. At the start of the study (day 1) blood was sampled in a $10 \mathrm{ml}$ EDTA tube (Monoject sterile, Sherwood Medical, Ballymoney, North Ireland), which was used for DNA isolation. Leukocytes were isolated from EDTA anticoagulated whole blood using lysis buffer (155 mM NH $\mathrm{KHCO}_{3}, 0.1 \mathrm{mM} \mathrm{Na}$ EDTA), followed by centrifugation. DNA from the leucocyte pellet was then isolated using the QIAamp Blood Kit (Westburg bv Leusden, The Netherlands)

Analysis of apoA-IV, SR-BI, CETP, apoE RFLPs and HMG-CoA reductase (TTA)n VNTR polymorphism

Genotyping was performed by analysis of restriction fragment length polymorphisms (RFLPS) (apoA-IV, SR-BI, CETP, and apoE) or by analysis of the variable number of tandem repeats (VNTR) (HMG-CoA reductase). For this, DNA was amplified in a Thermolyne Amplitronß) II PCR apparatus (Barnstead, Thermolyne Corporation, Dubuque, USA).

Genotyping for the apoA-IV GIn ${ }^{360} \rightarrow$ His polymorphism and the $\mathrm{Thr}^{347} \rightarrow \mathrm{Ser}$ was performed by $P v u I I$ and Hinf I restriction isotyping, as described by Hixon et al. (20). Both Pvu II and Hinf I digested apo-A-IV DNA fragments were electrophoresed for 1.5 hours at $125 \mathrm{~V}$ on a $3 \%$ agarose gel (Gibco Ultrapure) containing gelstar (Sanvertech, Heerhugowaard, The Netherlands). DNA fragments were visualized by UV at $312 \mathrm{~nm}$ using a Wratten gelatine filter on a VDS Imagemaster (Pharmacia Biotech, San Francisco, USA). For the apoA-IV GIn G $^{360} \rightarrow$ His polymorphism, a glutamine at position 360 is defined as apoA-IV allele-1, while a glutamine to histidine substitution at position 360 is defined as allele-2 (20)

For SR-BI genotyping, each reaction tube contained approximately $0.5 \mu \mathrm{g}$ DNA, 25 pmol of each primer (sequences of primers in reference 21), 2 units Taq 
polymerase (Pharmacia Biotech, Roosendaal, The Netherlands), $0.2 \mathrm{mM}$ of each dNTP (Pharmacia Biotech, Roosendaal, The Netherlands), and $1.5 \mathrm{mM} \mathrm{MgCl}_{2}$ in a final volume of $50 \mu \mathrm{L}$. Before amplification, each sample was denaturated for 5 minutes at $95^{\circ} \mathrm{C}$. Thirty cycles, consisting of 45 seconds at $95^{\circ} \mathrm{C}$ (denaturation), 30 seconds at $66^{\circ} \mathrm{C}$ (primer annealing), and 1 minute at $72^{\circ} \mathrm{C}$ (extension) were performed, followed by 7 minutes elongation at $72^{\circ} \mathrm{C}$. Next, 5 units Haelll (Promega Corporation, Madison, USA) were used to digest $35 \mu \mathrm{L}$ of the PCR reaction product $\left(1\right.$ hour at $37^{\circ} \mathrm{C}$ ). The digested SR-BI DNA samples were loaded on a $5 \%$ agarose gel (Gibco Ultrapure), electrophoresed for 1.5 hours at 125V and DNA fragments were visualized as decribed for apoA-IV polymorphism. Carriers of the SR-BI-2 allele (SR-BI-1/2 and SR-BI-2/2) were combined and compared versus homozygous SR-BI-1/1 subjects.

Determination of CETP Taq IB polymorphism was essentially carried out according procedures described by Kuivenhoven et al (22). However, the annealing temperature used was $60^{\circ} \mathrm{C}$, the Taq IB digestion temperature was $65^{\circ} \mathrm{C}$, and incubation lasted 2 hours. Taq IB digested CETP DNA fragments were electrophoresed for 90 minutes at $125 \mathrm{~V}$ on a $1.5 \%$ agarose gel (Gibco Ultrapure) and DNA fragments were visualized as described above. Subjects were identified as CETP-1/1, $-1 / 2$ or $-2 / 2$ (22).

ApoE genotyping was performed as described before (14). Subjects were divided into the apoE2 group (E2/2, E2/3 and E2/4), the E3 group (E3/3) or the E4 group (E3/4 and E4/4) (4).

The VNTR region of the HMG-CoA reductase gene was amplified as described by Zuliani and Hobbs (23) with some minor modifications. $0.3 \mu \mathrm{g}$ DNA was denaturated for 5 minutes at $95^{\circ} \mathrm{C}$. After adding $2 \mathrm{U}$ Taq polymerase (Pharmacia Biotech, Roosendaal, The Netherlands) thirty-three cycles, each consisting of 15 seconds at $95^{\circ} \mathrm{C}$ (denaturation) and 25 seconds at $58^{\circ} \mathrm{C}$ (primer annealing) were performed, followed by 5 minutes elongation at $72^{\circ} \mathrm{C}$. Final concentrations of components in the PCR mixture were $0.2 \mathrm{mM}$ dNTP's (Pharmacia Biotech, Roosendaal, The Netherlands), $1.5 \mathrm{mM} \mathrm{MgCl}_{2}$ and $25 \mathrm{pmol}$ of each primer GZ-1 and GZ-2 in a final volume of $25 \mu \mathrm{L}$. The GZ-1 primer was labeled with the fluorophore Cy-5. Next, Cy-5 labeled DNA fragments were size separated on an $8 \%$ polyacrylamide gel run on a ALF express sequencer (Pharmacia Biotech, San Francisco, USA). Peak detection was carried out using fragment analyzer software, as supplied by the manufacturer (Pharmacia Biotech, Roosendaal, The Netherlands). Size of the PCR fragments was determined from standard curves 
using a Cy-5 labeled sizer (Pharmacia Biotech, Roosendaal, The Netherlands). Subjects were divided into subgroups based on the number of repeats.

\section{Biochemical analyses}

Serum total cholesterol, HDL-cholesterol and triacylglycerol concentrations were analyzed by enzymatic reactions using commercially available assays, as described (14). LDL cholesterol was calculated with the Friedewald-equation (24).

Campesterol and lathosterol concentrations in samples from week 4 and 12 , were analyzed by gas liquid chromatography (GLC) as described before (25) and standardized for total cholesterol concentrations:

\section{Statistics}

For lipids and lipoproteins, concentrations of weeks 3 and 4 (run-in period) and from weeks 11 and 12 (experimental period) were averaged before data analysis. Values are reported as means $\pm S D$.

Differences between genotypes concerning lipid, lipoprotein, and cholesterol-standardized campesterol and lathosterol concentrations at the end of the run-in period were examined with ANOVA ( $\alpha$ 0.05). In view of their well-known relationships with cholesterol metabolism, BMI, gender and age were considered as potential confounders. As gender was not equally distributed over the three different apoE-groups and BMI did differ between the two apoA-IV GIn ${ }^{360} \rightarrow$ His groups, relationships for these two polymorphisms were corrected for gender and BMI, respectively.

Changes upon plant stanol ester feeding were calculated for each subject as the difference between values of the experimental period and run-in period. Since the responses for all lipid parameters were comparable between the two experimental groups $(14,25)$, we have combined the results of the vegetable oil based and the wood based plant stanol esters groups into one experimental group $(n=70)$. The effects of genotype on the plant stanol ester induced responses was examined with ANOVA ( $\alpha$. 0.05). As plant stanol esters did not affect serum HDL cholesterol and triacylglycerol concentrations in the population as a whole, we have not reported the possible interaction between genotype and the responses in HDL cholesterol and triacylglycerol. All statistical analyses were performed with Statview $4.5(26)$. 


\section{Results}

Frequency distributions of all genotypes are shown in table 1. For all polymorphisms, the genotype distributions were in accordance with HardyWeinberg equilibrium, while the various polymorphisms were not related to each other.

Table 1: Frequency distribution of the different genotypes in loci encoding apoA-IV, SR-BI, HMG-COA reductase, CETP, and apoE

\begin{tabular}{|c|c|c|c|}
\hline & All & Control group & Experimental group \\
\hline All & 112 & 42 & 70 \\
\hline \multicolumn{4}{|c|}{ ApoA-IV GIn $n^{360} \rightarrow$ His } \\
\hline$A-I V-1 / 1$ & $97(86.6)$ & $36(85.7)$ & $61(87.1)$ \\
\hline$A-I V-1 / 2$ & $15(13.4)$ & $6(14.3)$ & $9(12.9)$ \\
\hline \multicolumn{4}{|c|}{ ApoA-IV Thr $r^{347} \rightarrow$ Ser } \\
\hline$A-I V-T / T$ & $72(64.3)$ & $22(52.4)$ & $50(71.4)$ \\
\hline$A-I V-S / T$ & $34(30.4)$ & $16(38.1)$ & $18(25.7)$ \\
\hline$A-I V-S / S$ & $6(5.4)$ & $4(9.5)$ & $2(2.9)$ \\
\hline \multicolumn{4}{|l|}{ SR-BI Hae III } \\
\hline $1 / 1$ & $25(22.3)$ & $12(28.6)$ & $13(18.6)$ \\
\hline $1 / 2 \& 2 / 2$ & $87(77.7)$ & $30(71.4)$ & $57(81.4)$ \\
\hline \multicolumn{4}{|c|}{ HMG-COA reductase VNTR } \\
\hline $10 / 10$ & $35(31.3)$ & $15(23.8)$ & $20(28.6)$ \\
\hline $10 />10$ & $53(47.3)$ & $21(50.0)$ & $32(45.7)$ \\
\hline$>10 />10$ & $24(21.4)$ & $6(14.3)$ & $18(25.7)$ \\
\hline \multicolumn{4}{|l|}{ CETP Taq IB } \\
\hline $1 / 1$ & $42(37.5)$ & $17(40.5)$ & $25(35.7)$ \\
\hline $1 / 2$ & $52(46.4)$ & $18(42.9)$ & $34(48.6)$ \\
\hline $2 / 2$ & $18(16.1)$ & $7(16.7)$ & $11(15.7)$ \\
\hline \multicolumn{4}{|l|}{ ApoE: } \\
\hline E2 & $12(10.7)$ & $1(2.4)$ & $11(15.7)$ \\
\hline E3 & $72(64.3)$ & $31(73.8)$ & $41(58.6)$ \\
\hline E4 & $28(25.0)$ & $10(23.8)$ & $18(25.7)$ \\
\hline
\end{tabular}

Numbers are absolute frequencies (relative frequencies between parentheses)

ApoA-IV-1: codon 360 (exon 3) is glutamine; apoA-IV-2: codon 360 is histidine; ApoA-IV-T: codon 347 (exon 3) is threonine; ApoA-IV-S: codon 347 is serine; SR-Bl-1 versus SR-BI-2: silent base change at codon 350; HMG-CoA reductase 10: 10 repeats; HMG-CoA reductase $>10$ : 11 to 16 repeats; CETP-1 versus CETP-2: silent base change at position 227 bp in intron I; ApoE2: codons 112 and 158 are cysteine; ApoE3: codon 112 is cysteine and codon 158 is arginine; ApoE4: codon 112 and 158 are arginine. "ApoE2: E2/2 + E2/3; ApoE3: E3/3; ApoE4: E3/4 + E4/4. 
At the end of the four week run-in period, serum concentrations of total cholesterol were $4.96 \pm 0.80 \mathrm{mmol} / \mathrm{L}$. Concentrations of serum LDL cholesterol, HDL cholesterol. triacylglycerol, and of cholesterol-standardized campesterol, and lathosterol are given in table 2 .

In the 70 subjects, who received plant stanol esters, LDL cholesterol decreased with $0.42 \pm 0.31 \mathrm{mmol} / \mathrm{L}$, which was highly significant $(P<0.001)$ from the change of $-0.06 \pm 0.36 \mathrm{mmol} / \mathrm{L}$ in the control group (table 3 ). Serum HDL cholesterol and triacylglycerol concentrations did not change. Plant stanol ester consumption decreased cholesterol absorption and increased cholesterol synthesis, as indicated by the reduction in serum cholesterol-standardized campesterol and the increase in serum cholesterol-standardized lathosterol concentrations, respectively (table 3).

Apolipoprotein A-IV (Apo A-IV) GIn ${ }^{360} \rightarrow$ His and $T h r^{347} \rightarrow$ Ser polymorphism

Neither the apoA-IV GIn ${ }^{360} \rightarrow$ His polymorphism nor the apoA-IV $\mathrm{Thr}^{347} \rightarrow$ Ser polymorphism was associated with any of the lipid parameters at the end of the runin period. These two apoA-IV polymorphisms also were not significantly associated with the responses to plant stanol ester consumption (tables 2 and 3 ).

\section{Scavenger receptor BI (SR-BI) Haelll polymorphism}

At the end of the run-in period, HDL cholesterol concentrations in carriers of the SR-BI-2 allele were $1.56 \pm 0.36 \mathrm{mmol} / \mathrm{L}$, which tended to be lower as compared to the concentration of $1.72 \pm 0.42 \mathrm{mmol} / \mathrm{L}$ in the $\mathrm{SR}-\mathrm{Bl}-1 / 1$ group $(P=0.063)$. Cholesterol-standardized lathosterol concentrations were significantly lower in the SR-BI-2 allele carriers $\left(92.3 \pm 28.310^{2} \times \mu \mathrm{mol} / \mathrm{mmol}\right.$ cholesterol) compared to the SR$\mathrm{Bl}-1 / 1$ group $\left(114.8 \pm 43.810^{2} \times \mu \mathrm{mol} / \mathrm{mmol}\right.$ cholesterol) $(\mathrm{P}=0.003)$ (table 2). No differences in serum LDL cholesterol, triacylglycerol, and cholesterol-standardized campesterol concentrations were present. This SR-BI polymorphism was not associated with the response to plant stanol ester consumption (table 3 ). There was only a tendency of a smaller increase in cholesterol-standardized lathosterol concentrations in the SR-BI-2 allele carriers $(P=0.081)$.

\section{HMG-CoA reductase VNTR polymorphism}

The frequency of the different numbers of the (TTA)n repeat is shown in figure 1. This frequency distribution suggests that 10 repeats are the most common and can be considered as wild-type. We have therefore divided the subjects into three categories. The first group had two alleles with 10 repeats, the second group one 
allele, and the third group had two alleles with more than 10 repeats. As shown in table 2, no differences in any of the lipid parameters analyzed were evident between the three groups at the end of the run-in period.

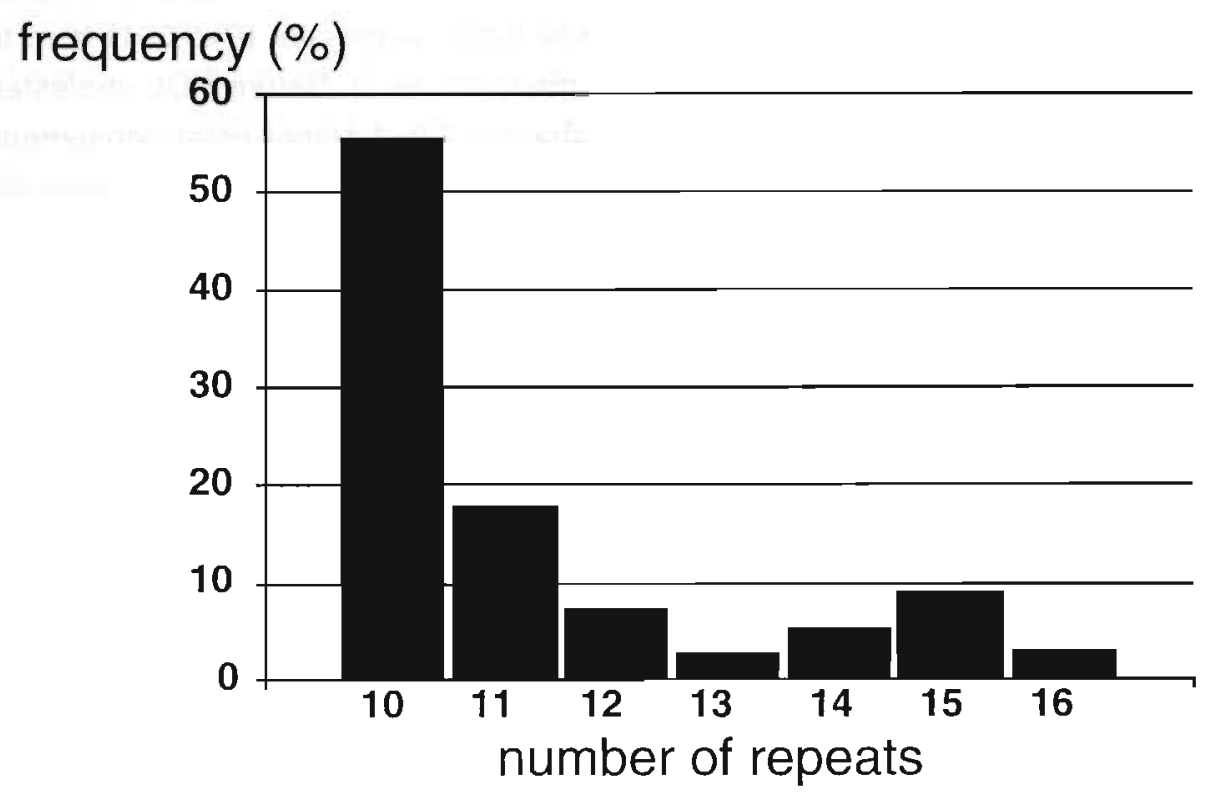

Figure 1: Frequency distribution of the tandem-repeat numbers in the HMG-CoA reductase gene.

The associations between HMG-CoA reductase VNTR genotype and the changes in LDL cholesterol, campesterol and lathosterol tended to be 'repeat-dosedependent' (table 3). However, only the difference in response in serum cholesterolstandardized campesterol concentrations between the $10 / 10$ group $(-122.7 \pm 68.9)$ and the $>10 />10$ group $(-85.5 \pm 24.9 ; P=0.087$ versus $10 / 10)$ nearly reach statistical significance. 
Table 2: Relationships between various genefic polymorphisms in proteins involved in cholesterol metabolism with serum lipoprotein, and cholesterol-standardized campesterol and lathosterol concentrations

\begin{tabular}{cccccc}
\hline & LDL-C & HDL-C & TG & Campesterol & Lathosterol \\
\hline All & $2.95 \pm 0.78$ & $1.59 \pm 0.38$ & $0.92 \pm 0.52$ & $303.4 \pm 98.0$ & $97.3 \pm 33.4$
\end{tabular}

ApoA-IV GIn $\mathrm{I}^{360} \rightarrow \mathrm{His}$

$\begin{array}{llllll}\text { A-IV }-1 / 1 & 2.96 \pm 0.78 & 1.59 \pm 0.37 & 0.93 \pm 0.50 & 307.8 \pm 101.3 & 97.0 \pm 32.5 \\ \text { A-IV-1/2 } & 2.86 \pm 0.81 & 1.64 \pm 0.43 & 0.85 \pm 0.60 & 275.1 \pm 69.2 & 99.4 \pm 41.0\end{array}$
ApoA-IV Thr ${ }^{347} \rightarrow$ Ser
A-IV-TIT
$2.99 \pm 0.77$
$1.60 \pm 0.40$
$0.93 \pm 0.56$
$304.4 \pm 99.6$
$99.0 \pm 37.5$
A-IV-S/T
$2.85 \pm 0.80$
$1.58 \pm 0.33$
$0.88 \pm 0.39$
$309.1 \pm 101.5$
$96.0 \pm 25.1$
A-IV-S/S
$2.96 \pm 0.81$
$1.57 \pm 0.42 \quad 1.07 \pm 0.64$
$259.0 \pm 39.9$
$84.9 \pm 23.1$

SR-BI Hae III

$\begin{array}{lllllr}1 / 1 & 2.87 \pm 0.70 & 1.72 \pm 0.42 & 0.97 \pm 0.56 & 289.6 \pm 71.6 & 114.8 \pm 43.8 \\ 1 / 2 \& 2 / 2 & 2.97 \pm 0.80 & 1.56 \pm 0.36 & 0.90 \pm 0.50 & 307.4 \pm 104.4 & 92.3 \pm 28.3^{3}\end{array}$

HMG-CoA reductase VNTR

$\begin{array}{llllll}10 / 10 & 2.81 \pm 0.63 & 1.69 \pm 0.39 & 0.83 \pm 0.36 & 316.6 \pm 98.3 & 101.4 \pm 36.8 \\ 10 />10 & 3.06 \pm 0.78 & 1.54 \pm 0.37 & 0.98 \pm 0.58 & 311.2 \pm 105.8 & 94.1 \pm 30.1 \\ >10 />10 & 2.90 \pm 0.96 & 1.58 \pm 0.38 & 0.93 \pm 0.56 & 266.8 \pm 70.6 & 98.5 \pm 36.5\end{array}$

CETP Taq IB

$\begin{array}{lllllr}1 / 1 & 3.09 \pm 0.92 & 1.51 \pm 0.34 & 0.98 \pm 0.63 & 285.3 \pm 86.1 & 92.4 \pm 23.2 \\ 1 / 2 & 2.88 \pm 0.66 & 1.67 \pm 0.40 & 0.88 \pm 0.45 & 318.4 \pm 109.8 & 104.6 \pm 40.5 \\ 2 / 2 & 2.82 \pm 0.73 & 1.58 \pm 0.35 & 0.89 \pm 0.40 & 302.1 \pm 84.5 & 87.9 \pm 28.3\end{array}$

apoE

\begin{tabular}{llllll} 
E2 & $2.25 \pm 0.63$ & $1.87 \pm 0.43$ & $1.02 \pm 0.92$ & $299.4 \pm 127.2$ & $91.6 \pm 24.4$ \\
E3 & $2.97 \pm 0.77^{\circ}$ & $1.56 \pm 0.37$ & $0.91 \pm 0.42$ & $305.0 \pm 94.4$ & $99.7 \pm 34.0$ \\
E4 & $3.18 \pm 0.72^{\circ}$ & $1.56 \pm 0.35$ & $0.91 \pm 0.52$ & $301.1 \pm 97.2$ & $93.6 \pm 35.9$ \\
\hline
\end{tabular}

All values are means $+S D$ and were analyzed after a four-week period consumption of rapeseed oil based margarine and shortening. LDL-C: LDL cholesterol (mmol/L), HDL-C: HDL cholesterol (mmol/L), TG: triacylglycerol (mmol/L), campesterol: cholesterol-standardized campesterol concentrations $\left(10^{2} \times \mu \mathrm{mol} / \mathrm{mmol}\right.$ cholesterol), lathosterol: cholesterol-standardized lathosterol concentrations (10 xumol/mmol cholesterol). For polymorphism nomenclature see table 1.

" SR-BI 1/1 versus SR-BI 1/2 \& 2/2 $(P<0.05)$

- ApoE3 versus ApoE2 $(P<0.01)$

CApoE4 versus ApoE2 $(P<0.001)$ 
Cholesteryl ester transfer protein (CETP) Taq IB polymorphism

Like in other studies (22), carriers of the CETP-1 allele had lower HDL cholesterol concentrations, although in our study differences in lipid parameters never reached statistical significance.

After plant stanol ester consumption the reduction in cholesterol absorption was comparable in all subjects. The compensatory increase in cholesterol synthesis, however, was larger in the CETP-2/2 subjects as compared to both CETP-1/1 $(P=0.039)$ and CETP-1/2 subjects $(P=0.003)$. As shown in table 3 , there was a tendency to a higher reduction in $L D L$ cholesterol of $-0.47 \pm 0.35 \mathrm{mmol} / \mathrm{L}$ in the CETP-1/1 subjects compared to the $-0.31 \pm 0.34 \mathrm{mmol} / \mathrm{L}$ reduction in CETP $2 / 2$ subjects. This difference, however, did not reach significance $(P=0.123)$.

Apolipoprotein E (apoE) polymorphism

At the end of the run-in period, mean LDL cholesterol concentrations were $2.25 \pm 0.63 \mathrm{mmol} / \mathrm{L}$ in the apoE2 group, which was significantly lower compared to the $\mathrm{LDL}$ cholesterol concentration of $2.97 \pm 0.77 \mathrm{mmol} / \mathrm{L}$ in the apoE3 group $(\mathrm{P}=0.002)$ and of $3.18 \pm 0.72 \mathrm{mmol} / \mathrm{L}$ in the apoE4 group $(\mathrm{P}<0.001)$. Differences between the apoE3 and E4 group did not reach significance $(P=0.218)$. No significant associations of apoE genotype were found with other variables.

Table 3 shows that the LDL cholesterol response in the plant stanol ester group was not significantly different between the apoE2, apoE3 and apoE4 subjects. The reduction of $-0.31 \pm 0.29 \mathrm{mmolL}$ in the apoE2 group tended to smaller than the decrease of $-0.49 \pm 0.30 \mathrm{mmolL}$ in the apoE 4 group $(P=0.082)$.

\section{Discussion}

Differences in genetic constitution of proteins involved in cholesterol absorption and in lipid and lipoprotein metabolism may interfere with the response to diet. Therefore, we have in this study first examined whether we could find associations between polymorphisms in the apoA-IV, SR-BI, HMG-CoA reductase, CETP, and apoE genes with serum lipid and lipoprotein concentrations and markers for cholesterol absorption and synthesis. Secondly we have tried to find a gene-diet interaction between plant stanol ester consumption - which are known to lower intestinal cholesterol absorption and increase cholesterol synthesis - and the same genetic polymorphisms. 
Table 3: Changes in serum LDL cholesterol and cholesterol standardized campesterol and lathosterol concentrations according genetic polymorphisms in various proteins involved in cholesterol metabolism during plant stanol ester intervention

\begin{tabular}{|c|c|c|c|}
\hline & LDL-C & Campesterol & Lathosterol \\
\hline \multicolumn{4}{|l|}{ All } \\
\hline Controls & $-0.06 \pm 0.36$ & $-5.9 \pm 39.2$ & $0.5 \pm 19.5$ \\
\hline Stanol esters & $-0.42+0.31^{a}$ & $-103.1 \pm 70.6^{a}$ & $17.4 \pm 22.2^{a}$ \\
\hline \multicolumn{4}{|c|}{ ApoA-IV GIn $n^{360} \rightarrow$ His } \\
\hline$A-I V-1 / 1$ & $-0.41 \pm 0.31$ & $-104.1 \pm 73.3$ & $16.7 \pm 22.7$ \\
\hline$A-I V-1 / 2$ & $-0.44 \pm 0.34$ & $-96.2 \pm 51.4$ & $22.2 \pm 18.7$ \\
\hline \multicolumn{4}{|c|}{ ApoA-IV Thr $r^{347} \rightarrow$ Ser } \\
\hline$A-I V-T / T$ & $-0.43 \pm 0.34$ & $-102.6 \pm 69.7$ & $16.6 \pm 21.3$ \\
\hline A-IV-S/T & $-0.40 \pm 0.25$ & $-109.0 \pm 77.4$ & $19.3 \pm 26.0$ \\
\hline A-IV-S/S & $-0.33 \pm 0.08$ & $-63.9 \pm 2.6$ & $19.0 \pm 8.9$ \\
\hline \multicolumn{4}{|l|}{ SR-BI Hae III } \\
\hline $1 / 1$ & $-0.44 \pm 0.34$ & $-109.1 \pm 48.8$ & $27.1 \pm 18.1$ \\
\hline $1 / 2 \& 2 / 2$ & $-0.41 \pm 0.31$ & $-101.8 \pm 75.0$ & $15.2 \pm 22.5$ \\
\hline \multicolumn{4}{|c|}{ HMG-CoA reductase VNTR } \\
\hline $10 / 10$ & $-0.47 \pm 0.28$ & $-122.7 \pm 68.9$ & $13.2 \pm 20.4$ \\
\hline $10 />10$ & $-0.41 \pm 0.30$ & $-100.7 \pm 86.1$ & $17.8 \pm 25.7$ \\
\hline$>10 />10$ & $-0.38 \pm 0.37$ & $-85.8 \pm 24.9$ & $21.2 \pm 17.0$ \\
\hline \multicolumn{4}{|l|}{ CETP Taq IB } \\
\hline $1 / 1$ & $-0.47 \pm 0.35$ & $-91.3 \pm 62.5$ & $18.5 \pm 17.3$ \\
\hline $1 / 2$ & $-0.41 \pm 0.27$ & $-118.0 \pm 81.2$ & $11.5 \pm 22.7$ \\
\hline $2 / 2$ & $-0.31 \pm 0.34$ & $-84.2 \pm 42.1$ & $33.1 \pm 23.9^{b, c}$ \\
\hline \multicolumn{4}{|l|}{ apoE } \\
\hline $\mathrm{E} 2$ & $-0.31 \pm 0.29$ & $-123.4 \pm 103.8$ & $27.1 \pm 20.7$ \\
\hline E3 & $-0.41 \pm 0.32$ & $-102.5 \pm 70.3$ & $12.2 \pm 21.6^{d}$ \\
\hline E4 & $-0.49 \pm 0.30$ & $-92.2 \pm 43.0$ & $23.1 \pm 22.0$ \\
\hline
\end{tabular}

Values are means $\pm \mathrm{SD}$. Changes in all parameters were calculated as the difference between values at the end of the run-in period (week $3+4$ ) and the experimental period (week 11+12). LDL-C: LDL cholesterol (mmol/L), campesterol: cholesterol-standardized campesterol concentrations $\left(10^{2} x \mu \mathrm{mol} / \mathrm{mmol}\right.$ cholesterol), lathosterol: cholesterol-standardized lathosterol concentrations $\left(10^{2} \mathrm{x \mu mol} / \mathrm{mmol}\right.$ cholesterol). For polymorphism nomenclature see table 1.

${ }^{2}$ Controls (all) versus stanol esters (alt) $(P<0.001)$

${ }^{b}$ CETP $2 / 2$ subjects versus CETP $1 / 2$ subjects $(P<0.01)$

${ }^{c}$ CETP $2 / 2$ subjects versus CETP $1 / 1$ subjects $(P<0.05)$

a apoE3 subjects versus apoE2 subjects $(P<0.05)$ 


\section{Apolipoprotein A-IV (Apo A-IV) Gin ${ }^{360} \rightarrow$ His and $\mathrm{Th}^{347} \rightarrow$ Ser polymorphism}

Heterogenicity of the apoA-IV gene locus at codon 360 may attenuate the hypercholesterolemic response to short term ingestion of a high cholesterol diet (27). These results, however, could not be confirmed in a recent carefully controlled study (28). Our results also suggest that there is no clear effect of the apoA-IV $\mathrm{Gln}^{360} \rightarrow$ His polymorphism on the plant stanol ester-induced changes in cholesterol metabolism. Moreover, there is no clear mechanism to explain the postulated association and the significance of this polymorphism as related to the hypocholesterolemic response may not be as strong as suggested (27). Also for heterogenicity at codon 347 no association with cholesterol metabolism was found, which was consistent with earlier findings (29).

\section{Scavenger receptor BI (SA-BI) Haelll polymorphism}

The scavenger receptor class B type I (SR-BI) was originally identified as the putative HDL receptor (30). Our results now suggest that in our population of nonhypercholesterolemic subjects, serum HDL cholesterol concentrations are lower in carriers of the SR-BI-2 allele compared to homozygous SR-BI-1/1 subjects. Cholesterol synthesis was also decreased in subjects carrying the SR-BI-2 allele, as indicated by the lower cholesterol-standardized lathosterol concentrations. Overexpression of SR-BI in the liver markedly reduced plasma HDL cholesteryl ester concentrations, while biliary cholesterol excretion increased (31). A high biliary cholesterol excretion is related with a high hepatic cholesterol content and a low endogenous cholesterol synthesis (32). It would therefore be interesting to examine if the lower HDL cholesterol and the lower endogenous cholesterol synthesis in SR-BI-2 allele carriers are due to a higher SR-BI HDL receptor activity.

SR-BI is also present in the intestinal brush border membrane of the enterocytes, where it is involved in absorption of cholesterol from mixed micelles (33). Acton et al. (21) have found a relationship between this SR-BI polymorphism and LDL cholesterol concentrations. It was therefore interesting to look for a relationship between SR-BI genotype with intestinal cholesterol absorption. Such a relationship, however, was not found. Our results do therefore not provide evidence that this polymorphic site in exon 8 of the SR-BI gene is a functional polymorphism with respect to intestinal cholesterol absorption. It should be noted, however, that in our study - in contrast to the findings of Acton et al (21) - serum LDL cholesterol concentrations were also comparable between the SR-Bl genotype groups. 


\section{HMG-COA reductase VNTR polymorphism}

HMG-CoA reductase is the rate-limiting enzyme in the mevalonate pathway for cholesterol synthesis. A (TTA)n repeat polymorphism in the HMG-CoA reductase gene has been associated with hypercholesterolemia (34). We have now found that wild-type subjects (10/10 repeats) showed a nearly statistically significant larger reduction in cholesterol-standardized campesterol concentrations as compared to homozygous $(>10 />10)$ subjects. Interestingly, this association seemed to be 'repeat-dose-dependent'. Despite the fact that changes in cholesterol-standardized lathosterol and serum LDL cholesterol were not statistically significant between the three groups, it is interesting to see that these variables also showed the same 'repeat-dose-dependent' relation (table 2). These consistent findings of course needs confirmation in other population groups, but studies on the functional effects of this polymorphism seems warranted.

\section{Cholesteryl ester transfer protein (CETP) Taq IB polymorphism}

CETP mediates the transfer and exchange of cholesteryl ester and triacylglycerol between $\mathrm{HDL}$ and apoB containing lipoproteins. The CETP Taq IB polymorphism is associated with the level of CETP protein and activity (22). The mutation however is situated in intron $\mathrm{I}$ and is therefore probably not functional. However, it is in linkage disequilibrium with a mutation in the CETP promotor region, which also had functional effects (35).

Subjects carrying the CETP-1 allele may have lower HDL cholesterol concentrations (22). Studies looking for a possible association between CETP TaqlB polymorphism and the response to diet have therefore mainly focussed upon changes in HDL cholesterol concentrations (36). However, Weggemans et al (29) have found that subjects with the CETP $2 / 2$ genotype responded with a higher increase in serum LDL cholesterol concentrations, when cholesterol intake was increased. We have now found that CETP2/2 subjects showed a significantly larger compensatory increase in cholesterol synthesis upon plant stanol ester consumption, while there was no difference in the effect on cholesterol absorption. This may suggest that CETP-2/2 subjects are less responsive for the cholesterol lowering effect of plant stanol esters. Indeed, reductions in LDL cholesterol were more pronounced in CETP $1 / 1$ than in CETP $2 / 2$ subjects, although the difference in response of $0.16 \mathrm{mmol} / \mathrm{L}$ did not reach statistical significance. 


\section{Apolipoprotein E (apoE) polymorphism}

In agreement with other studies, we have found that at the end of the run-in period apoE2 subjects had lower serum LDL cholesterol concentrations as compared to apoE4 subjects $(29,37)$. This difference could not be explained by the effects of apoE genotype on cholesterol absorption or cholesterol synthesis. Kesäniemi et al., however, have shown that subjects carrying an apoE4 allele had a higher intestinal cholesterol absorption (4). It has also been found that carriers of the apoE2 allele are less responsive to changes in dietary cholesterol intake compared to carriers of the apoE3 or E4 allele (38). In our study, however, we did not find that the LDL cholesterol response to plant stanol ester consumption did depend on apoE genotype, although the apoE2 group showed the lowest and the apoE4 group the highest reduction. If these effects are real, then our results do not suggest that they could be explained by differences in cholesterol absorption or synthesis. This agrees with findings of Hallikainen et al who also did not find an association between apoE genotype and changes of cholesterol precursors or plant sterols (39).

\section{Studies on diet-gene interactions}

The number of studies on the effects of genetic polymorphisms on response to dietary interventions is rapidly increasing. In general, however, results are not conclusive. One of the problems is, is that genotyping is usually performed after the study has been concluded. In other words, subjects are usually not selected on the basis of their genotypes. Such an approach may result in small groups, especially if the frequency of a polymorphism is low. As a consequence, the power of the design will be low. Prior to the analyses, it was estimated that the statistical power to detect a difference in $\mathrm{LDL}$ cholesterol of $15 \%$ (or $0.44 \mathrm{mmol} / \mathrm{L}$ ) or a difference in response to plant stanol ester consumption of $50 \%$ (or $0.21 \mathrm{mmol} / \mathrm{L}$ ) between two genotype groups was $80^{\circ} \%$. In retrospect, it can be estimated that the number of subjects needed in each group to detect a difference in HDL cholesterol between two genotype groups of $15 \%$ is $40-50$ subjects, in campesterol and lathosterol $70-80$ subjects, and in triacylglycerol more than 200 subjects. To find a difference in effect on the response to plant stanol esters consumption of $50 \%$ in campesterol, about 30-35 subjects are needed in each group. For lathosterol, the required number of subjects is 102. These numbers are of course higher if the numbers of subjects in each genotype group are not equal or if the number of genotype groups is more than two. This suggest, that in future studies on gene-diet interaction it might be preferable to select subject on the basis of their genotype, especially if the 
frequency of a polymorphism is low. In this way, groups with equal number can be obtained which will substantially increase the power of the design. Nevertheless, our results do suggest that it is not very likely that one single common polymorphism has an unequivocal impact on the dietary responsiveness to plant stanol ester consumption.

\section{Conclusions}

Our findings suggest an association between SR-BI Haell polymorphism and HDL metabolism (table 2), but this finding needs further studies. No clear associations at baseline were found for the other lipid parameters, except for the known relation between LDL cholesterol with apoE polymorphism. Although the response to plant stanol esters shows a high degree of variability, no significant differences between the polymorphisms and dietary responsiveness to plant stanol esters consumption could be found. Therefore, it is unlikely that one of the single polymorphisms analyzed in this study is a major factor in explaining the variation in serum LDL cholesterol responses. However, our findings do imply that all subjects who want to lower increased cholesterol levels, will benefit from plant stanol ester consumption, irrespective of their apoA-IV, SR-BI, HMG-CoA reductase, CETP or apoE genotype.

\section{References}

1. Katan, MB, Beynen AC, de Vries JHM, Nobels A. Existence of consistent hypoand hyperresponders to dietary cholesterol in man. Am J Epidemiol 1986;123:221-234

2. Ehnholm C, Lukka M, Kuusi T, Nikkila E, Uterman G. Apolipoprotein $E$ polymorphism in the Finnish population: gene frequencies and relation to lipoprotein concentrations. J Lipid Res 1986;27:227-235

3. Weintraub MS, Eisenberg S, Breslow JL. Dietary fat clearance im normal subjects is regulated by genetic variation in apolipoprotein E. J Clin Invest 1987;80:1571-1577

4. Kesäniemi, YA, Ehnholm C, Miettinen TA. Intestinal cholesterol absorption efficiency in man is related to apoprotein E phenotype. J Clin Invest 1987;80:578581

5. Utermann G. Apolipoprotein $E$ polymorphism in health and disease. Am Heart J 1987;113:433-440

6. Boerwinkle $E$, Brown SA, Rohrbach $K$, Gotto AM, Patch $W$. Role of apolipoprotein $E$ and $B$ gene variation in determining response of lipin, lipoprotein, and apolipoprotein levels to increased dietary cholesterol. Am J Hum Genet 1991;49:1145-1154

7. Sarkkinen $E$, Korhonen $M$, Erkkila $A$, 
Ebeling T. Uusitupa M. Effect of apolipoprotein E polymorphism on serum lipid response to the separate modification of dietary fat and dietary cholesterol. Am J Clin Nutr 1998;68:12:15-122.2

8. Weggemans RM, Zock PL, Ordovas JM, Pedro-Botet J, Katan MB. Apoprotein E genolype and the response of serum cholesterol to dietary fat, cholesterol and cafestol. Atheroscler 2001:154:547-555

9. Martin LJ, Connelly PW, Nancoo D, Wood N, Zharky ZJ. Maguire G, Quinet E, Tall AR, Marcel YL, McPherson R. Cholesteryl ester transfer protein and high density lipoprotein responses to cholesterol feeding in men: relationship to apolipoprotein E genotype. J Lipid Res 19.93;34:437-446

†0. Gylling $H_{r}$ Kontula $K$, Koivisto UM, Miettinen $H$, Miettinen TA. Polymorphisms of the genes encoding apoproteins A-I, B, C-III, and E and LDL receptor, and cholesterol and LDL metabolism during increased cholesterol intake. Arterioscler Thromb Vasc Biol 1997:17:38-44

11. Glatz JFC, Demacker PNM, Turner PR, Katan MB. Response of serum cholesterol to dietary cholesterol in relation to apolipoprotein $\mathrm{E}$ phenotype. Nutr Metab Cardiovasc Dis 1991;1:13-17

12. Heinemann T, Kullak-Ublick GA, Pietruck $B$, von Bergmann K. Mechanisms of action of plant sterols on inhibition of cholesterol absorption; Comparison of sitosterol and sitostanol. Eur J Clin Pharmacol 1991;40 [suppl.1]:\$59-\$63

13. Vanhanen, H. T., S. Blomqvist, C. Ehnholm, M. Hyvönen, M. Jauhiainen, I.
Torstila, and T. A. Miettinen. Serum cholesterol, cholesterol precursors, and plant sterols in hypercholesterolemic subjects with different apoE phenotypes during dietary sitostanol-ester treatment. J Lipid Res 1993;34: 1535-1544

14. Plat J, Mensink RP. Vegetable oil based versus wood based stanol ester mixtures: effects on serum lipids and nemostatic factors in non hypercholesterolemic subjects.

Atherosclerosis 2000;148:101-112

15. Gylling $H$, Puska $P$, Vartiainen $E$, Miettinen TA. Serum sterols during stanol ester feeding in a mildly hypercholesterolemic population. J Lipid Res 1999;40:593-600

16. Plat J, Mensink RP. Consumption of plant stanol esters increase LDL receptor expression in mononuclear cells from non-hypercholesterolemic subjects Atherosclerosis 151:86, 2000 (Abstract)

17. Miettinen TA, Tilvis RS, Kesäniemi YA. Serum plant sterols and cholesterol precursors reflect cholesterol absorption and synthesis in volunteers of a randomly selected male population. Am J Epidemiol 1990;131:20-31

18. Kempen HJM., Glatz JFC, Gevers Leuven JA, Voort van der HA, Katan MB., Serum lathosterol concentration is an indicator of whole- body cholesterol synthesis in humans. J Lipid Res 1988;29, 1149-1155

19. Plat J, Onselen van ENM, Mensink RP. Dietary plant stanol ester mixtures: effects on safety parameters and erythrocyte membrane fatty acid composition in non 
hypercholesterolemic subjects. Eur Heart J 1999; 1(Suppl):s58-s63

20. Hixson JE, Powers PK. Restriction isotyping of human apolipoprotein A-IV: rapid typing of known isoforms and detection of a new isoform that deletes a conserved repeat. J Lipid Res 1991;32:1529-1535

21. Acton $S$, Osgood $D$, Donoghue $M$, Corella D, Pocovi M, Cenarro A, Mozas P. Keilty J, Squazzo S, Woolfs EA, Ordovas JM. Association of polymorphisms at the SR-BI gene locus with plasma lipid levels and body mass index in a white population. Arterioscler Thromb Vasc Biol 1999; 19:1734-1743

22. Kuivenhoven JA, de Knijff P, Boer JMA, Smalheer HA, Botma GJ, Seidell JC, Kastelijn JJP, Pritchard PH. Heterogeneity at the CETP gene locus. Influence on plasma CETP concentrations and $\mathrm{HDL}$ cholesterol levels. Arterioscler Thromb Vasc Biol 1997;17:560-568

23. Zuliani G, Hobbs $\mathrm{HH}$. A high frequency of length polymorphisms in repeated sequences adjacent to Alu sequences. Am J Hum Genet 1990;46:963-969

24. Friedewald WT, Levy $\mathrm{RI}_{\mathrm{r}}$ Fredrickson DS. Estimation of the concentration of lowdensity lipoprotein cholesterol in plasma, without use of the preparative ultracentrifuge. Clin Chem 1972;18:499502

25. Plat J, Mensink RP. Effects of diets enriched with two different plant stanol ester mixtures on plasma ubiquinol-10 and fat-soluble antioxidant concentrations. Metabolism 2001:50:520-529
26. Statview (for the Macintosh) manual. Berkeley, CA: Abacus Concepts, Statview Abacus Concepts Inc., 1992

27. McCombs RJ, Marcadis DE, Ellis J, Weinberg RB. Attenuated hyper cholesterolemic response to a highcholesterol diet in subjects heterozygous for the apolipoprotein $A$ IV-2 allele. N Engl J Med 1994;331:706710

28. Weggemans RM, Zock PL, Meyboom S, Funke H, Katan MB. Apolipoproten A4$1 / 2$ polymorphism and response of serum lipids to dietary cholesterol in humans. J Lipid Res 2000;41:16231628

29. Weggemans RM. Genetic disposition and response of blood lipids to diet. Studies on gene-diet interaction in humans. Thesis, 2001 Wageningen University

30. Acton S, Rigotti A, Landschulz KT, Xu S, Hobbs $H$, Krieger $M$. Identification of scavenger receptor $\mathrm{SR}-\mathrm{BI}$ as a high density lipoprotein receptor. Science 1996; 271:518-520

31. Kozarsky KF, Donahee MH, Rigotti A, lqbal $S N$, Edelman ER, Krieger $M$. Overexpression of the $\mathrm{HDL}$ receptor SR$\mathrm{BI}$ alters plasma $\mathrm{HDL}$ and bile cholesterol levels. Nature 1997; 387:414-417

32. Sehayek E, Ono JG, Shefer S, Nguyen LB, Wang N, Batt AK, Salen G. Smith JD, Tall AR, Breslow JL. Biliary cholesterol excretion: A novel mechanism that regulates dietary cholesterol absorption. Proc Natl Acad Sci USA 1998; 95:1019410199

33. Hauser $\mathrm{H}$, Dyer $\mathrm{JH}$, Nandy A, Vega MA, Werder $M$, Bieliauskaite $E$, Weber $F E$, 
Compassi S, Gemperl: A. Botfelli D, Wehrli E, Schulthess G. Phillips MC. Identification of a receptor mediating absorption of dielary cholesterol in the intestine. Biochemistry 1998; 37:1784317850

34. Hubacek JA, Pistulkova $H$, Valenta $Z$, Poledne R. (TTA)n repeat polymorphism in the HMG-CoA reductase gene and cholesterolemia. VASA 1999;28:169171

35. Dachet $C$, Poirier $O$, Cambien $F$, Chapman J, Rouis M. New functional promotor polymorphism, CETP/.629, in cholesteryl ester transfer protein (CETP) gene related to CETP mass and high density lipoprotein cholesterol levels role of $\mathrm{Sp} 1 / \mathrm{Sp} 3$ in transcriptional regulation. Arterioscler Thromb Vasc Biol 2000;20:507-515

36. Clifton $P$, Kind $K$, Jones $C$, Noakes $M$. Response to dietary fat and cholesterol and genetic polymorphisms. Clin Exp Pharmacol Physiol 1997;24(S):A21-A25

37. Lehtimaki $T$, Moilannen $T$, Viikani $J$, Akerblom HK, Ehnholm C. Ronnemaa T, Marniemi J, Dahlen G, Nikkari T. Apolipoprotein $E$ phenotypes in Finnish youths: a cross-sectional and 6-year follow-up study. J Lipid Res 1990;31:487-495

38. Gylling $H$, Miettinen TA. Cholesterol absorption and synthesis related to low density lipoprotein metabolism during varying cholesterol intake in men with different apoE phenotypes. J Lipid Res 1992;33:1361-1371

39. Hallikainen MA, Sarkkinen ES, Uusitupa MI. Plant stanol esters affect serum cholesterol concentrations of hypercholesterolemic men and women in a dose-dependent manner. J Nutr 2000;130:767-776 


\section{Chapter 8}

Oxidized plant sterols in human serum and lipid infusions as measured by combined gas-liquid chromatography-mass spectrometry

Jogchum Plat ${ }^{1}$, Harald Brzezinka ${ }^{2}$, Dieter Lütjohann², Ronald P. Mensink', Klaus von Bergmann ${ }^{2}$

' Maastricht University, Department of Human Biology, Maastricht, the Netherlands

${ }^{2}$ University of Bonn, Department of Clinical Pharmacology, Bonn, Germany

(Based on: J Lipid Res;2001: in press) 


\section{Abstract}

Some oxidized forms of cholesterol (oxysterols) are thought to be atherogenic and cytotoxic. Since plant sterols are structurally related to cholesterol we examined whether oxidized plant sterols (oxyphytosterols) could be identified in human serum and soy-based lipid emulsions. For this we have first prepared both deuterated and nondeuterated reference compounds. We then analyzed by gas-liquid chromatography mass spectrometry the oxyphytosterol concentrations in serum from patients with phytosterolemia or cerebrotendinous xanthomatosis, in a pool serum and in two lipid emulsions.

7-Ketositosterol, $7 \beta$-hydroxysitosterol, $5 \alpha, 6 \alpha$-epoxysitosterol, $3 \beta, 5 \alpha, 6 \beta$-trihydroxysitosterol, and probably also $7 \alpha$-hydroxysitosterol were present in markedly elevated concentrations in serum from phytosterolemic patients only. Also campesterol oxidation products, such as $7 \alpha$-hydroxycampesterol and $7 \beta$-hydroxycampesterol were found. Interestingly sitosterol was oxidized for approximately 1.4 percent in phytosterolemic serum, which is rather high compared to the approximate 0.01 percent oxidatively modified cholesterol normally seen in human serum. The same oxyphytosterols were also found in two lipid emulsions in which the ratio oxidized sitosterol / sitosterol varied between 0.038 to 0.041 .

In conclusion, we have shown that oxidized forms of plant sterols are present in serum from phytosterolemic patients and two frequently used soy-based lipid emulsions. Currently it is unknown whether oxidized plant sterols affects health, as has been suggested for oxysterols. However, $7 \beta$-hydroxycholesterol may be one of the more harmful oxysterols and both sitosterol and campesterol were oxidized into $7 \beta$ hydroxysitosterol and $7 \beta$-hydroxycampesterol. The relevance of these findings therefore deserves further exploration. 


\section{Introduction}

Plant sterols are non-nutritive compounds, which differ from cholesterol only by an additional ethyl ( $\beta$-sitosterol) or methyl (campesterol) group at the 24-carbon atom of the sterol side chain. Western diets provide about 160 to $360 \mathrm{mg} /$ day of plant sterols, which consist for approximately $80 \%$ of $\beta$-sitosterol, some campesterol and stigmasterol, minor amounts of stigmasterol and only traces of delta-5 saturated plant stanols (1).

Cholesterol is susceptible to oxidation and cholesterol oxidation products, called oxysterols, can be formed by physical processes such as heating and radiation, by nonenzymatic processes involving reactive oxygen and free radical species (2), or enzymatically by specific cytochrome P450 (CYP450) monooxygenases (3). Consequently, cholesterol oxidation products, as present in the human body, may be derived from absorption of oxidized sterols present in the food, as well as from endogenous origin. The nuclear A- and B-rings of the cholesterol molecule are mainly oxidized by non-enzymatic processes. In this way, $7 \alpha$-hydroxycholesterol $(7 \mathrm{c} . \mathrm{OH}$ Chol), 7 $\beta$-hydroxycholesterol ( $7 \beta-\mathrm{OH}$-Chol), 7-ketocholesterol ( $7=\mathrm{O}$-Chol), $5 \alpha, 6 \alpha-$ epoxycholesterol ( $5(\alpha, 6 \alpha$-epoxy-Chol), $5 \beta, 6 \beta$-epoxycholesterol $(5 \beta, 6 \beta$-epoxy-Chol) and $3 \beta, 5 \alpha, 6 \beta$-tri-hydroxy-cholesterol $(3 \beta, 5 \alpha, 6 \beta$-tri-hydroxy-Chol) can be formed. The side chain, on the other hand, is mainly oxidized by CYP450 specific enzymes and various hydroxy derivatives of cholesterol are then formed (24S-OH-Chol and 27-OH-Chol) (4). The difference between the products formed by non-enzymatic and enzymatic oxidation is clearly illustrated by findings that during in vitro copper catalyzed LDL oxidation mainly oxysterols oxidized at $\mathrm{C} 7$ and $\mathrm{C} 5-\mathrm{C} 6$ are identified $(5,6)$, whereas $24 \mathrm{~S}-\mathrm{OH}$-Chol and $27-\mathrm{OH}-\mathrm{Chol}$ are not found (6).

Since plant sterols have a great structural similarity with cholesterol, analogous oxidation products can be formed from plant sterols (7). The terminology for oxidized plant sterols (oxyphytosterols) is similar as described for oxysterols. After stereospecific peroxidation of sitosterol to $7 \alpha$ - and / or $7 \beta$-hydroperoxy sitosterol $(7 \alpha-\mathrm{OOH}-\mathrm{Sit}$ and $7 \beta$ $\mathrm{OOH}-\mathrm{Sit}$ ), reduction of these compounds results in the formation of $7 \alpha-$ or $7 \beta-\mathrm{OH}-\mathrm{Sit}$ (figure 1), while dehydration of the hydroperoxide leads to the formation of $7=0$-Sit (figure 1). Further $5 \alpha, 6 \alpha$-epoxy-Sit and $5 \beta, 6 \beta$-epoxy-Sit are formed by epoxidation of the double bound between the $\mathrm{C} 5$ and $\mathrm{C} 6$ atoms of sitosterol. Epoxy-sterols at C5-C6 are rapidly converted into their triol end products, such as $3 \beta, 5 \alpha, 6 \beta$-tri-hydroxy-Sit (figure 1). Comparable products can be formed from campesterol and other plant sterols. Plant sterols may be oxidized even more easily than cholesterol (8). However, only little information is available on the presence of oxyphytosterols in food, but small 
amounts have been found in coffee, fried potatoes, wheat flour and vegetable oils $(9,10)$. Recently, it has been shown in rats that oxidized plant sterols $(7=0-S i t, 7=0-$ Camp $5 \alpha, 6 \alpha$-epoxy-Sit, $5 \beta, 6 \beta$-epoxy-Sit, $5 \alpha, 6 \alpha$-epoxy-Camp and 5 $3,6 \beta$-epoxy-Camp) are absorbed from the diet and incorporated into mesenteric lymph (11). Information on endogenous formation of oxidized plant sterols, either enzymatically or nonenzymatically, and information on the presence of oxyphytosterols in the human circulation is scanty (12). Expanding our knowledge on the presence of oxyphytosterols in the circulation is of great importance, in particular because oxysterols in general may be atherogenic. Further, it was recently found that oxysterols and oxyphytosterols showed similar cytotoxic effects in cultured macrophages (13). In this way, oxidation of plant sterols and the presence of these oxyphytosterols in the circulation might have implications for health.

Phytosterolemia is a rare inherited sterol storage disease characterized by highly elevated serum plant sterol concentrations up to $65 \mathrm{mg} / \mathrm{dL}$ (1.57 mmol / L) (14), tendon and tuberous xanthomas and by a strong predeposition to premature coronary atherosclerosis (15). Therefore, the primary aim of this study was to examine if, and what kind of oxyphytosterols are present at all in serum of phytosterolemic patients. Additionally we analyzed serum from patients suffering from cerebrotendinous xanthomatosis (CTX). Patients suffering from CTX, a rare autosomal recessive inherited disease, have decreased concentrations of $27-\mathrm{OH}-\mathrm{Chol}$ caused by a genetic absence or restriction of the CYP450 dependent 27-hydroxylase. As a consequence, these patients have a reduced formation of normal C24 bile acids. Moreover, there is a negative feedback from bile acids on cholesterol $7 \alpha$-hydroxylase (CYP7A). Consequently, CTX patients have extremely high concentrations of $7 \alpha$-hydroxylated bile acid precursors, since they lack the feedback on cholesterol $7 \alpha$-hydroxylase due to the absence of bile acids (15). It is therefore interesting to examine whether an increased activity of cholesterol $7 \alpha$-hydroxylase will result in the formation of endogenous $7 \alpha-\mathrm{OH}$ Sit. We therefore hypothesized that oxidized plant sterols, when formed in relevant concentrations and present in the circulation, should be found in serum of phytosterolemic and CTX patients. In addition, two different soy-bean oil based lipid emulsions known to be rich in plant sterols and frequently used as parenteral infusion for short- and long-term nutritive therapy, were analyzed for the presence of oxidized plant sterols. To address these issues, we have first developed a sensitive gas-liquid chromatography - mass spectrometry (GC-MS) method and synthesized all necessary reference compounds and deuterated internal standards. 

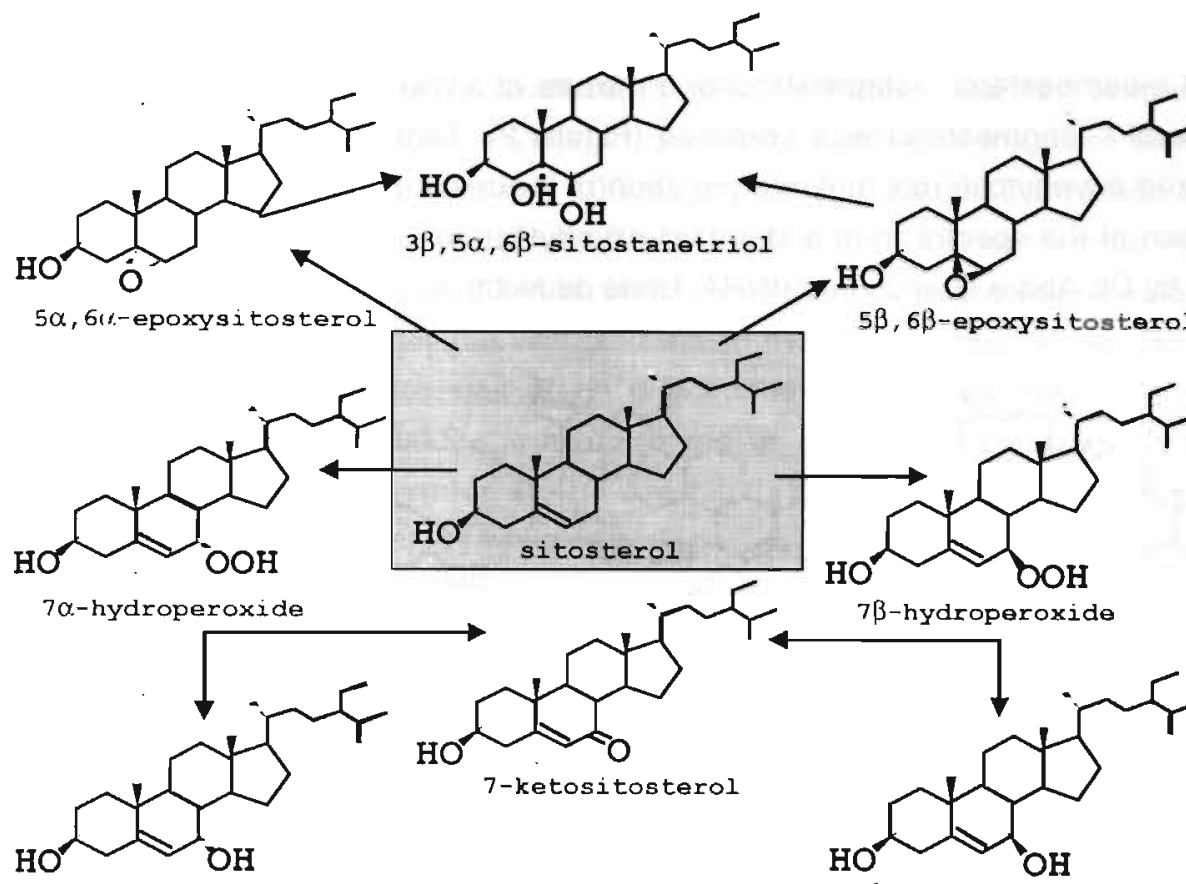

$5 \beta, 6 \beta$-epoxysitosterol

$7 \alpha$-hydroxysitosterol

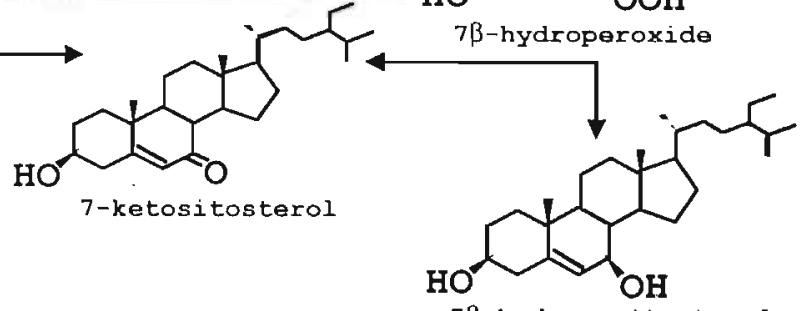

$7 \beta$-hydroxysitosterol

Figure 1: Possible in vivo oxidation of plant sterols, either by enzymatic or non-enzymatic mechanismsi. Besides the structures depicted for oxidation of sitosterol, similar products can be formed from campesterol and other plant sterols.

\section{Methods}

Materials

All reagents and solvents used were of analytical or high performance liquid chromatography (HPLC) grade. A plant sterol mixture consisting of approximately $60 \%$ sitosterol, $40 \%$ campesterol and traces of stigmasterol was purchased from SigmaAldrich (Steinheim, Germany).

In vitro synthesis of oxyphytosterols

In vitro synthesis of oxidized plant sterols was based on the methods as described for oxygenation of cholesterol by Li ef al. (16) with some minor modifications. Several oxygenated plant sterols were synthesized from the plant sterol mixture. In this way, a mixture of $7 \alpha-\mathrm{OH}$ and $7 \beta-\mathrm{OH}$-sitosterol / -campesterol / stigmasterol, a mixture of 
$7=0$-sitosterol / -campesterol / -stigmasterol, a mixture of $5 \alpha, 6 \alpha$ - and $5 \beta, 6 \beta$-epoxy sitosterol / -campesterol / -stigmasterol or a mixture of $3 \beta, 5 \alpha, 6 \beta$-tri-hydroxysitosterol / campesterol / -stigmasterol was prepared (Figure 2). Tentative identification of the synthesized oxyphytosterols and interpretation of the mass spectra was performed by comparison of the spectra from a standard oxyphytosterols mixture, which was kindly provided by Dr. André Grandgirard (INRA, Unité de Nutrition Lipidique, Dijon, France).

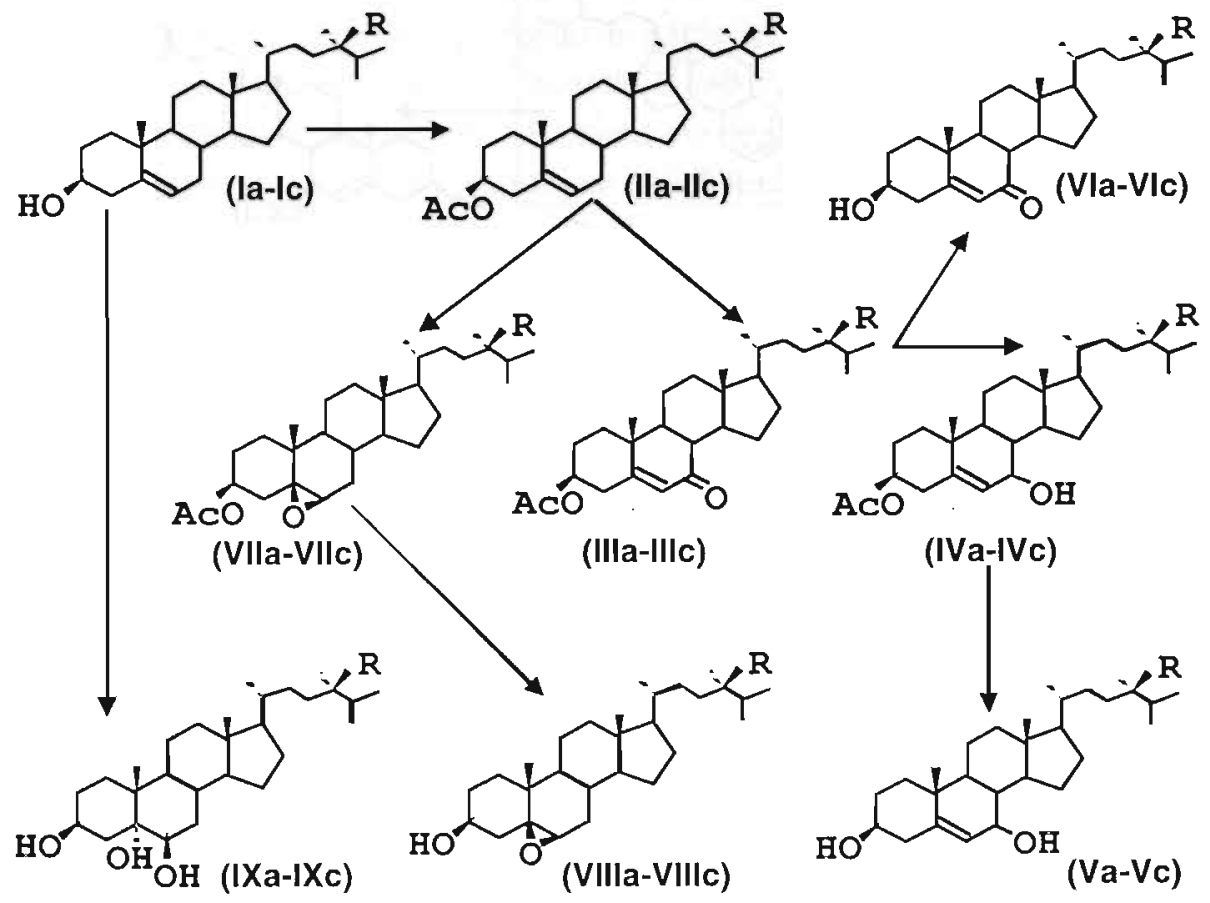

Figure 2: In vitro synthesis of oxidized plant sterols. Oxidized plant sterols were synthesized from a mixture consisting of sitosterol, campesterol and traces of stigmasterol (sitosterol: campesterol; 60:40) as described in the methods. Therefore all oxidized plant sterol standards contained isoforms from sitosterol, campesterol and stigmasterol, all approximately in the same percentages as the plant sterol distribution of the original plant sterol mixture.

$\begin{array}{ll}\text { Campesterol: } & R=-\mathrm{CH}_{3} \\ \text { Sitosterol: } & \mathrm{R}=-\mathrm{C}_{2} \mathrm{H}_{5} \\ \text { Stigmasterol: } & \mathrm{R}=-\mathrm{C}_{2} \mathrm{H}_{5} \text { (plus a double bound between C-atom } 22 \text { and 23) }\end{array}$ 
Acetylation of plant sterols

All plant sterols were acetylated prior to further use for synthesis of all oxyphytosterols, except for the triols. To this end, 2 grams of the plant sterol mixture (figure 2; la - Ic), were dissolved in $100 \mathrm{~mL}$ dry toluene (Merck, Darmstadt, Germany). After acetic anhydride (20 mL) (Fluka Chemika, Buchs, Swiss) was added, the mixture was heated under reflux for 5 hours, which resulted in a bright yellow solution. After evaporation of the solvents in a vacuum rotation evaporator, the residue was dissolved in methanol. This mixture was again dried under vacuum to evaporate the acetic anhydride. Next, the residue was dissolved in ethanol and allowed to stand for crystallization in a refrigerator at $4^{\circ} \mathrm{C}$ overnight. Filtration resulted in the acetylated products (figure 2 ; Ila - Ilc), as white crystals.
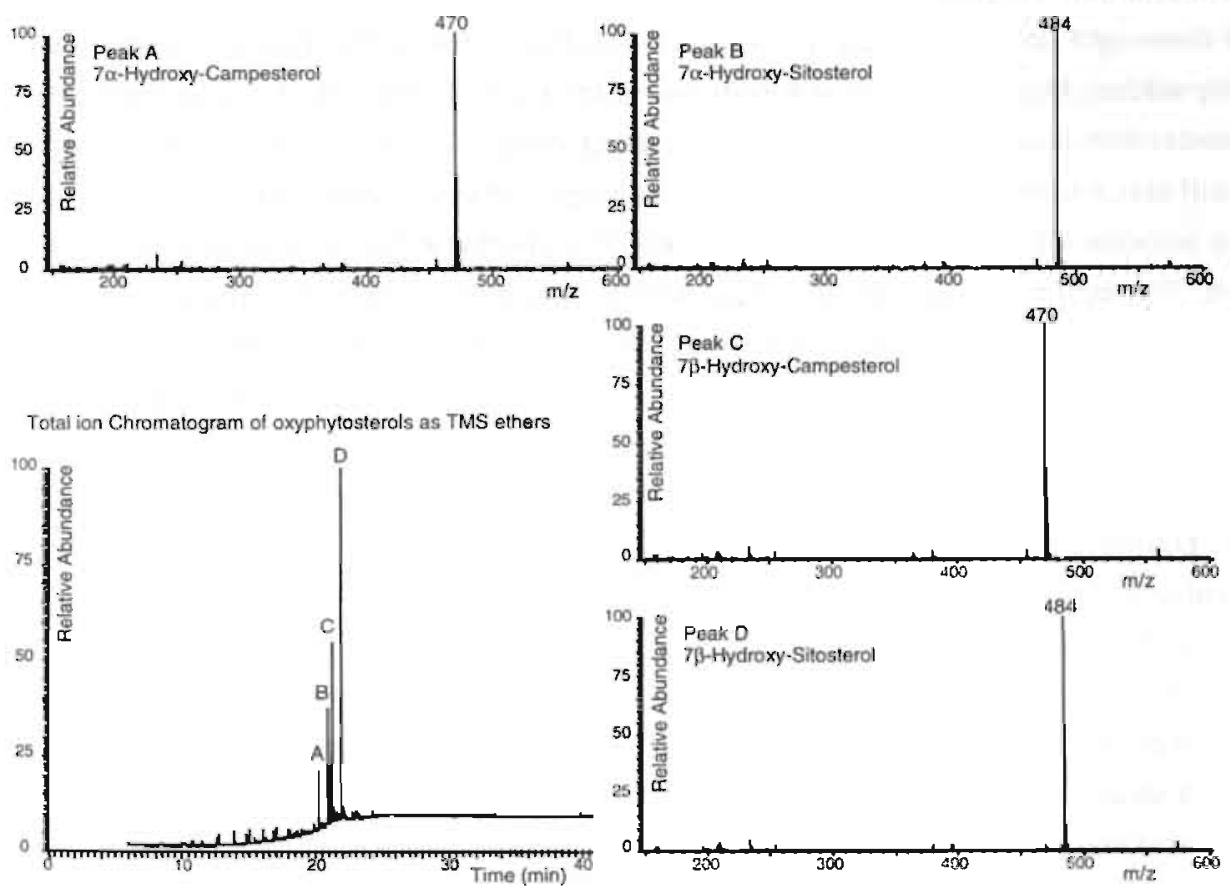

Figure 3: The fragmentation patterns of the 7-OH plant sterol standard analyzed by GC-MS as described in the methods. The chromatogram shows a pure mixture of $7 \alpha-\mathrm{OH}$-Sit ( $\mathrm{m} / \mathrm{z} 484, \mathrm{RT} 20.87$ ), $7 \alpha-$

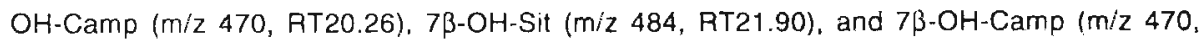
RT21.23). 


\section{7-Hydroxyphytosterols}

$200 \mathrm{mg}$ molecular sieve $0.4 \mathrm{~nm}$ (Merck, Darmstadt, Germany) and $3.2 \mathrm{~g}$ pyridinium chlorochromate (Sigma-Aldrich, Steinheim, Germany) were added to a solution of $340 \mathrm{mg}$ acetylated plant sterols (figure2; lla - Ilc) in $200 \mathrm{~mL}$ benzene. This mixture was heated under reflux for 24 hours under a nitrogen atmosphere. The dark reaction product was filtrated over a silica pad (230-400 mesh; Merck, Darmstadt, Germany) in cyclohexane and eluted with a mixture of ethylacetate-cyclohexane ( $80 /$ $20, v / v)$. The eluate was evaporated under vacuum and the residue was dissolved in methanol for crystallization. The so-formed white crystals (figure 2; IIla - IIIc) were used for further synthesis of the two isomeric 7-hydroxy phytosterols.

To a solution of $100 \mathrm{mg} \mathrm{IIla} \mathrm{-} \mathrm{IIlc} \mathrm{(figure} \mathrm{2)} \mathrm{dissolved} \mathrm{in} \mathrm{di-ethyl} \mathrm{ether}(100 \mathrm{~mL}$ ), lithium aluminium hydride (1 g) (Sigma-Aldrich, Steinheim, Germany) was added, and stirred overnight under nitrogen at room temperature. After a few drops of water were carefully added, $\mathrm{H}_{2} \mathrm{SO}_{4}$ (25\% by volume) was added until a final $\mathrm{pH}$ of 1-2 was reached. This acidic solution was extracted with di-ethyl ether $(250 \mathrm{~mL})$ and washed with a saturated $\mathrm{NaCl}$ solution. Anhydrous sodium sulphate (Merck, Darmstadt, Germany) was used to remove traces of water. After filtration, the di-ethyl ether was evaporated under vacuum. The residue (figure 2; IVa - IVc) was suspended in $100 \mathrm{~mL}$ methanol and 100 $\mathrm{mg}$ sodium carbonate $\left(\mathrm{Na}_{2} \mathrm{CO}_{3}\right)$ was then added, followed by stirring for $24 \mathrm{~h}$ at room temperature to saponify the acetylated bound. After evaporation, the residue was dissolved in chloroform, and washed twice with water and a saturated $\mathrm{NaCl}$ solution to remove the $\mathrm{Na}_{2} \mathrm{CO}_{3}$. The chloroform phase was dried with anhydrous sodium sulphate (Merck, Darmstadt, Germany). After filtration, the chloroform solution was evaporated under vacuum and the residue was taken up in methanol and allowed to stand overnight at $4^{\circ} \mathrm{C}$ for crystallization. Filtration resulted in the formation of white to light yellow crystals (figure 2; $\mathrm{Va}-\mathrm{Vb}$ ). The purity of the newly synthesized 7-hydroxy plant sterols was checked by thin layer chromatography (TLC). For this, TLC plates were developed in di-ethyl ether, dried and sprayed with $25 \% \mathrm{H}_{2} \mathrm{SO}_{4}$. After heating for a few minutes at $100^{\circ} \mathrm{C}, 7$-hydroxy plant sterols turned blue, while the non-hydroxylated plant sterols turned red. TLC showed that -besides hydroxy sterols-also non-hydroxylated plant sterols were still present. Therefore, the7-hydroxylated plant sterols were further purified by using a silica column in cyclohexane $(25 \mathrm{~cm}$, diameter $2 \mathrm{~cm}$ ). As mobile phase 500 $\mathrm{mL} 10 \%$ ethyl acetate in cyclohexane ( $\mathrm{v} / \mathrm{v}$ ) was used first. Next, $500 \mathrm{~mL} 20 \%$ ethyl acetate in cyclohexane ( $\mathrm{v} / \mathrm{v}$ ) was added, followed by $500 \mathrm{~mL} 30 \%$ ethylacetate in cyclohexane $(\mathrm{v} / \mathrm{v})$. Fractions of about $100 \mathrm{~mL}$ were collected, which were characterized by TLC and GC-MS. The fractions containing pure 7-hydroxy plant sterols 
-a mixture of alpha and beta isomers- were combined and crystallized in n-hexane. The GC-MS spectra showed a pure mixture of $7 \alpha-\mathrm{OH}-\mathrm{Sit}, 7 \alpha-\mathrm{OH}$-Camp, $7 \beta-\mathrm{OH}$-Sit and $7 \beta$ $\mathrm{OH}$-Camp and traces of $7-\mathrm{OH}$-stigmasterol (figure 3). The ratio of $7 \alpha-\mathrm{OH}$-Sit to $7 \alpha-\mathrm{OH}-$ Camp was $(69: 31)$, while the ratio of $7 \beta-\mathrm{OH}$-Sit to $7 \beta-\mathrm{OH}$-Camp was $(70: 30)$. This indicates that both sitosterol and campesterol from the initial plant sterol mixture were equally converted into 7-hydroxy plant sterols. Retention times and $\mathrm{m} / \mathrm{z}$ used for analysis of 7 -hydroxy sterols are shown in table 1.

\section{7-Keto plant sterols}

7-Keto plant sterols were formed from the same components (Ila - IIlc; figure 2), as used for the synthesis of 7-hydroxy plant sterols. However, the solution IIIa - IIIc in methanol $(100 \mathrm{~mL})$ was not crystallized, but immediately saponified with sodium carbonate $(100 \mathrm{mg})$ by stirring overnight at room temperature. Next, the solution was worked up similarly as described for the hydroxy plant sterols into white crystals (figure 2; Vla - VIc). The synthesized 7-keto plant sterols were also contaminated with free plant sterols, which were removed similarly as described for the hydroxy plant sterols. The purified 7-keto plant sterols were crystallized in n-hexane. GC-MS spectra showed a pure mixture of 7-keto sitosterol and 7-keto campesterol (figure 4). The ratio of $7=0$ Sit to $7=0$-Camp was $(67: 33$ ). Retention times and $\mathrm{m} / \mathrm{z}$ used for analysis of 7 -keto sterols are shown in table 1.

\section{5,6-Epoxy plant sterols}

$70 \mathrm{mg}$ of the acetylated phytosterol mixture (figure 2; $1 \mathrm{la}$ - Ilc) was dissolved in 15 $\mathrm{mL}$ chloroform and $26 \mathrm{mg} \mathrm{m}$-chloroperoxybenzoic acid (Sigma-Aldrich, Steinheim, Germany) and $17 \mathrm{mg}$ potassium bicarbonate were added. This mixture was stirred for 36 hours at room temperature. Next the solution was diluted with chloroform $(20 \mathrm{~mL})$, washed twice with $20 \mathrm{~mL} \mathrm{NaOH}(10 \%$ in water), $10 \mathrm{~mL} \mathrm{H}$, and a $10 \mathrm{~mL}$ saturated $\mathrm{NaCl}$ solution and dried over anhydrous sodium sulphate. Evaporation under vacuum gave white crystals (figure 2; VIla - VIIc), which were saponified as described for the hydroxy plant sterols. Finally the epoxy sterols were crystallized in $n$-hexane (figure 2; VIIIa - VIIIC). GC-MS spectra showed a pure mixture of $5 \alpha, 6 \alpha$-epoxy-Sit, $5 \alpha, 6 \alpha$-epoxyCamp, $5 \beta, 6 \beta$-epoxy-Sit, and $5 \beta, 6 \beta$-epoxy-Camp and traces of epoxy-stigmasterol (figure 5). The ratio of $5 \alpha, 6 \alpha$-epoxy-Sit to $5 \alpha, 6 \alpha$-epoxy-Camp was (63:37), while the ratio of $5 \beta, 6 \beta$-epoxy-Sit to $5 \beta, 6 \beta$-epoxy-Camp was $(59: 41)$. Mainly the $5 \alpha, 6 \alpha$-epoxy forms were formed during synthesis, since the ratio of $5 \alpha, 6 \alpha$-epoxy-Sit to $5 \beta, 6 \beta$-epoxy- 
Sit was $(79: 21)$ and the ratio of $5 \alpha, 6 \alpha$-epoxy-Camp to $5 \beta, 6 \beta$-epoxy-Camp was (76: 24). Retention times and $\mathrm{m} / \mathrm{z}$ used for analysis of epoxy sterols are shown in table 1.

Table 1: Rt and $\mathrm{m} / \mathrm{z}$ values of (oxidized) plant sterols, cholesterol and oxysterols as TMS derivatives

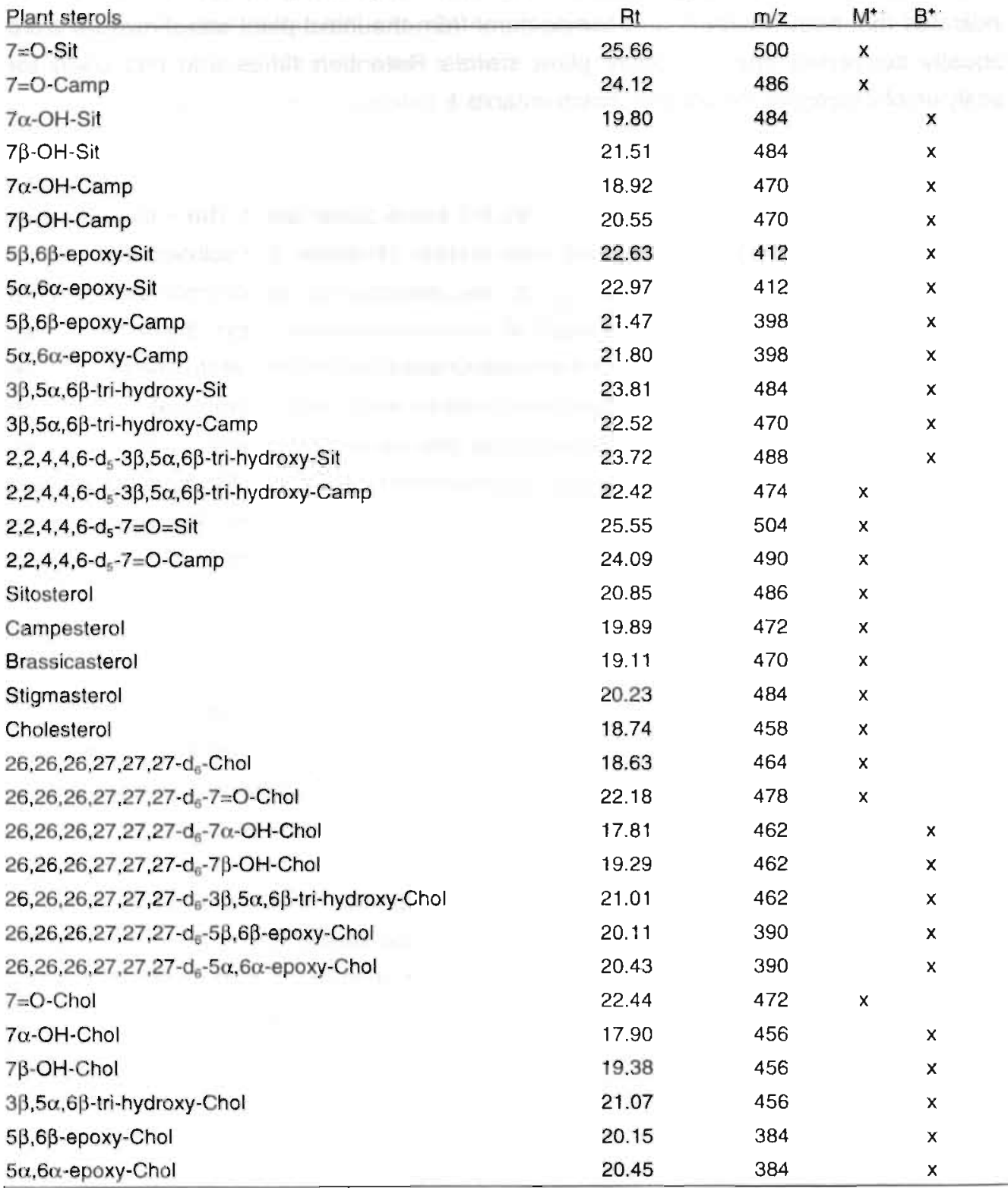

RT, retention time; $\mathrm{M}^{+}$, molecular ion; $\mathrm{B}^{+}$, base peak; Sit, Sitosterol; Camp, Campesterol 

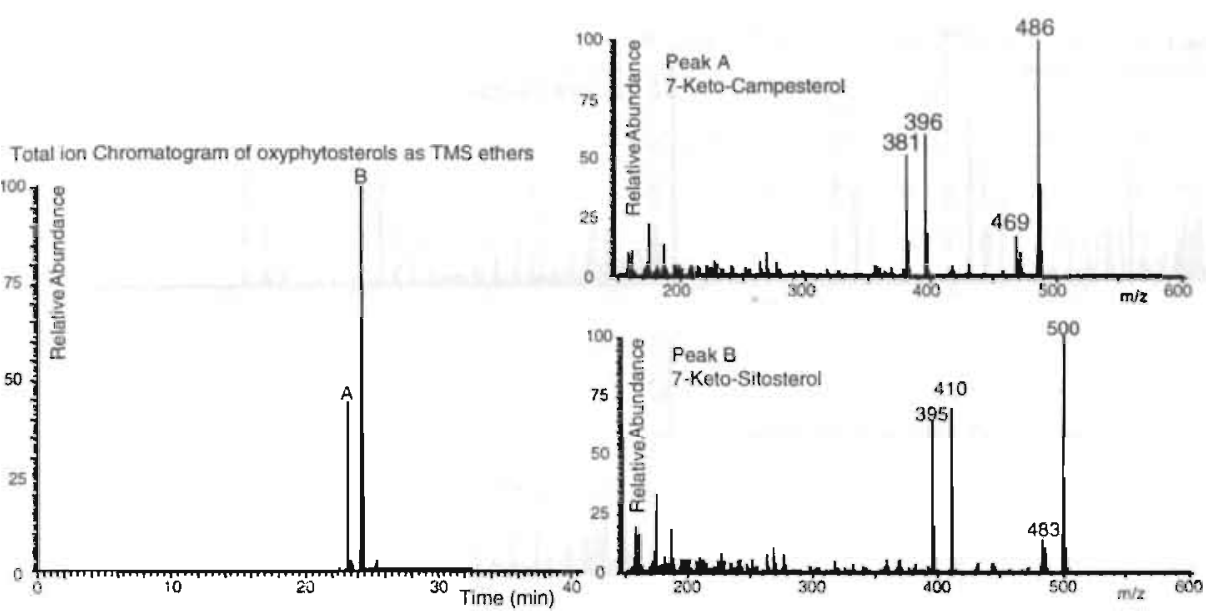

Figure 4: The fragmentation patterns of the $7=0$ plant sterol standard analyzed by GC-MS as described in the methods. The chromatogram shows a pure mixture of $7=0-S i t(m / z, 500, R T 24.35)$ and 7=O-Camp (m/z 486, RT23.32).

\section{$3 \alpha, 5 \beta, 6 \alpha$-triols}

$400 \mathrm{mg}$ plant sterols (figure 2; la - Ic) were dissolved in $20 \mathrm{~mL}$ formic acid (95\%) and heated for 5 minutes at $75^{\circ} \mathrm{C}$, while stirring. The dark mixture was cooled to $25^{\circ} \mathrm{C}$ and $5 \mathrm{~mL} \mathrm{H} \mathrm{O}_{2}(30 \%)$ was added carefully. During stirring for 6 hours at room temperature, the mixture turned white. After adding $200 \mathrm{~mL}$ boiling water. a white precipitate was formed, which was collected by filtration. This precipitate was dissolved in $50 \mathrm{~mL}$ chloroform and dried over sodium sulfate. After filtration, the chloroform was evaporated and the residue was taken up in $50 \mathrm{~mL}$ methanol. Then, $100 \mathrm{mg} \mathrm{NaOH}$ was added and the mixture was stirred for 30 minutes at room temperature. Next the methanol was evaporated and the residue was taken up in $100 \mathrm{~mL}$ chloroform, washed with a saturated $\mathrm{NaCl}$ solution and dried over anhydrous sodium sulfate. After filtration and evaporation, the triols (figure $2 ; \mid x a-I X C)$ were crystallized in chloroform at $4{ }^{\circ} \mathrm{C}$. GC-MS spectra showed a pure mixture of $3 \beta, 5 \alpha, 6 \beta$-tri-hydroxy-Sit, and $3 \beta, 5 \alpha, 6 \beta$-trihydroxy-Camp (figure 6 ). The ratio of $3 \beta, 5 \alpha, 6 \beta$-tri-hydroxy-Sit to $3 \beta, 5 \alpha, 6 \beta$-tri-hydroxyCamp was $(67: 33$ ). Retention times and $\mathrm{m} / \mathrm{z}$ used for analysis of tri-hydroxy sterols are shown in table 1 . 


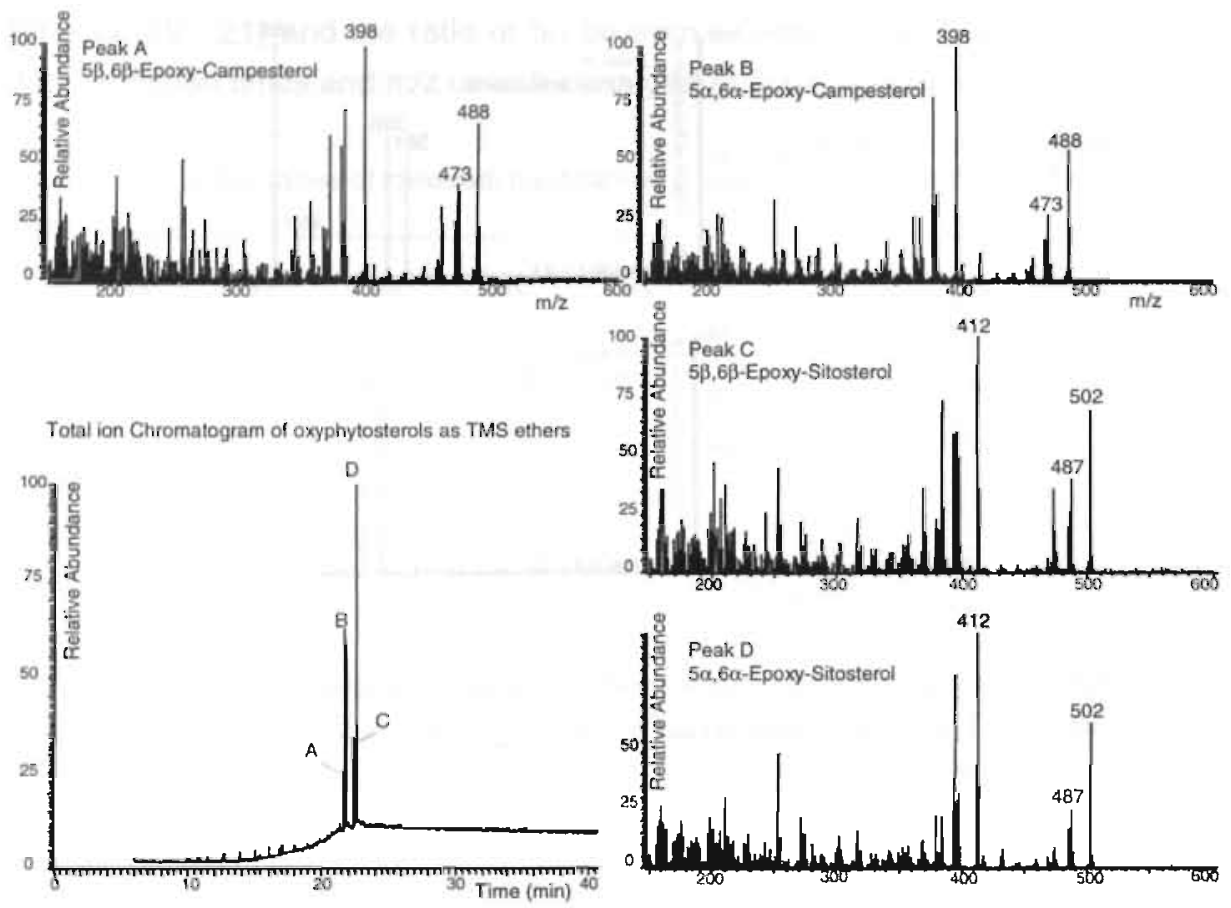

Figure 5: The fragmentation patterns of the 5,6-epoxy plant sterol standard analyzed by GC-MS as described in the methods. The chromatogram shows pure mixture of $5 \beta, 6 \beta$-epoxy-Sit $(\mathrm{m} / \mathrm{z}$

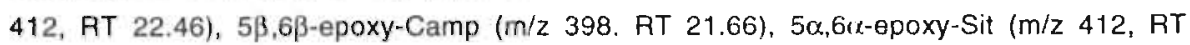
22.66), and $5 \alpha, 6 \alpha$-epoxy-Camp (m/z 398, RT 21.84).

Internal standard preparation $\left[2,2,4,4,6-{ }^{2} H_{5}\right]-3 \beta, 5 \alpha, 6 \beta$-tri-hydroxy-phytosterols and $\left[2,2,4,4,6-{ }^{2} \mathrm{H}_{5}\right]-7-k e t o-p h y t o s t e r o l s$

As internal standard's we synthesized deuterated tri-hydroxy-phytosterols and deuterated 7-keto-phytosterols from of mixture of $d_{5}-2,2,4,4,6$-sitosterol / campesterol / stigmasterol (Medical Isotopes Inc., Pelham, USA) by similar procedures as described for the unlabelled plant sterols. Identification of the synthesized triols revealed that both deuterated tri-hydroxy-Sit and tri-hydroxy-Camp were formed in a ratio (66:34) as well as traces of brassicatriol. Moreover, analyzing the isotope differentiation -corrected for the natural background of ${ }^{13} \mathrm{C}$ - showed the deuterium distribution as $\left(d_{0}-\right.$ tri-hydroxy-Sit $8.9 \% d_{1}$ - tri-hydroxy-Sit $3.9 \%, d_{2}$ - tri-hydroxy-Sit $9.2 \%, d_{3}$ - tri-hydroxy-Sit $21.2 \%, d_{4}$ - trihydroxy-Sit $29.8 \%, d_{5}-$ tri-hydroxy-Sit $22.4 \%, d_{6}-$ tri-hydroxy-Sit $2.7 \%$, and $d_{7}-$ tri- 
hydroxy-Sit $1.9 \%$ ). Since $d_{4}$ - tri-hydroxy-Sit was the most abundant isotope we have measured on $\mathrm{m} / \mathrm{z} 488$ for $\mathrm{d}_{4}$ - tri-hydroxy-Sit as internal standard.

The deuterated 7-keto standards were formed in a $(60: 40)$ distribution with some minor traces of stigmasterol as well. Analyzing the isotope differentiation corrected for the natural background of ${ }^{1 "} \mathrm{C}$ - showed the deuterium distribution as $\left(\mathrm{d}_{0}\right.$ $7=0-$ Sit $6.5 \%, d_{1}-7=0-S i t 4.2 \%, d_{2}-7=0-S i t 7.3 \%, d_{3}-7=0-S i t 20.3 \%, d_{1}-7=0-S i t 31.9 \%$, $d_{5}-7=0-S$ it $22.4 \%, d_{6}-7=0-S i t 5.7 \%$, and $d_{7}-7=0-S i t 1.8 \%$ ). Since $d_{4}-7=0-S$ it was the most abundant isotope we have measured on $\mathrm{m} / \mathrm{z} 504$ for $d_{4}-7=0$-Sit as internal standard. Retention times and $\mathrm{m} / \mathrm{z}$ used for analysis of both deuterated sterols are shown in table 1 (total ion chromatograms and fragmentation patterns are not shown).

\section{Oxyphytosterol analysis in serum}

Butylated hydroxy toluene (BHT) and EDTA were added to each blood sample, either already in the blood collection tube or otherwise to the serum just before analysis. Final amounts added corresponded with $10 \mu \mathrm{L} \mathrm{BHT} \mathrm{(25} \mathrm{mg/} \mathrm{mL} \mathrm{in} \mathrm{methanol)} \mathrm{and} 20$ $\mu \mathrm{L}$ EDTA (10 mg / mL in methanol) for $1 \mathrm{~mL}$ serum. Before saponification and extraction, $6 \mu \mathrm{g}$ each of each internal standard $\left[2,2,4,4,6-{ }^{2} \mathrm{H}_{5}\right]-3 \beta, 5 \alpha, 6 \beta$-tri-hydroxyphytosterol and $\left[2,2,4,4,6-{ }^{2} \mathrm{H}_{5}\right]-7$-keto-phytosterol, were added to the serum sample. Next the sample was saponified in a closed tube under nitrogen for 2 hours at room temperature by adding $10 \mathrm{~mL}$ of $0.35 \mathrm{M}$ ethanolic $\mathrm{KOH}$ solution. $130 \mu \mathrm{L}$ phosphoric acid $50 \%$ in water ( $\mathrm{v} / \mathrm{v}$ ) was added to neutralize the solution, followed by addition of $6 \mathrm{~mL}$ $\mathrm{NaCl}$ solution in water $(9 \mathrm{mg} / \mathrm{mL})$, according procedures for oxysterol analysis as described before (17). After extraction with $20 \mathrm{~mL}$ di-chloro-methane, the bottom layer was transferred into a round bottom flask and evaporated to dryness under vacuum at $50^{\circ} \mathrm{C}$. The residue was dissolved in $5 \mathrm{~mL}$ ethanol and again evaporated under vacuum to remove all traces of water. The non-saponifiable serum lipids were dissolved in $1 \mathrm{~mL}$ toluene. Silica cartridges (Bond Elut, bonded phase SI, $100 \mathrm{mg}, 1 \mathrm{~mL}$; Varian, Harbor city, CA, USA) were equilibrated with cyclohexane before the toluene fractions were loaded. Neutral sterols (including cholesterol) were eluted from the column with $4 \mathrm{~mL}$ $0.5 \%$ ethyl-acetate-cyclohexane $(v / v)$, while the absorbed oxysterols were eluted with $9 \mathrm{~mL}$ ethyl-acetate. The oxysterol fraction was dried under vacuum. Finally, the oxidized sterols were dissolved in $100 \mu \mathrm{L}$ cyclohexane and transferred to an injection vial. Sterols were silylated by addition of $100 \mu \mathrm{L}$ silylation reagent (dry pyridine / hexamethyldisilazane / trimethylchlorosilane (TMS) $(3: 2: 1 \mathrm{v} / \mathrm{v} / \mathrm{V})$ and incubating for 1 hour at $60^{\circ} \mathrm{C}$ for GC-MS analysis. 


\section{GC-MS analysis}

TMS derivates of the oxyphytosterois were analyzed by GC-MS. For this, $2 \mu \mathrm{l}$ of the TMS derivatives in cyclohexane were injected via an AS2000 autosampler (Thermoquest CE Instruments, Egelsbach, Germany) on a Trace GC2000 (Thermoquest CE Instruments, Egelsbach, Germany) gas chromatograph equipped with a RTX5MS column ( $30 \mathrm{~m} \times 0.25 \mathrm{~mm}$ internal diameter, $0.25 \mu \mathrm{m}$ film thickness) coupled to a GCQ-plus ion trap (Thermoquest CE Instruments, Egelsbach, Germany). The injector temperature was set at $280^{\circ} \mathrm{C}$. Helium was used as carrier gas (constant flow 1 $\mathrm{mL} / \mathrm{min}$ ). The oven temperature gradient was programmed for 150 seconds at $150^{\circ} \mathrm{C}$, then increased with $10^{\circ} \mathrm{C} /$ minute towards $290^{\circ} \mathrm{C}$ and then increased by $7^{\circ} \mathrm{C} /$ minute towards $320^{\circ} \mathrm{C}$ and kept there for 20 minutes. Thus, one analytical-run lasted approximately 42 minutes. As can be seen on the total ion chromatograms (figures 3 to 6) of the individual standards, all oxyphytosterols can be separated by this procedure. The ions and retention times of all individual compounds are given in table 1.
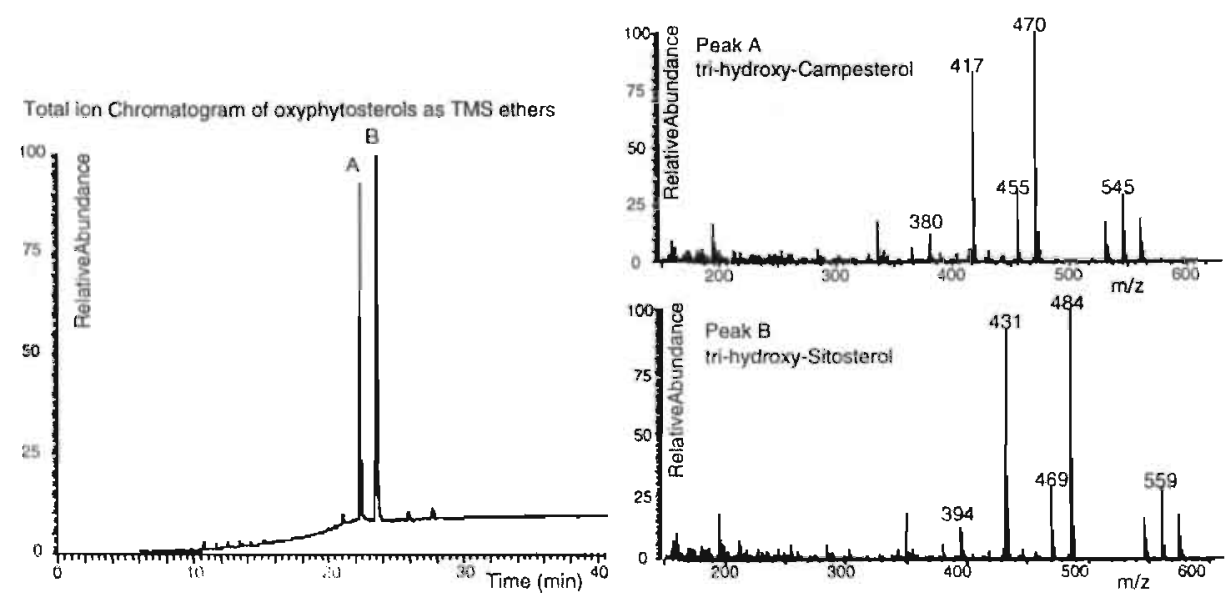

Figure 6: The fragmentation patterns of the $3 \beta, 5 \alpha, 6 \beta$-tri-hydroxy plant sterol standard analyzed by GCMS as described in the methods. The chromatogram shows a pure mixture of $3 \beta, 5 \alpha, 6 \beta$ - tri-

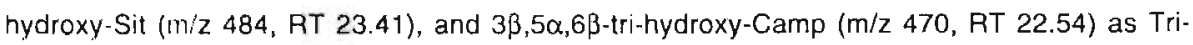
TMS derivatives.

Patients and fat emulsions

Serum, sampled at three different time points, from a phytosterolemic patient was used for analysis of oxidized plant sterols. The patient was in 1998 a 12 year-old girl 
and treated for her illness with cholestyramine ( $4 \mathrm{~g} /$ day). Two serum samples obtained at different time points in 1998 , stored at $-20^{\circ} \mathrm{C}$ with $\mathrm{BHT}$ added, as well as a recent fresh blood sample from the year 2000 obtained on the day of analysis, were used. Furthermore, serum from two CTX patients, not treated at the moment of blood sampling, was used. The blood samples were taken in 1998 and stored at $-20^{\circ} \mathrm{C}$ with $\mathrm{BHT}$ since then. In addition, serum from 15 patients, not suffering from any sterol metabolism related disease, was pooled and analyzed.

Two soy-bean oil based fat emulsions, which are frequently used in total parental nutrition protocols were analyzed by the same procedures as described for serum samples.

$7 \alpha-\mathrm{OH}-\mathrm{Chol}$ and plant sterol analysis

$7 \alpha-\mathrm{OH}-\mathrm{Chol}(18)$ and plant sterol concentrations (19) were analyzed as described before.

\section{Results}

Plant sterols and $7 \alpha-\mathrm{OH}-\mathrm{Chol}$

Serum plant sterol concentrations from the phytosterolemic patient contained large amounts of plant sterols at all time points (table 2). PSerum plant sterol concentrations (sitosterol + campesterol) from the phytosterolemic patient were 47.3, 44.5 and $40.3 \mathrm{mg} / \mathrm{dL}$ respectively compared to $1.3 \mathrm{mg} / \mathrm{dL}$ in the pool serum of nonphytosterolemic patients (table 2). Since esterified plant sterols are transported in the circulation in lipoproteins, concentrations are usually expressed relative to those of cholesterol. However, since serum cholesterol concentrations were not increased to the same extent as plant sterol concentrations, cholesterol-standardized sitosterol and campesterol concentrations were also still extremely high. Sitosterol concentrations were $19714 \times 102,18007 \times 102$, and $16714 \times 10^{2} \mu \mathrm{mol} / \mathrm{mmol}$ cholesterol, while campesterol concentrations were $9200 \times 10^{2}, 8289 \times 10^{2}$, and $8909 \times 10^{\prime \prime} \mu \mathrm{mol} / \mathrm{mmol}$ cholesterol. Compared to concentrations from the pool serum of non-phytosterolemic patients, cholesterol-standardized plant sterol concentrations were approximately 60 to70 times increased.

Serum concentrations of $7 \alpha-\mathrm{OH}-\mathrm{Chol}$ were approximately $83.3 \mathrm{ng} / \mathrm{mL}$ in the phytosterolemic patient receiving $4 \mathrm{~g} /$ day of cholesteryramine. This concentration was comparable to the value of $76.3 \mathrm{ng} / \mathrm{mL}$, as observed in pool serum (table 3). As expected, CTX patients had very high concentrations of $7 \alpha-\mathrm{OH}-\mathrm{Chol}$, about 10 to 15 times higher compared to pool- and phytosterolemic serum. 
Table 2: Serum plant sterol and oxidized sitosterol concentrations in a

phytosterolemic patient treated with cholestyramine ( $4 \mathrm{~g} /$ day)

\begin{tabular}{lccc}
\hline & 1998 & 1998 & 2000 \\
\hline Plant sterols $(\mathrm{mg} / \mathrm{dL})$ & 47.3 & 44.5 & 40.3 \\
Oxidized sitosterol forms $(\mu \mathrm{g} / \mathrm{mL})$ & & & \\
$7=\mathrm{O}-$ Sit & 0.82 & 0.99 & $\mathrm{ND}$ \\
$7 \beta-\mathrm{OH}$-Sit & 0.82 & 0.93 & 1.90 \\
$5 \alpha, 6 \alpha$-epoxy-Sit & 2.77 & 2.23 & 1.38 \\
$3 \beta, 5 \alpha, 6 \beta$-tri-hydroxy-Sit & 0.08 & 0.15 & 4.21 \\
Total oxıdized sitosterol & 4.49 & 4.30 & \\
\end{tabular}

Plant sterols are calculated as the sum of sitosterol and campesterol

ND: not detectable

Serum from a phytosterolemic patient at three different time points was used for analysis of oxidized plant sterols. Two serum samples were obtained at different time points in 1998 , stored at $-20^{\circ} \mathrm{C}$ with $\mathrm{BHT}$ added, and analyzed together with a fresh blood sample from the year 2000, obtained on the day of analysis.

\section{GC-MS assay for oxidized plant sterols}

For the identification and quantification of oxidized plant sterols in serum we have first developed a GC-MS assay, as described in the method section. First, standard curves of all individual compounds were made, after preparing a standard mixture with the same procedures as described for the serum samples. For this, crystals of all synthesized standards were dissolved in ethanol in a final concentration of $10 \mathrm{mg} / 100$ $\mathrm{mL}$. Correlation coefficients for the different standards, as measured in a range of 0 to 4 $\mu \mathrm{g} / \mathrm{mL}$, were at least 0.96 . The detection limits, as calculated according DIN32645 procedures, were $0.41 \mu \mathrm{g} / \mathrm{mL}$ for $7=0$-Sit, $0.48 \mu \mathrm{g} / \mathrm{mL}$ for $7 \alpha-\mathrm{OH}-\mathrm{Sit}, 0.67 \mu \mathrm{g} / \mathrm{mL}$ for $7 \beta$-OH-Sit, $0.54 \mu \mathrm{g} / \mathrm{mL}$ for $5 \alpha, 6 \alpha$-epoxy-Sit, $0.83 \mu \mathrm{g} / \mathrm{mL}$ for $5 \beta, 6 \beta$-epoxy-Sit, and 0.65 $\mu \mathrm{g} / \mathrm{mL}$ for tri-hydroxy-Sit.

\section{Artificial ex vivo oxidation}

As indicated above we were extremely careful to inhibit artificial oxidation of plant sterols during work-up. For example, BHT was added in excess both during serum sampling and again before work-up procedures. Further, EDTA was also added before work-up, and fluids were saturated with nitrogen to remove oxygen before being used. Finally, oxysterols were separated from non-oxidized sterols as fast as possible. To 
examine the possibility of ex vivo oxidation during sample preparation, we worked up four different amounts of the plant sterol mixture, corresponding to the range of plant sterol concentrations as can be present in phytosterolemic serum (10 to $40 \mathrm{mg} / \mathrm{dL}$ ) according the same procedures as described for the serum samples. As shown in figure 7, a small amount of $7=\mathrm{O}$-Sit, $7 \alpha-\mathrm{OH}$-Sit, $5 \alpha .6 \alpha$-epoxy-Sit and tri-hydroxy-Sit was present in all samples. These amounts, however, were independent of the initial sitosterol concentration. For $7=0$-Sit and tri-hydroxy-Sit these amounts were derived from $d_{0}-7=0$-Sit and $d_{0}$-tri-hydroxy-Sit as present in the deuterated intemal standards. This finding means that the formation of these specific oxidized plant sterols in our assay is independent of the sitosterol concentration of the sample. We therefore corrected the serum samples of the patients and the lipid emulsions by subtracting the base amounts of these oxyphytosterols. As shown in figure 7 , the amount of $7 \beta-\mathrm{OH}$-Sit increased linearly in relation to the sitosterol concentration of the sample. The correction for ex vivo oxidation for $7 \beta-\mathrm{OH}$-Sit was therefore based on the sitosterol concentration present in the serum samples of the patients. For campesterol, $7 \alpha-\mathrm{OH}-\mathrm{Camp}$ and $7 \beta-$ $\mathrm{OH}$-Camp formation were also related to the campesterol concentration in the sample.

\section{Oxyphytosterols}

Serum from the phytosterolemic patient contained significant amounts of oxyphytosterols at all time points (table 2). $7 \alpha-\mathrm{OH}$-Sit was the most abundant oxidized plant sterol in serum, followed by $5 \alpha, 6 \alpha$-epoxy-Sit, $7=\mathrm{O}-\mathrm{Sit}, 7 \beta-\mathrm{OH}-\mathrm{Sit}$, and tri-hydroxySit. $5 \beta, 6 \beta$-Epoxy-Sit could not be detected. Concentrations of $7 \alpha-\mathrm{OH}$-Sit in all phytosterolemic serum samples - and also in both lipid emulsions - were rather high as we can not exclude the possibility of autoxidation of $7 \alpha-\mathrm{OH}$-Sit. However, based on the corrections for autoxidation as described above, there was no indication of artificial oxidation of sitosterol during work-up of our samples. Further, most of the non-oxidized plant sterols were separated from oxidized sterols during elution on the Bond Elut silica cartridges, making oxidation of plant sterols after this separation impossible. However, since we are not entirely sure that the analyzed $7 \alpha-\mathrm{OH}$-Sit concentration is a real reflection of the in vivo situation, we have decided not to use $7 \alpha-\mathrm{OH}$-Sit in the calculations. The percent of oxidized sitosterol in serum of phytosterolemic patients was around $1.4 \%$. If at least a part of the $7 \alpha-\mathrm{OH}$-Sit signal is from non-artificial $7 \alpha-\mathrm{OH}$-Sit formation, this is even an underestimation. Also $7 \alpha-\mathrm{OH}$-Camp and $7 \beta$-OH-Camp could be identified in serum, while no $7=0$-Camp, epoxy-Camp and tri-hydroxy-Camp could be detected. Although a positive identification of oxidized campesterol molecules ( $7 \alpha-$ $\mathrm{OH}$-Camp and $7 \beta-\mathrm{OH}$-Camp) was possible, exact concentrations can not be calculated 
because of difficulties in analyzing the campesterol internal standards. If we used the sitosterol internal standards for these calculations, it appeared that the percent of oxidized campesterol in serum of phytosterolemic patients was similar to sitosterol.
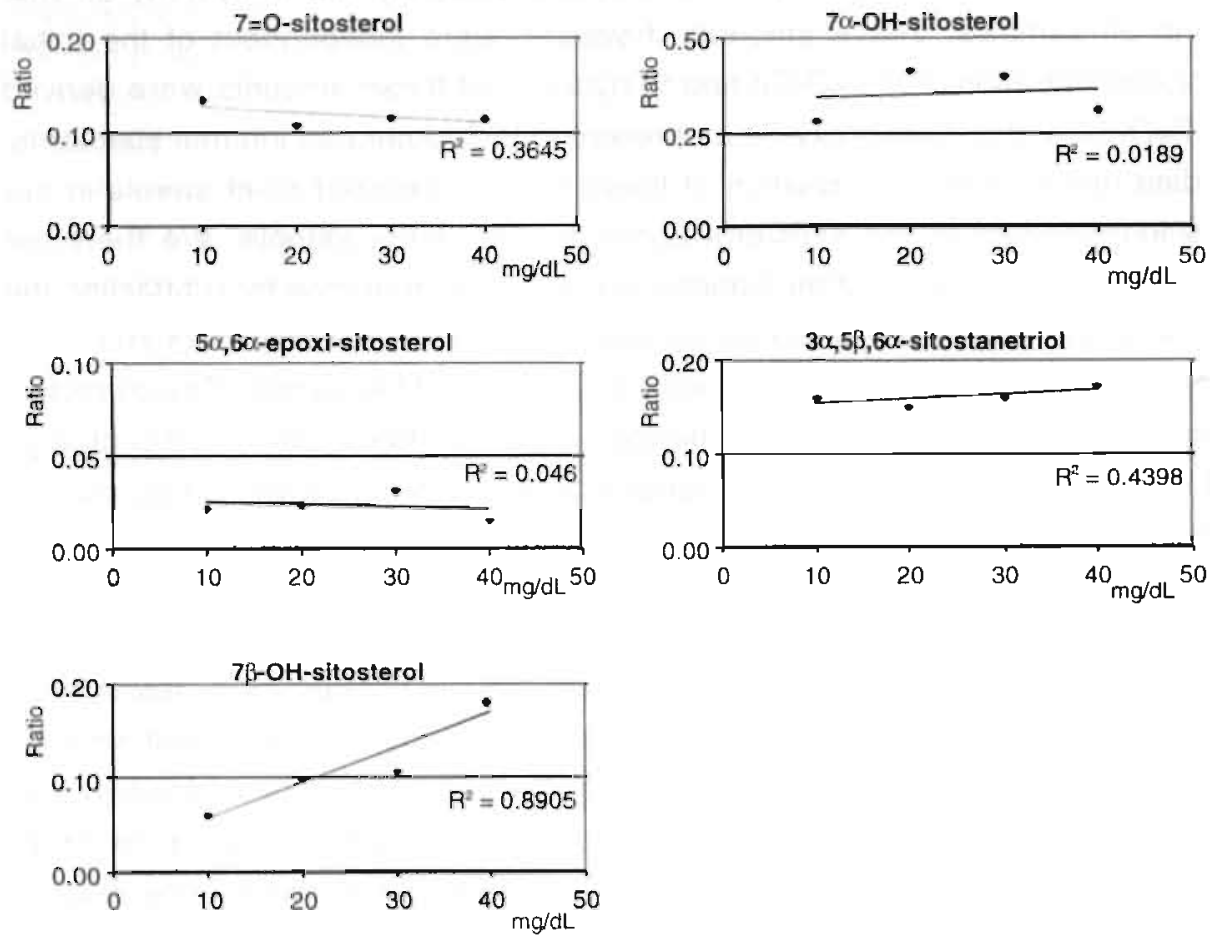

Figure 7: To determine ex vivo oxidation and to create correction factors for our further calculations, we worked up four different amounts of a plant sterol mixture. A constant amount of $7=0-S i t, 7 \alpha-$ $\mathrm{OH}$-Sit, $5 \alpha, 6 \alpha$-epoxy-Sit and tri-hydroxy-Sit was present in all samples, which was independent of the sitosterol concentration. This amount was subtracted from the values found in all samples. The $7 \beta-\mathrm{OH}$-Sit concentration, however, increased in relation to the sitosterol concentration. Therefore the correction for ex vivo oxidation for $7 \mathrm{\beta}-\mathrm{OH}$-Sit was based on the individual sitosterol concentration present in the serum samples of the patients. The concentration sitosterol in the sample (mg/dL) on the $x$-axis is plotted versus the ratio of the peak area oxyphytosterol/peak area intemal standard ( $y$-axis). 
Table 3: Serum plant sterol and oxidized sitosterol concentrations in three samples of a phytosterolemic patient versus two CTX patients and pool serum

\begin{tabular}{|c|c|c|c|c|c|c|}
\hline \multirow[b]{2}{*}{ Plant sterols (mg / dL) } & \multirow{2}{*}{$\begin{array}{c}\text { Control serum } \\
\text { \.3 }\end{array}$} & \multicolumn{2}{|c|}{ Phytosterolemia } & \multicolumn{3}{|c|}{ CTX } \\
\hline & & 44.0 & \pm 3.5 & 1.2 & and & 1.4 \\
\hline \multicolumn{7}{|c|}{ Oxidized sitosteral forms $(\mu \mathrm{g} / \mathrm{mL})$} \\
\hline $7=0-$ Sit & ND & 0.92 & \pm 0.09 & 0.04 & and & ND \\
\hline $7 \beta-\mathrm{OH}-\mathrm{Si}$ & ND & 0.88 & \pm 0.08 & 0.01 & and & ND \\
\hline $5 u, 6 \alpha$-epoxy-Sit & ND & 2.33 & \pm 0.44 & ND & and & ND \\
\hline $3 \beta .5 \alpha, 6 \beta$-tri-hydroxy-Sit & ND & 0.54 & \pm 0.73 & ND & and & ND \\
\hline $7 \propto-\mathrm{OH}-\mathrm{Chol}(\mathrm{ng} / \mathrm{mL})$ & 76.3 & 83.3 & \pm 36.9 & 1221 & and & 671 \\
\hline
\end{tabular}

Values are mean $\pm S D$

Plant sterols are calculated as the sum of sitosterol and campesterol

ND: not detectable

To examine whether $7 \alpha-\mathrm{OH}$-Sit could be formed endogenously, we have analyzed serum from CTX patients. These CTX patients are characterized by a very high $7 \alpha$-hydroxylase activity, which may also lead to the endogenous formation of $7 \alpha$ $\mathrm{OH}$-Sit. In these two CTX patients, serum plant sterol concentrations were respectively 1.2 and $1.4 \mathrm{mg} / \mathrm{dL}$, which was comparable to concentrations in pool serum (table 3). As expected, $7 \alpha-\mathrm{OH}-\mathrm{Chol}$ concentrations were increased. We could however not identify $7 \alpha-\mathrm{OH}$-Sit in serum from CTX patients. In fact, none of the oxidized plant sterols was present in CTX serum in amounts above our detection limits. This might indicate that no enzymatic formation of $7 \alpha-\mathrm{OH}-\mathrm{Sit}$ occurs in vivo in humans, even in a situation of high $7 \alpha$-hydroxylase activity. However, it is also possible that serum oxidized plant sterol concentrations in CTX patients are below our detection limits.

\section{Lipid emulsions}

Analysis of two different frequently used soy-bean oil based lipid emulsions showed that emulsion A contained less plant sterols compared to emulsion $B$ whereas emulsion A contained more cholesterol. Oxidized plant sterol concentrations were somewhat higher in emulsion $\mathrm{B}$. The ratios of oxidized sitosterol / sitosterol were, however, comparable and 0.038 in emulsion $A$ and 0.041 in emulsion $B$. This suggests that the higher oxyphytosterol concentrations in emulsion $\mathrm{B}$ were simply due to higher 
plant sterol concentrations. $7 \alpha-\mathrm{OH}-\mathrm{Chol}$ concentrations in emulsion $\mathrm{A}$ were twice as high as compared to emulsion $\mathrm{B}$.

Table 4: Serum plant sterol and oxidized sitosterol concentrations in lipid emulsions

\begin{tabular}{lcc}
\hline & Emulsion A & Emulsion B \\
\cline { 2 - 3 } Cholesterol (mg / dL) & 29.8 & 17.8 \\
Plant sterols (mg / dL) & 11.3 & 27.7 \\
Sitosterol (mg / dL) & 8.6 & 20.1 \\
Campesterol (mg/ dL) & 2.7 & 7.6 \\
Oxidized sitosterol forms $(\mu \mathrm{g} / \mathrm{mL})$ & & \\
$7=$-Sit & 0.70 & 1.26 \\
$7 \beta$-OH-Sit & 0.65 & 0.37 \\
$5 \alpha, 6 \alpha$-epoxy-Sit & 2.73 & 9.24 \\
$3 \beta, 5 \alpha, 6 \beta$-tri-hydroxy-Sit & 0.16 & 0.49 \\
$7 \alpha$-OH-Chol (ng/ mL) & 19.5 & 9.7 \\
\hline
\end{tabular}

Plant sterols are calculated as the sum of sitosterol and campesterol

ND: not detectable

\section{Discussion}

Feeding LDL receptor (-/-) and apoE (-/-) mice oxysterols (a mixture of $7-10 \%$ $7 \alpha-\mathrm{OH}$-Chol, $15-20 \% 7 \beta-\mathrm{OH}$-Chol, $15-20 \% 5 \beta, 6 \beta$-epoxy-Chol, $10-15 \% 5 \alpha, 6 \alpha-$ epoxy-Chol, $40-45 \% 7$-keto-Chol and traces of $25-\mathrm{OH}-\mathrm{Chol}$ ) accelerated fatty streak leasion formation as compared to cholesterol feeding (20). This confirms earlier ideas that oxidized forms of cholesterol (oxysterols) are atherogenic and may play a role in plaque development in humans (4). Most information about their possible atherogenicity, however, is derived from in vitro studies showing that oxysterols are cytotoxic to several cell types (21) -including endothelial cells $(22,23)$, U937 monocytes (24) and HepG2 liver cells (24)- and may induce apoptosis $(24,25,26)$. For humans, however, no causal relation so far has been established between oxysterols and leasion formation, but several findings are suggestive. For example, the highest oxysterol / cholesterol ratio was found in the most atherogenic LDL subfractions (LDL) (27). Furthermore, the ratio of oxysterol / cholesterol is higher in foam cells isolated from atherosclerotic plaques than in plasma (28). Foam cells play a crucial role in early fatty streak formation. Therefore, expanding our knowledge about the presence of oxysterols in the circulation is of great importance. Not only because of their potential 
atherogenicity, but also because oxysterols have several other biological effects, such as the regulation of gene expression (28). Whether oxyphytosterols also possess atherogenic and / or gene regulatory characteristics needs further study.

It is very difficult to distinguish between oxysterols derived from the diet and endogenously formed (29). Breuer et al. (30) have shown that $7=\mathrm{O}-\mathrm{Chol}, 7 \mathrm{\beta}-\mathrm{OH}-\mathrm{Chol}$. 24- $\mathrm{OH}-\mathrm{Chol}$ and $25-\mathrm{OH}-\mathrm{Chol}$ are formed endogenously in contrast to epoxides. In our study we have not tried to trace the origin of the oxyphytosterols. From the literature, there was only limited evidence on the presence of oxyphytosterols in the circulation (12). We therefore decided first to set-up a sensitive GC-MS assay, which enabled us to accurately analyze many different oxyphytosterols in human serum. We have shown that similar oxidation products as formed from cholesterol were present in serum from phytosterolemic patients. We were able to identify $7=\mathrm{O}-\mathrm{Sit}, 7 \beta-\mathrm{OH}$-Sit, $5 \alpha, 6 \alpha$-epoxy-Sit, $3 \beta, 5 \alpha, 6 \beta$-tri-hydroxy-Sit, and most probably $7 \alpha-\mathrm{OH}$-Sit as well. $7 \alpha-\mathrm{OH}$-Camp and $7 \beta$ $\mathrm{OH}$-Camp, two campesterol oxidation products, were also found. A recent study found that plant sterol oxides and cholesterol oxides showed the same cytotoxic effects in a cultured macrophage-derived cell line (13).

It is generally accepted that $7 \alpha-\mathrm{OH}-\mathrm{Chol}$ is derived from both enzymatic and nonenzymatic oxidation, whereas $7 \beta-\mathrm{OH}-\mathrm{Chol}$ is entirely derived from non-enzymatic origin (4). Therefore, $7 \beta-\mathrm{OH}-\mathrm{Chol}$ may be a better marker for free radical related lipid peroxidation than $7 \alpha-\mathrm{OH}-\mathrm{Chol}$. Two separate studies have now shown that in humans especially $7 \beta-\mathrm{OH}-\mathrm{Chol}$ is associated with the risk for atherosclerosis $(31,32)$. Interestingly, the in vitro toxicity of $7 \beta-\mathrm{OH}-\mathrm{Chol}$ could not be counteracted by antioxidants (33). Rabbit studies also showed no reduction in serum $7 \beta-\mathrm{OH}-\mathrm{Chol}$ concentrations after probucol treatment (34), vitamin E supplementation (35) or vitamin $\mathrm{E}+\mathrm{C}$ supplementation (36). In human diabetic patients, however, vitamin $\mathrm{E}$ supplementation lowered both $7 \beta-\mathrm{OH}-\mathrm{Chol}, 7=\mathrm{O}-\mathrm{Chol}$, and triols (37). However, since antioxidant supplementation may lower the risk for atherosclerosis, these findings indicate that a causal relation between $7 \mathrm{\beta}-\mathrm{OH}$-Chol with coronary heart disease, is still controversial. However, since $7 \beta-\mathrm{OH}$-Sit and $7 \beta-\mathrm{OH}$-Camp are also present in serum from phytosterolemic patients, it seems relevant to determine whether these oxyphytosterols are also atherogenic in vivo and whether antioxidants affect oxyphytosterol concentrations and toxicity.

It has been suggested that sitosterol inhibits cholesterol $7 \alpha$-hydroxylase activity $(38,39)$, possibly by stereochemical hindrance of the ethyl group at C24 in sitosterol. 
Indeed, patients with phytosterolemia have a reduced cholesterol $7 \alpha$-hydroxylase activity (40) and consequently a lower bile acid synthesis (19). However, in cholesterol free microsomes $7 \alpha-\mathrm{OH}$-Sit was formed, suggesting that at a relatively high ratio of sitosterol to cholesterol some conversion of sitosterol may occur (41). Since this ratio is increased in serum from phytosterolemic patients, $7 \alpha-\mathrm{OH}$-Sit might be formed in phytosterolemic patients. This might also explain why Boberg et al. (38) could not show any conversion of sitosterol into $7 \alpha-\mathrm{OH}$-Sit in human liver microsomes isolated from non-phytosterolemic patients. The fact that we were able to identify $7 \alpha-\mathrm{OH}$-Camp strengthens our assumption that $7 \alpha-\mathrm{OH}$-Sit may be formed to some extent in phytosterolemic subjects.

Interestingly, approximately $1.4 \%$ of the sitosterol molecules in phytosterolemic serum was oxidized, which is rather high compared to the approximate $0.01 \%$ oxidatively modified cholesterol $(37,42)$ normally present in human serum. This could indicate that plant sterols are more susceptible to oxidation, as suggested before (8). Another explanation might be that - in contrast to cholesterol - plant sterols can not be converted into bile acids. In pool serum from non-phytosterolemic patients and in CTX patients no oxyphytosterols could be detected. This suggests that with our assay rather high serum concentrations are needed to find oxidized forms of these plant sterols. It should be mentioned that others recently reported oxyphytosterol concentrations of 0.3 $\mu \mathrm{g} / \mathrm{mL}$, but no details on the type of analysis and the origin of the serum were provided (12). It seems therefore worthwhile to lower the detection limits of our assay, for example by using $\mathrm{Cl}$-negative-ion-GC-MS.

Soy-based lipid emulsion used in parental nutrition protocols- may be associated with a higher prevalence of cholestasis, especially in children $(43,44)$. Indeed, a 3-yearold patient with total parenteral nutrition associated cholestasis showed a high serum plant sterol concentration (45). It is therefore tempting to suggest that the intravenous administration resulted in accumulation of plant sterols (44). We have now found that two different soy-bean oil based lipid emulsions contain not only plant sterols, but that a part of these plant sterols is present in its oxidized form. It would be interesting to examine the role of oxyphytosterols in the pathology described.

In conclusion, we have shown that oxidized forms of plant sterols are present in serum from phytosterolemic patients and two frequently used lipid emulsions. It is however unknown whether oxidized plant sterols also affects health, as has been 
suggested for oxysterols. One of the most atherogenic oxysterols is $7 \beta-\mathrm{OH}-\mathrm{Chol}$ and we have now found both $7 \beta-\mathrm{OH}$-Sit and $7 \beta-\mathrm{OH}$-Camp in serum from phytosterolemic patients. The relevance of these findings needs further investigation.

\section{References}

1. Ling WH, Jones PJH. Minireview dietary phytosterols: a review of metabolism, benefits and side effects. Life Sciences. 1195; 57: 195-206

2. Smith LL.Review of progress in sterol oxidations: 1987-1995. Lipids 1996;31:453-487

3. Russell DW, Setchell KD. Bile acid biosynthesis. Biochemistry 1992;31:47374749

4. Brown, A.J., and W. Jessup. Oxysterols and atherosclerosis. Atherosclerosis 1999;142:1-28

5. Chang $\mathrm{YH}_{2}$ Abdalla DSP, Sevanian A. Characterization of cholesterol oxidation products formed by oxidative modification of low density lipoprotein. Free Rad Biol Med 1997;23:202-214

6. Patel RP, Diczfalusy U, Dzeletovic $S$, Wilson MT, Darley-Usmar VM. Formation of oxysterols during oxidation of low density lipoprotein by peroxynitrite, myoglobin, and copper, J Lipid Res 1996;37:2361-2371

7. Daly $G G$, Finocchairo $E T$, Richardson $T$. Characterization of some oxidation products of sitosterol. J Agric Food Chem 1983;31:46-50

8. Li W, Przybylski R. Oxidation products formed from phytosterols. INFORM 1995;6:499-500

9. Dutta, PC, Appelquist L. Studies on phytosterol oxides I: Effect of storage on the content in potato chips prepared in different vegetable oils. JAOCS 1997;74:647-65T

10. Dutta PC. Studies on phytosterol oxides. II: Content in some vegetable oils and in French fries prepared in these oils. JAOCS 1997;74:659-666

11. Grandgirard A, Sergiel JP, Nour M, Demaison-Meloche $J$, Ginies $C$. Lymphatic absorption of phytosterol oxides in rats. Lipids 1999;34:563-570

12. Grandgirard A, Bretillon L, Martine L, Beaufrere B. Oxyphytosterols in human plasma. Chem Phys Lipids 1999;101:198

13. Adcox G, Boyd L, Oehrl L, Allen J, Fenner G. Comparative effects of phytosterol oxides and cholesterol oxides in cultures macrophage-derived cell lines. J Agric Food Chem 2001;49:2090-2095

14. Salen G, Horak I, Rothkopf M, Cohen JL, Speck J, Tint GS, Shore V, Dayal B, Chen $T$, Shefer S. Lethal atherosclerosis associated with abnormal plasma and tissue sterol composition in sitosterolemia with xanthomatosis. I Lipid Res 1985;26:1126-1133

15. Bjorkhern I, Buberg KM. Inborn errors in bite acid biosynthesis and storage of sterols other than cholesterol. In The metabolic basis of inherited diseases. C.R. Scriver, A.L. Beaudet, W.S. Sly, and D. Valle, editors. McGraw Hill, New York, NY. 1994;2073-2100

16. Li S, Pang J, Wilson WK, Schroepfer GJ. Sterol synthesis. Preparation and characterization of fluorinated and 
deuterated analogs of oxygenated derivatives of cholesterol. Chem Phys Lipids 1999;99:33-71

17. Lutjohann D, Papassotiropoulos A, Bjorkhem I, Locatelli S, Bagli M, Oehring RD, Schlegel U, Jessen F, Rao ML, von Bergmann K, Heun R. Plasma 24Shydroxycholesterol (cerebrosterol) is increased in alzheimer and vascular demented patients. J Lipid Res 2000;41:195-198

18. Hahn $C_{2}$, Reichel $C$, von Bergmann $K$. Serum concentration of $7 \alpha$ hydroxycholesterol as an indicator of bile acid synthesis in humans. J Lipid Res 1995;36:2059-2066

19. Lütjohann D, Björkhem I, Beil UF, von Bergmann K. Sterol absorption and sterol balance in phytosterolemia evaluated by deuterium-labeled sterols: effect of sitostanol treatment. J Lipid Res 1995; $36: 1763-1773$

20. Staprans I, Pan XM, Rapp JH, Grunfeld C, Feingold KR. Oxidized cholesterol in the diet accelerates the development of atherosclerosis in LDL receptor- and apolipoprotein E-deficient mice. Arterioscler Thromb Vasc Biol. 2000;20:708-714

21. Smith LL, Johnson BH. Biological activities of oxysterols. Free Rad Biol Med $1989 ; 7: 285-332$

22. Zhou Q, Wasowicz E, Handler $B$, Fleischer L, Kummerow KA. An excess concentration of oxysteruls in the plasma is cytotoxic to cultures endothelial celis. Atherosclerosis 2000;149:191-197

23. Pettersen JS, Boberg KM, Stabursvik A, Prydz $H$. Toxicity of oxygenated cholesterol derivatives towards cultured human umbilical vein endothelial cells. Arterioscler Thromb 1991;11:423-428

24. O'Callaghan YC, Woods JA, O'Brien NM. Oxysterol induced cell death in U937 and HepG2 cells at reduced and normal serum concentrations. Eur J Nutr 1999;38:255262

25. Nishio E, Watanabe Y. Oxysterols induced apoptosis in cultured smooth muscle cells through CPP32 protease activation and bcl-2 protein down regutation. Biochem Biophys Res Com 1996;226:928-934

26. Harada K, Ishibashi S, Miyashita T, Osuga J, Yagyu $H$, Onashi $K$, Yazaki $Y$, Yamada N. Bct-2 protein inhibits oxysterol-induced apoptosis through suppressing CPP32-mediated pathway. FEBS Letters 1997;411:63-66

27. Sevanian A, Bittolo-Bon G, Cazzolato G, Hodis $\mathrm{H}_{2}$ Hwang $\mathrm{J}$, Zamburlini A, Maiorino $M$, Ursini F. LDL- is a lipid hydroperoxideenriched circulating protein. J Lipid Res 1997;38:419-428

28. Mattson-Hulten L, Lindmark H, Diczfalusy $U$, Björkhem I, Ottosson M, Liu $Y$, Bondjers G, Wiklund $\mathrm{O}$. Oxysterols present in atherosclerotic tissue decrease the expression of lipoprotein lipase messenger RNA in human monocytederived macrophages. J Clin Invest 1996;97:461-468

29. Sevanian A, Seraglia R, Traldi P, Rossato $P$, Ursini $F$, Hodis $H$. Analysis of plasma cholesterol oxidation products using gasand high performance liquid chromatography / mass spectrometry. Free Rad Biol Med 1994;17:397-409

30. Breuer $\mathrm{O}$, Björkhem $\mathrm{I}$. Use of an ${ }^{18} \mathrm{O}_{2}$ inhalation technique and isotopomer 
distribution analysis to study oxygenation of cholesterol in rat: evidence for in vivo formation of 7-oxo-, 7b-hydroxy-, 24hydroxy- and 25-hydroxycholesterol. J Biol Chem 1995;270:20278-20284

31. Salonen JT, Nyyssonen $K$, Salonen R, Porkkala-Sarataho $E$, Tuomainen $T$. Diczfalusy U, Björkhem I. Lipoprotein oxidation and progression of carotid atherosclerosis. Circulation 1997;95:840845

32. Zieden B, Diczfalusy U. Higher $7 \beta$ hydroxycholesterol in high cardiovascular risk population. Atherosclerosis 1997:134:172

33. Colles SM, Irwin KC, Chisolm GM. Roles of multiple oxidized LDL lipids in cellular injury: dominance of $7 \beta$ hydroperoxycholesterol. J Lipid Res 1996;37:2018-2028

34. Stalenhoef AFH, Kleinveld HA, KosmeijerSchuil TG, Demacker PNM, Katan MB. In vivo oxidized cholesterol in atherosclerosis. Atherosclerosis 1983;98:113-114

35. Wiseman SA, van den Boom MAP, de Fouw NJ, Wassink MG, op den Kamp JAF, Tijburg LBM. Comparison of the effects of dietary vitamin $E$ on in vivo and in vitro parameters of lipid peroxidation in the rabbit. Free Rad Biol Med 1995:19:617-627

36. Mahfouz MM, Kawano $H$, Kummerow FA. Effect of cholesterol-rich diets with and without added vitamins $E$ and $C$ on the severity of atherosclerosis in rabbits. Am J Clin Nutr 1997;66:1240-1249

37. Mol MJTM, de Rijke YB, Demacker PNM, Stalenhoef AFH. Plasma levels of lipid and cholesterol oxidation products and cytokines in diabetes mellitus and cigaretle smoking: effects of vitamin $E$ treatment. Atherosclerosis 1997; 129:16917638.

38. Boberg KM, Einarsson K, Björkhem 1. Apparent lack of conversion of sitosterol into C24-bile acids in humans. J Lipid Res 1990;31:1083-1088

39. Boberg KM, Akerlund JE, Björkhem I. Effect of sitosterol on rate limiting enzymes in cholesterol synthesis and degradation. Lipids 1989;24:9

40. Shefer S, Hauser S, Lapar V, Mosbach EH. Regulatory effects of sterols and bile acids on hepatic hydroxy-3-methyl-glutaryl Coa reductase and cholesterol $7 \alpha$-hydroxylase in the rat. J Lipid Res 1973;14:573

41. Shefer S, Salen G, Nguyen L, Batta AK, Packin V, Tint GS, Hauser S. Competative inhibition of bile acid synthesis by endogenous cholestanol and sitosterol in sitosterolemia with xanthomatosis; Elfect on cholesterol $7 \alpha$-hydroxylase. J Clin Invest 1988;82:1833-1839

42. Murakami $H$, Tamasawa $N$, Matsui J, Yasujima $M$, Suda T. Plasma oxysterols and tocopherol in patients with diabetes mellitus and hyperlipidemia. Lipids 2000:35:333-338

43. Moss RL, Amii LA. New approaches to understanding the etiology and treatment of total parenteral nutrition- asscciated cholestasis. Semin Pediatr Surg 1999:8:140-147

44. Bindl L, Lütjohann D, Buderus S, Lentze $\mathrm{MJ}$, von Bergmann K. High plasma levels of phytosterols in patients on parenteral nutrition: a marker of liver dysfunction. J Pediatr Gastroenterol Nutr 2000:31:313316 
45. Ciayton $P T$, Whitfield $P$, Lyer $K$. The role of phytosterols in the pathogenesis of liver complications of pediatric parental nutrition. Nutrition 1998:14:158-164 
Chapter 9

General discussion 


\section{General discussion}

The major objectives of the studies described in this thesis were to evaluate effects of plant stanol ester consumption on cardiovascular risk markers and to obtain a better understanding of the mechanisms underlying these effects. Except for effects on serum lipids and lipoproteins, we have in particular paid attention to the effects of plant stanol ester consumption on fat-soluble antioxidant concentrations. Furthermore, we have analyzed the presence of oxidized plant sterols in serum of phytosterolemic patients.

In the first part of this chapter effects of plant stanol ester consumption on serum lipids, (apo)lipoproteins and fat-soluble vitamins will be discussed, in the second part effects on cholesterol metabolism and the interaction between plant stanol ester consumption with genetic background, while the third part discusses the study on the presence of oxidized plant sterols in plasma. For parts (I) and (II) two double-blind, placebo-controlled human intervention studies were carried out and for part (III) serum from phytosterolemic patients was used. In both intervention studies experimental plant stanol ester mixtures were used, which were especially prepared for us by the RAISIO GROUP, Raisio, Finland. For this, plant sterols were first isolated from pine wood pulp or vegetable oils. Then the delta5 double bounds of these plant sterols were saturated, which resulted in the formation of plant stanols. Finally the plant stanols were esterified at the third Catom with fatty acids derived from rapeseed oil. These fat-soluble plant stanol esters can easily be incorporated into oil-based foods such as the margarines and shortenings used in the experiments described in this thesis. It should be noted, however, that plant stanol esters can also easily be incorporated into lowfat products (1). In most of the studies that will be discussed, plant stanols or sterols were esterified. If free plant sterols or stanols have been examined, this will explicitly be mentioned. It should be realized, however, that $1.6 \mathrm{~g}$ plant stanol (or sterol) esters provides roughly $1.0 \mathrm{~g}$ plant stanols and $0.6 \mathrm{~g}$ fatty acids. In many studies, like we will do, this is simply described as ' $1.0 \mathrm{~g}$ plant stanols provided as fatty acid esters' or as ' $1.0 \mathrm{~g}$ plant stanols'

\section{(I) Effects on lipids, (apo)lipoproteins and fat-soluble vitamins}

A major objective of the first study was to compare the cholesterol-lowering effects of two different plant stanol esters. At that time most studies had used plant 
stanol esters derived from pine wood, although vegetable oils are also al good source for the production of plant stanol esters. These two plant stanol sources, however, differ in their sitostanol / campestanol ratios. Pine wood contains about $92 \%$ sitostanol and $8 \%$ campestanol, while these values are $68 \%$ and $32 \%$ respectively for the vegetable oil based plant stanol ester mixture. In the literature it was postulated that the less absorbable plant stanols reduced cholesterol absorption more effectively (2). Since humans absorb less sitostanol than campestanol (3). we now hypothesized that the sitostanol / campestanol ratio might affect the cholesterol lowering efficacy of a mixture. Another aspect was that at that time all human intervention trials with wood based plant stanol esters had been carried out in Finland, the land of origin of the plant stanol esters. Therefore, a minor objective was to compare the efficacy of wood based plant stanol esters in a non-Finnish population.

Our first study showed that a daily intake of $3.8 \mathrm{~g}$ of the vegetable oil based mixture and of $4.0 \mathrm{~g}$ of the wood based mixture lowered serum LDL cholesterol concentrations to the same extent, with 14.6 and $12.8 \%$ respectively (Chapter 3 ). Relative changes in serum apo-B concentrations were essentially the same as found for LDL cholesterol, which suggests that the number of LDL particles was reduced. Serum HDL cholesterol and triacylglycerol concentrations were not affected, which agreed with all other studies in normotriglyceridemic subjects $(4,5)$.

The amount of plant stanols used in this study ( 3.8 to $4.0 \mathrm{~g} /$ day) was relatively high compared to amounts used in other studies. Therefore, it is interesting to analyze whether the decreases in serum LDL cholesterol were larger as compared to studies with lower daily intakes. In our second study (Chapter 5), also with non-hypercholesterolemic subjects, the daily consumption of plant stanols was $2.5 \mathrm{~g}$, which resulted in an LDL cholesterol reduction of around $10 \%$. In a third placebo-controlled study (not described in this thesis) a low-fat yogurt, that provided $3 \mathrm{~g}$ plant stanols a day, lowered LDL cholesterol levels with $13.7 \%$ in non-hypercholesterolemic subjects (1). Based on these data, it is tempting to suggest that LDL cholesterol concentrations are further lowered when the daily consumption exceeds $2.5 \mathrm{~g}$ plant stanols. Based on a metaanalysis of 14 independent intervention trials (6), Law, however, concluded that at a daily intake above $2 \mathrm{~g}$ / day no further LDL cholesterol reduction is apparent. In that meta-analysis, changes in $L D L$ cholesterol were expressed in $\mathrm{mmol} / \mathrm{L}$. It might be more appropriate, however, to use relative LDL cholesterol reductions, 
as the change in LDL cholesterol may depend on baseline levels. For example, the reduction of $0.47 \mathrm{mmol} / \mathrm{L}$ in a hypercholesterolemic population (7) after consumption of $2.3 \mathrm{~g}$ plant stanols was $10.6 \%$, while the decrease of $0.30 \mathrm{mmol} / \mathrm{L}$ in a non-hypercholesterolemic population after consumption of $2.5 \mathrm{~g}$ plant stanols was also $10 \%$ (Chapter 5). Figure 1 now shows the results of the same studies as used in the meta-analysis by Law (6), but we have now plotted the LDL cholesterol reductions as percentages. From this figure it may be concluded, that - in agreement with the data of our studiesa daily plant stanol intake above $2 \mathrm{~g}$ further lowers serum LDL cholesterol concentrations, but that the additional hypocholesterolemic effect diminishes. The maximal effect is reached at a daily intake around $2.5 \mathrm{~g}$. At this intake the estimated LDL cholesterol reduction is 12 to $13 \%$. It has been estimated that a reduction of $10 \%$ in serum LDL cholesterol lowers the risk for coronary heart disease by $50 \%$ at the age of 40 and by $20 \%$ at the age of 70 (8). This suggests that plant stanol ester enriched products may contribute significantly to the lowering of coronary heart disease risk.

Regarding the efficacy of plant stanol esters consumption, there were some general unproven assumptions. For example, it was thought that plant stanol esters should be consumed with each cholesterol-containing meal to reach its maximal effectiveness (9). In our second study, however, we found that consumption of $2.5 \mathrm{~g}$ plant stanol esters only at lunch resulted in a similar LDLcholesterol reduction as compared to consumption of plant stanol esters divided over the three meals (Chapter 5). Based on these results we concluded that it is not necessary to consume plant stanols at each meal or simultaneously with dietary cholesterol. In fact. post-hoc analysis showed that also no effect of consumption frequency on the cholesterol-lowering efficacy of plant stanols and sterols is evident in other studies. To illustrate this, we have depicted in figure 1 the consumption frequency of plant stanol or sterol esters. From this figure it is clear that no relationship is evident between the consumption frequency of plant sterol and stanol esters and the reduction in LDL cholesterol.

The fact that plant stanol esters lower serum LDL cholesterol concentrations effectively if consumed once a day, suggests that a reduced incorporation of cholesterol into mixed micelles is not the only mechanism for plant stanol induced cholesterol reductions. We therefore hypothesized that plant stanols remain in the intestinal lumen or enter the enterocytes thereby affecting intestinal lipoprotein metabolism. Further research is therefore necessary to better understand the 
mechanisms by which plant stanols and sterols change lipid and lipoprotein metabolism. In these studies, specific attention should be given to effects on intestinal lipoprotein metabolism.

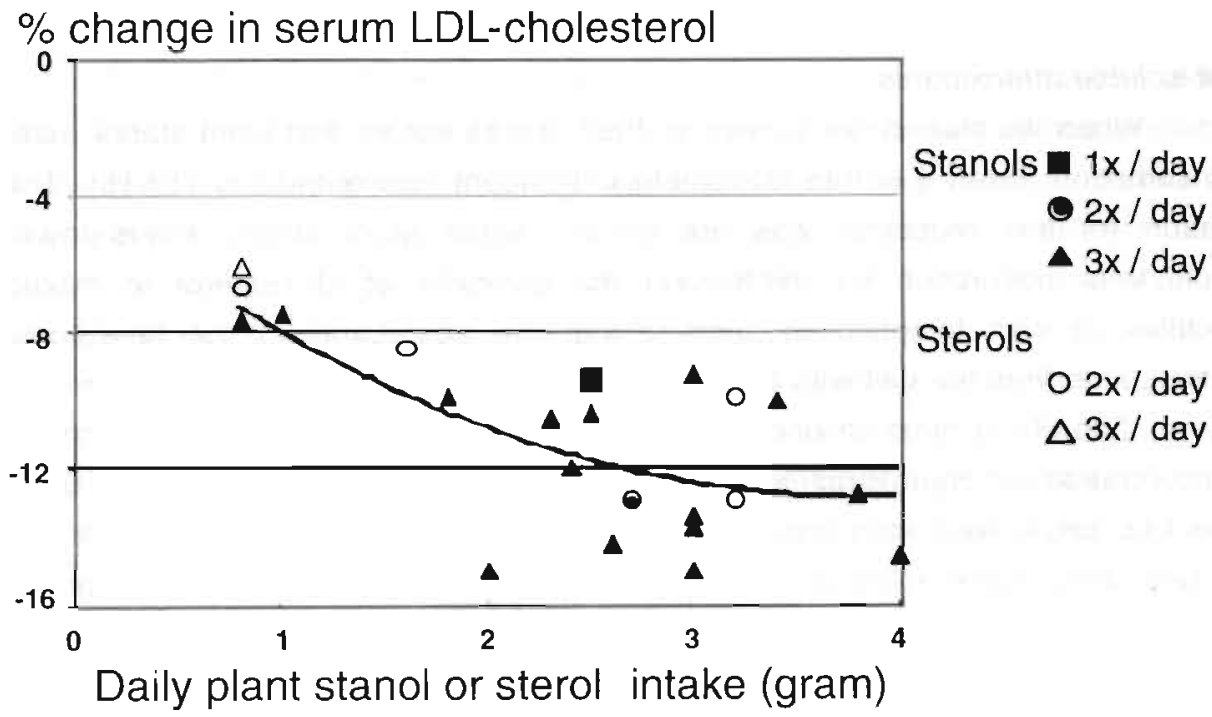

Figure 1: Placebo-adjusted percent changes in serum LDL cholesterol concentrations from randomized, double-blind trials using products enriched with plant stanols or sterols. Consumption frequency of the experimental products over the day is indicated by different symbols (based on reference 6).

HDL and apolipoprotein A-I

The fact that plant stanols do not lower serum HDL cholesterol and apoA-I concentrations is a remarkable and interesting finding. Decreasing dietary cholesterol intake or inhibiting cholesterol absorption with neomycin lowers serum HDL cholesterol concentrations $(10,11)$. Obviously these interventions affect HDL metabolism in a different way than plant stanols. In man, apoA-I is formed in the intestine and in the liver. Most information on apoA-I metabolism comes from hepatic studies, whereas the role of the intestine has not received much attention. In rats, however, at least $50 \%$ of serum apoA-I is from intestinal origin. Therefore, information on the effects of plant stanols on intestinal lipid metabolism could provide an explanation concerning the unchanged serum apoA-I concentrations. 
Since plant stanol esters lower serum total cholesterol without changing serum HDL cholesterol concentrations, there was a highly significant improvement in the total cholesterol / HDL cholesterol ratio. This ratio is a strong risk predictor for coronary heart disease (12)

\section{Fat-soluble antioxidants}

When we started our studies in 1997, it was known that plant stanol ester consumption lowered serum fat-soluble antioxidant concentrations (13-15). The reason for this reduction was not known. Since plant stanol esters lower cholesterol absorption by decreasing the solubility of cholesterol in mixed micelles, it was tempting to suggest that the absorption of the fat-soluble antioxidants from the diet was also reduced.

One of our most striking findings was the reduction in serum $\beta$-carotene concentrations of approximately $25 \%$ after the consumption of plant stanols. Even after LDL cholesterol standardization, serum $\beta$-carotene concentrations were still around 10\% lower (Chapter 4). Also concentrations of the other lipophylic hydrocarbon carotenoids ( $\alpha$-carotene and lycopene) were lowered, while concentrations of the more polar oxygenated carotenoids (lutein/zeaxanthin and $\beta$-cryptoxanthin) and of tocopherols were not lowered. An important aspect of the lowered absolute serum fat-soluble antioxidant concentrations is whether this reduction should be ascribed to a lower amount of carriers (lipoproteins) in the circulation or to a lowered intestinal absorption. Regression analysis now suggested that only the reduction of the lipophylic hydrocarbon carotenoids was associated with the lowered cholesterol absorption. Changes in oxygenated carotenoids and tocopherols were mainly associated with the lower serum cholesterol concentrations (Chapter 4).

Also in our second study we found that especially the serum hydrocarbon carotenoid concentrations were lowered during plant stanol ester consumption. Although differences between the once and the three times per day period never reached statistical significance, changes for all antioxidants studied were more pronounced after the three times per day period (Chapter 5). This may suggest that a frequent supply of small amounts of plant stanols into the intestinal tract has a more pronounced effect on fat-soluble antioxidant absorption as compared to eating the plant stanols at once. Based on the findings of both studies we suggested that plant stanols may lower the incorporation of the lipophylic hydrocarbon carotenoids into the mixed micelles. 
Not only in our studies, but in most other studies described in the literature it was found that plant stanols lowered plasma levels of the carotenes, but not of retinol (vitamin A) (16). Vitamin D is also not affected, as reviewed in chapter 2. This finding is not surprising as carotenes are transported by lipoproteins, while retinol and vitamin $D$ are not.

Figure 2 shows the percent changes in the absolute concentrations of the sum of $\alpha$-plus $\beta$-carotene and of $\alpha$-tocopherol from several randomized placebocontrolled trials with plant stanols or sterols. Values have been corrected for changes in the placebo group that did not receive products enriched with plant sterols or stanols. It appeared that the sum of $\alpha$-plus $\beta$-carotene and of $\alpha$ tocopherol decreased after consumption of plant stanols or sterols in almost all the trials. Based on this figure, it might be concluded that the percent decrease in $\alpha$ - plus $\beta$-carotene is much larger compared to $\alpha$-tocopherol. Further, there appears to be a dose-dependent relation between plant sterol or stanol intake and the percent reduction in $\alpha$ plus $\beta$-carotene levels. It may be concluded that above a daily intake of $2 \mathrm{~g}$ plant stanols or sterols no further reduction in $\alpha$ plus $\beta$ carotene reduction is evident. For $\alpha$-tocopherol, reductions were also larger at higher intakes, although no consistent dose-response relationship was apparent.

The clinical importance of the reductions in plasma carotenoids is not known, but certainly warrants attention. Based on cohort studies, antioxidants are thought to protect against various diseases such as lung cancer, as well as cardiovascular and age-related eye diseases. Greenberg et al (17), for example, showed that during a 8.2 years follow-up period, subjects in the highest quartile of plasma $\beta$-carotene concentrations at the entry of the study had a $43 \%$ and $48 \%$ decreased risk of CHD and cancer mortality respectively, as compared to subjects from the lowest quartile. Thus, also within the "normal" range of $\beta$-carotene concentrations, a relationship with the risk for cardiovascular disease may be present. Large-scale intervention trials, however, have consistently found no beneficial effect of $\beta$-carotene supplementation $(18,19)$. Unfortunately, there is not clear explanation for this apparent discrepancy. 


\section{plant stanols $\square$ / sterols $\square$ (g/day)}

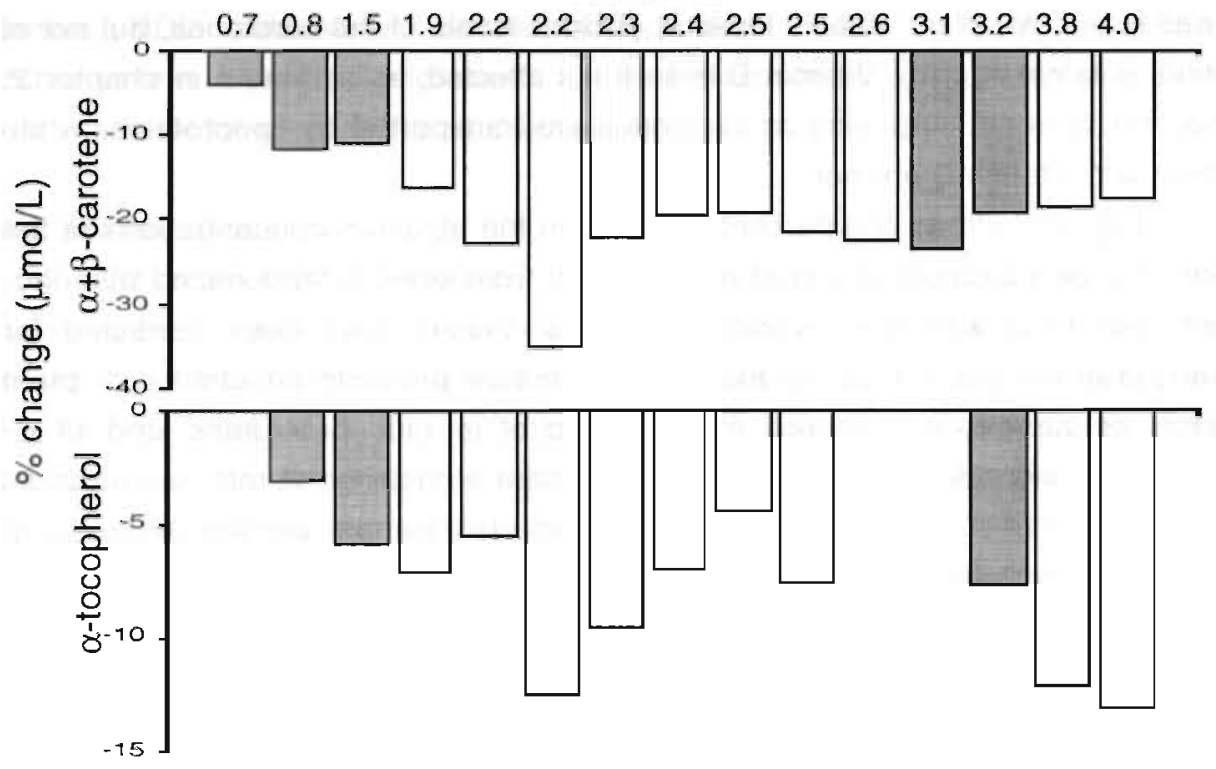

Figure 2: Placebo adjusted percent changes ( $\mu$ mol/L) in plasma $\alpha$ plus $\beta$-carotene and $\alpha$ tocopherol concentrations derived from randomized double blind trals using products enriched with plant stanols or sterols (based on reference 16).

In vitro mixed micelles

The mechanism by which plant stanols lower the concentrations of the fatsoluble vitamins is not known. In a small in vitro experiment, we have therefore compared the incorporation of three different fat-soluble antioxidants into mixed micelles with increasing sitostanol concentrations. $\beta$-Carotene was used as a hydrocarbon carotenoid, lutein as an oxygenated carotenoid and $\alpha$-tocopherol as a tocopherol. As shown in figure 3 , the incorporation of $\beta$-carotene decreases when the concentration of sitostanol increases. No effects of sitostanol were observed on the incorporation of lutein and $\alpha$-tocopherol. Results for sitosterol were essentially the same (not shown). This experiment suggests that the lower serum hydrocarbon carotenoid concentrations after plant stanol or sterol consumption is due to a lowered incorporation of $\beta$-carotene into the mixed micelles. The fact that in particular the incorporation of the highly apolar $\beta$ carotene is lowered and not of the oxygenated carotenoids might be related to the 
surface-to-core distribution of these compounds in the mixed micelles. It has been suggested that the apolar hydrocarbon carotenoids ( $\alpha$-carotene, $\beta$-carotene, lycopene) are solubilized almost exclusively in the core, white the oxygenated carotenoids are preferentially solubilized in the surface phospholipid layer (20). This suggests that plant stanols and sterols may replace not only cholesterol, but other lipophylic core compounds as well. Sheanut oil derived plant sterols, however, do significantly lower absolute and lipid standardized $\alpha+\beta$-carotene and lycopene concentrations (21), but do not change serum cholesterol concentrations. There is no explanation, however, why these components should selectively affect the incorporation of hydrocarbon carotenoids into micelles, but not of cholesterol. The precise mechanism by which plant stanols and sterols affect antioxidant metabolism remains therefore to be elucidated.

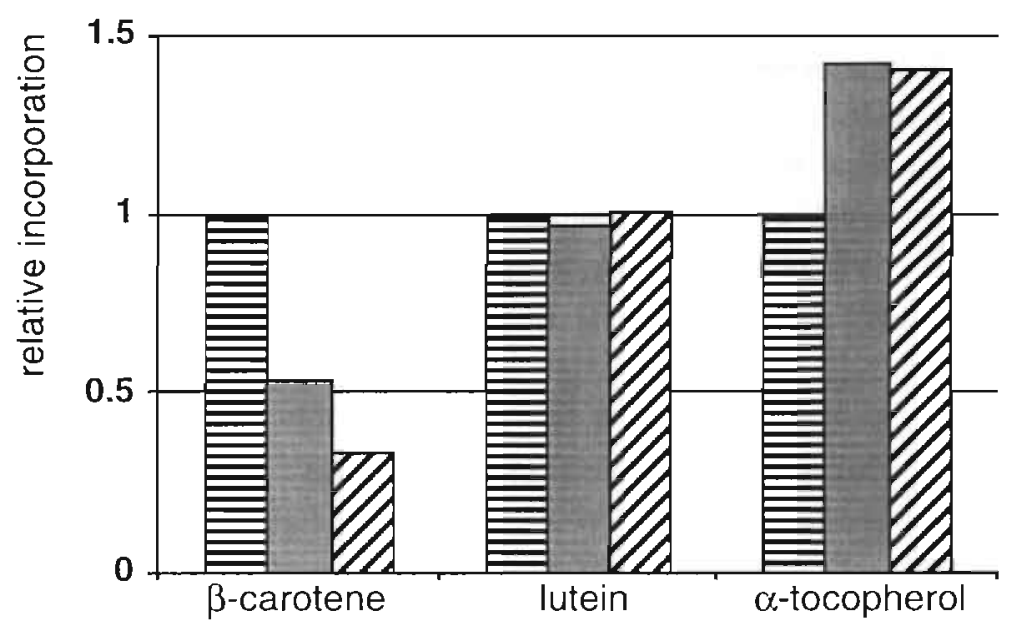

$0 \mu \mathrm{M}$ sitostanol $125 \mu \mathrm{M}$ sitostanol

Z $250 \mu \mathrm{M}$ sitostanol

Figure 3: Effect of incorporation of increasing amounts sitostanol on hydrocarbon carotenoid ( $\beta$. carotene), oxygenated carotenoid (lutein) and tocopherol ( $\alpha$-tocopherol) concentrations in mixed micelles. Mixed micelles were prepared in a $15 \mathrm{mM}$ soclium phosphate buffer, $\mathrm{pH}$ 7.4, by combining $250 \mu \mathrm{M}$ free cholesterol, $5 \mathrm{mM}$ taurocholate, $390 \mu \mathrm{M}$ oleic; acid, 110 $\mu \mathrm{M}$ mono-olein, and the respective antioxidants, followed by 30 minutes sonification at $37^{\circ} \mathrm{C}$. The micellar phase was separated by ultracentrifugation. Micellar antioxidant concentrations were quantified by HPLC analysis as described in Chapter 4 . The eritire procedure was carried out in the dark to minimize artificial losses of antioxidants. 


\section{Coagulation and fibrinolysis}

Besides lipids and lipoproteins, coagulation and fibrinolytic parameters are also risk markers for the development of coronary heart disease. Vitamin $\mathrm{K}$ (a fatsoluble vitamin) plays an important role in the coagulation cascade. Since plant stanol esters may not only affect absorption and consequently lower serum concentrations of cholesterol, carotenoids and tocopherols, but also of vitamin K, we have analyzed effects of plant stanols on coagulation factors. We found, that the coagulation variables measured (fibrinogen, F-VIIc, F-VIlam, and AT-III) remained essentially the same during plant stanol ester consumption (Chapter 3 ). Fibrinolytic variables did also not change. Nuygen found that subjects on warfarin therapy also did not experience any adverse bleeding events at a daily consumption of $4.5 \mathrm{~g}$ of plant stanol esters for eight weeks. No changes in warfarin dose had to be made (22). Therefore, these results suggest that plant stanol esters do not affect coagulation. In only one study with plant sterol esters, plasma vitamin $\mathrm{K} 1$ concentrations have actually been measured and it was concluded that concentrations were not significantly lowered (23). There was, however, an apparent dose-dependent reduction in serum vitamin $\mathrm{K} 1$ concentrations from $-5.4 \%$ to $-18.6 \%$ when the daily plant sterol intake was increased from $0.83 \mathrm{~g}$ to $3.24 \mathrm{~g}$. Therefore, it cannot be excluded that plant sterols and stanols may affect vitamin $\mathrm{K} 1$ concentrations, especially at higher daily intakes

(II) Effects on cholesterol metabolism and the interaction with genetic background

Plant stanol esters lower intestinal cholesterol absorption as shown by a reduction in cholesterol-standardized campesterol concentrations (Chapter 4), which is a marker for changes in cholesterol absorption (24). The mechanisms underlying the hypocholesterolemic effects of plant stanol esters are however still poorly understood. It is known that plant stanol esters lower cholesterol incorporation into mixed micelles and consequently lowers intestinal cholesterol absorption and serum LDL cholesterol concentrations. However, based on our own studies, as well as on several other publications, it has become evident that the lower solubility of cholesterol into the mixed micelle only explains a part of the hypocholesterolemic effect of plant stanol ester consumption. 
Plant sterols and stanols are hardly absorbed from the intestinal lumen, but it is important to clearly differentiate between absorption and uptake. We suggest that plant sterols and stanols, are taken up into the enterocytes, but - in contrast to cholesterol -, are hardly incorporated and excreted into the circulation via the chylomicrons (absorption). For incorporation into chylomicrons, sterols and stanols must first be esterified. Already in 1983 it was shown that sitosterol is not a suitable substrate for acyl-coenzyme A: cholesterol acyltransferase (ACAT) (25), the enzyme responsible for esterification of sterols in the intestine and liver. This, however, does not mean that plant stanols do not affect intestinal lipid and lipoprotein metabolism. The recent identification of ATP binding cassette protein $(A B C-1)$ in the intestine (26), together with the possible presence of plant stanols in the enterocytes, is the basis of our current hypothesis of the mechanism to further explain the hypocholesterolemic effects of plant stanol esters. We hypothesize that plant stanols, when captured in the enterocyte, upregulate ABC1 expression, which shuttles cholesterol out of the enterocyte back into the lumen (figure 4). We are therefore currently analyzing the effects of plant stanols on expression of $\mathrm{ABC}-1$ in human intestinal caco- 2 cells. If plant stanols indeed upregulate intestinal $A B C-1$ expression, this may - at least partly - explain our finding that plant stanol ester consumption once a day lowers serum LDL cholesterol concentrations to the same extent as three times a day.

A lower flux of intestinal derived cholesterol secreted as chylomicrons into the body triggers cells to acquire their cholesterol by other mechanisms. For example, cholesterol may be derived from endogenous synthesis or from receptor-mediated uptake of circulating lipoproteins such as intermediate density lipoproteins (IDL) and low-density lipoproteins (LDL). Circulating LDL particles are taken up by the LDL receptor, which is transcriptionally regulated by low cellular free sterol concentrations, initiating the activation of sterol response element binding proteins (SREBPs) (27). It had been shown that plant stanol ester consumption lowered LDL production from IDL in NIDDM men (28). It was, however, unknown whether changes in LDL-receptor expression also contributed to the LDL-cholesterol lowering effect of plant stanol esters. We have now shown that plant stanol ester consumption increases LDL receptor mRNA and cellsurface protein expression in human monocytes and T-lymphocytes. Also because the change in LDL receptor expression correlates negatively with the change in serum LDL cholesterol concentrations, it is tempting to suggest that the 
increased LDL receptor expression contributes to a lowered LDL formation along the apoB cascade (figure 5) (Chapter 6).

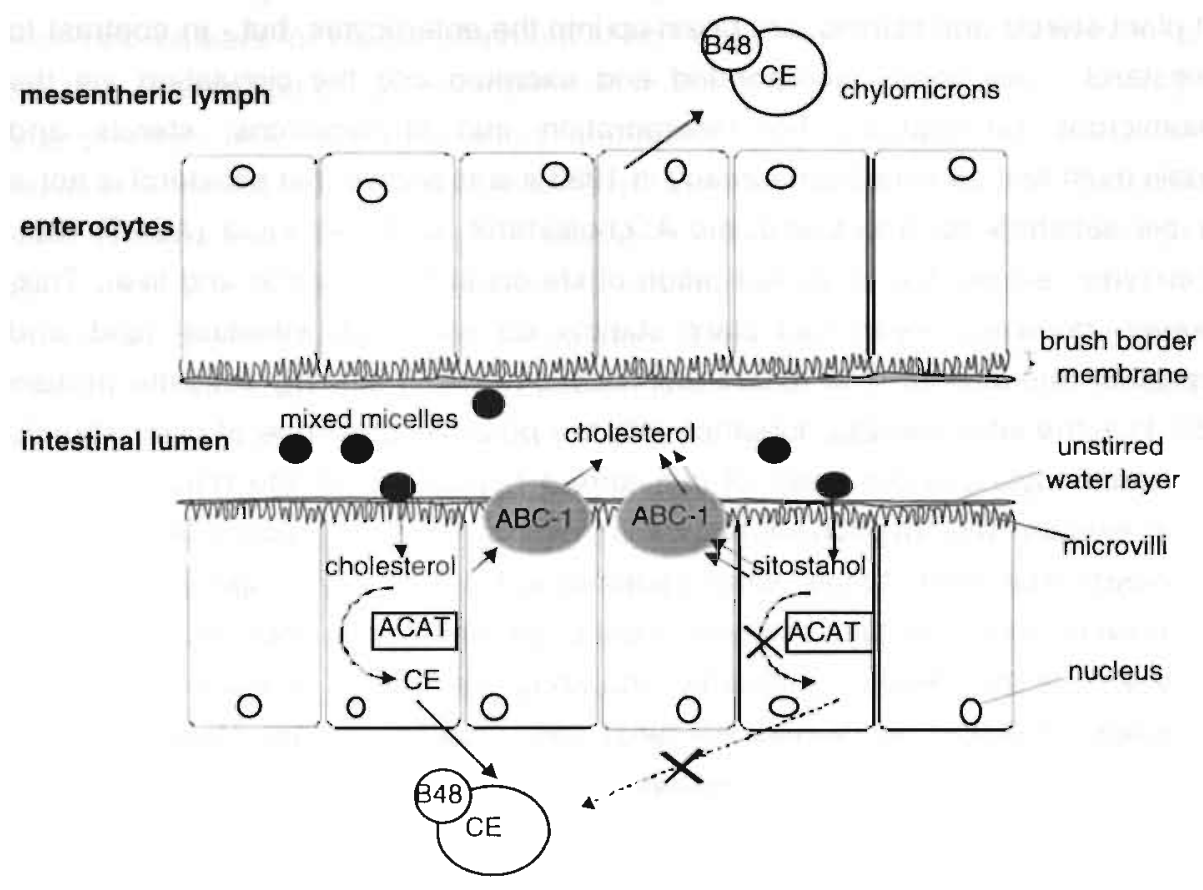

Figure 4: Hypothesized effect of plant stanols (and sterois) on intestinal lipoprotein metabolism. Plant stanols or sterols are taken up into the enterocytes, however these compounds are not esterified by ACAT, but instead are captured in the enterocyte. We now hypothesize that plant sterols or stanols induce a higher ABC-1 expression, which shuttles cholesterol out of the enterocyte back into the lumen.

Besides an upregulation of the LDL receptor expression a second mechanism to maintain cellular cholesterol homeostasis is an increase in the endogenous cholesterol synthesis. Indeed plant stanol esters increased cholesterol synthesis as shown by increased serum cholesterol standardized concentrations of the cholesterol precursor lathosterol (Chapter 4), a validated marker for whole body cholesterol synthesis $(24,29)$. Our findings further illustrated that the increase in HMG-CoA reductase activity, may be only partly regulated at a transcriptional level. HMG-CoA reductase inhibitors, agents that lower endogenous cholesterol synthesis, are currently the first choice for treating patients with hypercholesterolemia. Combination therapy with two different 
hypocholesterolemic compounds, each affecting another pathway of cholesterol metabolism may be more effective in lowering cholesterol concentrations than single-drug therapy. Theoretically even a synergistic effect on LDL cholesterol of statins in combination with plant stanol esters can be expected, since the increased endogenous synthesis due to plant stanol ester consumption may be blocked by statin treatment. From several studies, however, it appeared that plant stanols and statins have rather additive than synergistic effects $(30,31)$. Surprisingly, combination of plant stanol esters with atorvastatin - probably the most potent statin available - appeared the least effective combination as compared to other statins (30). The reason for this interesting finding remains unknown and should be analyzed more into detail.

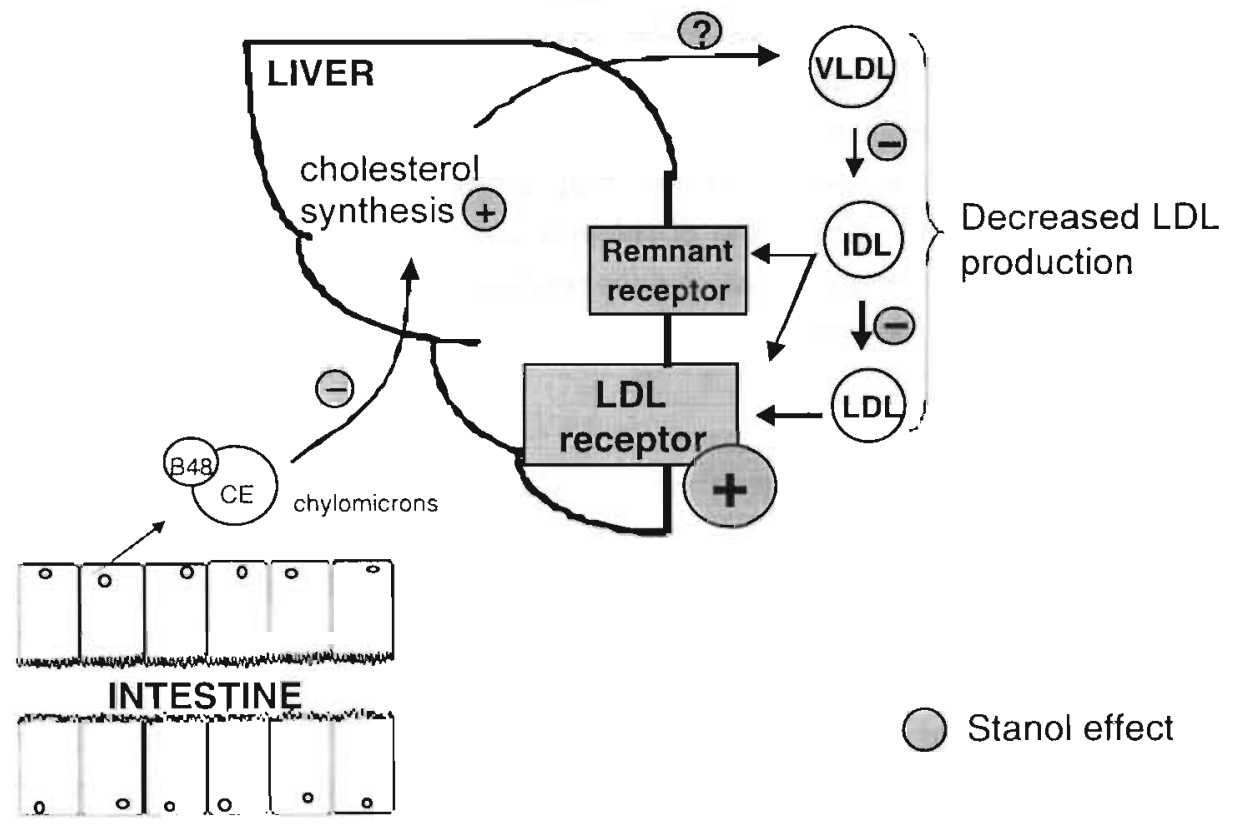

Figure 5: Plant stanol esters lower intestinal cholesterol absorption. Since less cholesterol enters the circulation this induces a compensatory increase in the endogenous cholesterol synthesis. Despite this increased synthesis, the net effect is a reduction in serum LDL cholesterol concentrations. From the literature it is known that LDL production from VLDL and LDL is reduced in male NIDDM patients. We have now shown that LDL receptor expression increased. This might not only enhance LDL clearance from the circulation, but IDL clearance as well and therefore also explain the reduced LDL formation. 
Some people are more responsive to changes in dietary fat and cholesterol intake than others $(10,32)$. It has been proposed that common variations in genes (polymorphisms) may be related to dietary responsiveness Identification of these polymorphisms is therefore an attractive goal to be able to prescribe individually tailored diets for the treatment of dyslipidemia. The amount of data regarding the effects of genetic polymorphisms related to serum lipid and lipoprotein concentrations, as well as with the responsiveness to diet is rapidly increasing, but hardly any consistent effects have been found. The possible reasons for the discrepancies between studies may be numerous, but in general we suggest that future studies, should be more focussed. As also discussed by Rosenthal and Schwartz (33) it is necessary that the effects of the polymorphism should be explained by a plausible mechanism. This means that more attention should be paid to underlying mechanisms. Also, in future studies subjects should be genotyped before the start of the study to be able to form groups of each genotype with sufficient numbers. It may be possible that such a study can not be conducted by one single center and that multi-center-studies are needed. If wellcontrolled studies with large number of subjects are carried out, it is also possible to analyze the effect of many genes at once instead of analyzing one gene at the time and to look at gene-gene interactions.

\section{(III) Oxidized plant sterols}

Oxysterols (cholesterol oxidation products) are atherogenic and cytotoxic compounds (34). Plant sterols are also sensitive to oxidation. Indeed, oxidized plant sterols (oxyphytosterols) are found in various foods $(35,36)$, and 7 -hydroxy, 7-keto and 5,6-epoxy compounds of sitosterol and campesterol are formed upon thermooxidation of sitosterol (37) or rapeseed oil sterols (38). It should however be mentioned that oxidation conditions in both studies were rather extreme. The method used to analyze concentrations of oxidized sterols is very important to avoid artificial formation of oxidation products. For example, for analysis of plant sterol concentrations in serum, the samples are saponified at $70^{\circ} \mathrm{C}$, but for oxysterol analysis cold-saponification is the preferred method. In addition, BHT and EDTA must be added to the serum samples to prevent oxidation, while the serum samples must be extensively flushed with nitrogen before closing the tube for saponification. Further, all evaporation steps needs to be done under vacuum to avoid oxidation in the presence of air. By using a newly developed GC-MS method we have now shown that 7-ketositosterol, $7 \beta$-hydroxysitosterol, $5 \alpha, 6 \alpha$ - 
epoxysitosterol, $3 \alpha, 5 \beta, 6 \alpha$-tri-hydroxysitosterol, and probably also $7 \alpha$ hydroxysitosterol were present in serum from phytosterolemic patients (Chapter 8). Interestingly sitosterol was oxidized for approximately $1.4 \%$ percent in phytosterolemic serum, which is rather high compared to the approximate $0.01 \%$ percent oxidatively modified cholesterol normally seen in human serum. This may indicate that plant sterols are more susceptible to oxidation. Since plant sterols can not be converted into bile acids (39), another explanation for the high percent plant sterol oxidation products may be the higher susceptibility for oxidation due to the prolonged half-life of plant sterols in the circulation. The relevance of these findings remains to be elucidated, since it is unknown whether oxidized plant sterols are also atherogenic, as shown for oxysterols (34). However, a recent study in cultured macrophage derived cell lines has shown comparative cytotoxic effects of oxyphytosterols and oxysterols (40). It is, however, too early to ascribe the onset of cardiovascular disease at a very young age in patients suffering from phytosterolemia to the presence of oxyphytosterols in view of their many metabolic abnormalities.. In this respect, in vivo animal studies would be helpful to examine the atherogenicity of oxyphytosterols. Further, information in man on the endogenous formation of oxidized plant sterols - either enzymatically or nonenzymatically - and absorption from the diet is still missing. For rats it has been shown that oxidized plant sterols ( $7=0$-Sit, $7=0$-Camp $5 \alpha, 6 \alpha$-epoxy-Sit, $5 \beta, 6 \beta$ epoxy-Sit, $5 \alpha, 6 \alpha$-epoxy-Camp and $5 \beta, 6 \beta$-epoxy-Camp) supplied in the diet are absorbed and are incorporated into mesenteric lymph (41).

\section{Conclusions and recommendations}

The development of functional foods containing plant stanol esters is a welcome additional tool in the dietary management of unfavorable serum lipoprotein profiles. Plant stanol ester enriched products lower serum LDL cholesterol concentrations by 10 to $14 \%$, hereby leaving HDL cholesterol levels unaffected. Consumption of these products appears to be safe, and these functional foods have therefore a great potential for cardiovascular risk management. Recent findings suggest that plant stanols have not only effects on the incorporation of cholesterol into micelles. To better understand the effects of plant stanols on intestinal cholesterol metabolism, detailed studies at the molecular level, especially in the intestine, are needed. Further, attention should also be paid to changes in hepatic VLDL metabolism. 
Although the effects of plant stanol esters on several risk markers for cardiovascular heart disease - such as lipoproteins, fat-soluble vitamins, and coaqulation and fibrinolytic parameters - have been analyzed, the ultimate question is whether plant stanol esters indeed lower cardiovascular risk. To look at this functional endpoint human studies are of course ideal but for various reasons, difficult to perform. Although animal studies with apoE` 3 -Leiden and apoE knock-out mice have shown that both plant stanol and sterol esters reduce plaque formation (42-44) human studies with different user groups remain needed.

\section{References}

1. Mensink RP, Ebbing S, Lindhout M, Plat $J$ van Heugten MMA. Effects of plant stanol esters supplied in low-fat yoghurt on serum lipids and lipoproteins, noncholesterol sterols and fat soluble antioxidant concentrations. Atheroscler, in press

2. Ikeda I., Tanaka K., Sugano M., Vahouny G.V., Gallo L.L. Inhibition of cholesterol absorption in rats by plant sterols. J Lipid Res 1988;29:1573 1582

3. Heinemann, T., G. Axtmann, and K. von Bergmann. Comparison of intestinal absorption of cholesterol with different plant sterols in man. Eur $\mathrm{J}$ Clin Invest 1993;23:827-831

4. Miettinen TA, Puska P, Gylling $H$, Vanhanen $H$, Vartiainen $E$. Reduction of serum cholesterol with sitostanol-ester margarine in a mildly hypercholesterolemic population. N Eng J Med 1995;333:1308-1312

5. Hallikainen MA, Sarkkinen ES, Gylling $H_{\text {, }}$ Erkkila AT. Uusitupa MU (2000) Comparison of the effects of plant sterol ester and plant stanol ester-enriched margarines in lowering serum cholesterol concentrations in

hypercholesterolaemic subjects on a low-fat diet. Eur J Clin Nutr 54: 671-677

6. Law M. Plant sterol and stanol margarines and health. BMJ 2000:320:861-864

7. Hallikainen MA, Uusitupa MI. Effects of 2 low-fat stanol ester-containing margarines on serum cholesterol concentrations as part of a low fat diet in hypercholesterolemic subjects. Am J Clin Nutr 1999;69:403-410

8. Law MR, Wald NJ, Thompson SG. By how much and how quickly does reduction in serum cholesterol concentration lower risk of ischaemic heart disease? BMJ 1994; 308:367-72

9. Mattson $\mathrm{FH}$, Grundy SM, Crouse JR. Optimizing the effect of plant sterols on cholesterol absorption in man. Am J Clin Nutr 1982;35:697-700

10. Katan $M B$, Beynen $A C$, de Vries JHM, Nobels A. Existence ol consistent hypoand hyperresponders to dietary cholesterol in man. Am $J$ Epidemiol 1986:123:221-234

11. Kesäniemi YA, Grundy SM. Turnover of low density lipoproteins during inhibition 
of cholesterol absorption by neomycin.

Arterioscler 1984:4:41-48

12. Grover SA, Coupal L, Hu XP. Identifying adults at increased risk of coronary disease. How well do the current cholesterol guidelines work? JAMA 1995;274:801-806

13. Gylling HK, Puska $P$, Vartiainen $E$, et al. Serum retinol, $\alpha$-tocopherol, carotenes, and lipid peroxide production during serum cholesterol lowering by sitostanol ester margarine in a mildly hypercholesterolemic population (abstract 3379). Circulation 1996;94(Supp| 1):I-578

14. Gylling $H$, Miettinen TA. Sitostanol ester margarines lower serum total and LDL cholesterol level in humans. $88^{\text {th }}$ AOCS Annual Meeting and Expo. Seattle, Washington. May 11-14, 1997a. Page 19

15. Gylling $\mathrm{H}$, Miettinen TA. Retinol, vitamin $D$, carotenes, and $\alpha$-tocopherol in serum of a mildly hypercholesterolemic population treated with sitostanol ester margarine (abstract). Finnish Atherosclerosis Club, Kuopio, Finland; 1997b

16. Plat J, Kerckhoffs DAJM, Mensink RP. Therapeulic potential of plant sterols and stanols. Curr Opin Lipidol. $2000 ; 11: 571-576$

17. Greenberg R, Baron JA, Karagas MR, Stukel TA, Nierenberg DW, Stevens MM, Mandel JS, Haile AW. Mortality associated with low plasma concentration of beta carotene and the effect of oral supplementation. JAMA 1996:275:699-703
18. Christen WG, Buring JE, Manson JE, Hennekens $\mathrm{CH}$. Beta-carotene supplementation: a good thing, a bad thing, or nothing? Curr Opin Lipidol 1999; 10:29-33.

19. Stocker R. Dietary and pha.macological antioxidants in atherosclerosis. Curr Opin Lipidol 1999; 10:589-597.

20. Borel $P$, Grolier $P$, Armand $M$, Partier A, Lafont $H$, Lairon D, Azais-Braesco $V$ Carotenoids in biological emulsions: solubility, surface-to-core distribution, and release from lipid droplets. J Lipid Res 1996;37:250-61

21. Weststrate JA, Meijer GW. Plant sterolenriched margarines and reduction of plasma total- and LDL-cholesterol concentrations

in

normocholesterolaemic and mildly hypercholesterolaemic subjects. Eur J Clin Nutr 1998:52:334-343

22. Nguyen TT, Dale LC. Plant stanol esters and vitamin K. Mayo Clinic Froc 1999;4: $642-643$

23. Hendriks HFJ, Weststrate JA, van Vliet T, Meijer GW. Spreads enriched with three different levels of vegetable of sterols and the degree of cholesterol lowering in normocholesterolemic and mildy hypercholesteroiemic subjects. Eur J Clin Nutr 1999;53:319-327

24. Miettinen TA, Tilvis RS, Kesäniemi YA. Serum plant sterols and cholesterol precursors reflect cholesterol absorption and synthesis in volunteers of a randomly selected male population. Am J Epidemiol 1990;131:20-31

25. Field FJ, Mathur SN. _-sitosterol: esterification by intestinal acylcoenzyme A: cholesterol acyltransferase (ACAT) 
and its effect on cholesterol esterification. J Lipid Res 1983;24:409417

26. Repa $\mathrm{JJ}$, Turley SD, Labaccaro JMA, Medina J, Li L, Lustig K, Shan B, Heyman RA, Dietchy JM, Mangelsdorf DJ. Regulation of absorption and $A B C 1$. mediated efflux of cholesterol by RXR heterodimers. Science 2000;289:15241529

27. Brown MS, Goldstein JL. The SREBP pathway: regulation of cholesterol metabolism by proteolysis of a membrane-bound transcription factor. Cell 1997;89:331-340,

28. Gylling $H_{1}$ Miettinen TA. Serum cholesterol and lipoprotein metabolism in hypercholesterolemic NIDDM patients before and during sitostanol estermargarine treatment, Diabetologia 1994;37:773-780

29. Kempen HJM, Glatz JFC, Gevers Leuven JA, Voort van der HA, Katan $M B$. Serum lathosterol concentration is an indicator of whole- body cholesterol synthesis in humans, J Lipid Res 1988;29:1149-1155

30. Blair S, Capuzzi DM, Gortlieb SO, Nguyen $T$, Morgan JM, Cater NB Incremental reduction of serum total cholesterol and low-density lipoprotein cholesterol with the addition of plant stanol ester containing spread to statin treatment. Am J Cardiol 2000;86:46-52

31. Gylling $H_{1}$ Miettinen TA. Effects of inhibiting cholesterol absorption and synthesis on cholesterol and lipoprotein metabolism in hypercholesterolemic non-insulin-dependent diabetic men. J Lipid Res 1996:37: 1776-1785
32. McNamara DJ, Kolb R, Parker TS, Batwin $H$, Samuel P, Brown CD, Ahrens EH Jr. Heterogeneity of cholesterol homeostasis in man. Response to changes in dietary fat quality and cholesterol quantity. J Clin Invest 1987;79:1729-39

33. Rosenthal N, Schwartz RS. In search of perverse polymorphisms. N Engl J Med 1998;338:1626

34. Brown AJ, Jessup W. Oxysterols and atherosclerosis. Atherosclerosis. 1999;142:1-28.

35. Dutta PC, Appelqvist L. Studies on phytosterol oxides I: Effect of storage on the content in potato chips prepared in different vegetable oils. JAOCS 1997;74:647-657

36. Dutta PC.Studies on phytosterol oxides. II: Content in some vegetable oils and in French fries prepared in these oils. JAOCS 1997:74:659-666

37. Daly GG, Finocchiaro ET, Richardson $T$. Characterization of some oxidation products of _-sitosterol. J Agric Food Chem 1983;31:46-50

38. Lampi M, Juntunen L, Toivo J, Piironen $V$. Analysis of thermooxidation products of plant sterols. Inform S10, $92^{\text {nd }}$ AOCS Annual Meetings \& Expo, Minneapolis 2001

39. Boberg KM, Einarsson K, Björkhem I. Apparent lack of conversion of sitosterol into C24-bile acids in humans. J Lipid Res 1990;31:1083-1088

40. Adcox C, Boyd L, Oehrl L, Allen J, Fenner $G$. Comparative effects of phytosterol oxides and cholesterol oxides in cultured macrophage-derived 
cell lines. J Agric Food Chem 2001;49:2090-2095

41. Grandgirard A, Sergiel JP, Nour $M$, Demaison-Meloche $J$, Ginies $C$. Lymphatic absorption of phytosterol oxides in rats. Lipids 1999:34:563-570

42. Moghadasian MH, McManus BM, Godin DV, Rodrigues B, Frohlich JJ. Proatherogenic and antiatherogenic effects of probucol and phytosterols in apolipoprotein E-deficient mice. Circulation 1999;99:1733-1739

43. Moghadasian MH, McManus BM, Pritchard PH, Frohlich JJ. Tall oil-derived phytosterols reduce atherosclerosis in apoE deficient mice. Arterioscler Thromb Vasc Biol 1997;17:119-126

44. Volger OL, van der Boom J, de Wit ECM, Duyvenvoorde van W, Hornstra G, Plat J, Havekes LM, Princen HMG, Mensink RP. Dietary vegetable- wood- or vegetable/wood derived stanol esters reduce atherosclerotic leasion size and severity in apoE*3-Leiden transgenic mice. Atherosclerosis 2000;151:77 


\section{2}




\section{Summary}

Improvement of an unfavorable lipoprotein profile is a proven strategy for lowering the risk of coronary heart diseases (CHD). Current dietary recommendations are therefore based on decreasing low-density lipoprotein (LDL) cholesterol concentrations or the total cholesterol : HDL cholesterol ratio. For a large majority of the people this can be achieved by changing the intake of dietary fat and type of fatty acids. However, despite strict dietary compliance, the target values for these two lipid parameters are not reached by a substantial part of the population. For these people functional foods may offer new possibilities. Functional foods contain (or miss) one or more food components (whether nutrients or not) that affects one or more target functions in the body. Plant stanol esters incorporated into margarines are one of the first examples of a functional food with proven scientific effectiveness. Plant stanols are structurally related to cholesterol and are in the intestinal lumen incorporated into the mixed micelles. In this way, plant stanols replace cholesterol from the mixed micelles, which results in a reduced intestinal cholesterol absorption and consequently into lower serum LDL cholesterol concentrations. Many effects of plant stanol esters are however unknown, while its hypocholesterolemic mechanism has only been partly elucidated. Therefore, in this thesis studies are presented that have not only examined the effects of plant stanol esters on various parameters associated with coronary heart disease, but have also analyzed effects on cholesterol metabolism at the molecular level.

\section{Lipids and (apo)lipoproteins}

Plant stanols can be derived from pine wood or vegetable oils. These two sources of plant stanols differ in their sitostanol : campestanol ratios. It has been postulated that the less absorbable plant sterols reduces cholesterol absorption more effectively. As humans absorb sitostanol less than campestanol, differences in plant stanol ester composition may affect a mixtures effects on the serum lipoprotein profile. In our first study with 112 nonhypercholesterolemic volunteers, however, we have demonstrated that a daily intake of $4.0 \mathrm{~g}$ wood based (92\% sitostanol and $8 \%$ campestanol) or $3.8 \mathrm{~g}$ vegetable oil based $(68 \%$ sitostanol and $32 \%$ campestanol) plant stanols as its fatty acid esters lowered serum LDL cholesterol concentrations to the same extent, respectively with $12.8 \%$ and $14.6 \%$. This suggests that the sitostanol : campestanol ratio is not an important determinant for the hypocholesterolemic capacity of a plant stanol ester mixture. 
The second intervention trial examined if it was necessary to consume plant stanol esters with each cholesterol-containing meal. For this, 39 nonhypercholesterolemic subjects consumed in random order no plant stanols, 2.5 $\mathrm{g}$ plant stanols at lunch, or $2.5 \mathrm{~g}$ plant stanols divided over the three meals (breakfast $0.42 \mathrm{~g}$, lunch $0.84 \mathrm{~g}$, and dinner $1.25 \mathrm{~g}$, which is proportional to dietary cholesterol intake). Plant stanols were given as its fatty acid esters. Consumption of plant stanol esters at lunch only resulted in a similar LDL cholesterol reduction $(-9.4 \%)$ as compared to consumption of plant stanol esters divided over the three meals $(-10.4 \%)$. Based on these results it is concluded that it is not necessary to consume plant stanols at each meal or simultaneously with dietary cholesterol. This suggests that the reduced incorporation of cholesterol into mixed micelles may not be the only mechanism by which plant stanols lower LDL cholesterol. We therefore hypothesize that plant stanols affect lipoprotein metabolism in the intestinal cells as well.

Decreasing cholesterol absorption by lowering dietary cholesterol intake normally lowers HDL cholesterol. In our two intervention studies, however, the plant stanol ester induced decreases in cholesterol absorption were not accompanied by a change in serum HDL cholesterol concentrations, which is an interesting finding. Since the intestine is an important site for apo A-1 synthesis, it reinforces our suggestion of an effect of plant stanols on lipoprotein metabolism in the intestinal cells themselves. The lack of effect on HDL cholesterol concentrations also led to a significant improvement in the total cholesterol: $\mathrm{HDL}$ cholesterol ratio. It was further found that changes in apoB and apo A-I paralleled those in LDL and HDL cholesterol, while serum triacylglycerol concentrations were not affected.

\section{Cholesterol metabolism and interaction with genetic background}

Like in all other studies, plant stanol ester consumption lowered serum cholesterol-standardized campesterol concentrations, a validated marker for cholesterol absorption. A lower supply of exogenous cholesterol into the body triggers cells to increase their endogenous synthesis, which was shown by a significant increase in serum cholesterol-standardized lathosterol concentrations, an established marker for whole body cholesterol synthesis. Despite this increased cholesterol synthesis, the overall effect is a lower serum LDL cholesterol concentration. Whether changes in LDL-receptor expression also contributed to the LDL-cholesterol lowering effect of plant stanol esters was not known. We have now shown that plant stanol ester consumption increased 
LDL receptor mRNA concentrations in mononuclear blood cells. Also LDLreceptor protein expression on the surface of mononuclear blood cells was significantly higher, which correlated negatively with changes in serum LDL cholesterol. We now hypothesize that the increased LDL receptor expression not only increases LDL clearance, but also contributes to a lower LDL formation along the apoB- 100 cascade. Further, we found that the increased endogenous cholesterol synthesis is probably not regulated only at a transcriptional level: HMG-CoA reductase mRNA concentrations were not significantly increased and - more importantly - changes in HMG-CoA reductase did not correlate with changes in serum cholesterol-standardized lathosterol concentrations.

Differences in genetic constitution affect cholesterol metabolism and responses to diet. Identification of common variations in genes related to dietary responsiveness is therefore an attractive goal to be able to prescribe individually tailored diets for the treatment of an unfavorable lipoprotein profile. However, we found that common polymorphisms of 5 candidate genes - apo AIV, SR-BI, CETP, HMG-CoA reductase, and apoE - do not explain to a significant extent variation in serum $L D L$ cholesterol responses between individuals.

\section{Hemostasis and fat-soluble antioxidants}

Besides lipid and lipoprotein concentrations, other parameters associated with the risk for $\mathrm{CHD}$ were examined in our first intervention trial. Coagulation and fibrinolytic parameters, such as fibrinogen, F-VlIc, F-VIlam, AT-III, PAI-I, and t-Pa remained essentially the same during plant stanol ester consumption. Concerning effects on fat-soluble antioxidants, tocopherol (vitamin E) and carotenoid concentrations were lowered. A part of this effect can be explained by a lower number of LDL particles, the carriers for fat-soluble antioxidants. However, after LDL-cholesterol standardization, concentrations of the lipophylic hydrocarbon carotenoids ( $\beta$-carotene, $\alpha$-carotene, and lycopene) were still lowered, while LDL-cholesterol standardized concentrations of the more polar oxygenated carotenoids (lutein/zeaxanthin and $\beta$-cryptoxanthin) and tocopherols were not. We have also shown that the reduction of the lipophylic hydrocarbon carotenoids was associated with the lowered cholesterol absorption. Although serum concentrations of all hydrocarbon carotenoids studied remained the normal range, the clinical importance of these reductions is not known, but certainly warrants attention. Vitamin A concentrations did not change. 


\section{Oxidation of plant sterols}

Not only plant stanols, but also plant sterols show a large structural similarity with cholesterol. Since oxysterols (oxidation products of cholesterol) are atherogenic and cytotoxic compounds, we wondered whether - like cholesterol - oxidized plant sterols (oxyphytosterols) are also found in the serum. Therefore, we first developed a sensitive gas chromatography mass spectrometry (GC-MS) assay, which enabled us to measure oxyphytosterol concentrations. We found that approximately $1.4 \%$ of sitosterol in the serum was present in its oxidized form in serum from phytosterolemic patients. Phytosterolemia is a rare inheritable disease in which patients have highly elevated serum plant sterol concentrations. Although this value of $1.4 \%$ is rather high compared to the approximate $0.01 \%$ percent oxidatively modified cholesterol normally seen in human serum the relevance of these findings remains to be elucidated. However, in vitro studies have indicated that oxidized plant sterols showed the same cytotoxic effects as oxysterols. It remains to be determined, however, whether in plasma of healthy subjects also oxidized plant sterols can be detected. We could not demonstrate oxyphytosterols in the plasma of healthy volunteers, which may be due to the relatively high detection limit of our assay.

\section{Conclusions}

Based on these studies we conclude that the incorporation of functional foods containing plant stanol esters into a recommended diet can be useful in the dietary management of unfavorable serum lipoprotein profiles. A daily intake of 2.0 to 2.5 grams of plant stanols lowers serum LDL cholesterol concentrations by $10 \%$ to $14 \%$, hereby leaving HDL cholesterol levels unaffected. We further hypothesize that plant stanol esters lower LDL cholesterol, not only by lowering cholesterol solubilization into mixed micelles, but also by affecting lipoprotein metabolism in the intestinal cells. To better understand the effects of plant stanols, detailed studies at the molecular level, especially in intestinal cells, are therefore needed. Although plant stanol esters do not have detrimental effects on several other risk markers for CHD such as fat-soluble antioxidants and markers for coagulation and fibrinolyis, the ultimate question is whether plant stanol esters indeed lower cardiovascular risk. Therefore, human studies with different patient groups, looking at functional endpoints are also needed. 


\section{Samenvatting}

Het verbeteren van een ongunstig lipoproteïnenprofiel verlaagt het risico op hart- en vaatziekten. De huidige voedingsrichtlijnen zijn er dan ook met name opgericht om het cholesterolgehalte in de atherogene lage dichtheidslipoproteinen (LDL) of om de totaal cholesterol : HDL cholesterol verhouding te verlagen. Dit kan worden bereikt door de inname van vet en het type vetzuren te veranderen. Echter, ondanks strikte dieettrouw, zal het lipoproteïnenprofiel van een groot deel van de bevolking te ongunstig blijven. Voor deze mensen bieden "functional foods" nieuwe mogelijkheden. Functional foods bevatten (of missen) een of meerdere bestanddelen die een gunstig effect hebben op één of meerdere (patho)fysiologische. Margarines verrijkt met plantaardige stanolesters zijn één van de eerste voorbeelden van een functional food met een wetenschappelijk onderbouwde effectiviteit. De moleculaire structuur van plantaardige stanolen vertoont grote overeenkomsten met die van cholesterol. In het darmlumen worden zij dan ook - net zoals cholesterol ingebouwd in micellen. De plantaardige stanolen verdringen echter het cholesterol uit de micellen, hetgeen resulteert in een verlaagde cholesterolabsorptie in de darm. Hierdoor daalt de LDL-cholesterolconcentratie in het serum. Vele effecten van plantaardige stanolen zijn echter nog onbekend, terwijl het mechanisme dat ten grondslag ligt aan de cholesterolverlagende werking slechts ten dele is ontrafeld. Het doel van de studies, die in dit proefschrift staan beschreven, was dan ook niet alleen om effecten van plantaardige stanolen op diverse risico-indicatoren voor hart- en vaatziekten te bestuderen, maar ook om deze effecten op moleculair niveau te verklaren.

\section{Lipiden en (apo)lipoproteïnen}

Plantaardige stanolesters kunnen afkomstig zijn van verschillende bronnen, zoals houtpulp en plantaardige oliën. De verkregen mengsels van plantaardige stanolen verschillen echter in de sitostanol : campestanol verhouding. Het is gesuggereerd dat plantaardige stanolen, die minder goed in de darm worden opgenomen, de cholesterolabsorptie sterker remmen. Aangezien de mens minder sitostanol dan campestanol opneemt, zou de samenstelling een effect kunnen hebben op cholesterolverlagende werking van het mengsel. In onze eerste studie, waaraan 112 mensen met een nietverhoogd cholesterolgehalte deelnamen, hebben wij echter aangetoond dat een dagelijkse inname van 4,0 gram plantaardige stanolen gewonnen uit houtpulp (92\% sitostanol en $8 \%$ campestanol) of 3,8 gram stanolen gewonnen uit 
plantaardige olie ( $68 \%$ sitostanoi en $32 \%$ campestanol) een vergelijkbaar effect hadden op het LDL-cholesterolgehalte: de dalingen waren respectievelijk $12,8 \%$ en $14,6 \%$. Dit suggereert dat de sitostanol : campestanol verhouding geen groot effect heeft op de cholesterolverlagende werking van een mengsel van plantaardige stanolen.

In een tweede interventie studie is bestudeerd of het noodzakelijk is om plantaardige stanolesters bij elke maaltijd te consumeren. Hiervoor kregen 39 mensen met een niet-verhoogd cholesterolgehalte in willekeurige volgorde verschillende margarines en bak- en braadvetten verstrekt. De samenstelling van de margarines en bak- en braadvetten was zodanig, dat er of geen extra plantaardige stanolen werden gegeten, of 2,5 gram extra plantaardige stanolen bij de lunch, of 2,5 gram extra plantaardige stanolen verdeeld over de drie maaltijden van de dag $(0,42$ gram bij het ontbijt, 0,84 gram bij de lunch, en 1,25 gram bij het diner). Gedurende deze laatste voeding was de stanol : cholesterol verhouding in de drie maaltijden vergelijkbaar. Het bleek dat het cholesterolgehalte met $-9,4 \%$ daalde, indien de stanolen alleen bij de lunch werden gegeten, hetgeen vergelijkbaar was met de daling van $-10,4 \%$, indien bij alle maaltijden stanolen werden gegeten. Uit deze studie werd dan ook geconcludeerd, dat het niet noodzakelijk is om de plantaardige stanolesters bij elke cholesterolbevattende maaltijd te gebruiken. Dit suggereert dat de verlaging van de inbouw van cholesterol in de micellen door plantaardige stanolen niet het enige werkingsmechanisme is, waardoor stanolen het LDL. cholesterolgehalte verlagen. Daarom hebben wij gesuggereerd dat stanolen ook een effect hebben op het lipoproteïnenmetabolisme in de darmcel zelf.

Een verlaging van de cholesterolabsorptie door een lagere cholesterolinname met de voeding verlaagt het cholesterolgehalte in de hoge dichtheidslipoproteinen (HDL). Uit onze studies bleek echter dat plantaardige stanolesters het HDL cholesterol niet verlaagden, ondanks het feit dat stanolen de cholesterolabsorptie verlagen. Dit is een interessante bevinding. Aangezien de darm een belangrijke rol speelt bij de synthese van apo A-I (een belangrijk eiwit van het $\mathrm{HDL}$ ), versterkt dit onze hypothese dat plantaardige stanolen een effect hebben op het lipoproteïnenmetabolisme in de darmcellen. De bevinding dat serum HDL-cholesterolconcentraties niet dalen, betekent verder dat de totaal cholesterol: HDL cholesterol verhouding sterk verbetert. Tenslotte bleek dat de veranderingen in apoB en apo A-l vergelijkbaar waren aan die van LDL en HDL cholesterol. Serum triacylglycerolconcentraties bleven onveranderd. 


\section{Cholesterolmetabolisme en de interactie met genetische achtergrons}

In overeenstemming met andere studies vonden wij dat consumptie van plantaardige stanolesters de serum cholesterol-gestandaardiseerde campesterolconcentraties, een gevalideerde indicator voor veranderingen in cholesterolabsorptie, verlagen. Een lagere toevoer van exogeen cholesterol in het lichaam heeft een verhoging van de synthese van cholesterol tot gevolg, hetgeen bleek uit een toename van de cholesterol-gestandaardiseerde lathosteral concentraties, een geaccepteerde indicator voor de cholesterolsynthese in het lichaam. Ondanks de toegenomen cholesterolsynthese daalde het serum LDL-cholesterolgehalte. Of veranderingen in de LDL-receptorexpressie ook hebben bijgedragen aan het LDL-cholesterol verlagend effect van plantaardige stanolesters was onbekend. Wij hebben nu getoond dat consumptie van plantaardige stanolesters de LDLreceptor mRNA concentraties in mononucleaire bloedcellen verhoogde. Ook de LDL-receptor eiwitexpressie op het oppervlak van mononucleaire bloedcellen was signficant hoger en deze toename correleerde bovendien negatief met de verandering in serum LDL-cholesterolconcentraties. Dit leidde tot de hypothese dat de verhoogde LDL-receptor expressie niet alleen de LDL klaring uit de circulatie verhoogt, maar dat deze toename ook heeft bijgedragen aan een lagere LDL vorming. Bovendien hebben wij aangetoond dat do toegenomen cholesterolsynthese waarschijnlijk niet op transcriptie niveau gereguleerd is. De mRNA concentraties van HMG-CoA reductase - het snelheidsbepalende enzym in de cholesterolsynthese - waren niet significant verhoogd en nog belangrijker, de veranderingen in HMG-CoA reductase correleerden niet met de veranderingen in cholesterol-gestandaardiseerde lathosterolconcentraties.

Verschillen in genetische achtergrond tussen mensen beïnvloeden het cholesterolmetabolisme en verklaren mogelijkerwijs waarom sommige mensen sterker op een cholesterolverlagende voeding reageren dan andere mensen. Identificatie van frequent voorkomende variaties in genen, die gerelateerd zijn aan de response ten gevolge van voedingsveranderingen, is derhalve een belangrijke stap om een individueel voedingsadvies op te stellen in de behandeling van een ongunstig lipoproteïnenprofiel. Echter analyse van variaties in vijf verschillende kandidaatgenen - apoA-IV, SR-BI, CETP, HMGCoA reductase en apoE - heeft tot de conclusie geleid, dat deze genen geen grote bijdrage leveren aan het verklaren van verschillen in veranderingen van 
serum LDL-cholesterolconcentraties gedurende plantaardige stanolester consiumptie.

\section{Hemostase en vetoplosbare antioxidanten}

Naast lipiden en lipoproteïnenconcentraties zijn ook effecten op andere parameters, die geassocieerd zijn met het risico op hart- en vaatziekten bestudeerd. Concentraties van parameters betrokken bij de bloedstolling en de fibrinolyse, zoals fibrinogeen, F-VIIc, F-VIlam, AT-III, PAl-1 en t-Pa, veranderden niet door de consumptie van plantaardige stanolesters. Wat betreft de vetoplosbare antioxidanten, daalden alle tocoferol (vitamine E) en carotenoïdenconcentraties. Een deel van dit effect kan worden verklaard door een daling in het aantal LDL deeltjes, die de vetoplosbare antioxidanten door de bloedbaan vervoeren. Echter na standardizatie voor LDL-cholesterolconcentraties waren de concentraties van de lipofiele hydrocarbon carotenoïden ( $\beta$-carotene, $\alpha$-carotene, lycopene) nog steeds verlaagd, terwij concentraties van de meer polaire geoxygeneerde carotenoïden en de tocoferolen niet meer verlaagd waren. De verlaging van de lipofiele hydrocarbon carotenoïdenconcentraties was geassocieerd met de verlaagde cholesterolabsorptie, hetgeen suggereert dat plantaardige stanolesters ook de opneming van andere vetoplosbare componenten kan beïnvloeden. Vitamine A concentraties bleven onveranderd. Ondanks het feit dat de verlaagde serumconcentraties van de hydrocarbon carotenoïden nog steeds binnen de normaalwaarden lagen, is het klinische belang van deze dalingen onbekend.

\section{Oxidatie van plantaardige sterolen}

Niet alleen plantaardige stanolen, maar ook plantaardige sterolen vertonen een grote structurele gelijkenis met cholesterol. Aangezien oxysterolen (oxidatie produkten van cholesterol) atherogene en cytotoxische componenten zijn, vroegen wij ons af of geoxideerde plantaardige sterolen (oxyfytosterolen), evenals geoxideerd cholesterol, ook in het plasma aantoonbaar zouden zijn. Daartoe hebben wij eerst een gevoelige GC-MS methode opgezet, die het mogelijk maakte om oxyfytosterolconcentraties in het plasma te meten. Wij hebben aangetoond dat $1,4 \%$ van het sitosterol in het plasma van een fytosterolemische patiënt - een zeldzame erfelijke aandoening, waarbij plant sterolconcentraties in het bloed sterk verhoogd zijn - in geoxideerde vorm aanwezig is. Ondanks het feit dat deze waarde van 1,4\% hoog is ten opzichte van de $0,01 \%$ oxidatief gemodificeerd cholesterol wat normaal in het plasmaaanwezig is, is de relevantie van deze bevinding 
vooralsnog niet geheel duidelijk. Echter in vitro studies hebben aangetoond dat geoxideerde plantaardige sterolen dezelfde cytotoxische eigenschappen bezitten als oxysterolen. Of geoxideerde plantaardige sterolen ook in het bloed van gezonde vrijwilligers aantoonbaar zijn, blijft vooralsnog een vraag. Wij konden in ieder geval geen oxyfytosterolen in het plasmavan gezonde personen aantonen, hetgeen echter te maken kan hebben met de relatief hoge detectielimiet van de huidige analyse methode.

\section{Conclusies}

Op basis van deze studies concluderen wij dat voedingsmiddelen verrijkt met plantaardige stanolesters als onderdeel van een gezonde voeding een bijdrage kunnen leveren tot het verbeteren van een ongunstig lipoproteïnenprofiel. Een dagelijkse consumptie van 2,0 - 2,5 gram plantaardige stanolen kunnen het LDL-cholesterolgehalte met $10 \%$ tot $14 \%$ verlagen, terwijl het HDL-cholesterolgehalte onveranderd blijt. Verder postuleren wij dat plantaardige stanolesters het LDL-cholesterolgehalte niet alleen verlagen door een verminderde inbouw van cholesterol in de micellen, maar dat ze ook zelf een effect uitoefenen op het lipoproteïnenmetabolisme in de darmcellen. Om de effecten van plantaardige stanolen beter te begrijpen moeten daarom gedetaileerde studies op moleculair niveau, met name gericht op effecten in de darm, worden uitgevoerd. Ondanks het feit dat plantaardige stanolesters geen nadelige effecten lijken te hebben op andere risicoindicatoren voor hart- en vaatziekten, zoals de vetoplosbare antioxidanten, en indicatoren betrokken bij de bloedstolling en de fibrinolyse, blijft uiteindelijk de vraag of plantaardige stanolesters het risico op hart- en vaatziekten daadwerkelijk verlagen. Hiervoor zijn studies bij verschillende patiëntengroepen nodig, waarbij naar het atherosclerotische proces zelf moet worden gekeken. 


$$
212
$$




\section{Dankwoord}

Ik wil allereerst mijn promotor Prof. Dr. ir. Ronald Mensink hartelijk danke?n voor de plezierige samenwerking gedurende de afgelopen jaren. Mijn wetenschappelijke carrière is feitelijk begonnen toen jij mijn begeleider werd tijdens de afstudeerstage in het kader van de opleiding Biologische gezondheidkunde. De manier waarop jij humaan voedingsonderzoek tot in uiterste precisie uitvoert, hierbij niets aan het toeval overlatend, heeft mijn enthousiasme voor deze tak van wetenschappelijk onderzoek alleen maar verder versterkt. Jij hebt mij min of meer de richting van de moleculaire voedingskunde ingestuurd en ik besef mij nu dat dit één van de beter zetten is geweest die ik had kunnen maken. Ronald, jij had natuurlijk gelijk wat betreft de weddenschap over de uitkomst van de frequentie studie (die fles wijn ligt al een tijdje bij mij thuis te rijpen), bedankt voor het zorgvuldig doorworstelen en tactisch inkorten van mijn altijd veel te lange manuscripten, een betere werkbaas had ik me niet kunnen wensen en ik vind het een ongelooflijke eer dat jij mijn promotor wilt zijn.

Prof. Dr. Gerard Hornstra, jij bent mijn tweede promotor. Ik wil je danken voor je vele enthousiaste en motiverende woorden. Ik heb waardering voor je onvermoeibare inzet waarmee je het onderzoek naar gezondheidseffecten van verschillende vetzuren al vele jaren aan de top weet te houden.

Alle analisten met wie ik heb samengewerkt, met de één wat langer en intensiever dan de ander maar toch allemaal op hun eigen manier belangrijk voor het welslagen van onze experimenten: Rene (vetzuren zijn ook niet zaligmakend; jij hebt duidelijk een goede keuze gemaakt), Jo (ik bewaar een prettige herinnering aan onze samenwerking), Dennis, Martijn (het blijft interessant te filosoferen over wat eigenlijk echte research is), Sjoerd, Maurice, Adje, Joan, Jos, Antionne, Freek, Suzanne, Wendy en natuurlijk Frank. Dennis, inmiddels weer terug uit het avontuur dat je voor een jaar naar Australië en Nieuw Zeeland bracht. Hopelijk kunnen we binnenkort weer als voorheen onze mountainbike tochten rijden. Samen met jouw heb ik denk ik een van mijn meest recente sportieve prestaties geleverd. Samen hebben we elkaar door de $100 \mathrm{~km}$ van de Low Countries Mountainbike Tour (LCMT) 1999 geloodst. Sjoerd, jij hebt mij wegwijs gemaakt binnen het CPV waar we nu samen met de LDL receptor knock-out muizen werken. Maurice, jij bent onze moleculair analist in wording. Jij hebt je kunnen reeds getoond in de analyses van de $\mathrm{HMG}-\mathrm{Co} A$ reductase tandem repeats en de $A B C 1$ mRNA concentraties en ik voorzie voor de toekomst een prettige en 
succesvolle samenwerking. Frank, jij bent altijd mijn aanspreekpunt geweest op onze labs. Onze eerste kennismaking was toen ik mijn afstudeerstage bij Ronald en Gerard Oostenbrug (nog bedankt voor de lipoproteïnen scheiding met behulp van de ultracentrifuge en de antioxidant analyse op de HPLC die ik van jou heb mogen leren) begon in 1996 (Ja toen was jij er ook al). Sindsdien hebben we samen -zeer succesvol mag ik wel zeggen- aan diverse nieuwe analyses gewerkt. Ons mooiste avontuur was zonder twijfel een weekje Finland om de sterolen analyse op de GC aan te leren. Ik denk dat mede dankzij de onbetaalbare Belgische bieren en de ongedwongen sfeer in "The Bank" in RAISIO we die methode nu mooi hebben lopen op ons lab. Ook ons bezoek aan de locale derby in het Finse ijshockey seizoen is gedenkwaardig. Als ik het me goed herinner duurde het minstens 15 minuten voordat we door hadden dat we voor de ploeg die niet door RAISIO werd gesponsord juichten. Frank, ik hoop nog veel met je samen te kunnen werken de komende jaren en ik ben je ontzettend dankbaar dat je als paranimf aan mijn zijde wilt staan.

Binnen het voedingsonderzoek zijn vanzelfsprekend mensen nodig die kennis hebben van voeding. Ik bedoel dan niet zozeer theoretische maar juist de praktische kennis omtrent de diverse facetten van voeding. Met andere woorden een goede diëtist(e) is onontbeerlijk voor het welslagen van een humane voedingsproef, Marjolien, ik heb het geluk gehad dat jij gedurende drieëneenhalf jaar met mij hebt samengewerkt (zit dat kanariegele tegeltje er nog altijd?).

Een universiteit is niet in de eerste plaats een onderzoekscentrum maar een opleidingsinstituut (al wordt dat nog wel eens over het hoofd gezien). Het begeleiden van stagaires is dan ook een van de mogelijkheden om een bijdrage te leveren aan het onderwijs. Esther, jij was mijn eerste stagaire en dat zal ik mij wellicht nog lang blijven herinneren. Het is niet zozeer het werk dat je geleverd hebt (al was dit van hoog niveau) maar meer je persoonlijkheid die een ieder binnen onze groep heeft aangesproken. Ik heb veel nieuwe vloeken van je geleerd en overigens "ik ben nu pas (een beetje) gesetteld". Elke, jij was de tweede student die ik mocht begeleiden en wederom mocht ik mij gelukkig prijzen met een zeer gemotiveerde stagaire. Dat is dan ook een van de redenen dat wij nu nog steeds dagelijks erg plezierig samen werken.

I would like to thank Prof. Dr. ir. Wim H.M. Saris, Prof. Dr. Martijn B. Katan, Prof Dr. Martin H. Hofker, Dr. Bruce H. Wolfenbuttel, and Prof. Dr. Klaus Von Bergmann for their critical evaluation of this thesis. 
De capaciteitsgroep Humane Biologie is een grote groep ik heb de afgelopen jaren dan ook met veel verschillende collegae mogen kennismaken en van (wetenschappelijke) gedachten kunnen wisselen. Allereerst in wisselende samenstelling mijn collega AIO kamergenoten: Liesbeth, Gerard, Susan, Danielle en Wilhelmine. Allemaal hartelijk bedankt voor de gezelligheid en de bereidheid om als luisterend oor te fungeren voor mijn soms oeverloos geneuzel. Verder de vele anderen binnen de capaciteitgroep. In het bijzonder wil ik noemen de mountainbike bikkels van de woensdagavond: Joost, Erwin M, Marco the guide, Luc, Edgar, Patrick, Dennis, Reinout, Mathijs, Lars, Erwin T., Michiel (heel soms), en Iron Freddy (ik wil hier slechts heel kort memoreren aan onze internationale antioxidanten cursus te Wageningen waar wij mijns inziens niet alleen veel kennis hebben opgedaan maar zeker ook een gezonde portie radicaalschade hebben opgelopen). Trouwens, ik wil nog wel eens ter discussie stellen wie er nou een echte bikkel is (ik noem een mergel heuvelland etappe -die ik nadat werkelijk iedereen had afgebeld omdat het een beetje regende-, alleen heb moeten rijden). Mannen, bedankt voor alle uren gezamenlijke inspanning. Yvette, ik vond het erg fijn toen jij onze middenlob verrijkte met jouw aanwezigheid, Jij gaf de groep een verfrissende nieuwe impuls die mijns inziens helaas veel te vroeg is onderbroken. Patrick (Dr. Schrauwen), jij was, naast Arjen en Ronald, een van de weinigen op de vakgroep met wie ik eens op een normale manier (nou ja) over (toegepast) moleculair biologisch onderzoek kon brainstormen. Ik hoop dat we de komende jaren wat intensiever kunnen samenwerken en ik waardeer het dat je mijn tweede paranimf wilt zijn. Loek en Paul, bedankt voor het altijd adequate reageren als er weer eens problemen waren met de computers of het netwerk (hoe goed jullie het ook aanleggen, storingen zijn mijns inziens onvermijdelijk). Verder alle andere mensen binnen Humane Biologie en andere capaciteitsgroepen die ik hier niet heb genoemd, bedankt voor alle bijdragen, opmerkingen en gezelligheid. Ik wil tenslotte de staf van de capaciteitsgroep Humane Biologie (en Ronald in het bijzonder) bedanken voor het in mij gestelde vertrouwen door mij mijn huidige aanstelling te geven. I $\mathrm{k}$ zal met evenveel plezier en enthousiasme als ik de afgelopen vierenhalf jaar heb gewerkt, ook de komende jaren tegemoet treden.

I am also indebted to Professor Klaus Von Bergmann for his kind invitation to offer me the possibility to participate in his research group at the Department of Clinical Pharmacology of the University of Bonn. During my four-month stay I have really learned a lot about plant stanol and sterol analysis with combined gas liquid chromatography - mass spectrometry (GC-MS). In particular I would like to thank 
Dr. Harald Brzezinka (I think you are one of the most skilled people in the lab I know), Dr. Bernhard Lindenthal, and Dr. Dieter Lütjohann. Dieter, although we haven't spend thiat much time together, in my opinion you are one of the most enthusiastic researchers I have ever met.

I would also thank the RAISIO GROUP for making this project financially possible. In particular I would like to thank Ingmar Wester for the many and often very interesting discussions we have had with respect to effects of plant stanol esters on cholesterol metabolism. I have really enjoyed our cooperation and hope to continue this for many years. I also want to thank Tapio Palmu, Anu Hopia, and Paula Virtanen for their help, stimulation and interest. Tapio, I still appreciate you sending me those brochures about Norway when I mentioned planning my holiday with Anita in Scandinavia.

Voor het succesvol functioneren op je werk is een stabiele, stimulerende thuissituatie een must. Ik wil dan ook mijn familie bedanken. Angela en Marco, Cor en Pita, Ronald en Annelies, bedankt voor alle getoonde interesse en de gegeven steun. Tenslotte natuurlijk paps en mams. Jullie stonden en staan altijd in alle opzichten voor mij klaar. Jullie zijn voor mij een voorbeeld van hoe een ouder hun kind kunnen stimuleren iets van zijn leven te maken. Ik heb het gelukkig met jullie getroffen. Verder wil in Monique en Erik bedanken voor alle gezelligheid buiten het werk om. Al blijft Maastricht-Nijmegen-Maastricht een takke-eind rijden, het is het altijd weer waard.

Anita, we zijn al een hele tijd samen, en ik ben nog steeds ontzettend blij dat we dat vorig jaar hebben kunnen bezegelen met het "ja" woord (de rit naar het poeltje van Aphrodite was het zeker waard). Ik ben ongelooflijk gelukkig dat jij mijn vrouw, en de moeder van Stijn bent. Ik waardeer je niet te evenaren gedrevenheid en hoop dat je mij zult blijven enthousiasmeren zoals je dat doet sinds ik je heb leren kennen. Tot slot, Stijn, jij bent de jongste aanwinst in mijn leven, maar zonder meer een van de meest waardevolle.

ledereen, hartelijk dank.

Jogchum 


\section{Curriculum Vitae}

Jogchum Plat was born on May 8, 1970, in Epe, the Netherlands. In 1990 he passed secondary school at the "Rijksscholengemeenschap de Springborn" in Epe. From 1991 to 1994 he studied food and dietetics at the "Hanzehogeschool, Hogeschool van Groningen" following the profile of "medical specialization", in which he graduated "Cum Laude". The internships of this study were performed at the departments of dietetics of the revalidation center Beatrixoord in Haren and the Sahl-Grenska hospital in Göteborg, Sweden.

In 1994 he started to study Biological Health Science at the Faculty of Health Sciences, Maastricht University. His internship was spent at the department of Human Biology, Maastricht University, in which the effects of different LDL isolation procedures on LDL antioxidant status and in vitro oxidizability were compared. He graduated Cum Laude in 1996. During the last four months of 1996, he was appointed as research assistant at the Department of Human Biology to assist in writing a research proposal for his following PhD-project, which started in January 1997.

He participated in several dietary intervention studies to investigate the effects of plant stanol esters on lipoprotein metabolism and cardiovascular risk markers. In May 2000 he received a travel grant from the Netherlands Organization for Scientific Research (NWO) for a four months visit at the department of clinical pharmacology, Bonn University in Bonn, Germany. In Bonn he was involved in the development of an assay to measure oxidized plant sterols in serum samples by mass spectrometry. In October 2000 he was the winner of the NWO Foppe ten Hoor Young Investigator Award. Nowadays the Department of Human Biology is still his employer. 


\section{Publications}

\section{Full papers}

Plat J, Mensink RP. Vegetable oil based versus wood based stanol ester mixtures: effects on serum lipids and hemostatic factors in non hypercholesterolemic subjects. Atherosclerosis 2000;148:101-112

Plat J, Mensink RP. Dietary plant stanol ester mixtures: effects on safety parameters and erythrocyte membrane fatty acid composition in non hypercholesterolemic subjects. Eur Heart J 1999;1(Suppl):s58-s63

Plat J, Mensink RP. Safety aspects of dietary plant sterols and stanols. Postgr Med 1998; Nov:32-38

Plat J, Onselen van ENM, Heugten van MMA, Mensink RP. Effects on serum lipids, lipoproteins and fat-soluble antioxidant concentrations of consumption frequency of margarines and shortenings enriched with plant stanol esters. Eur $\mathrm{J}$ Clin Nutr 2000;54:671-677

Plat J, Kerckhoffs DAJM, Mensink RP. Therapeutic potential of plant sterols and stanols. Curr Opin Lipidol 2000;11:571-576

Plat J, Mensink RP. Effects of diets enriched with two different plant stanol ester mixtures on plasma ubiquinol-10 and fat-soluble antioxidant concentrations. Metabolism (2001;50:520-529)

Plat J, Mensink RP. Effects of plant sterols and stanols on lipid metabolism and cardiovascular risk. Nutrition Metabolism and Cardiovascular Diseases $(2001 ; 11: 31-40)$

Mensink RP., Plat J. Efficacy of dietary plant stanols. Postgr Med 1998; Nov:27-31

Volger OL, Boom van der $\mathrm{H}$, Wit de ECM, Duyvenvoorde van W, Hornstra G, Plat J, Havekes LM, Mensink RP, Princen HMG. Dietary plant stanol esters reduce VLDL-cholesterol secretion and bile saturation in apoE ${ }^{*} 3$-Leiden transgenic mice. Arterioscler Thromb Vasc Biol 2001;21:1046-1052 
Volger OL, Mensink RP, Plat J, Hornstra G, Havekes LM, Princen HMG. Dietary vegetable oil and wood derived plant stanol esters reduce atherosclerotic leasion size in apoE*3-Leiden transgenic mice. Atherosclerosis 2001;157:375-381

Plat J, Brzezinka $H$, Lütjohan D, Mensink RP, von BergmannK. Oxidized plant sterols in human serum and lipid infusions as measured by combined gas-liquid chromatography-mass spectrometry. J Lipid Res in press

Mensink RP, Ebbing S, Lindhaut M, Plat $\mathrm{J}$, Heugten van MMA. Effects of plant stanol esters supplied in low-fat yogurt on serum lipids and lipoproteins, noncholesterol sterols and fat-soluble antioxidant concentrations. Atherosclerosis, in press

Plat J, Mensink RP. Hypocholesterolemic mechanisms of plant stanol esters; effects on LDL receptor mRNA and cell surface protein expression, and HMG-CoA reductase mRNA expression in non-hypercholesterolemic subjects (submitted).

Plat J, Mensink RP. Relationship of genetic variation in genes encoding apolipoprotein A-IV, scavenger receptor BI, HMG-CoA reductase, CETP, and apolipoprotein $E$ with cholesterol metabolism and the response to plant stanol ester consumption (submitted)

\section{Abstracts}

Plat J, Mensink RP. Consumption of plant stanol esters increase LDL receptor expression in mononuclear cells from non-hypercholesterolemic subjects. XIlth IAS 2000, Atherosclerosis 2000;151 (suppl 1): 86

Mensink RP, Plat J. SR-BI gene polymorphism does not affect cholesterol absorption, but is related with serum HDL cholesterol levels and endogenous cholesterol synthesis. XIIth IAS 2000, Atherosclerosis 2000;151 (suppl 1): 269

Plat J., Mensink RP., Hornstra G. Effects of a vegetable oil based or pine wood based phytostanol ester mixtures on serum lipoproteins in healthy normocholesterolemic subjects. International Symposium on Drugs Affecting Lipid Metabolism 1998, Florence, Italy 
Mensink RP, Plat J. Studies of effects of plant stanol ester on lipid parameters, vitamin levels, and thrombogenic factors in a normocholesterolemic population. Plant Stanol Ester: A New Tool in Dietary Management of Cholesterol. Dallas, October 1-2, 1998, pp. 39-40

Mensink RP, van Heugten MMA, Cox FJJ, Plat J. Effects of dietary plant stanol esters on plasma tocopherols and carotenoids in humans. Lipid Forum Seminar "From the farm to our heart", Uppsala, Sweden, November 17-18, 1999

Volger OL, Boom van der J, Wit de ECM, Duyvenvoorde van W, Hornstra G, Plat J, Havekes LM, Princen HMG, Mensink RP. Effects of dietary stanol esters on hepatic lipid metabolism in apoE3 leiden transgenic mice. 71st EAS 1999, Atherosclerosis 1999;144 (suppl 1): 95.

Volger OL, Boom van der J, Wit de ECM, Duyvenvoorde van W, Hornstra G, Plat J, Havekes LM, Princen HMG, Mensink RP. Dietary vegetable- wood- or vegetable/wood derived stanol esters reduce atherosclerotic leasion size and severity in apoE ${ }^{\star} 3$-Leiden transgenic mice. Xllth IAS, Atherosclerosis 2000;151 (suppl 1): 77

Plat J, Mensink RP. Effects of low-fat yoghurt with plant stanol esters and of consumption frequency on LDL cholesterol levels. Inform S63, 92 ${ }^{\text {nd }}$ AOCS Annual Meetings \& Expo, Minneapolis 2001

Mensink RP, Plat J. Effects of dietary plant stanol esters on human cholesterol metabolism. Inform S63, 92 ${ }^{\text {nd }}$ AOCS Annual Meetings \& Expo, Minneapolis 2001

\section{Book contributions}

Mensink RP, Temme EHM, Plat J. Dietary fats and coronary heart disease. In: Akoh CC, Min DB, eds. Food Lipids. New York: Marcel Dekker, 1998: 507-35

Plat J, Mensink RP. Consumption of plant stanol esters increase LDL receptor expression in mononuclear cells from non-hypercholesterolemic subjects. In: Stemme S, Olsson AG, eds. Atherosclerosis XII, Exerpta Medica International Congress Series 1215, Amsterdam: Elsevier Science BV, 2000:186-187 


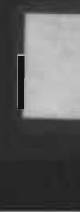

